\title{
The acquisition of gender agreement in L3 English by Basque/Spanish bilinguals
}

\author{
Author: Ainara Imaz Agirre \\ Supervisor: María del Pilar García Mayo
}

PhD Dissertation

2015

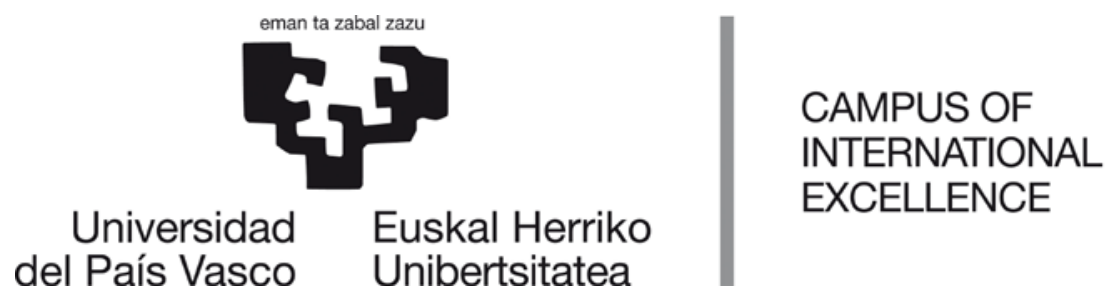




\section{Acknowledgments}

My deepest gratitude goes first to my supervisor, María del Pilar García Mayo, for her support, guidance, encouragement, and especially her confidence in my work from the very beginning. Despite her busy schedule, she always provided insightful comments and exhaustive feedback on drafts of the thesis, papers, conference abstracts, and even e-mail and WhatsApp communications. It was a pleasure to be your student. ¡iGrazas por todo o que me ensinaches!!

I am greatly thankful to the members of the committee and the two international experts Antonio Fábregas (University of Tromsø) and Roumyana Slabakova (University of Southampton), who gratefully accepted to read this work and whose comments, I am sure, will refine the quality of this work.

I would also like to thank the predoctoral grant awarded by the University of the Basque Country (ref.: PIFUPV011/2001) and the research projects from the Basque Government (Language and Speech-IT-311-10) and the University of the Basque Country (UFI11/06).

I would also like to thank Professor Juana Muñoz Liceras for receiving me at the University of Ottawa during my research stay and the members of the Language Acquisition Research Laboratory (LAR LAB) research group for their kindness and readiness to help.

The Language Acquisition in Multilingual Contexts (LAMS) master program also deserves some lines in this dissertation. Thank you to all the teachers who helped me in the first stages of this long process. Era berean, eskerrik asko LAMS masterrean izan nituen klasekideei zuen laguntzagatik eta ikasturte hura ahaztezina bihurtzeagatik. Hurrengo LAMS meeting-erako eguna eta tokia pentxatzen hasi beharko gara!

Eskerrak eman nahi dizkiet baita nire “PhD Girls”-ei (Agurtzane, Argiñe, Marta, Oihane eta Ruth) zuen babesa eta laguntzagatik. Bereziki, Agurtzane eta Martari zuen animoengatik eta distantzian egonda ere, momentu on eta txarrak nirekin konpartitzeagatik (eta oraindik konpartitzeko ditugunengatik), mila esker neskak!!! 
Ez nuke ahaztu nahi laborategian egondako jendeaz (Adam, Edurne, Idoia, Kepa, Luis, Marian, Marta, Mikel, Yolanda), mila esker zuen diziplina-anitzeko laguntzagatik! Plazerra izan da zuekin txoko hori partekatu ahal izatea.

Azkenik nire lagun eta familiari eskertu nahiko niece emandako babesa. Eskerrak eman kuadrilakoei (Ainara, Ainhoa, Ane, Aran, Garazi, Leire eta Maider) askotan lan honek eskatzen duen dedikazioa ulertzen zaila izan arren, beti hor zaudetelako. Familiari, eskerrik beroenak eman nahi dizkiot, ni honaino iristeko egin duzuen ahaleginagatik, alaitasun momentuak nirekin partekatzeagatik eta nire umore txarra aguantatzeagatik.

Last but not least, nire aldamenean dagoenari, miloi bat esker nirekin izan duzun pazientziagatik eta ilusioa itzultzeagatik. Eskerrik asko guztiagatik Ibon!!! 25/25 
Es un tema muy conocido en base a evidencia anecdótica que los aprendices bilingües euskera/castellano de inglés como tercera lengua (L3) tienen dificultades a la hora de establecer la concordancia de género en los posesivos (his/her). Como se aprecia en el ejemplo (1), la concordancia no se establece con el poseedor (Mary) y, por tanto, la oración es agramatical:

(1) * Mary is brushing his teeth.

El objetivo de esta tesis es investigar la adquisición de la concordancia de género en inglés como L3 por parte de hablantes bilingües euskera/castellano. Esta tesis adopta presupuestos de la lingüística generativa $\mathrm{y}$, más concretamente, del Programa Minimalista (PM) (Chomsky, 1995, 1998, 2001) en el que los rasgos se han identificado como el centro de la teoría del aprendizaje.

En el área de adquisición de segundas lenguas (L2), las propuestas más recientes han optado por predecir las condiciones en las que determinados tipos de rasgos causan problemas en el proceso de adquisición (Lardiere, 2009). La interpretabilidad de dichos rasgos, es decir, su naturaleza intrínseca, determina si contribuye a su interpretación semántica y de lugar a la variación paramétrica (Adger, 2003; Pesetsky y Torrego, 2004). Dentro del PM se han identificado dos tipos de rasgos: [+interpretable] y [+nointerpretable]. Los rasgos [+interpretables] (por ejemplo, el género en inglés) interactúan con el sistema semántico-conceptual de la mente. En la derivación sintáctica de una oración, dichos rasgos se comprueban pero no se eliminan, mientras que los rasgos [+no-interpretables], que no realizan ninguna contribución semántica, tienen que ser comprobados y eliminados por medio de las operaciones de concordancia (por ejemplo, la concordancia de género entre el sustantivo y el adjetivo en castellano) (Liceras, 2009; Liceras, Zobl and Goodluck, 2008b).

Recientemente, el estudio de la adquisición de L2/Ln dentro del marco generativo se ha concentrado en los problemas de procesamiento (Juffs, 1998, 2006) y también en las contribuciones del área de la neurolingüística (Yusa, Koizumi, Kim, Kimura, Uchida, Yokoyama, Miura, Kawashima and Hagiwara, 2011). Esta atención ha contribuido a incorporar y desarrollar técnicas del estudio de la psicolingüística, tales como los tiempos de reacción a un estímulo, y de la enseñanza de lenguas (por ejemplo, el uso de tareas más contextualizadas) (Whong Gil y Marsden, 2013). 
Asimismo, los estudios más recientes sobre la adquisición de L3 se han concentrado en la adquisición de aspectos morfosintácticos. Dichos estudios se han llevado a cabo con aprendices de L3 en los estadios iniciales con el fin de identificar las variables que influyen en la transferencia morfosintáctica en las primeras etapas de la adquisición (Bardel and Falk, 2007; Flynn, Foley and Vinnitskaya, 2004; García Mayo and Rothman, 2012; Rothman, 2011; Rothman and Halloran, 2013). No obstante, son escasos los trabajos realizados desde la perspectiva generativa que hayan investigado el proceso de la adquisición de la L3 por parte de aprendices en estadios intermedios de desarrollo de su interlengua con el fin de delinear las secuencias de desarrollo, la disponibilidad de rasgos y el logro final en hablantes multilingües (García Mayo and Rothman, 2012; García Mayo and Villarreal Olaizola, 2011; Iverson, 2010; Jaensch, 2009, 2011; Leung, 2007, 2009; Villarreal Olaizola and García Mayo, 2009).

El objetivo general de esta tesis es investigar el desarrollo de la adquisición de la concordancia de género en los posesivos de tercera persona en inglés (his/her) por parte de hablantes bilingües euskera/castellano. Dicho objetivo general se desglosa en cuatro más específicos:

i) analizar si las diferencias en el rasgo de la animacidad y la direccionalidad para establecer la concordancia de género (efectos de atracción de género) afectan a cómo se establece la concordancia de género en inglés;

ii) contribuir al debate actual sobre si la variabilidad en las gramáticas de los hablantes no-nativos es debida a la dificultad de los rasgos [+nointerpretable] o también a los [+interpretables]. Si esa variabilidad existe, determinar si se puede atribuir a dificultades de re-ensamblaje o a la deficiencia de la gramática subyacente;

iii) establecer si el nivel de conocimiento de la lengua inglesa por parte de los aprendices afecta a la adquisición de un rasgo determinado y determinar una secuencia de desarrollo en la interlengua de los bilingües euskera/castellano cuando aprenden inglés;

iv) definir hasta qué punto el conocimiento previo de otras lenguas afecta a la adquisición de un rasgo en la L3. 
Las tres lenguas que se consideran en este estudio (euskera, castellano e inglés) difieren considerablemente en lo que respecta a cómo se establece la relación de posesión y la concordancia de género. Respecto a la posesión, tanto el euskera como el inglés establecen la concordancia entre el posesivo y el poseedor, mientras que en castellano el posesivo concuerda con el poseído. El género en euskera y en inglés se muestra en el sustantivo por lo que se considera un rasgo interpretable. A pesar de que el género en castellano se determina semánticamente en el nombre, la concordancia de género que se refleja en el determinante y el adjetivo es un rasgo no-interpretable.

Los estudios que se han llevado a cabo hasta el momento sobre el efecto del rasgo de la animacidad en la concordancia de género en adquisición de L2 no han ofrecido resultados concluyentes. Algunos estudios indican que los hablantes nativos y no nativos tienes más facilidad para establecer la concordancia de género en sustantivos animados que inanimados mientras que en otros el rasgo [+animado] del sustantivo parece ser la causa de las dificultades para los aprendices. Un tercer grupo de estudios no encuentran ninguna diferencia entre sustantivos animados e inanimados a la hora de establecer concordancia de género.

Respecto a los efectos de la atracción de género, es decir, la influencia que ejerce el sustantivo que acompaña al posesivo en el sintagma nominal a la hora de establecer la relación de concordancia, existen estudios que demuestran que, efectivamente, los aprendices tienen dificultades causadas por el género del sustantivo en su primera lengua (L1).

La influencia del conocimiento de otras lenguas en el proceso de adquisición de una L3, así como las diferencias entre ese proceso y el de aprendizaje de una L2, es un tema que ha despertado gran interés en la última década en el ámbito de la lingüística generativa (de Bot y Jaensch, 2015; Cabrelli Amaro, Flynn y Rothman, 2012). La gran mayoría de estos estudios se han centrado en los primeros estadios del proceso de la adquisición y se han propuesto cuatro hipótesis con el fin de determinar las posibles fuentes de transferencia. Sin embargo, a día de hoy, todavía es objeto de debate si el origen de la transferencia es la L1 o la L2 o si también la (psico-) tipología desempeña un papel importante en el proceso. Por otra parte, más recientemente, varios estudios también se han centrado en diferentes aspectos morfosintácticos en la adquisición L3 por parte de aprendices en estadios intermedios de su interlengua. 
El presente estudio tiene como objetivo contribuir al análisis de la adquisición de la concordancia de género en inglés como L3 por parte de aprendices que se encuentran en estadios intermedios de su interlengua y también determinar cuál es la posible fuente de transferencia cuando establecen operaciones de concordancia. En el estudio consideramos el efecto de distintas propiedades lingüísticas, del tipo de tarea que realizan los aprendices, del nivel de conocimiento de la lengua inglesa y de los sistemas previamente adquiridos.

Hemos analizado datos de un total de 211 participantes que se organizaron en tres grupos: 117 bilingües euskera/castellano, 70 hablantes nativos de castellano (sin ningún conocimiento de euskera) y 24 hablantes nativos de inglés. Los participantes en los grupos de bilingües euskera/castellano y L1 castellano se subdividieron en tres grupos de acuerdo a su nivel de conocimiento de inglés: nivel principiante, nivel intermedio y nivel avanzado. Todos los participantes completaron un cuestionario de perfil lingüístico y siete tareas experimentales: tres tareas de compresión (una tarea de selección de tareas, una tarea de juicios de gramaticalidad y una tarea de ventana en movimiento), dos tareas de producción escrita (una tarea de rellenar los huecos y una tarea de narración escrita) y dos tareas de producción oral (una tarea de elicitación y una tarea de descripción oral).

Cada tarea tenía 144 oraciones experimentales divididas en 12 condiciones. Las condiciones experimentales se distribuyeron de acuerdo al rasgo de la animacidad y al género (gramatical) del poseído. Las condiciones del rasgo de la animacidad se organizaron en tres contextos donde en poseído en inglés era animado, inanimado o una parte del cuerpo. Para la condición de género (gramatical) se tuvo en cuenta el género semántico de los poseídos animados y para los poseídos inanimados y las partes del cuerpo el género gramatical del sustantivo correspondiente en castellano. Se distribuyeron por igual el número de antecedentes masculinos y femeninos así como las condiciones donde el género del poseedor y el poseído coincidían y aquellas donde no.

Los resultados obtenidos con respecto a la animacidad y a los efectos de atracción de género demostraron que los bilingües euskera/castellano y los hablantes de L1 castellano tenían dificultades en contextos donde el poseído era animado y no coincidía en género con el poseído (e.g. John is playing with her sister). Por una parte, el efecto de la animacidad parece estar relacionada con las tareas de producción espontánea. En 
los contextos en los que el género del poseedor y el poseído no coincidían (e.g. Mary is brushing her hair) los resultados indicaron que los dos grupos de aprendices no se comportaban de forma similar. En el grupo de hablantes de euskera/castellano los efectos de la animacidad se apreciaban de forma más clara en las tareas de producción mientras que en todas las tareas de comprensión tuvieron más dificultades en los sustantivos inanimados. Estas dificultades fueron corroboradas en la tarea en línea. Los hablantes de L1 castellano mostraron efectos de atracción de género en los tres niveles de conocimiento de inglés, en especial en la condición inanimada. En la condición donde el género de poseedor y poseído coincidían, estos hablantes mostraron claras preferencias por el género masculino en la forma por defecto.

El análisis del uso de errores de concordancia en las distintas tareas indicó que los hablantes mostraron mayor acierto en las tareas de comprensión en comparación a las tareas de producción. Además, los hablantes de L1 castellano mostraron mayor acierto que los bilingües euskera/castellano. Sin embargo, las diferencias entre las tareas parecen no explicarse por la mera dicotomía entre comprensión y producción.

En el estudio se encontraron correlaciones significativas entre el nivel de inglés y los porcentajes de acierto, en especial en el grupo de bilingües euskera/castellano puesto que el porcentaje de errores disminuyó cuando más alto era el nivel de conocimiento de la lengua inglesa. La comparación entre los resultados del grupo de aprendices de inglés y el grupo de hablantes nativos demostró que los bilingües euskera/castellano no consiguieron unos niveles de acierto similares a los de los hablantes nativos en ninguna de las condiciones, mientras que los hablantes de L1 castellano mostraron porcentajes similares al grupo control. Asimismo, los bilingües euskera/castellano mostraron dificultades en las condiciones de animacidad y los efectos de atracción de género mientras que los hablantes de L1 castellano tuvieron dificultades con los efectos de atracción de género. En términos de transferencia, los resultados indicaron que los bilingües euskera/castellano muestran la influencia tanto del euskera como del castellano cuando cometen errores de concordancia de género en inglés y también en los errores de desarrollo.

En resumen, los hablantes bilingües euskera/castellano muestran dificultades persistentes al establecer la concordancia de género en ingles en comparación a la asignación de género a los pronombres de sujeto y objeto. Estos resultados confirman 
las predicciones realizadas por la hipótesis del re-ensamblaje de rasgos (Feature reassembly hypothesis) (Lardiere, 1998, 2008). Asimismo, el rasgo animacidad se ha identificado como uno de los factores más relevantes para predecir las dificultades al establecer la concordancia de género. No obstante, los resultados indican que los factores extralingüísticos (e.g. la naturaleza de las tareas, el nivel de inglés o la transferencia) son factores relevantes que influyen en la comprensión y la producción acertada de la concordancia de género. Los resultados de las tareas experimentales indicaron que los bilingües euskera/castellano cometen más errores de concordancia que los hablantes nativos de castellano, lo cual indicaría que el re-ensamblaje de los rasgos en la L3 podría ser más dificultoso que en la L2. 


\section{Table of contents}

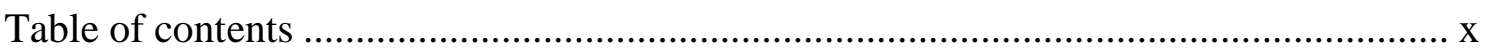

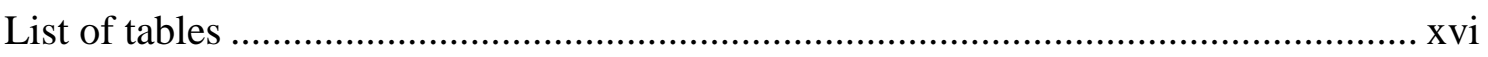

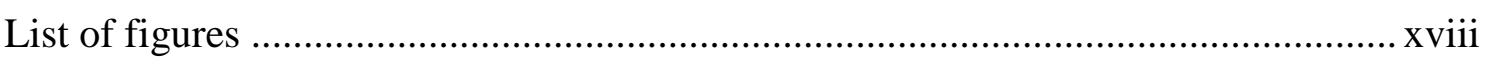

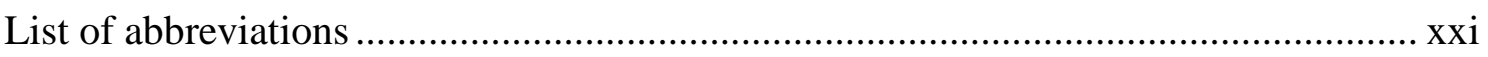

CHAPTER 1. INTRODUCTION ………………….................................. 1

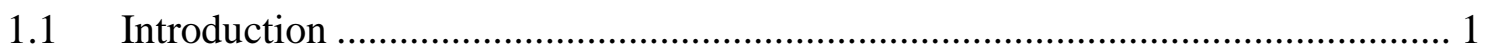

1.1.1 Aim and rationale of the study ................................................................. 3

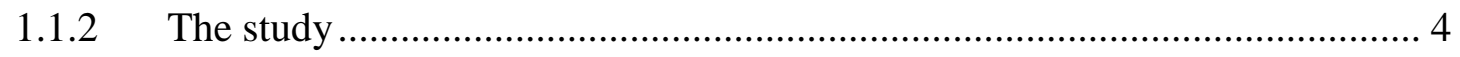

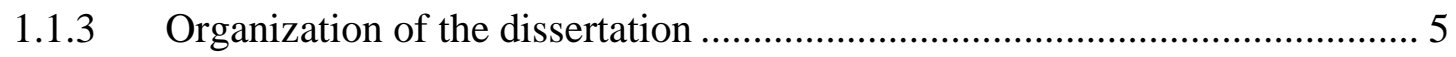

CHAPTER 2. THEORETICAL FRAMEWORK .................................... 7

2.1 General review of the structure of the Determiner Phrase (DP).......................... 8

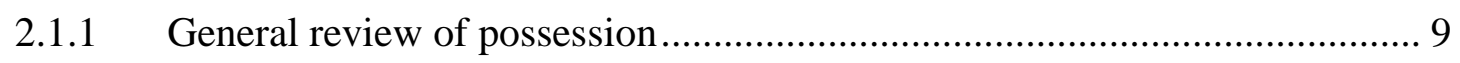

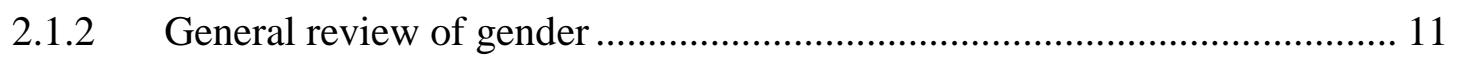

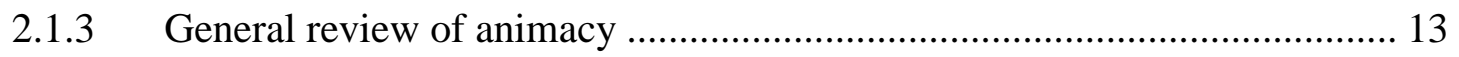

2.2 Feature comparison in the three languages: Basque, Spanish and English ......... 14

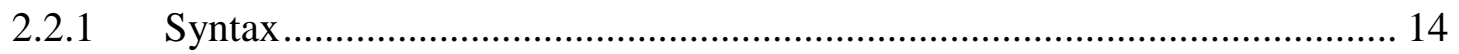

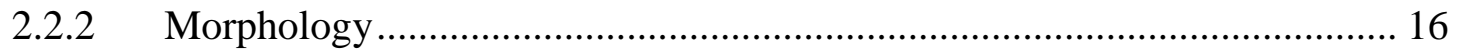

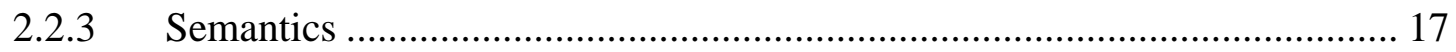

2.3 Evidence from linguistic aspects: animacy and gender attraction effects ........... 20

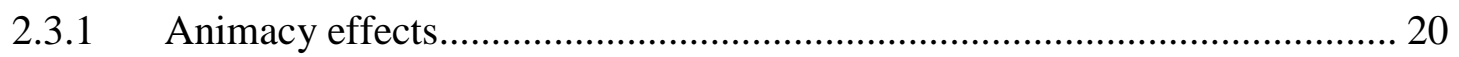

2.3.1.1 Animacy effects in L2 acquisition research ......................................... 20

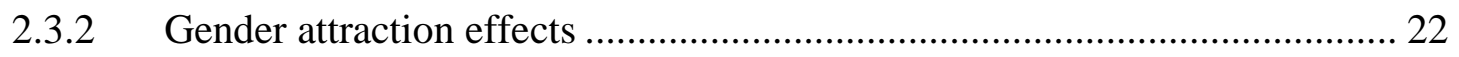

$2.4 \quad$ Feature availability accounts for non-native grammars .................................... 24

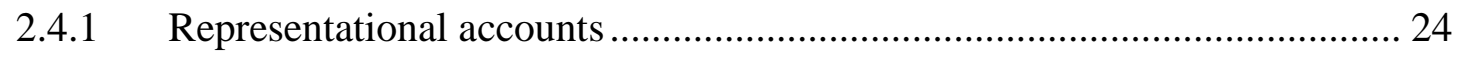

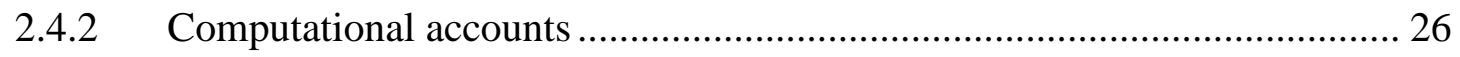

2.4.3 Morphological Underspecification hypothesis (MUH) .............................. 29

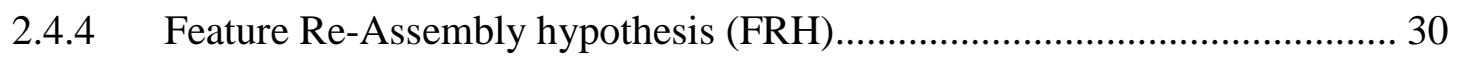

2.4.5 Summary of the different explanations of non-native variability ................ 32

2.5 L3 morphosyntax: Current approaches to transfer effects................................ 33 


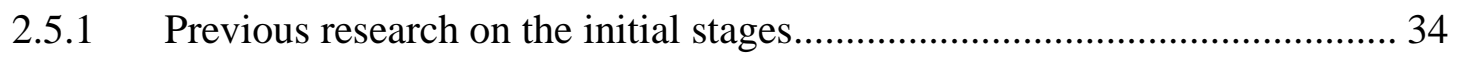

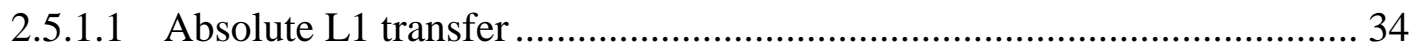

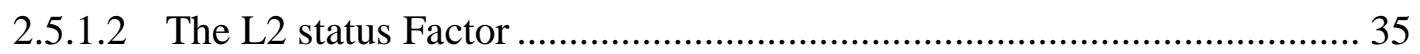

2.5.1.3 The Cumulative Enhancement Model .................................................... 35

2.5.1.4 The Typological Primacy Model............................................................ 36

2.5.2 Previous research on developing interlanguages ..................................... 37

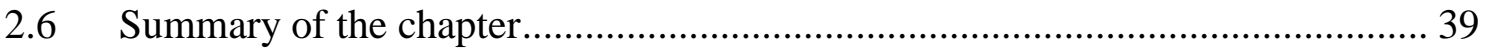

\section{CHAPTER 3. GENDER AGREEMENT IN NATIVE AND NON-}

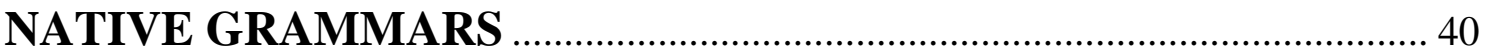

3.1 Gender agreement in native systems …......................................................... 40

3.1.1 Evidence from monolingual children.............................................................. 40

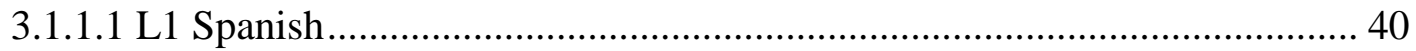

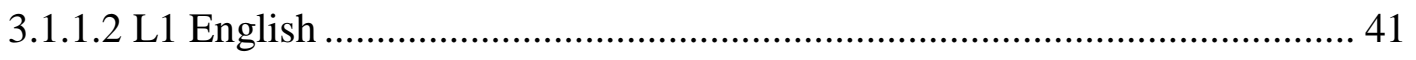

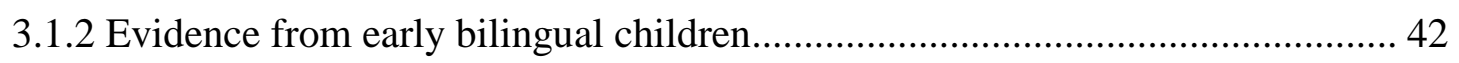

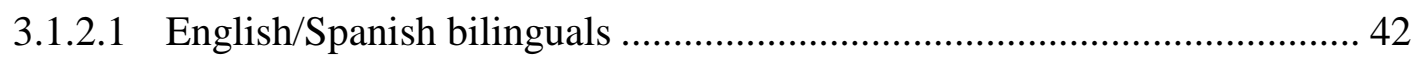

3.1.2.2 Basque/Spanish bilinguals ..................................................................... 44

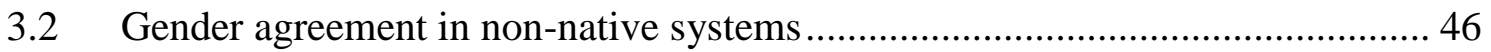

3.2.2.1 Evidence from the acquisition of gender agreement in L2 Romance

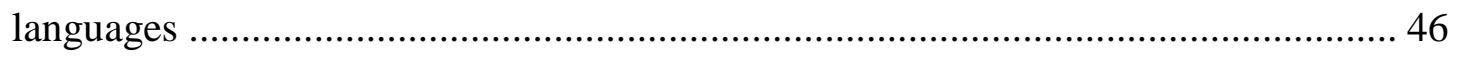

3.2.3 Evidence from the acquisition of gender agreement in L2/L3 English........ 48

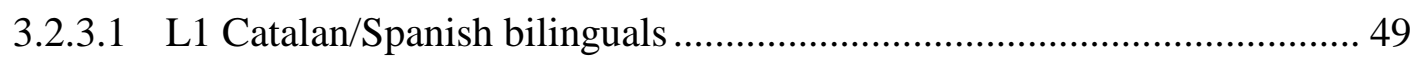

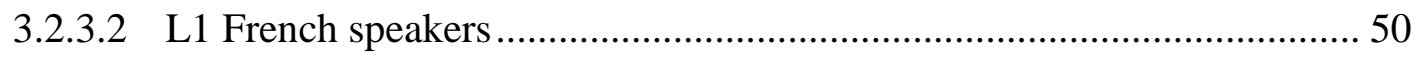

3.2.3.3 Basque/Spanish bilinguals............................................................. 53

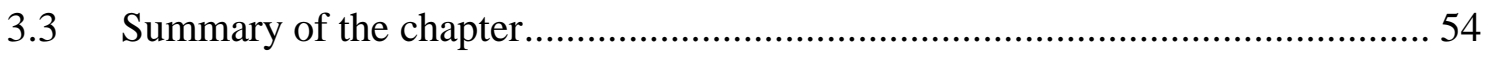

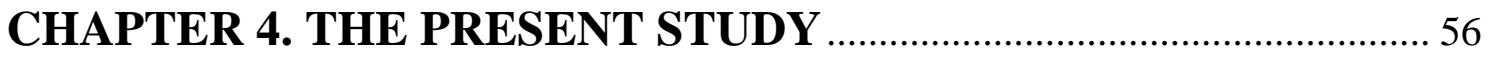

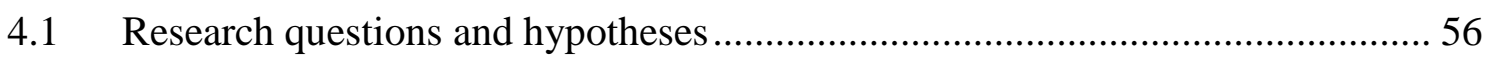

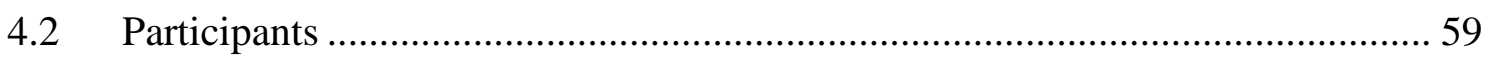

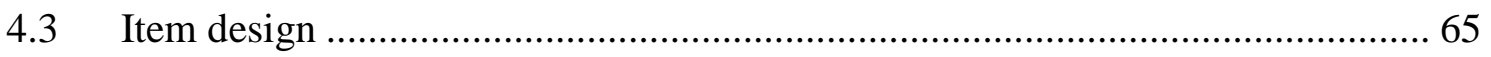

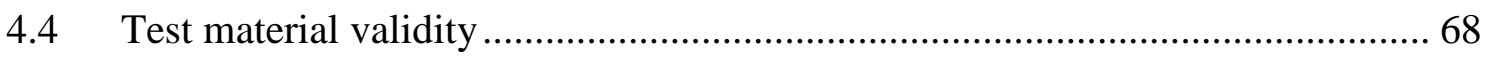

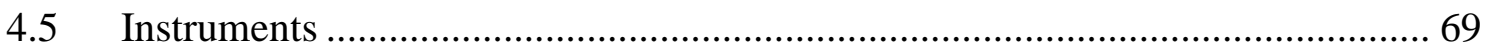

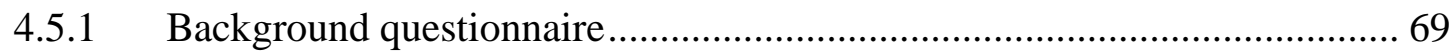




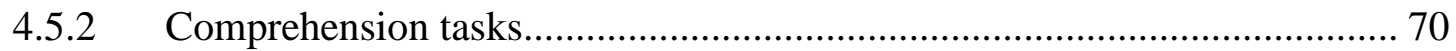

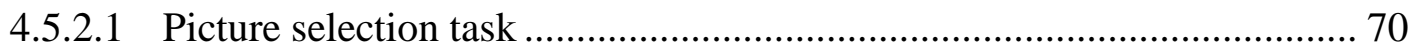

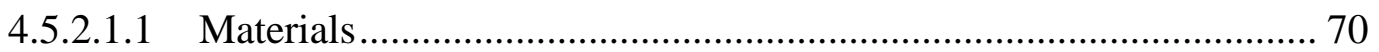

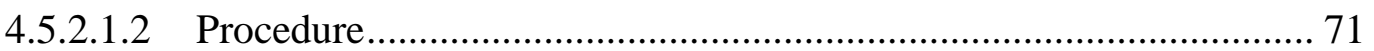

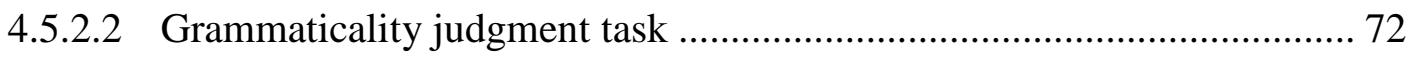

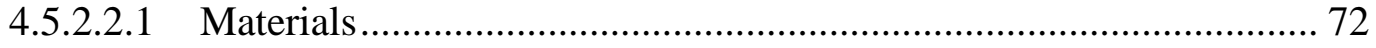

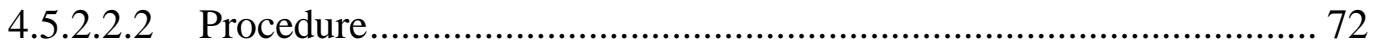

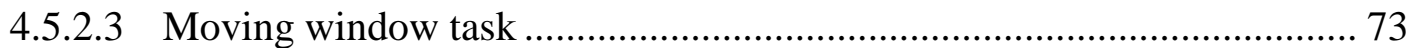

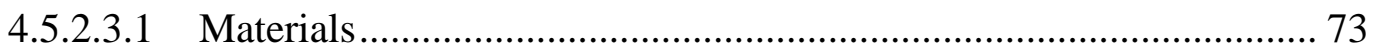

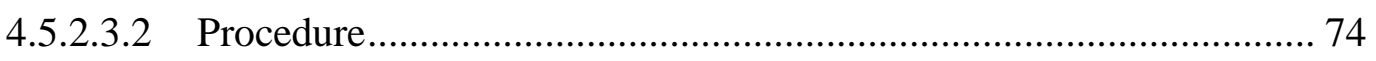

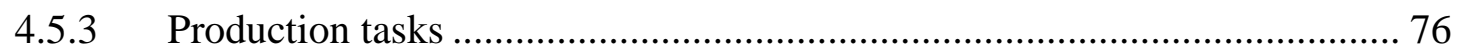

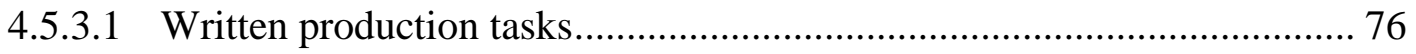

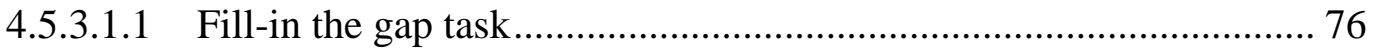

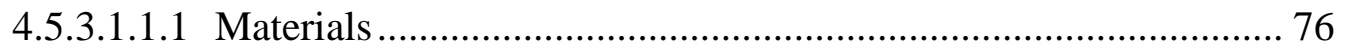

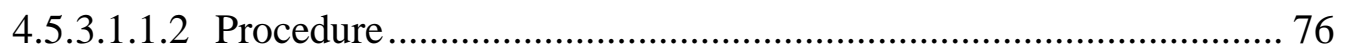

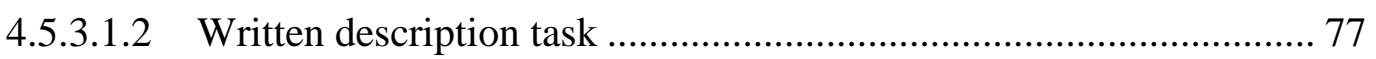

4.5.3.1.2.1 Materials ....................................................................................... 77

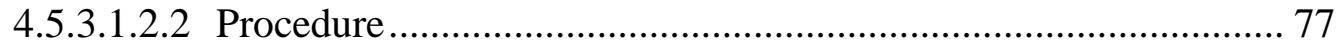

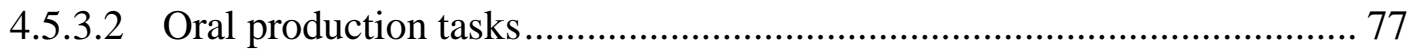

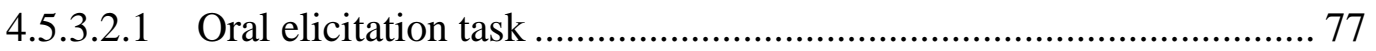

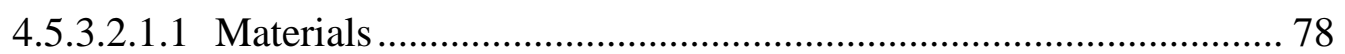

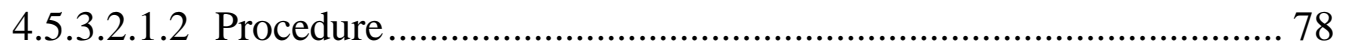

4.5.3.2.2 Oral picture description task .......................................................... 79

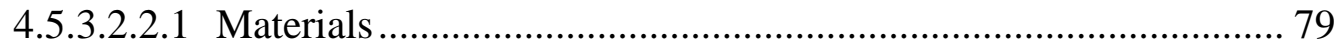

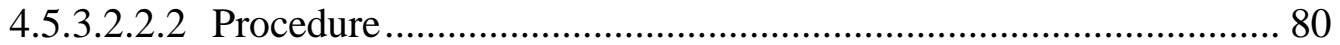

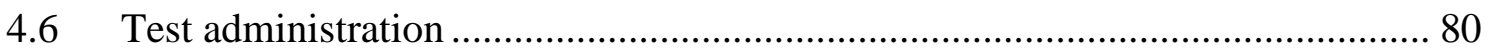

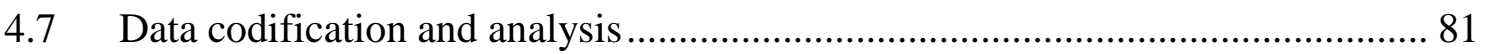

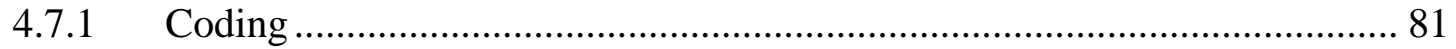

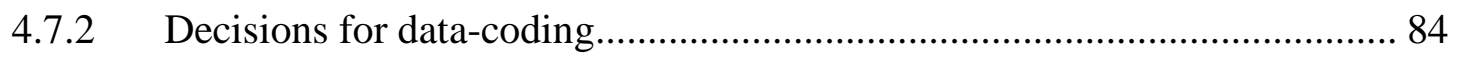

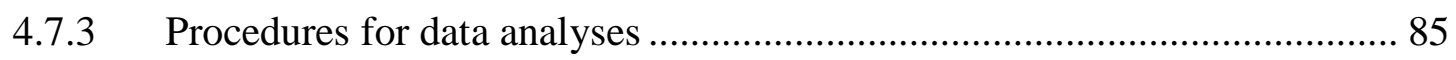

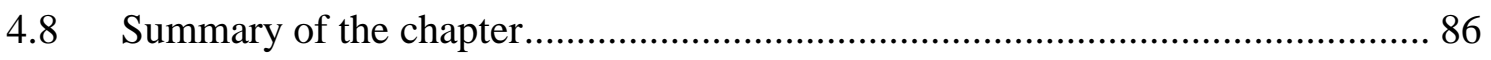

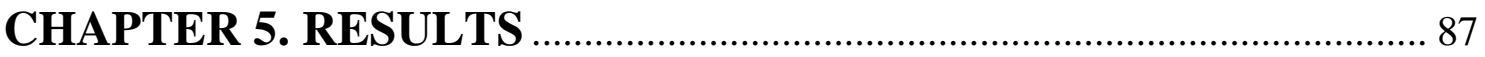


5.1 Overall use of possessive adjectives 87

5.2 Animacy and gender attraction effects in gender agreement errors ................... 90

5.2.1 Animacy and gender attraction effects in the picture selection task ............ 90

5.2.2 Animacy and gender attraction effects in the grammaticality judgment task..

5.2.3 Animacy and gender attraction effects in the moving window task ............ 93

5.2.3.1 Animacy and gender attraction effects in accuracy ................................. 93

5.2.3.2 Animacy and gender attraction effects in RTs .................................... 95

5.2.4 Animacy and gender attraction effects in the fill-in the gap task................ 99

5.2.5 Animacy and gender attraction effects in the written description task ...... 101

5.2.6 Animacy and gender attraction effects in the elicitation task ................... 102

5.2.7 Animacy and gender attraction effects in the picture description task ...... 104

5.2.8 Summary of the main findings in animacy and gender attraction effects.. 107

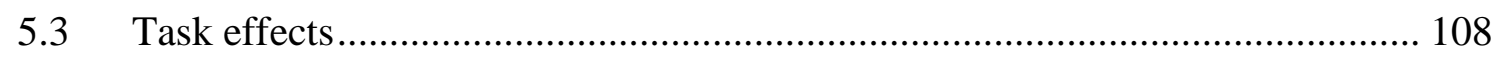

5.3.1 Task differences in Basque/Spanish bilingual groups ................................... 108

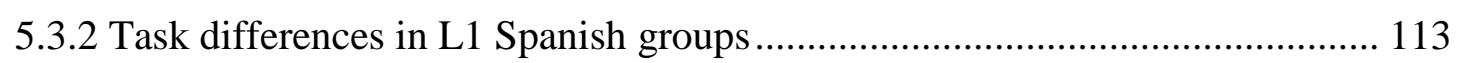

5.3.3 Summary of the main findings for task effects ............................................ 118

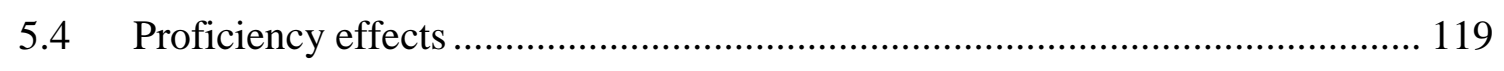

5.4.1 Proficiency effects in gender agreement errors ............................................ 119

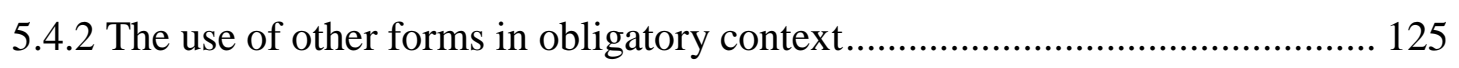

5.4.2.1 Analysis of other forms in obligatory contexts for Basque/Spanish bilingual

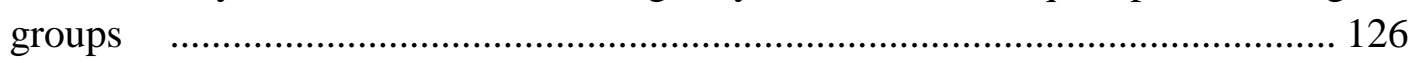

5.4.2.2 Analysis of other forms in obligatory contexts for L1 Spanish learner

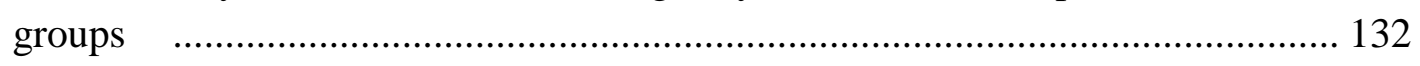

5.4.2.3 Summary of the main findings for proficiency effects ......................... 137

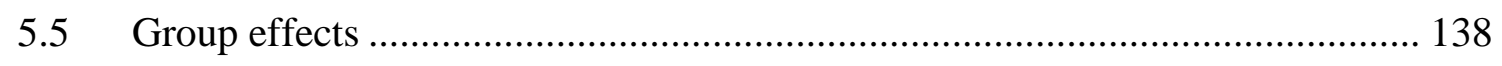

5.5.1 Group effects in the picture selection task .................................................. 138

5.5.2 Group effects in the grammaticality judgment task....................................... 139

5.5.3 Group effects in the moving window task ................................................... 140

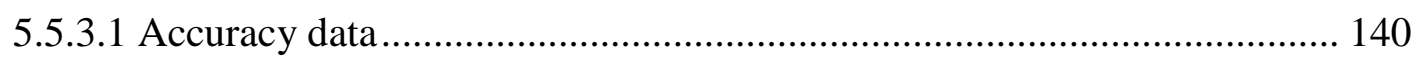

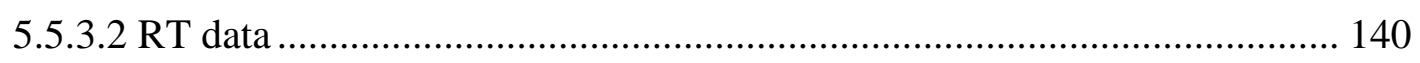

5.5.4 Group effects in the fill-in the gap task ....................................................... 144

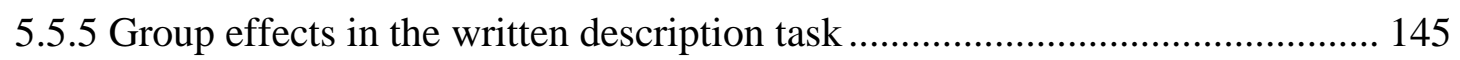




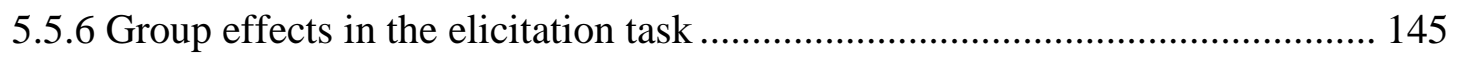

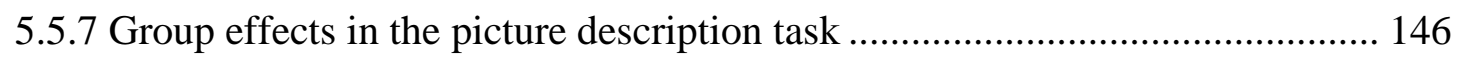

5.5.8 Summary of the main findings for group effects .......................................... 147

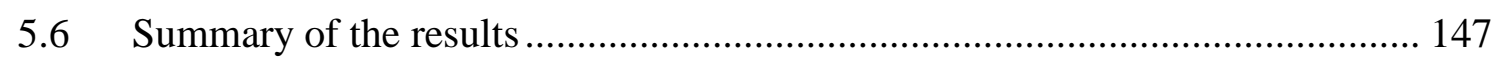

5.6.1 Main results regarding linguistic conditions.............................................. 147

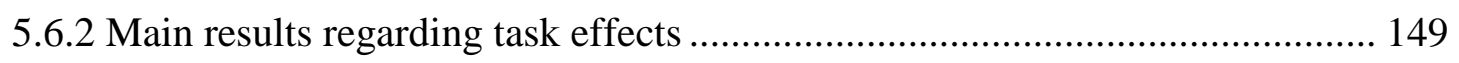

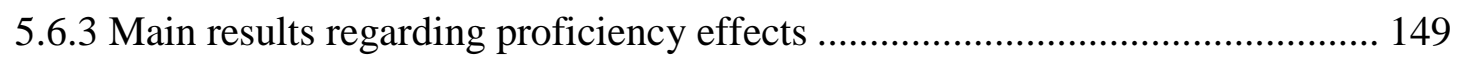

5.6.4 Main results regarding transfer effects and developing interlanguage ............ 150

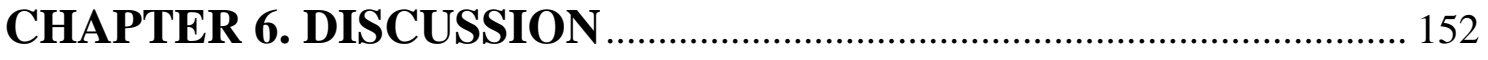

6.1 Third person pronouns: omission vs. commission errors ............................... 152

6.2 Summary of research questions and hypotheses ........................................ 153

6.3 Discussing RQ and hypothesis 1: Animacy and attraction effects .................... 154

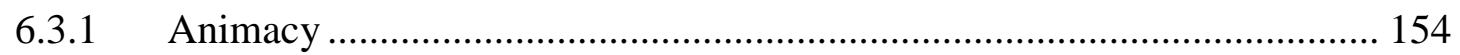

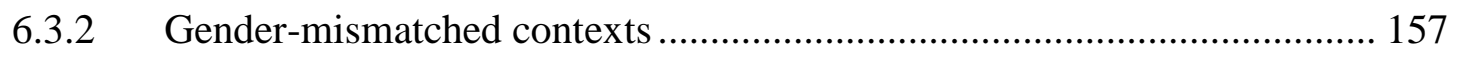

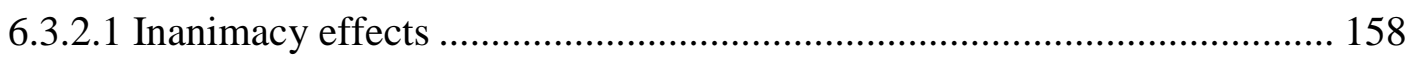

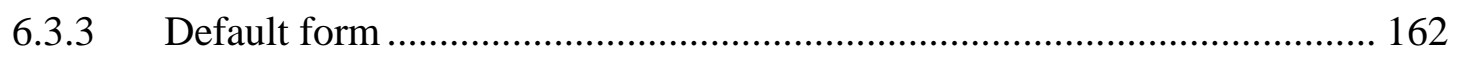

6.3.4 Summary of the discussion of RQ and hypothesis 1............................... 163

6.4 Discussing RQ and hypothesis 2: Feature availability and task differences ..... 165

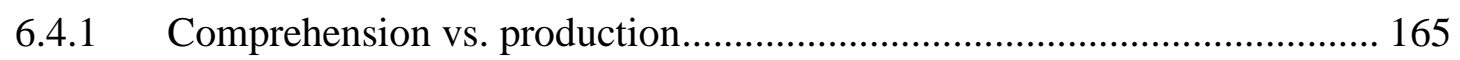

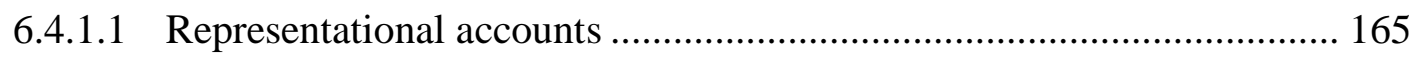

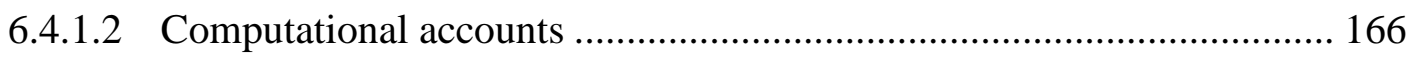

6.4.1.3 Feature Re-assembly hypothesis ..................................................... 166

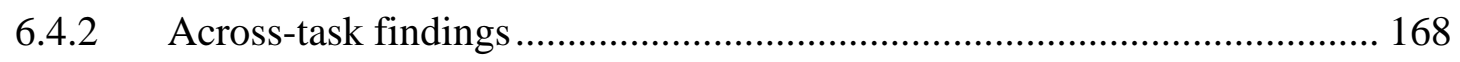

6.4.3 Summary of the discussion of RQ and hypothesis 2................................ 169

6.5 Discussing RQ and hypothesis 3: Proficiency effects .................................... 171

6.5.1 First stages in the acquisition of third person singular possessive adjectives..

6.5.2 Summary of the discussion of RQ and hypothesis 3.............................. 173

6.6 Discussing RQ and hypothesis 4: Transfer effects in developing interlanguages...

6.6.1 Transfer in the linguistic conditions under study: Animacy and attraction effects 
6.6.1.1 Animacy, attraction and default forms ............................................. 175

6.6.2 Transfer effects in the developmental stages ............................................. 178

6.6.3 Summary of the discussion of RQ and hypothesis 4............................... 179

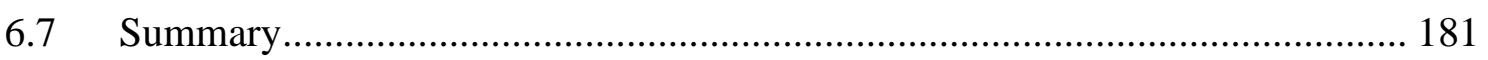

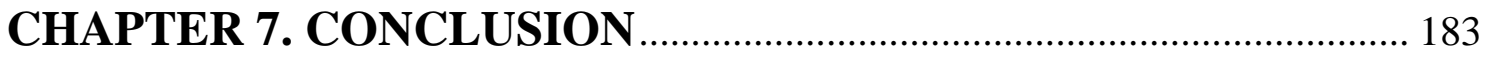

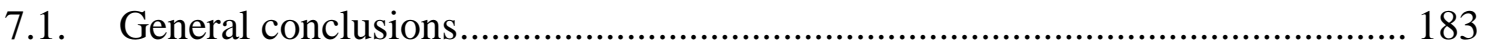

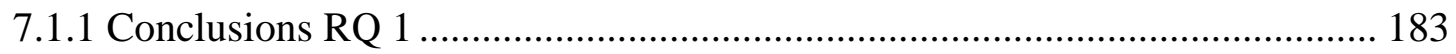

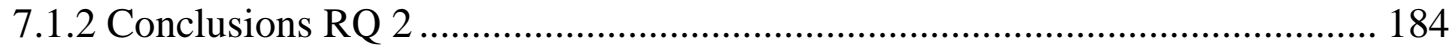

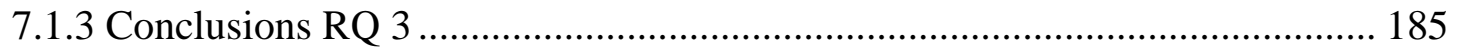

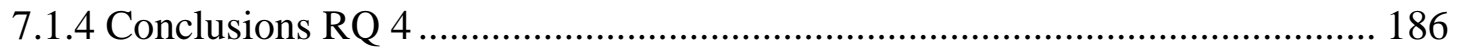

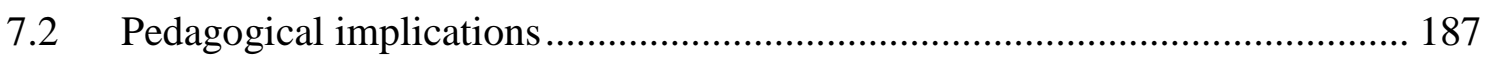

7.3 Limitations and lines for further research.................................................. 188

7.4 Final implications and concluding remarks.................................................. 190

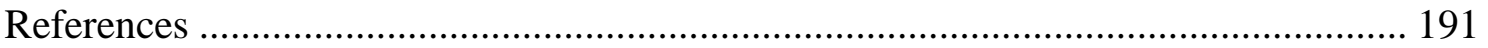




\section{List of tables}

Table 1. Summary of the encoding of possession and gender in Basque, Spanish and English

Table 2. Summary of the hypotheses for the availability of interpretable features in L2 acquisition.

Table 3. Developmental sequence in the acquisition of the English agreement rule for

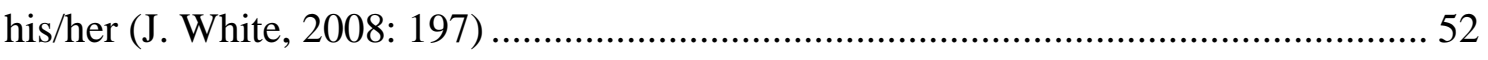

Table 4. Task effects on the basis of the different hypotheses ..................................... 58

Table 5. Distribution of the participants in the experimental groups ........................... 61

Table 6. Characteristics of the participants in the Basque/Spanish bilingual groups..... 62

Table 7. Mean scores of each Basque/Spanish bilingual group in the OPT test............ 63

Table 8. Characteristics of the participants in the L1 Spanish groups ............................ 64

Table 9. Mean scores of each L1 Spanish group in the OPT test................................... 64

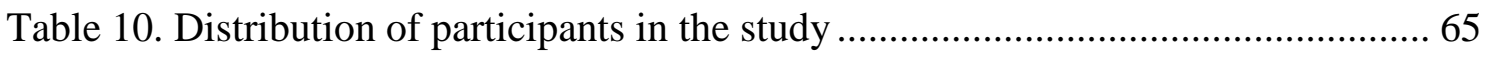

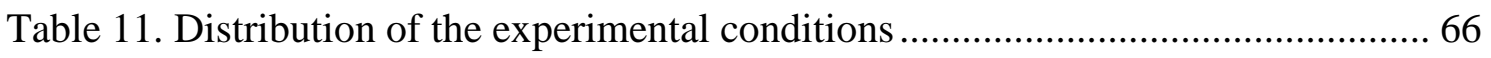

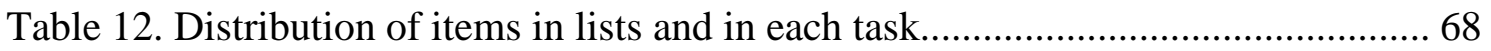

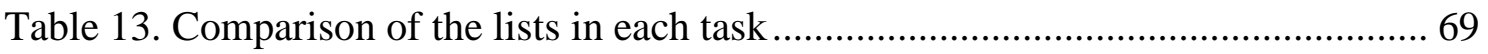

Table 14. Chronological distribution of test administration of the non-native learner

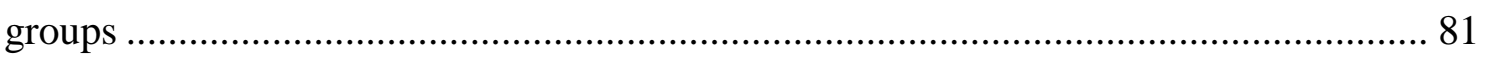

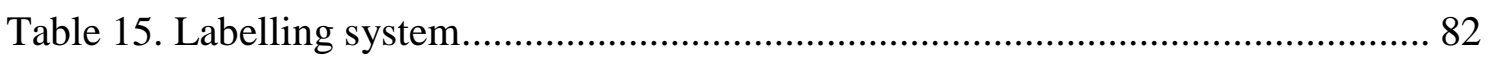

Table 16. Coding criteria for the experimental conditions......................................... 83

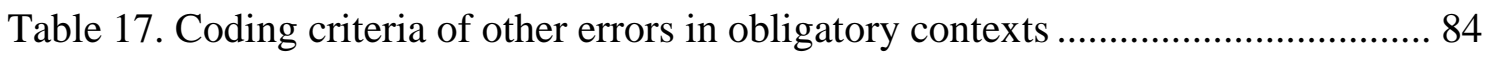

Table 18. Third person singular subject and object pronouns vs. third person singular

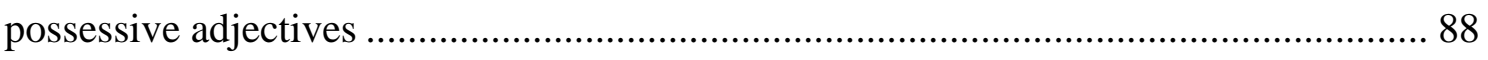

Table 19. Correct and incorrect third person singular possessive adjectives vs. other errors in obligatory contexts across groups

Table 20. Number of gender agreement errors in comprehension and production tasks in the Basque/Spanish bilingual group 109

Table 21. $p$-values of the comparison between tasks in the Basque/Spanish bilingual $\mathrm{DBH}$ group 
Table 22. $p$-values of the comparison between tasks in the Basque/Spanish bilingual BATXI group.....

Table 23. $p$-values of the comparison between tasks in the Basque/Spanish bilingual UNI group.

Table 24. Number of gender agreement errors in comprehension and production tasks in the L1 Spanish group 115

Table 25. $p$-values of the comparison between tasks in the L1 Spanish DBH group .. 116

Table 26. $p$-values of the comparison between tasks in the L1 Spanish BATXI group117

Table 27. $p$-values of the comparison between tasks in the L1 Spanish UNI group.... 118

Table 28. The number of other forms in obligatory context in the three Basque/Spanish experimental groups

Table 29. Summary of the $p$-values in the experimental groups in the use of other forms in obligatory contexts 131

Table 30. Developmental errors in the L1 Spanish DBH group 134

Table 31. Developmental errors in the L1 Spanish BATXI group 135

Table 32. Developmental errors in the L1 Spanish UNI group 136

Table 33. Summary of the $p$-values in the use of other forms in the L1 Spanish groups 137

Table 34. Summary of the predictions of feature availability..... 170

Table 35. Summary of the predictions of L3 models 181 


\section{List of figures}

Figure 1. Tasks used in the experimental design 67

Figure 2. An example of one of the target sentences in the picture selection task......... 71

Figure 3. Example of the moving window task 75

Figure 4. Percentages of incorrect gender agreement in the mismatched conditions in the picture selection task 91

Figure 5. Percentages of incorrect gender agreement in gender-matched conditions in the picture selection task.

Figure 6. Percentages of incorrect gender agreement in gender-matched conditions in the grammaticality judgment task

Figure 7. Percentages of incorrect gender agreement in gender-matched conditions in the grammaticality judgment task.

Figure 8. Percentages of incorrect gender agreement in animacy conditions in the moving window task

Figure 9. Percentages of incorrect gender agreement in gender-mismatched conditions in the moving window task 95

Figure 10. Mean RTs in gender-mismatched conditions in the possessive interest area 96 Figure 11. Mean RTs in gender-mismatched conditions in the possessee interest area. 96 Figure 12. Mean RTs in gender-mismatched conditions in the context interest area .... 97

Figure 13. Mean RTs in animacy conditions in the response interest area 98

Figure 14. Mean RTs in gender-mismatched conditions in the response interest area .. 98 Figure 15. Percentages of incorrect gender agreement in animacy conditions in the fillin the gap task 99

Figure 16. Percentages of incorrect gender agreement in gender-mismatched conditions in the fill-in the gap task. 100

Figure 17. Percentages of incorrect gender agreement in gender-matched conditions in the fill-in the gap task 100

Figure 18. Percentages of incorrect gender agreement in animacy conditions in the written description task. 101

Figure 19. Percentages of incorrect gender agreement in gender-mismatched conditions in the written description task. 
Figure 20. Percentages of incorrect gender agreement in animacy conditions in the

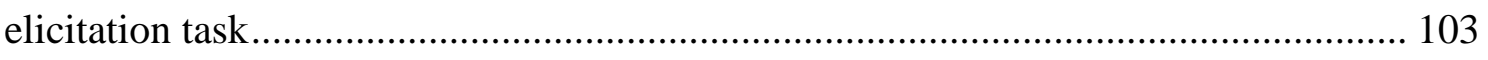

Figure 21. Percentages of incorrect gender agreement in gender-mismatched conditions in the elicitation task. 103

Figure 22. Percentages of incorrect gender agreement in gender-matched conditions in the elicitation task. 104

Figure 23. Percentages of incorrect gender agreement in animacy conditions in the picture description task 105

Figure 24. Percentages of incorrect gender agreement in gender-mismatched conditions in the picture description task. 105

Figure 25. Percentages of incorrect gender agreement in gender-matched conditions in the picture description task 106

Figure 26. Percentages of incorrect gender agreement in comprehension and production task

Figure 27. Percentages of incorrect gender agreement between comprehension and written and oral production task in the Basque/Spanish bilingual groups 110

Figure 28. Percentages of incorrect gender agreement in comprehension and production tasks in the L1 Spanish groups 114

Figure 29. Percentages of incorrect gender agreement in comprehension and written and oral production tasks in the three L1 Spanish control groups 115

Figure 30. Percentages of errors in the three proficiency levels in the picture selection task. 120

Figure 31. Percentages of errors in the three proficiency levels in the grammaticality judgment task 121

Figure 32. Percentages of errors in the three proficiency levels in the moving window task

Figure 33. Percentages of errors in the three proficiency levels in the fill-in the gap task 123

Figure 34. Percentages of errors in the three proficiency levels in the picture description task.

Figure 35. Percentages of errors in the three proficiency levels in the elicitation task 124 Figure 36. Percentages of errors in the three proficiency levels in the picture description task. 
Figure 37. Comparison of the percentages in gender agreement errors and other errors in the experimental groups.

Figure 38. Percentages of incorrect gender agreement and other forms in the L1 Spanish groups

Figure 39. Percentages of errors in the native and non-native groups in the picture selection task 138

Figure 40. Percentages of errors in the native and non-native groups in the grammaticality judgment task 139

Figure 41. Percentages of errors in the native and non-native groups in the moving window task

Figure 42. Mean RTs in the native and non-native groups in the possessive interest area 141

Figure 43. Mean RTs in the native and non-native groups in the possessee interest area

Figure 44. Mean RTs in the native and non-native groups in the contextual interest area 142

Figure 45. Mean RTs in the native and non-native groups in the response interest area

Figure 46. Percentages of errors in the native and non-native groups in the fill-in the gap task

Figure 47. Percentages of errors in the native and non-native groups in the written description task

Figure 48. Percentages of errors in the three proficiency levels in the elicitation task 146 Figure 49. Percentages of errors in the three proficiency levels in the picture description task.

Figure 50. Syntactic representation of gender agreement for the participants 161

Figure 51. Difficulty scale of the experimental tasks 170 


\section{List of abbreviations}

1: First person

3: Third person

[V2]: Verb second

AdjP: Adjective Phrase

AgrP: Agreement Phrase

AspP: Aspect Phrase

AUX: Auxiliary

BATXI: Batxilergoa

BQ: Background questionnaire

BS: Basque/Spanish bilinguals

CEM: Cumulative Enhancement Model

CLIL: Content and Language

Integrated Learning

Dao: Definite article overuse

DBH: Derrigorrezko Bigarren

Hezkuntza

DEM: Demostrative

DET: Determiner

DM: Distributed Morphology

DP: Determiner Phrase

ERP: Event-related potential

ET: Elicitation task

FEM: Feminine

FFFH: Failed Functional Feature

Hypothesis

FIG: Fill-in the gap task

FL: Foreign Language

FonF: Focus on Form

FRH: Feature Reassembly Hypothesis

FT/FA: Full Transfer/Full Access

GEN: Genitive

GenS: Saxon genitive overuse
GenP: Gender Phrase

GJT: Grammaticality judgment task

GMAN: Animate gender-matched condition

GMBP: Body-part gender-matched condition

GMIN: Inanimate gender-matched condition

GMMAN: Animate gender-mismatched condition

GMMBP: Body-part gendermismatched condition

GMMIN: Inanimate gendermismatched condition

IH: Interpretability Hypothesis

IL: Interlanguage

L1: First language

L2: Second language

L3: Third language

MASC: Masculine

MP: Minimalist Program

MSIH: Missing surface inflection hypothesis

MUH: Morphological

Underspecification Hypothesis

MW: Moving window task

Myo: 'My' overuse

$\mathbf{N}$ : Noun

NP: Noun Phrase

nP: Noun Phrase

NUM: Number

NumP: Number Phrase 
Omi: Omission

OPT: Oxford Placement Test

PDT: Picture description task

PF: Phonological Form

Pl: Plural

Poss: Possessive

PossP: Possessive Phrase

Posspl: Possessive adjectives plural

PP: Prepositional phrase

PRES: Present

PROG: Progressive

PST: Picture selection task

PTH: Prosodic transfer hypothesis

RDH: Representational Deficit

Hypothesis

REFL: Reflexive

RT: Reaction time
SG: Singular

SLA: Second language acquisition

SP: L1 Spanish speakers

SSC: Shallow Surface Hypothesis

Tda: Two definite articles

TL: Target language

TP: Tense Phrase

Tp: Two pronouns

TPM: Typological Primacy Model

UG: Universal Grammar

UNI: University

$\mathbf{V}$ : verb phrase

VP: verb phrase

vP: verb phrase

WDT: Written description task

Yo: 'Your' overuse 


\section{CHAPTER 1. INTRODUCTION}

\subsection{Introduction}

The goal of this dissertation is to examine the acquisition of gender agreement with third person singular possessive adjectives (his/her) in English as a third language (L3) by Basque/Spanish bilinguals in a minimal input setting. Anecdotal evidence as well as a previous exploratory study on this topic (Imaz Agirre and García Mayo, 2013) showed the problems L3 English learners have establishing gender agreement between the possessor and the possessee, as in (1).

(1) *She is brushing his teeth.

The sentence in (1) is ungrammatical with the reading in which the possessive adjective is intended to refer to the feminine subject.

This dissertation is framed within a formal approach to language acquisition, namely, generative grammar, and, more specifically, within the Minimalist Program (MP) (Chomsky, 1995, 1998, 2001), in which features have become the center of learnability theory. In generative linguistic theory, features have been defined as the primitive elemental units that make up the lexical items of every language, and the differences between languages have been claimed to be due to the differences among these features.

Recent proposals on adult second language (L2) acquisition have attempted to predict the conditions under which features of certain types (interpretable vs. uninterpretable) will ultimately fail to be acquired (Lardiere, 2009). Feature interpretability has been claimed to be one of the sources of parametric variation. Interpretability has to do with the intrinsic nature of features and bears on whether a feature of a particular item makes a semantic contribution to interpretation (Adger, 2003; Pesetsky and Torrego, 2004). Two types of features have been identified in the MP: [+ interpretable] and [+ uninterpretable] features. [+ interpretable] features (i.e. gender in English) interface with the semantic-conceptual system of the mind. In the derivation of a sentence, such features are checked but never eliminated, whereas [+ uninterpretable] features, which make no semantic contribution, need to be both checked and eliminated by agreement operations (i.e. gender agreement between the noun and the adjective in Spanish) (Liceras, 2009; Liceras, Zobl and Goodluck, 2008b). 
Two main accounts have been proposed to explain the acquisition of morphosyntactic features in an L2, which have been extended to L3 acquisition (Jaensch, 2011; Villarreal Olaizola, 2011). On the one hand, the first feature availability accounts explained the difficulties in the acquisition of [+ uninterpretable] features on the basis of maturational constraints (i.e. Hawkins and Casillas, 2008; Hawkins and Chan, 1997; Hawkins and Hattori, 2006; Tsimpli and Dimitrakopoulou, 2007; Tsimpli and Mastrovapoulou, 2007). These accounts claimed that learners of languages that do not have a certain [+uninterpretable] feature would not reach native-like acquisition of that feature in the L2. On the other hand, non-maturational accounts claimed that non-native learners seem to attain native-like mastery of those features that are not activated in their L1 (i.e. Prévost and White, 2000; White, Valenzuela, Kozkowska-MacGregor and Leung, 2004). Proponents of maturational accounts argued in favor of a permanent syntactic impairment motivated by age of acquisition whereas those of non-maturational accounts explained feature availability difficulties on the basis of performance difficulties. According to the latest proposals in generative research, feature availability or feature re-assembly of both interpretable and uninterpretable features has been identified as one of the most challenging task learners have to face the process of L2 acquisition (Liceras, 2010). Apparently, the mapping between semantic gender and pronominal 'gender' in English seems to be quite a simple and direct one-to-one correspondence (Lardiere, 2000). The acquisition of gender distinctions in English third person pronouns has been suggested as an example of a basic point of modularity (Lardiere, 2000). In other words, the assignment of morphological gender to third person pronouns in English (he, she and it) is co-extensive with the semantic notion of 'natural gender' associated with sex distinctions of 'male', 'female' and 'neuter'.

In the last decade, generative L2/Ln researchers have also focused their attention on problems of processing (Juffs, 1998, 2006) and more recently on neurolinguistics (Yusa, Koizumi, Kim, Kimura, Uchida, Yokoyama, Miura, Kawashima and Hagiwara, 2011). This attention has contributed to incorporate and develop techniques from psycholinguistic research (i.e. reaction time studies) and ideas from language pedagogy (i.e. using more contextualized tasks instead of decontextualised traditional grammaticality judgment tasks) (Whong, Gil and Marsden, 2013). Furthermore, recent research on L3 acquisition has concentrated on the acquisition of morphosyntactic aspects. This research has mainly dealt with initial state L3 learners in order to examine 
the variables conditioning morphosyntactic transfer at these early stages (Bardel and Falk, 2007; Flynn, Foley and Vinnitskaya, 2004; García Mayo and Rothman, 2012; Rothman, 2011; Rothman and Halloran, 2013). However, more recently, a new subfield in the generative framework has targeted the L3 acquisition process in learners beyond the initial state in order to delineate developmental sequences, feature availability and ultimate attainment in multilingual speakers (García Mayo and Rothman, 2012; García Mayo and Villarreal Olaizola, 2011; Iverson, 2010; Jaensch, 2009, 2011; Leung, 2007, 2009; Villarreal Olaizola and García Mayo, 2009). The present dissertation aims to contribute to this recent line of research.

\subsubsection{Aim and rationale of the study}

The present study investigated the developing English interlanguage (IL) of Basque/Spanish bilingual learners in a foreign language (FL) setting. In particular, we examine the acquisition of gender agreement with third person singular possessive adjectives (his/her). The study had four goals:

i) to explore whether the differences among the three languages in terms of animacy and the directionality of the agreement relationship between the possessive and the possessor or the possessee (i.e. 'gender attraction effects) have an impact how learners establish on gender agreement in English;

ii) to contribute to the ongoing debate about whether variability in non-native grammars only affects [+uninterpretable] features or whether [+interpretable] features are similarly susceptible to variation. If variability is found, in [+interpretable] whether it can be attributed to a reassembly difficulty or to the impairment of underlying grammars;

iii) to assess the role of language proficiency in the acquisition of a specific linguistic feature and to establish a developmental sequence for Basque/Spanish bilinguals regarding the establishment of gender agreement;

iv) to determine the extent to which previous linguistic knowledge affects the acquisition of an existent feature in the L3.

Only a few studies have analyzed the acquisition of interpretable features in non-native grammars (cf. Guijarro-Fuentes, 2012). Besides, the acquisition of these features in L3 has not been investigated from a generative perspective yet. Thus, this study innovates 
by analyzing data of Basque/Spanish bilingual learners acquiring an interpretable gender feature in L3 English. By discussing feature availability in the light of L3 transfer models, these findings will hopefully make significant contributions to feature availability accounts with a new language combination as well as shed some light on the developmental sequence and ultimate attainment of multilingual learners.

A current line of research in generative L2 acquisition focuses on the role of explicit teaching on learning (Whong et al. 2013; Whong, Gil and Marsden, 2014). The research tackling the acquisition of specific linguistic properties could be useful for teachers to help their students make sense of the language they are learning. In this vein, the present dissertation could provide interesting pedagogical implications so that teachers could be familiar with those gender agreement contexts which learners find particularly difficult and could thus focus their attention on them.

\subsubsection{The study}

A total of 211 participants were included in the present study: an experimental group of 117 Basque/Spanish bilinguals and two control groups of 70 L1 Spanish learners (without any knowledge of Basque) and 24 English native speakers. Besides, in both non-native groups learners were divided into three groups on the basis of their proficiency level: elementary, intermediate and advanced. Participants completed seven experimental tasks: three comprehension tasks (a picture selection task, a grammaticality judgment task and a moving window task), two written production tasks (a fill-in-the gap task and a written description task) and two oral production tasks (an elicitation task and a picture description task). For the methodological design of the experiment, animacy and gender contexts were manipulated in the antecedent and in the possessee creating three animacy contexts (animate, inanimate and body part) and two gender conditions (gender-matched and gender-mismatched).

Within the experimental group(s) three analyses were conducted for the comparison of learners' accuracy in linguistic contexts (i.e. animacy and gender contexts), the comparison between tasks and the comparison between proficiency levels. Besides, these same analyses were conducted with the non-native control group in order to analyze whether both non-native groups showed similar results. Finally, learners in the non-native groups were compared to native speakers in order to examine the former. 
Findings revealed that Basque/Spanish learners make persistent gender agreement errors, reaching a fossilization state under some experimental conditions. Hence, learners seem to show re-assembling difficulties in establishing a gender agreement relationship (Lardiere, 2009) since they did not reach native-like accuracy even at advanced levels. Moreover, potential facilitative transfer does not seem to emerge from the typological differences between the three languages involved in terms of animacy and gender attraction effects. Finally, the nature of the task (comprehension vs. production and online vs. offline), cross-linguistic influence and proficiency level seem to be important factors in explaining accuracy rates in establishing gender agreement. The present dissertation, contributes current non-native generative research in two ways: the number of participants and data triangulation obtained from various offline and online tasks.

\subsubsection{Organization of the dissertation}

This dissertation is organized in six chapters. Chapter 1 has introduced the topic and has provided the rationale for the study. Chapter 2 provides an overview of the theoretical framework. More specifically, the general structure of possession and gender in the determiner phrase (DP) that will be assumed throughout the study will be presented first, as well as the characteristics of the three languages under study (Basque, Spanish and English) regarding the nature of the gender and possession relationship. Next, recent psycholinguistic evidence that could affect the acquisition of the target structure (due to the differences between the three languages) will be displayed. Afterwards, feature availability accounts proposed for non-native learners' grammars will be summarized. The final section of this chapter presents current approach to transfer in L3 acquisition. Chapter 3 presents the most relevant findings from studies carried out on gender agreement. Specifically, findings on the acquisition of gender agreement in native monolingual and early bilingual children will be presented as well as on the acquisition of L2 and L3 learners. Chapter 4 introduces the research questions and the hypotheses entertained as well as the methodology followed, including participants, data collection instruments and data codification. Chapter 5 presents the results obtained for the experimental Basque/Spanish bilingual groups and for the L1 Spanish and native speakers' control groups as well as the comparison of non-native learner groups with native speakers. In Chapter 6, the discussion of the major findings will be 
presented in the light of the hypotheses entertained. Finally, Chapter 7 summarizes the final conclusions and opens new lines for further research. 


\section{CHAPTER 2. THEORETICAL FRAMEWORK}

Current linguistic theory within the generative framework claims that parametric differences are due to functional categories such as complementizer, tense, agreement, determiner and number and their features (tense, number, person, gender and case). Following minimalist analyses (Chomsky, 2001) gender and number are $\Phi$ (phi)features (agreement features) that are found on the head noun and enter into a checking relationship with the corresponding features in the structure. The $\Phi$-features of nouns are said to be interpretable, that is, they contain information that is needed for semantic interpretation. The corresponding features of determiners and adjectives are uninterpretable and have to be deleted by means of the operation known as feature checking (Carstens, 2000), more specifically the operations check, value and merge (Chomsky, 2001). Nevertheless, gender, as opposed to number, is realized on one of the syntactic heads of the noun phrase (NP) and the choice of the syntactic head that bears gender specification is subject to cross-linguistic variation (Liceras, 2010; Ritter, 1993; White et al. 2004). This variation between languages has been shown to follow from a treatment of gender as a feature and not as a functional category. The nature of the gender feature will be further discussed in section 2.3.

The work by Chomsky (2001, 2007, 2008) has set the way for the minimalist research agenda in second language acquisition (SLA) that has been conducted within the generative framework in the recent decades. Within the MP (Chomsky, 1993, 1995), features (both interpretable and uninterpretable features) have become the center of learnability theory. Three main sources of variability have been identified: feature strength, hierarchical variability and interpretability. Interpretable features are required for semantic representation whereas uninterpretable features are required for purely formal reasons (i.e. movement), they must be checked against corresponding features in the course of a derivation and must be deleted (Ionin, 2013).

In more recent work, it has been proposed that the set of features is no longer divided into two subsets made up of interpretable and uninterpretable features. Instead, all features come in pairs so that all interpretable features have the same features that are uninterpretable (make no semantic contribution). In this framework, the interpretable features value their uninterpretable counterparts, which are subsequently eliminated. Hence, features could be arranged in pairs: a valued and an unvalued counterpart that 
requires valuing via the operation Agree. However, the existence of a dichotomy between interpretable and uninterpretable features has been questioned in L1 acquisition and it has been suggested that the most 'minimalist' possible conception of language would admit nothing but interpretable features (Pesetsky and Torrego, 2004).

Regarding SLA, the learnability task focused on the acquisition of uninterpretable features since the absence of a formal feature in the grammar could entail an absence in the interlanguage (IL) and therefore, a breakdown in feature checking. Nevertheless, if the proposal of features having an interpretable and an uninterpretable value is correct, one possible consequence is that the focus of L2 acquisition research shifts from feature availability accounts to difficulties in reassembling features.

This chapter will be structured as follows: Section 2.1 provides a general review on the DP with a special focus on possession and gender. Section 2.2 describes the possession relationship and the gender feature make-up in the three languages involved in this study (i.e. Basque, Spanish and English). Then, Section 2.3 will present the relevant evidence on the linguistic aspects (i.e. animacy and gender attraction effects) examined in this dissertation. In Section 2.4, the feature variability accounts posited in current generative SLA will be reviewed. Section 2.5 will illustrate the empirical evidence on L3 acquisition during the initial stage as well as in developing interlanguages.

\subsection{General review of the structure of the Determiner Phrase (DP)}

All current generative research on the syntax of the nominal projection has been influenced by the proposal of the 'DP hypothesis' (Abney, 1987) ${ }^{1}$. This hypothesis assumes that the projection of the noun is part of a complex functional projection, the DP. One of the central issues with respect to the syntax of DPs concerns the parallelisms between the nominal domain and the clausal domain (verbal domain). The former is claimed to contain functional projections just like the latter does (i.e. Tense Phrase (TP), Agreement Phrase (AgrP), Aspect Phrase (AspP), etc.).

\footnotetext{
${ }^{1}$ The traditional view of the nominal system (the DP functional structure) has been put into question in recent research studies. Thus, based on evidence from L2 studies in Serbian/Croatian/Bosnian (languages without articles), Trenkic argues that neither is the DP projected on the top of nominal phrases in these languages, nor is it a universal category (see Trenkic, 2004 for further discussion). Nevertheless, in this study Abney's (1987) proposal for DP structure will be assumed for Basque (Artiagoitia 1998, 2002), Spanish and English.
} 
Under many current analyses, DPs contain a functional category NumP (number phrase), located between D and NP, as shown in (2) (Bernstein, 1993, 2008; Carstens, 1993; Ritter, 1991; Valois, 1991). Num (number) has number features as well as gender features in some accounts (Ritter, 1993).

(2)

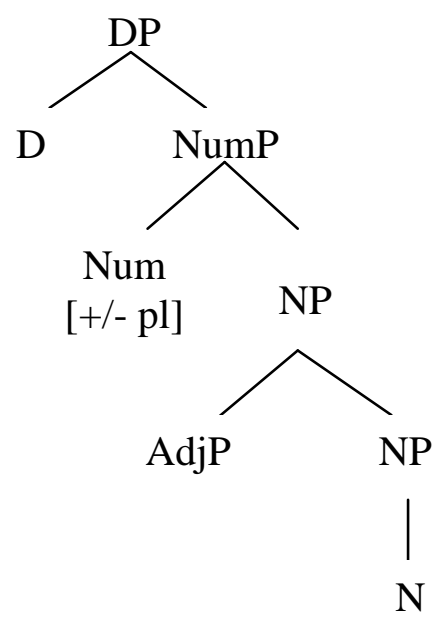

Further research in this framework proposed a series of other functional categories between DP and NP. It has been hypothesized that PossP (possessive phrase) (Alexidou, Haegeman and Stavrov, 2007) could also be projected between the DP and $\mathrm{NP}^{2}$. However, the proposal of an independent projection for Gender (Bosque and Picallo, 1996) has been a controversial issue. These proposals will be analyzed in section 2.1.1 (for possessives) and in section 2.1.2 (for gender).

\subsubsection{General review of possession}

Possession is an asymmetric relationship between two constituents, the referent of one of which (the possessor) in some sense possesses (i.e. owns, has a part, rules over, etc.) the referent of the other (the possessee). The base position of the possessor has been a controversial issue within generative linguistic theory ${ }^{3}$ (Alexidou and Wilder, 1998). Similar to the proposal of the complex structure of VP (verb phrase) (Chomsky, 1993, 1995; Hale and Keyser, 1993; Larson, 1988) and assuming cross-categorical symmetry between the structure of the VP and DP, Alexidou et al. (2007) propose that NPs should comprise an outer $\mathrm{nP}$ (noun phrase) shell headed by a light noun and an inner NP

\footnotetext{
${ }^{2}$ See Mallén (1997) for further discussion on the structure of DPs.

${ }^{3}$ It has been proposed that VPs have a complex internal structure comprising an outer VP shell headed by an abstract light verb (' $v$ ') and an inner VP core headed by a lexical verb (V).
} 
headed by a lexical noun. The outer $\mathrm{nP}$ shell itself would be the complement of a higher functional head, such as Number and Gender (see Alexidou et al. (2007) for further discussion). Following Radford's (2000) analysis, Alexidou et al. (2007) propose that possessors receive the possessor role in the specifier position of $\mathrm{nP}$ (or PossP) and move to a higher functional position. Although the possessor DP is outside the projection of the noun, it does form a constituent, labeled PossP or nP with the noun, as (3) illustrates:

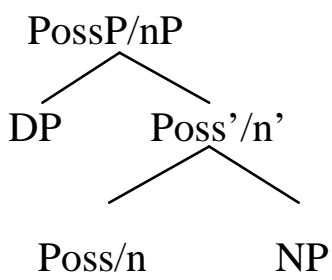

In addition to this hypothesis, there are a number of alternative proposals concerning the base position of possessors (see Alexidou et al. 2007 for further discussion). However, the common claim is that possessors often appear relatively high in the DP, suggesting they may have undergone some DP-internal movement.

Moreover, two types of possession can be distinguished: alienable possession (4) and inalienable possession (4):

(4) a. John's book

b. John's hand, John's father

Both types of possession relate a possessor and the entity he or she possesses, the possessee. In alienable possession, there is no intrinsic dependency relationship between the possessor and the possessee (Alexidou et al. 2007). The noun book is not defined by its relation to John, the concept 'book' does not directly invoke an intrinsic relation to some individual. Moreover, the relationship between John and book is not uniquely defined. John's book could refer to a book that John bought, wrote, owned, etc.

However, in inalienable possession the two entities, the possessor and the possessee, are semantically dependent (Vergnaud and Zubizarreta, 1992). An inalienable object is a semantically dependent entity in the sense that it is intrinsically defined by another 
object (e.g. body parts or kinship relations) ${ }^{4}$. For example, human body parts are defined with respect to a typical individual, which consists of two eyes, a mouth, two hands and so on. Similarly, kinship terms such as mother, father, brother, sister, etc. are defined by the relationship between two entities. That is, when we evoke the entity defined as father we automatically evoke an entity that is his child ${ }^{5}$.

\subsubsection{General review of gender}

Gender is most commonly defined as 'classes of nouns reflected in the behavior of associated words' (Hockett, 1958:231). The term gender may refer to both the classes of nouns (a language may have two or more genders) and the grammatical category (a language may or may not have the category of gender (Kibort and Corbett, 2008, 2010).

The central aspect of the gender system in any language is the gender assignment system, a set of rules by which nouns are designated gender. According to Corbett (1991, 2013), assignment may depend on two types of information about the noun: the meaning (semantics) and the form. Information about form may be of two types: wordstructure, comprising both derivation and inflection (morphology) and sound-structure (phonology). Thus two gender assignment systems are attested in languages: the semantic gender assignment system and the semantic-and-formal gender assignment system. In languages with a strict semantic gender assignment system the meaning of a noun is sufficient to determine its gender. Many languages have a predominantly semantic gender assignment system, where assignment of gender to some nouns is semantically transparent but there are some exceptions. Besides, in many languages, apart from the semantic gender assignment, there are additional rules (phonological and morphological) for assigning gender to nouns according to their form (Kibort and Corbett, 2008).

\footnotetext{
${ }^{4}$ Kin-different contexts are those where the (natural) gender possessor and the gender of the possessed entity are different, whereas kin-same contexts are those where the gender of the possessor and the gender of the possessed entity coincide. For example:

(i) John (m) talks with his (m) mother (f) (kin-different context).

(ii) John (m) talks with his $(\mathrm{m})$ father $(\mathrm{m})$ (kin-same context).

${ }^{5}$ In the experimental part of this study both alienable and inalienable possession structures will be targeted.
} 
Moreover, gender is characterized by a constituent outside the noun itself that must agree in gender with the noun. Thus, a language has a gender system only if there is an agreement dependent on nouns of different classes (Corbett, 1991). Agreement can appear in the noun phrase, on the predicate of the clause, on an adverb and on an anaphoric pronoun outside the clause boundary. As Barlow (1992) suggested antecedent-anaphor relations are accepted as agreement, languages in which gender distinctions are absent from NP modifiers and from predicates and in which free pronouns present the only evidence for gender, can be counted as having a (pronominal) gender system. The best known example of a pronominal gender system is English.

Regarding morphosyntax, gender is a morphosyntactic feature since it is required for agreement (Kibort and Corbett, 2008). Gender is an inherent feature of nouns, and a contextual feature (determined through agreement) for any other elements that have to agree with the nouns in these features. Typically, gender is lexically supplied and its value is fixed for the noun.

In contrast, the gender of a noun in a gendered language must be available, but it can be derived from other information (i.e. semantic, morphological or phonological).

Thus, in some languages, gender values (i.e. masculine, feminine, neuter) are not predictable on the basis of some semantic feature or property of the noun, e.g. sex. Gender values are largely arbitrary and their features could be said to be uninterpretable precisely because they embody a purely grammatical function. Concerning the relationship between gender and syntax, although there seems to be a relatively systematic link between the form of the noun and its gender for some languages, a head Gender cannot be designated (Alexidou et al., 2007) ${ }^{6}$.

Di Domenico (1997) distinguishes between two gender types: i) a non-intrinsic gender which is variable and necessarily [+interpretable] and ii) an intrinsic gender which is

\footnotetext{
${ }^{6}$ Alternative hypotheses advocate for the existence of a GenP. For instance, Bernstein (1993) proposed that the stem of the noun should be decomposed into $\mathrm{N}$ and the Word Marker and that Word Marker projects a separate projection: a Word Marker Phrase (other linguists, such as Picallo (1991), use the label Gender or Gender Phrase (GenP)). As gender is an inherent property of noun, GenP is taken to be more closely associated with $\mathrm{N}$. Postulating a syntactic projection for gender creates a way to account for Gender agreement between the noun and the adjective.
} 
invariable. The former is related to animacy, while the latter is unpredictable. Consider the examples in (5):

(5) a. chica ('girl') [+interpretable, +variable]

b. mujer ('woman') [+interpretable, -variable]

c. casa ('house') [-interpretable, -variable]

In (5a) the gender of chica is variable (chica as opposed to chico ('boy')) and interpretable, the gender of (5b) is interpretable but cannot be varied and the gender on (5c) is uninterpretable and cannot be varied. Consequently, an interpretable feature can be non-intrinsic (hence variable), but a non-interpretable feature must be non-intrinsic.

Regarding the syntactic representation of the category Gender, it is argued that, universally, variable (i.e. interpretable) gender is located on Num and that invariable (i.e. uninterpretable) gender is located on the $\mathrm{N}$ itself. In other words, for Di Domenico (1997) gender does not project its own functional projection. In order to capture the relation between varied gender and animacy of the referent of the noun, Di Domenico (1995, 1997) proposes that animacy is an inherent feature of those nouns: actor/actress, king/queen, horse/mare. In this case Gender is assigned to the noun as it enters the numeration, a procedure assumed by Chomsky (1995) for non-intrinsic features (De Vincenzi and Di Domenico, 1999). The assumption that Gender is related to Number has also been proposed by Ritter (1993).

Summarizing, there is meager evidence for postulating a Gender functional category in the syntax. Gender is predetermined in nouns, it is arbitrary in some languages (i.e. Spanish), and consequently, uninterpretable. Apart from the cases in which Gender is driven by the feature [animacy], it cannot be chosen. It is an inherent part of the lexical entry of the noun and is to be learnt with the noun itself.

\subsubsection{General review of animacy}

Languages in the world categorize nouns into classes being animacy a classification of nouns in some languages (Corbett, 1991). This value refers to the degree to which nouns are "alive" or animate. Some languages separate a noun into whether it is animate or inanimate (i.e. a person versus a window). Within a language there is never overlap or ambiguity of noun class, but across languages, classification can differ. Other 
languages therefore may have a more complex animacy structure that may be a class, not only of division, but also of hierarchy.

The feature gender always has a semantic core (Corbett, 1991); the system is based on sex or on animacy, though there may be parts of the system that are less clear. In fact, linguistic gender systems are frequently linked to biological sex although alternatively other languages have larger gender systems based on grammatical forms. In cases where biological sex is not the semantic core, the core will be some type of animacy (Corbett, 2012). There is no problem about expressing distinctions based on sex in such languages when required, by the use of separate lexical items or by qualifying items with the meaning 'male/female'.

\subsection{Feature comparison in the three languages: Basque, Spanish and English}

Basque, Spanish and the target language, English, are typologically different languages. Basque is an SOV (Subject Object Verb) ergative-absolutive language with non-Indo European roots and unknown origin. Spanish is a SVO nominative-accusative language of Latin origin. Finally, English is a Germanic nominative-accusative SVO language. In this section, the typological differences regarding possession and gender in terms of syntax, morphology and semantics between the three language involved in the study, Basque, Spanish and English, will be outlined.

\subsubsection{Syntax}

In Basque possessive pronouns are inflected pronominal DPs bearing genitive suffixes and they may co-occur with the definite article (Artiagoitia, 1998, 2002, 2009), as illustrated in (6):

(6) Ber- e liburu-a.

DEM-GEN book- DET

'His/her book'

Possessive pronouns establish agreement between the possessive and the possessor in number. This relationship could be referred to as backward agreement and it is illustrated in (7): 
(7) a. Jon ber- e rekin jolaste-n ari da.

John DEM-GEN mother.DET-with play- PRES PROG AUX

'John is playing with his mother.'

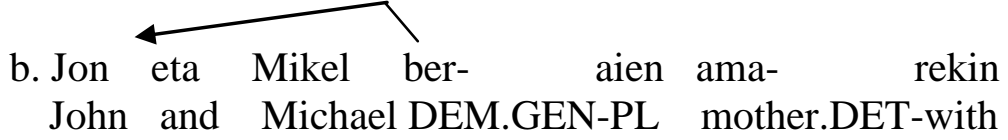

jolast-en ari dira.
play.PRES PROG AUX
'John and Michael are playing with their mother.'

In Spanish the possessive occupies the position of the determiner and, in fact, functions as such. Unstressed possessives usually appear prenominally and DPs may only have one prenominal possessive (Picallo and Rigau, 1999). Possessive pronouns can appear neither with the indefinite article (cf. (8)) nor with a quantifier (cf. (8)):

(8) a. *Un mi-

DET.MASC my.SG friend

'A my friend'

b. *Algún mi-Ø libro

some my.SG book

'Some my book'

C. *Muchos mi-s amigo-s

many my-PL friend-PL

'many my friends'

Monosyllabic possessives (mi (my), tu (your), su (his/her)), weak possessives according to Cardinaletti (1998), agree only in number with the head noun, therefore, forward agreement is established as illustrated in (9): 
(9) a. Él juega con su- $\varnothing$ hermano.

he play.3.SG with his-SG brother-SG

'He is playing with his brother.'

b. Él juega con su-s herrttano-s.

he play.3sg with his-PL brother-PL

'He is playing with his brothers.'

Thus, Spanish displays a syntactic form of agreement between the possessive and the noun it accompanies (the possessee) and there is no gender marking for the third person singular possessive.

In English, the possession relationship may be expressed by (i) prenominal genitive DPs represented by the so-called Saxon genitive 's' (John's house), (ii) postnominal 'of prepositional phrase (PP)', and (iii) possessive pronouns. Possessive pronouns do not exhibit overt morphological agreement except for third person singular possessives that show gender differences for masculine, feminine and neuter (his, her, its) (Haegeman, 1994). Like in Basque, these pronouns agree with the possessor in gender so backward agreement is established, as illustrated in (10):

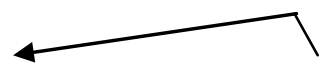

a. $\mathbf{H e}_{\mathbf{i}}$ is playing with $\mathbf{h i s}_{\mathbf{i}}$ brother.

b. She $\mathbf{e}_{\mathbf{i}}$ is playing with her $_{\mathbf{i}}$ brother.

\subsubsection{Morphology}

Basque is a morphologically rich language. Nouns display affixes showing genitive case morphology and verbs have person and case agreement suffixes. Pronouns have number features but no gender feature. The rich morphological system allows for the omission of the pronouns indicating possession since this relation is shown through suffixes. In specific contexts, such as inalienable contexts and more specifically in body part contexts, no possessive relationship is expressed as illustrated in (11), where a plural determiner is used: 
Hortz-a-k garbitzen ditu.

Tooth-DET-PL wash.PRES. AUX

'He brushes his teeth.'

Morphologically, possessive forms in Spanish present an inherent lexical feature of person, more specifically of third person. The feature number will depend on the number of the head noun the possessive has to agree with (e.g. su bolígrafo (his/her/their pen) vs. sus bolígrafos (his/her/their pens)). Like in Basque, a definite article is used with nouns denoting inalienable nouns (i.e. body parts) (Ambadiang, 1999), as (12) illustrates:

$$
\text { Se lava }
$$

los

diente-s.

REFL brush.PRES DET.MASC.PL tooth-PL

'He brushes his teeth'

The use of pronominal possessive adjectives is obligatory in order to show possession relationships. In English, unlike in Basque and Spanish, possession relationships (either alienable or inalienable contexts) are always realized by means of a possessive adjective (Alexidou et al. 2007), as (13) shows:
a. He is watering his plant.
b. He is brushing his teeth.

Bernstein and Tortora (2005) argued that the pronouns in Engish are morphologically complex, consisting of a nominative pronoun (he, you) and the endings -s or -r, which correspond to the copular forms is and are (he's, you're). As such, they are not real possessive markers, but rather, sg./pl. copulas, which together with the nominative pronoun yield a possessive pronominal form (his, your).Within this hypothesis it is accounted that the agreement between pronoun and copula is triggered in a spec-head configuration in a DP-internal agreement projection (Ritter, 1995).

\subsubsection{Semantics}

From a semantic point of view, nouns are classified in terms of [+/-animate] in Basque, rather than in masculine/feminine gender classes but there are two special cases among the [+animate]: 
(i) Nouns that are characterized as 'emea' (female) by means of suffixes, such as '-sa' s (i.e. 'markes'/'markesa' (marquis/marchioness)). 'Markes' is obligatorily [+masculine] and 'markesa' is [+feminine] (Artiagoitia, 2011).

(ii) In some non-standard varieties (and due to Spanish loans), there are some masculine/feminine differences like in 'ingeniero'/'ingeniera' (engineer (masc)/ engineer (fem)).

Semantically, there are two types of gender in Spanish (Ambadiang, 1999). Firstly, semantically determined gender is based on natural gender (i.e. gato (cat)). There are items that require two denominations like 'caballo-yegua'(horse/mare), which could, at the same time, display canonical word-encoding (caballo-yegua) or not (padre-madre (mother/father)). This gender distribution is essentially based on sex references.

Secondly, inanimate nouns are classified in terms of masculine/feminine on the basis of an arbitrary criterion although in some cases gender assignment follows a morphosyntactic pattern: '- $o$ ' for masculine and '- $a$ ' for feminine illustrate a canonical word ending and $-e$ and -consonant a non canonical word ending. The former is considered the unmarked form in Spanish whereas the latter is the marked counterpart (Harris, 1991). Besides, Spanish (unlike Basque and English) shows agreement between the head noun of a phrase and the DET and the adjective modifying it.

Gender in English is assumed to be only semantic in nature (interpretable according to Adger (2003)) since there do not seem to be any syntactic rules which refer to gender distinctions explicitly. More specifically, gender is encoded either in different lexical items (e.g. mare/horse) (suppletion) or in forms like actor/actress; lion/lioness, where the feminine form can be considered as derived from the masculine via suffixation and only third person singular pronouns distinguish gender morphologically (he/she/it) (Haegeman and Guéron, 1994).

In sum, the three languages involved in this study differ considerably when establishing possession relationships and gender agreement. Regarding possession, both Basque and English establish agreement between the possessive and the possessor (semantic /interpretable agreement) whereas in Spanish such agreement is found between the 
possessive and the possessee (syntactic/uninterpretable agreement). In the case of gender, gender is encoded in nouns in Basque and English hence gender could be considered an interpretable feature. In Spanish, even though gender is also semantically determined in animate nouns, uninterpretable gender features are found in the determiner and the adjective. Table 1 presents a summary of the most relevant characteristics.

Table 1. Summary of the encoding of possession and gender in Basque, Spanish and English

\begin{tabular}{|c|c|c|c|c|}
\hline & \multirow{3}{*}{$\begin{array}{c}\text { BASQUE } \\
\text { Det and Poss NOT } \\
\text { in complementary } \\
\text { distribution }\end{array}$} & \multirow{3}{*}{$\begin{array}{c}\text { SPANISH } \\
\text { Det and Poss in } \\
\text { complementary } \\
\text { distribution }\end{array}$} & \multirow{3}{*}{$\begin{array}{c}\text { ENGLISH } \\
\text { Det and Poss in } \\
\text { complementary } \\
\text { distribution }\end{array}$} \\
\hline & & & & \\
\hline \multirow{3}{*}{ 斏 } & $\begin{array}{c}\text { Placement } \\
\text { and general } \\
\text { structure }\end{array}$ & & & \\
\hline & $\begin{array}{l}\text { Agreement } \\
\text { with } \\
\text { possessor vs. } \\
\text { possessee }\end{array}$ & $\begin{array}{l}\text { Possessor (in } \\
\text { number). } \\
\text { Backwards } \\
\text { agreement }\end{array}$ & $\begin{array}{c}\text { Possessee (in } \\
\text { number). Forward } \\
\text { agreement }\end{array}$ & $\begin{array}{l}\text { Possessor (in } \\
\text { gender). } \\
\text { Backwards } \\
\text { agreement }\end{array}$ \\
\hline & $\begin{array}{l}\text { Overt vs. } \\
\text { optional }\end{array}$ & Optional & $\begin{array}{l}\text { Overt (except for } \\
\text { inalienable } \\
\text { contexts) }\end{array}$ & Overt \\
\hline \multirow{2}{*}{ 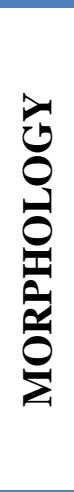 } & $\begin{array}{l}\text { Genitive } \\
\text { suffixes vs. } \\
\text { (quasi } \\
\text { suppletive } \\
\text { forms) } \\
\end{array}$ & Genitive suffixes & Suppletive form & $\begin{array}{l}\text { (quasi) suppletive } \\
\text { forms }\end{array}$ \\
\hline & $\begin{array}{l}\text { Person- } \\
\text { number- } \\
\text { gender } \\
\text { feature } \\
\text { variability }\end{array}$ & Person and number & Person and number & $\begin{array}{l}\text { Person, number } \\
\text { and gender }\end{array}$ \\
\hline \multirow{2}{*}{$\sum_{\substack{n=1 \\
\infty}}^{\infty}$} & $\begin{array}{l}\text { Natural } \\
\text { gender vs. } \\
\text { grammatical } \\
\text { gender }\end{array}$ & $\begin{array}{l}\text { Natural gender } \\
\text { [interpretable] }\end{array}$ & $\begin{array}{l}\text { Natural gender and } \\
\text { grammatical } \\
\text { gender } \\
\text { [uninterpretable] }\end{array}$ & $\begin{array}{l}\text { Natural gender } \\
\text { [interpretable] }\end{array}$ \\
\hline & $\begin{array}{l}\text { Alienable } \\
\text { vs. } \\
\text { inalienable } \\
\text { expression }\end{array}$ & $\begin{array}{l}\text { Definite article in } \\
\text { inalienable } \\
\text { contexts }\end{array}$ & $\begin{array}{l}\text { Definite article in } \\
\text { inalienable } \\
\text { contexts }\end{array}$ & No difference \\
\hline
\end{tabular}

The following section compiles evidence from psycholinguistic research on animacy effects and agreement directionality (i.e. 'gender attraction effects') in L2/L3 grammars. 


\subsection{Evidence from linguistic aspects: animacy and gender attraction effects}

The representation of gender in the three languages involved in this dissertation draws logical paths for the investigation of third person possessive adjectives. Semantic gender ([+ interpretable]) in Basque and English as opposed to grammatical gender ([+uninterpretable]) could indicate that noun animacy and the gender of the possessee could play an important role in the acquisition of the agreement relationship. Therefore Section 2.3.1 summarizes the findings on animacy effects and Section 2.3.2 outlines the evidence showing gender attraction effects.

\subsubsection{Animacy effects}

Noun animacy has been identified as a problematic feature for non-native language learners (Alarcón, 2014; Sagarra and Herschensohn, 2011). Research in the last decades has focused on the relationship between natural and grammatical gender agreement, whether noun animacy affects agreement processes and, if it does, whether it facilitates (due to gender correlation with biological sex and L1 transfer) or it inhibits them due to the greater cognitive demands of animate nouns. However, in terms of animacy, most of the research conducted in native and non-native language acquisition has been carried out from psycholinguistic and neurolinguistic approaches. In fact, neurocognitive evidence showed that monolinguals are sensitive to gender agreement violations with both animate nouns (Barber, Salillas and Carreiras, 2004; Corral, Barber and Carreiras, 2008; Osterhaut, Bersick and McLaughlin, 1997) and inanimate nouns (Barber et al. 2004). Nonetheless, research reached no conclusive findings with respect to this discussion. Moreover, this research has focused on the analysis of Spanish as a native and a non-native language, which will be reported in the next sections.

\subsubsection{Animacy effects in L2 acquisition research}

A range of studies on gender agreement in Spanish monolinguals shows differential effects in animate and inanimate nouns. Igoa, García-Albea and Sánchez-Casas (1999) found that participants made more errors in animate nouns than in inanimate ones. On the other hand, other studies showed that animate nouns were easier to process than inanimate nouns (Alarcón, 2010). These results were explained on the basis of the correlation between gender on animate nouns and biological sex. For instance, behavioral studies revealed shorter reaction times (RTs) for adjectives (Alarcón, 2009) 
and fewer agreement production errors (Antón-Méndez, 1999; Vigliocco and Franck, 1999) in conditions with animate than inanimate head nouns. Finally, there have been some other findings illustrating the lack of differences in the processing of gender agreement with animate and inanimate head nouns (Alarcón, 2014; Antón-Méndez, Nicol and Garrett, 2002; Barber et al. 2004; Corral et al. 2008). Summarizing, Spanish monolingual data on the effects of noun animacy on agreement seem to be inconclusive.

Data on the acquisition of L2 Spanish show different tendencies between gender agreement processing and agreement production errors in the comparison of animate and inanimate contexts. In processing research, Alarcón (2014) found shorter RTs in adjectives preceded by animate head nouns but longer RTs in adjectives preceded by animate attractor nouns (i.e. the attractor noun refers to the second noun in the NP). These findings indicate that animate nouns preceding the adjective are easier to process than inanimate nouns, as in (14) and (14b) (cf. Keating (2009) for further evidence on the influence of proximity between noun and modifiers in L2 processing).

a. Un libro aburrido es más difícil de

DET.MASC.SG book boring.MASC be.PRES more difficult to leer que un libro interesante

read.INF than DET.MASC.SG book interesting

'A boring book is harder to read than an interesting book.'

(Inamimate)

b. El pollo frío tiene tantas calorías

DET.MASC.SG chicken cold.MASC have.PRES as calorie.PL

y proteínas como el pollo caliente.

and protein.PL as DET.MASC.SG chicken hot

'Cold chicken has as many calories and proteins as hot chicken.'

(Animate)

However, studies within the generative framework have presented inconclusive findings. Some research showed more agreement production errors with animate nouns (Bruhn de Garavito and White, 2002) whereas others report fewer agreement production errors with animate nouns (see Fernández-García, 1999; Finneman, 1992).

In conclusion, previous research on animacy has provided mounting evidence on the difficulty or lack of it of processing gender agreement violations with animate and inanimate nouns. However, little research has analyzed whether animacy effects are 
reflected in the gender acquisition of non-native languages other than Romance languages. Moreover, the majority of these findings on animacy effects come from processing studies. Thus, the present study addresses this issue combining evidence from comprehension and production tasks as well as RTs measurements in L3 English.

\subsubsection{Gender attraction effects}

Processing research has examined whether the gender of a local noun can interfere with agreement processes in establishing gender agreement leading to so-called 'gender attraction effects' in noun-adjective relationships in Italian and French (Franck, Vigliocco, Antón-Méndez, Collina, 2008; Vigliocco and Franck, 1999) and in antecedent-pronoun relationships in Dutch (Meyer and Bock, 1999). Santesteban, Foucart, Pickering, Branigan (2010) used gender attraction effects to explore whether L1 syntax affects the processing of L2 English gender agreement. They investigated the production of possessive adjectives and possessive pronouns by 24 upperintermediate/advanced Spanish/English, French/English and Greek/English bilinguals. Regarding possessive adjectives, findings showed that only bilinguals showed gender attraction effects when the possessee did not intervene linearly between the antecedent and the pronoun, as in (15).

(15) * The waitress chases his son.

In fact, similar attraction effects were found in the three bilingual groups. These findings were interpreted in terms of the 'weaker' syntactic representation effects rather than the lack of L1 syntax effects. However, the fact that the three L1s, Spanish, French and Greek, exhibit grammatical gender or some kind of gender agreement relationship could have an effect on the results.

Besides, findings in the production of possessive pronouns revealed gender attraction effects when the possessee linearly intervened between the possessor and the pronoun. Besides, Spanish and French/English bilinguals showed more gender attraction effects than Greek/English bilinguals and English monolinguals. Hence, data suggested that bilingual learners' L2 gender agreement errors during the production of possessivepronouns production is affected by L1 syntax. 
Furthermore, regarding L3 transfer studies, there is some evidence for L1 syntax effects in the L3 acquisition literature. Jaensch (2011) examined the acquisition of gender agreement in L3 German by 6 L1 Japanese and 20 L1 Spanish learners with English as an L2. In both languages gender is exhibited differently. On the one hand, Spanish has grammatical gender as well as natural gender in animate nouns as opposed to Japanese that does not show gender. Three fill-in-the-gap tasks targeting gender assignment as well as gender agreement in the determiner and the adjective revealed differences in the representation of gender in Japanese and in Spanish. Japanese learners assigned gender on the basis of the morphophonological shape of the noun. In contrast, Spanish learners accessed the L1 when establishing gender. In the light of Distributed Morphology (DM) (Halle and Marantz, 1993), evidence supported that Spanish learners have a syntaxbased agreement system in L3 German, while the Japanese learners have associativelylearned entries in the vocabulary.

More recently Morales, Paolieri, Cubelli and Bajo (2014) examined whether grammatical gender affected 48 L1 Spanish speakers' speech production in L2 English in immersion and non-immersion settings. Participants were highly proficient in English. Using a picture-word task, participants had to name pictures in their L2 while ignoring distractor words that could be either gender-congruent (i.e. cepillo gusano) or gender-incongruent (i.e. cepillo naranja) according to the Spanish translation. Results revealed that non-immersed participants were slower naming the pictures in the congruent condition, suggesting that bilingual people are influenced by knowledge about gender in their native language, even when producing utterances in a language in which this information does not apply. However, no such influence was observed for immersed bilinguals, suggesting that immersion environment attenuates access to the native language. Authors claimed that results as evidence of transfer effects between languages with different lexical systems, which seem to depend on language immersion.

In sum, findings are not conclusive for animacy research. Psycholinguistic evidence has been found for the facilitative effect of animate nouns when establishing gender agreement (Antón-Méndez, 1999; Vigliocco and Franck, 1999) whereas some other research has found difficulties in agreement in animate nouns (Igoa et al. 1999). There is also evidence for the lack of differences in processing gender agreement in animate and inanimate noun (Alarcón, 2014; Barber et al. 2004; Corral et al. 2008). Nevertheless, acquisition data have shown more difficulties in the production of 
animate nouns (Bruhn de Garavito and White, 2002; Imaz Agirre and García Mayo, 2013). Moreover, in the L3 acquisition literature, evidence has shown that agreement relationships in L3 German are based on the L1 syntax of Spanish learners as opposed to the associatively-learned vocabulary learning of Japanese speakers (Jaensch, 2011). On the other hand, processing studies on the interference of locality on agreement processes revealed 'gender attraction effects' in Italian as well as in French (Franck et al. 2008; Vigliocco and Franck, 1999), in Dutch (Meyer and Bock, 1999) and in English (Santesteban et al. 2010).

\subsection{Feature availability accounts for non-native grammars}

In the MP features have become the center of learnability theory since they are conceptualized as the elementary building units of linguistic structure (Liceras, 2010). While the inventory of formal features is available to all human beings, not all features are activated in any given language. One of the most recent developments is shifting from the investigation of the availability of features to the different ways in which features may be combined or assembled and the problems this may create for the L2 learners (White, 2008). The next sections summarize the most relevant accounts that have been proposed on feature availability for non-native language learners (namely, representational and computational accounts).

\subsubsection{Representational accounts}

A number of related but different proposals have been suggested arguing that L2 learners' grammars are syntactically impaired. Representational impairment accounts comprise hypotheses such as the Failed Functional Features Hypothesis (FFFH) (Hawkins and Chan, 1997), the Representational Deficit Hypothesis (RDH) (Hawkins, 2003) and the Interpretability Hypothesis (IH) (Hawkins and Hattori, 2006; Tsimpli and Dimitrakopoulou, 2007; Tsimpli and Mastropavlou, 2007). Although these proposals differ in some aspects, they all claim the syntactic representations in the IL of L2 learners are somehow impaired for learners that past the critical period for language acquisition (Hawkins and Hattori, 2006). Thus, late L2 learners are claimed to be incapable of selecting and/or valuing new uninterpretable features (Herschensohn, 2013). 
These accounts focus on whether L2 learners are capable of acquiring formal features that are not present in their L1. According to the influential FFFH, IL grammars of postpuberty L2 learners are restricted to those uninterpretable formal features which are realized in the L1. If the L1 grammar represents certain features also required in the L2, the learner will not have problems. However, learners will be unable to acquire 'new' uninterpretable features.

In the $\mathrm{RDH}$, it is predicted that there should be no task differences, as an underlying deficit in the grammar should affect linguistic performance regardless of the task (oral vs. written). However, contrary to this prediction, the results show that learners were more accurate in grammaticality judgment tasks (GJT) than in production (Hawkins and Chan, 1997). These authors claimed that the GJT could be too metalinguistic and classroom knowledge would be tapped rather than the unconscious representations.

In the light of representation deficit accounts, Hawkins (1998) found inconsistency in gender agreement marking between determiners and nouns in the spoken French of L1 English speakers. The group consisted of 20 high proficient participants (10 in the United Kingdom and 10 in Canada). All the participants had to describe an animated film and only unambiguous cases of $l e$ (masculine definite article), la (feminine definite article), un (masculine indefinite article), une (feminine indefinite article) were analyzed. Results indicated a tendency to use one member of the article in a target-like way, while the other member was overgeneralized. In other words la was used only with feminine nouns (the correct form) but le was used both with masculine and feminine nouns. However, there was individual variability in terms of overgeneralizing the feminine or the masculine forms, some speakers overgeneralized the masculine form le, while others overused the feminine form la. It appeared that native speakers of English (a language without grammatical gender) overgeneralize one member of each pair of article forms.

Later formulations of representational accounts (i.e. IH) have claimed that L2 learners are specifically unable to acquire uninterpretable features whereas interpretable features remain fully acquirable (Tsimpli and Dimitrakopoulou, 2007).

More recently, VanPatten, Keating and Leeser (2012) examined 25 non-advanced Spanish learners' acquisition of verbal morphology, subject-verb inversion and adverb placement completing a self-placed reading task. Findings revealed that the non- 
nativelike performance of L2 learners with morphological inflection could be due to representational problems and not only to performance issues. However, as the authors themselves acknowledge, the fact that participants were not advanced learners, could not be indicative of learners' mental representation for morphological representation. Thus, these results may indicate a possibility that morphological problems for L2 learners may begin as representational problems in the earlier stages of acquisition and later once representations are established more robustly, they become performance problems due to mapping issues during production.

In sum, according to the representational accounts absence of overt morphology is indicative of representational deficits. The IL of post-puberty L2 learners is restricted to those uninterpretable formal features which are realized in the L1. It is predicted that there should be no task differences, as the underlying deficit in the grammar should affect linguistic performance.

\subsubsection{Computational accounts}

An alternative approach to representational impairment has suggested that problems with morphology are not necessarily representative of syntactic impairment, rather, they reflect problems with the retrieval of lexical items (or difficulty with prosody). In other words, when variable or missing inflection is observed in L2, it is missing only at a surface level. There is some kind of breakdown between the syntax and the lexicon, a processing or computational breakdown, rather than a permanently defective underlying representation (White, 2008). The problem is attributed to difficulties either in accessing particular lexical items (i.e. the Missing Surface Inflection Hypothesis (MSIH) (Prévost and White, 2000) or prosody difficulties (Prosodic Transfer Hypothesis (PTH) (Goad and White, 2006; Goad, White and Steele, 2003)).

For the MSIH, difficulties are due to a mapping problem between syntax and morphology (not to underlying deficits). Following Full Transfer/Full Access (FTFA) approaches (Schwartz and Sprouse, 1996), adult L2 learners are capable of acquiring a target language (TL) syntactic representation. Researchers predict that learners will make errors (primarily) in production (especially oral production), due to difficulties with lexical retrieval. However, in comprehension or judgments, learners are predicted to be more target-like since learners are not under the same pressure to retrieve lexical items. 
There are a number of observations related to L2 morphology that support such accounts and suggest that failed features are not implicated. On the one hand, variability is manifested as missing inflection alternating with appropriate inflection. Faulty forms (i.e. case mismatches) are much less common. The issue is the degree to which learners supply inflection rather than the accuracy of inflection. This is unexpected if certain features are totally absent or defective. Accurate suppliance suggests the presence of appropriate features and feature-checking mechanisms. On the other hand, substitutions have been reported, rather than omissions, which might seem to suggest that learners are using morphology randomly because of the absence of the corresponding underlying features (e.g. the use of the masculine gender in place of feminine but not vice versa (Bruhn de Garavito and White, 2002)). This is again unexpected if certain features are totally absent. Instead, it suggests the insertion of default vocabulary items (themselves underspecified as to certain features), consistent with the theory of Distributed Morphology (DM) (Halle and Marantz, 1993).

Regarding L1 effects, proponents of the MSIH argue for a general absence, although there can, in fact, be L1 effects consistent with these hypotheses. White (2003b) speculates that the presence of overt inflectional morphology in the L1 sensitizes L2 speakers to overt morphology in the L2. However, for the PTH, task-based differences are expected to show learners' lower accuracy in oral production.

Bruhn de Garavito and White (2002) analyzed 42 intermediate L2 Spanish speakers with no contact with Spanish outside the classroom. In the comparison of definite and indefinite article errors, the researchers observed individual variability when adopting a default form: some participants adopted masculine as a default form (overgeneralizing the masculine form to feminine contexts), while others adopted the feminine (overgeneralizing the feminine form to masculine contexts). This variability might be a consequence of the greater working memory space required to compute more complex structures.

White et al. (2004) analyzed the IL of 48 speakers of French and 68 speakers of English learning Spanish as an L2. An interesting point in this analysis was the combination of languages in order to examine the possible influence of the availability/accessibility of features of the L1 in the L2. More specifically, French, as well as Spanish, classifies lexical items in terms of grammatical gender. Thus, the uninterpretable feature for 
gender ([ugender]) is already available for L1 French speakers when learning Spanish. In contrast, nouns in English do not differ regarding grammatical gender and therefore, those learners have to acquire the uninterpretable feature when learning Spanish. Participants in this study were post-puberty learners, whose first exposure to Spanish had been in the mid or late teens.

Four instruments were used in the study, two elicited production tasks, a vocabulary test, and a comprehension task (a picture identification task). The results regarding gender (those on number are not reported because they are not relevant for the present study) indicate that accuracy in production is lower with feminine nouns than masculine nouns. In other words, masculine forms of determiners and adjectival forms were used rather than the feminine forms. Besides, this tendency for a masculine default is more noticeable in complex DPs (e.g. Det $+\mathrm{Adj}+\mathrm{N}$ ) rather than simple Det $+\mathrm{N}$ structures and for low and intermediate proficiency learners. Learners at more advanced proficiency levels reached a high degree of accuracy on gender and number agreement in a written completion task, suggesting that English-speaking learners of Spanish can acquire features that are not present in their L1. On the other, regardless of the status of the L1, adult learners of Spanish were able to acquire uninterpretable gender features on determiners and adjectives and to show gender concord within DPs, even if their L1 (English) lacked grammatical gender.

The influence of age and context of acquisition on the acquisition of gender agreement by adult L2 Spanish learners has also been investigated (Montrul, Foote and Perpiñán, 2008; Montrul, de la Fuente, Davidson and Foote, 2013). In these studies, 72 L2 learners of Spanish and 69 Spanish heritage learners were compared. The researchers conducted three experiments. In the first one they tested the comprehension of gender features (using White et al.'s 2004 methodology) in order to investigate whether heritage learners were more accurate in gender comprehension. Results indicated that, contrary to the representational deficit view, L2 learners were more accurate than Spanish heritage speakers with gender agreement marking on determiners when interpreting written sentences with null nominals. The second experiment tested the written recognition of the correct gender form. Contrary to the predictions of the representational view hypothesis, L2 learners showed an overall advantage over heritage learners. However, the patterns of the errors made by the L2 learners are systematic: the feminine forms are more affected than the masculine ones, and 
agreement with adjectives is more affected than with determiners. The third experiment consisted in an oral picture description task with 65 pictures. In this task heritage learners were more accurate than L2 learners.

The analysis of errors of the three experiments indicated that almost $80 \%$ of errors occurred with feminine words and $20 \%$ with masculine words. This pattern is consistent with the MSIH (Prévost and White, 2000) and the Morphological Underspecification Hypothesis (MUH) (McCarthy, 2007, 2008). Montrul et al. (2008) argue that when errors with the masculine nouns occur, these are agreement errors at the level of syntax, suggesting that learners correctly classify masculine words as such in the lexicon. By contrast, many more feminine than masculine nouns appear to be incorrectly classified as masculine in the lexicon suggesting that default forms also occur at the level of gender assignment, not just agreement. The overall results indicate that L2 learners' problems with gender agreement are more pronounced in production than in comprehension supporting the predictions of the MSIH.

Summarizing, computational accounts predict a processing or computational breakdown rather than a permanently defective underlying representation. L2 learners sometimes fail to access the relevant overt morphology or they have difficulties in mapping the syntactic component and other areas of grammar (White, 2008). Besides, availability differences are not expected to be dependent on the L1 since the presence of overt morphology in the L1 sensitizes L2 speakers to overt morphology in the L2 (White, 2003a). Thus, mapping abstract categories and their overt morphological realization may be easier for speakers whose L1 has overt morphology.

\subsubsection{Morphological Underspecification hypothesis (MUH)}

McCarthy $(2007,2008)$ examined the acquisition of number and gender agreement in L2 Spanish clitics and adjectives. Intermediate and advanced learners completed an elicited production task and a picture selection task. Intermediate participants showed variability across comprehension and production tasks and in both tasks masculine default forms were preferred. Advanced participants showed less variability although masculine default forms were used in both tasks. Number agreement proved to be relatively unproblematic whereas learners show more problems in gender agreement. Thus, morphological variability was suggested to be a representational issue that does 
not derive from production-based problems. Under the MUH, performance is thought to be limited to production, as it is for the MSIH.

\subsubsection{Feature Re-Assembly hypothesis (FRH)}

Most previous research has settled on functional features as the basic unit for comparing formal properties of the L1 and L2, in terms of their selection (or not) from the universal inventory, their assembly into language-specific lexical items and their role in computational operations such as triggering movement. However, recent proposals have attempted to predict the conditions under which features of certain types (interpretable vs. uninterpretable) will fail to be acquired. In these approaches the presence or absence of such features in the L1 determines whether they are acquirable in the L2 (i.e. FFFH, MSIH ...). Several studies, including those employing feature geometry (Harley and Ritter, 2002) have argued that features are monovalent, having only a positive value (Pesetsky and Torrego, 2004). Therefore, the absence of a particular feature within an entailment hierarchy of features simply triggers a default interpretation of that specific feature.

In this vein, the Feature Reassembly Hypothesis (FRH), framed within the MP, assumed the inventory of features to be universal (Lardiere, 1998). According to Lardiere (2009), features are the elemental units that compose lexical items of a certain language. However, not all languages use all the features in the universal set. Hence, L2 learners have to either select new features for the L2 or reassemble the existing features. In other words, L2 acquisition will require that the learner reconfigure or remap features from the way there are represented in the L1 into new formal configurations on possibly quite different types of lexical items in the L2. Even if the same subset of relevant features has been selected by the L1-L2 pair, learners must figure out how to reconfigure them into the TL. Following Lardiere (2009), one of the greatest sources of difficulty may be transfer of the representations of how the same features are assembled in lexical items in the L1. If a full-transfer hypothesis is assumed, where the initial state of acquisition is the L1 grammarr (as the FTFA (Schwartz \& Sprouse, 1996) hypothesis claims) learners must 'de-link' features in their interlanguage and reassemble them in the target language. A number of factors that could cause difficulty at any point in the process of detection and reassembly are: 
(i) The target language feature might be expressed on a different grammatical class or in a different location.

(ii) The target language could also be fused on a single morpheme with one or more features, one that is or is not present in the L1. In contrast, this situation could also be reversed in the case where several L1 features are conflated on a single morpheme but expressed on separate morphemes in the target language.

The FRH goes beyond the question of whether specific syntactic features are acquirable and looks at whether semantic properties of a given feature can be acquirable. A study by Montrul and Slabakova (2003) showed that a large proportion of advanced L2 Spanish learners performed in a targetlike manner in perfective and imperfective and other aspectual contrasts, providing evidence against those formulations of representational impairment which claimed that adult L2 learners are incapable of acquiring uninterpretable features or reassembling interpretable features.

For the FRH, interpretable features are also subject to reassembly by L2 learners. Therefore, the relevant question here would be how features are assembled or mapped. In this sense, the learning task would consist of reassembling formal and semantic bundles in the L2 lexicon, and determining the specific conditions under which their properties may or may not be morphophonologically expressed. Similar to McCarthy's (2007) MUH, the FRH advocated that morphological errors are at the level of morphological competence rather than performance (Lardiere, 2008, 2009). The most pervasive challenge for language learners may not be the acquisition of new features but rather the acquisition of features that are reconfigured differently from the native language. In recent research, some factors (i.e. different grammatical class, location and morphological encoding) have been identified as the source of difficulties for the reconfiguration (Dekydtspotter and Renaud, 2009; Guijarro-Fuentes, 2012; Renaud, 2010, 2011).

In sum, the FRH assumes that the inventory of features is universal. However, L2 learners have to select new features for the L2 or reassemble the existing features. Assuming syntactic L1 transfer, learners will have to select and reassemble these already existing features. Nevertheless, the representations of the same features could be one of the greatest sources of difficulty for transfer for L2 learners (Lardiere, 2009). 
Thus, feature re-assembly has been identified as a potential candidate for fossilization for non-native language learners (Liceras, 2010).

\subsubsection{Summary of the different explanations of non-native variability}

L2/Ln speakers fail to produce target-like morphology that is exemplified in the L2 input. In order to account for this variability, four alternatives have been proposed as explanation for the divergences: an L1-based deficit in morphosyntactic representation (FFFH), an L1-based missing or incorrect morphology account (MSIH) and a feature mapping or assembly deficit account (FRH). In the first hypothesis, the L2 learners are argued to have only those features in the syntactic representation that are available in their L1 and cannot acquire new features (Hawkins and Chan, 1997). Besides, later formulations of this hypothesis have stated that adult L2 learners are specifically unable to acquire uninterpretable features (Tsimpli and Dimitrakopoulou, 2007). However, interpretable features are advocated to be fully acquirable for non-native learners. Thus, neither L1 effects nor task effect are expected to be found with interpretable features.

In the MSIH, problems are due to a mapping problem between syntax and the underlying morphology. However, following FT/FA to Universal Grammar (UG) features remain fully acquirable and hence adult L2 learners are fully capable of acquiring a target-like syntactic representation. In fact, ample evidence in the acquisition of gender agreement in various Romance languages showed that highly proficient L2 learners had a comparable accuracy to that by native speakers. Nevertheless, like in the previous account, these constraints are specifically found in uninterpretable features and not in interpretable ones. Hence, interpretable features remain acquirable and L1 effects or task effects are not expected. 
According to the FRH, L2 learners will require to remap features from the way they are represented in the L1 into new formal configurations. Thus, one of the major difficulties may be the transfer of the representations of how the same features are assembled in lexical items in the L1. Assuming features are monovalent, reassembly or remapping difficulties are extended to both interpretable and uninterpretable features (Lardiere, 2009). Due to the fact that interpretable features are the focus of the present dissertation, Table 2 displays a summary of the hypotheses entertained by the accounts presented in this section regarding the availability or accessibility of interpretable features in nonnative languages.

Table 2. Summary of the hypotheses for the availability of interpretable features in L2 acquisition

\begin{tabular}{|c|c|c|c|}
\cline { 2 - 4 } \multicolumn{1}{c|}{} & Representational & Computational & Reassembly \\
\hline L1 effects & No & Yes, facilitative & Yes, full access \\
\hline $\begin{array}{c}\text { Task differences } \\
\text { availability }\end{array}$ & $\begin{array}{c}\text { Yes, from early } \\
\text { stages (before the } \\
\text { Critical Period) }\end{array}$ & $\begin{array}{c}\text { Yes, from early } \\
\text { stages }\end{array}$ & $\begin{array}{c}\text { Yes, but difficulties } \\
\text { may emerge at } \\
\text { early stages }\end{array}$ \\
\hline
\end{tabular}

In the next section, current approaches on transfer effects at initial and developmental stages are presented.

\subsection{L3 morphosyntax: Current approaches to transfer effects}

Over the last decades, research within generative linguistics has examined the role of previous languages on the acquisition of a L3 and how this process differs from L2 acquisition (Cabrelli Amaro, Flynn and Rothman, 2012; de Bot and Jaensch, 2015). Research has mainly focused on the learners' initial state and several hypotheses have been proposed in order to account for potential transfer sources. Although these models (except for the Cumulative Enhancement Model (CEM) and to a certain stage the Typological Primacy Model (TPM)) have mainly been proposed to account for the initial stages of L3 acquisition, they make implicit predictions about L3 development (García Mayo and Slabakova, 2015), which will be outlined below for each of the experimental groups. In the present dissertation, evidence for developmental stages in L3 acquisition is examined since they could still feature some evidence of transfer from 
previously known languages. Initial state hypotheses will be discussed in section 2.5.1. Section 2.5.2 describes the research conducted for IL development and ultimate attainment in the L3.

\subsubsection{Previous research on the initial stages}

L3 research on initial state learners has produced four formal models in order to explain the source or selection of transfer at the L3 at this early stage. In the next sections the most representative models for transfer in L3 will be outlined. Section 2.5.1.1 summarizes the main hypothesis for the Absolute L1 transfer, section 2.5.1.2 for the L2 Status Factor, section 2.5.1.3 for the Cumulative Enhancement Model and section 2.5.1.4 for the Typological Primacy Model.

\subsubsection{Absolute L1 transfer}

The Absolute L1 transfer model maintains that the L1 functions as a filter for transfer impeding access to the acquired L2 properties (Hermas, 2010, 2014a, b). This position would imply that adult L2 learners would not have access to UG and that nativelike representations in the L2/L3 would not be attainable. Thus, if the mental representations of the L2 that differ from the L1 cannot be acquired, the only source of transfer for L3 learners would be the L1. Hermas (2014a) examined the acquisition of resumptive pronouns by L1 Arabic-L2 French learners of L3 English with different proficiency levels. Findings from an acceptability judgment and a preference task showed that the knowledge of restrictive relatives in the L3 initial stages is influenced by L1 Arabic. However, performance was nativelike in the advanced group.

In a follow-up study, Hermas (2014b) investigated Moroccan Arabic speakers of L2 French and L3 English. Participants were advanced learners of French and English who acquired both languages at the age of 8 and 16 respectively. Participants completed an acceptability judgment task and a preference task that tapped adverb placement, negation, verb-subject inversion in declaratives and expletive constructions. Results indicated that advanced L3 learners showed nativelike accuracy on the four constructions, whereas L2 learners were less accurate. Findings indicated that nativelike ultimate attainment is possible for post-puberty L3 learners in a formal foreign language setting. 


\subsubsection{The L2 status Factor}

The L2 Status Factor advocates that the L2 has a stronger role in the initial state of the L3 morphosyntax than the typology of the L1 (Bardel and Falk, 2007; Falk and Bardel, 2011). Thus, it is claimed that the L2 works as a filter to the L1 grammar. Bardel and Falk (2007) examined the acquisition of verb-second ([V2]) structures in two groups of L1 [+V2]/L2 [-V2] and L1 [-V2]/L2 [+V2] learners of Dutch and Swedish as an L3. Findings indicated that L3 learners with a [+V2] L2 outperformed the learners with a [V2] L2.

More recently, the prevalence of the L2 when transferring to the L3 has been explained due to the high degree of cognitive similarity between the L2 and L3 rather than between the L1 and the L3. Following a neurolinguistic account, the distinction between declarative and procedural memory has been claimed to be a possible factor for L2 prevalence (Bardel and Falk, 2007, 2012; Falk, Lindqvist and Bardel, 2015). Based on Paradis' (2008) model, successive language learning is sustained by declarative memory. Thus, they are expected to manifest dynamic interference from the L2 on the L3 rather than from the native language. Falk et al. (2015) compared the oral production of 40 participants with different degrees of explicit metalinguistic knowledge of the L1. L1 speakers of Germanic and Romance languages with L2 English were exposed to L3 Dutch at the moment of data collection in order to examine adjective placement in the L3. As expected, the results displayed that the degree of explicit metalinguistic knowledge in the L1 plays a role at the initial state of L3 learning.

\subsubsection{The Cumulative Enhancement Model}

The Cumulative Enhancement Model (CEM) was proposed for the initial state of L3 morphosyntax as well as for the developing IL and ultimate attainment in the L3 (Flynn et al. 2004). This hypothesis suggests that L3 acquisition is conditioned by previous language acquisition, in which previously acquired properties remain available for language learners. Transfer is claimed to be facilitative, transfer is only expected to occur when it has positive or facilitative effects, otherwise, it is not expected to occur.

In an innovative study, Flynn et al. (2004) examined the acquisition of three types of restrictive relative clauses in adult and child L1 Kazakh-L2 Russian-L3 English speakers by means of an elicited imitation task. In Kazakh, a head final SOV Turkic language, relative clauses show a left-branching structure, whereas in Russian and 
English, both head initial SVO languages, feature a right-branching structure. Findings indicated that prior knowledge of restrictive clauses enhance its acquisition in the L3.

More recently, Berkes and Flynn (2012) examined L1 Hungarian-L2 German-L3 English learners and compared with L1 German-L2 English learners. Hungarian and English pattern relative clause constituent word order similar to one another but differ from German. Results indicated a facilitative transfer from L1 Hungarian to L3 English since learners do not pattern developmentally with L1 German-L2 English group.

\subsubsection{The Typological Primacy Model}

Similar to the CEM, the Typological Primacy Model (TPM) sustains that neither the L1 nor the L2 has the privileged status for the initial state in L3 transfer (Rothman, 2010, 2011). It is argued that either of the two previously acquired systems could be the source for transfer to occur. However, unlike the CEM, the TPM advocates that transfer is constrained either by the typological proximity or perceived typological proximity between the three language systems. The TPM predicts that transfer will be nonfacilitative in the initial stages of L3 acquisition when the psycho-typological relation or proximity with the previously acquired system is misanalyzed. In order to test the L2 Status Factor, the CEM and the TPM, Rothman (2010) examined the acquisition of word order restrictions and relative clause attachment preferences in L3 Brazilian Portuguese. Two groups of learners were compared: L1 English speakers who were highly successful learners of L2 Spanish and L1 Spanish speakers who were highly successful learners of English. Findings revealed that Spanish was transferred no matter the order of acquisition even though transfer from English would be facilitative. These data were explained on the basis of the fact that Spanish and Brazilian Portuguese are typologically similar despite the fact that Brazilian Portuguese patterns like English in these related domains.

A more recent version of the TPM advocates that transfer is motivated by economic considerations. Thus, the parser establishes typological or structural proximity assessment at the initial stage in the L3 acquisition process. Assuming Full transfer (Schwartz and Sprouse, 1996), once typological proximity is assessed, the entire L1 or L2 is transferred. At the underlying grammatical representation, the transfer from either the L1 or the L2 is claimed to occur at the earliest possible moment. The earliest possible moment obtains when the parser has had minimally sufficient exposure to the 
target L3 input to assess relative structural similarity (Giancaspro, Halloran and Iverson, 2015; Rothman, 2015).

If transfer is to avoid redundancy in acquisition and, hence, diminish the cognitive burden of an additional grammar, the L3 should be acquired as early and completely as possible to be useful towards these goals (Rothman, 2015). Thus, the TPM does not advocate transfer on a structure-by-structure basis since this transfer would be a slow and gradual process (Rothman, 2013).

In the latest versions of this model, Rothman (2015) suggested four linguistic factors that determine holistic or complete transfer from either the L1 or the L2 to the L3:

The lexicon

Phonological/phonotactic cues

Functional morphology

Syntactic structure

The TPM relies on formal linguistic theory to specify how the parser detects and determines what is structurally similar across the languages based on generative proposals of underlying representation (Rothman, 2015). Nonetheless, it makes different predictions for early and successive bilinguals.

\subsubsection{Previous research on developing interlanguages}

There is growing body of research examining the developmental sequences of L3 acquisition in learners who are beyond the initial state (García Mayo and Rothman, 2012). Research conducted in the Basque Country showed the difficulties of Basque/Spanish bilingual children acquiring English as an L3 in a school setting. Research provided evidence about the difficulties these learners show in various morphosyntactic aspects, such as suppletive and inflectional morphology (García Mayo, Lázaro Ibarrola and Liceras, 2005), long-distance wh-questions (Gutierrez Mangado and García Mayo, 2008), sentential negation (Perales, García Mayo and Liceras, 2009), copula and auxiliary be as well as third person morpheme $-s$ and past tense morpheme ed (García Mayo and Villarreal Olaizola Olaizola, 2011) and gender agreement (Imaz Agirre and García Mayo, 2013). 
In one of the pioneering studies on L3 acquisition in developing IL within a featurebased model, Jaensch (2011) investigated the grammatical number and gender concord in L3 German attributive adjectives by 37 L1 Japanese L2 English speakers. In order to test the CEM and the L2 Status Factor, speakers of Japanese and English, languages that do not feature grammatical number and gender agreement, were tested. L2 proficiency level effects and task effects were two other variables that were examined in this study. Three groups of Japanese native speakers with different proficiency levels in English completed a balanced gap-filling task and two oral elicitation tasks in the form of games. The CEM and the L2 Status Factor hypotheses did not seem to fully account these findings since the results showed that neither of these two models can be used to predict an L2 effect for this particular property, either because the features examined were not present in the same form in the L1 or L2, or because the phenomena of adjectival inflection involves both syntax and morphology, or possibly due to a combination of both factors. Alternatively, variation in task and number agreement seems to be consistent with DM (Halle and Marantz, 1993). Besides, Jaensch (2011) claimed that her results provide support that such a feature-based model may be extended from SLA to account for the variation found in the production of L3 learners.

More recently, L3 research has expanded its focus from the initial stages to the developing IL. The predictions of the L3 models for initial learners have been tested with non-initial stage learners. However, these studies have not reported conclusive results. In one of the first studies testing L3 transfer models with developing IL learners García Mayo and Slabakova (2015) examined the acquisition of object drop in L3 English by 119 Basque/Spanish bilinguals. Findings revealed that non-native learners preferred null objects successfully and they were able to overcome the non-facilitative transfer from Spanish, confirming the predictions of the TPM.

Furthermore, by examining the syntax-discourse interface, Slabakova and García Mayo (2015) showed that transfer from the native language helped Basque/Spanish bilingual $(n=110)$ learners of L3 English with an intermediate proficiency level who completed an online acceptability judgment task. The authors interpreted the results as providing evidence in favor of the CEM (Flynn et al. 2004) uniquely. In contrast, Cabrelli Amaro, Amaro and Rothman (2015) analyzed the acquisition of raising structures with and without an intervening dative experiencer and with and without embedded tense in L3 Brazilian Portuguese at the initial stages $(n=33)$ as well as intermediate stages $(n=15)$. 
Findings from an acceptability judgment task revealed that Spanish was the source of transfer irrespective of its status as an L1 or L2.

Summarizing, current generative research with a focus on L3 acquisition has emphasized transfer effects at the initial stage. However, whether the source of transfer is the L1 or the L2 or whether (psycho-)typology has a role to play is still under debate. On the other hand, several studies have also focused on different morphosyntactic aspects in L3 acquisition in learners that were beyond the initial state. The present study aims at contributing to the analysis of the acquisition of L3 English past the initial state in order to determine learners' developmental sequence in the acquisition of gender agreement measured at different proficiency levels as well as the role and source of transfer in the acquisition of gender agreement.

\subsection{Summary of the chapter}

This chapter has contextualized the dissertation in terms of the variables that will be examined to analyze the acquisition of gender agreement in English. First, a description of the three languages involved in this study has been provided. Then, on the basis of this description, a revision of the linguistic aspects (i.e. animacy and grammatical gender) relevant for the study was presented. Findings summarized current research on animacy effects and 'gender attraction effects' in nonnative learners. Afterwards, the feature availability accounts posited within current generative linguistics in L2 acquisition have been introduced. These representational (i.e. FFFH and the IH) and computational accounts (i.e. MSIH) disagree as to whether [+uninterpretable] features are available for L2 learners, whereas they maintain that [+interpretable] features remain fully acquirable for non-native learners. On the contrary, the FRH maintains that the learnability problem is caused by the fact that L2 learners have to reassemble and remap features in the L2. This may affect similarly both [+interpretable] and [+uninterpretable] features. In fact, these accounts have inspired most of the research conducted on the acquisition of gender agreement, especially in Romance languages. Finally, L3 models that have been proposed for transfer effects have been presented.

The following chapter, Chapter 3, introduces previous evidence from research studies on gender agreement in native and non-native learners. 


\section{CHAPTER 3. GENDER AGREEMENT IN NATIVE AND NON- NATIVE GRAMMARS}

The acquisition of the gender feature in the learner's L1 has been examined with participants from various linguistic backgrounds, L1 monolinguals as well as early bilinguals (Larrañaga and Guijarro-Fuentes, 2013; Liceras, Fernández-Fuertes, Perales, Pérez-Tattam and Spradlin, 2008a; Manterola and Ezeizabarrena, 2004; Spradlin, Liceras and Fernández-Fuertes, 2003a/b; Unsworth, 2013). Regarding non-native acquisition, several combinations of languages with (grammatical) gender have been used to test feature availability accounts (i.e. for Spanish: Montrul et al. 2008; Montrul, de la Fuente, Davidson and Foote, 2013; Sagarra and Herschensohn, 2010, 2011, 2013; White et al. 2004; for French: Dewaele and Veronique, 2001; for Dutch: Sabourin, Stowe and Haan, 2006; Unsworth, 2008; 2013; for English: Muñoz, 1991, 1994; White and Ranta, 2002; White, Muñoz and Collins, 2007; for German: Jaensch, 2011 among others). The following sections summarize the most relevant findings on the acquisition of gender agreement by native and non-native speakers. More specifically section 0 summarizes the findings on gender for L1 learners, section 3.2.2.1 illustrates the findings on the acquisition of gender agreement in Romance languages and section 3.2.3 presents evidence for the acquisition of L2/L3 English from different backgrounds.

\subsection{Gender agreement in native systems}

\subsubsection{Evidence from monolingual children}

\subsubsection{L1 Spanish}

L1 Spanish children have to acquire both lexical (semantic properties of nouns) and syntactic (the operationalization of agreement) properties when acquiring gender.

Hernández Pina (1984) conducted a longitudinal case study in order to examine the acquisition of Spanish as L1. Her findings indicated that during the first 2-3 months of the two-word period, the child was not consistent in the use of gender. He produced sentences that were grammatical together with sentences that were not. At 21 months, the child seemd to realize that phrases should carry gender agreement. During this period, the child started to distinguish the semantic gender, for instance, niño-niña ('boy'-'girl') (age 22-25 months); nena ('girl') (23 months). At this stage, the child also 
went through an overgeneralization period in which he used the masculine determiner with all nouns (i.e. un llave 'a key'). This period was followed by a stage in which the child overgeneralized the feminine form (i.e. una pájaro 'a bird'). At 27 months, gender agreement gained more consistency, using the feminine determiner form with nouns ending in $-a$. At 31 months, appropriate gender agreement was found between the determiner and the noun (not with the adjective).

Pérez-Pereira (1991) investigated 160 Spanish-speaking children (age range 4-11) in order to determine the relevance of syntactic and semantic cues in establishing gender agreement. Evidence from a picture naming task indicated that children use the masculine form as default. Besides, the feature animacy does not seem to produce any substantial difference for participants. Findings maintain that Spanish children learn the gender system around age 3 and they are able to master gender marking and gender agreement before age 4 . Children seem to mainly rely on syntactic cues rather than semantic information to recognize the gender of a noun and to establish gender agreement. Moreover, regularity, transparency and productivity of the Spanish gender system may also facilitate acquisition.

Mariscal (2008) analyzed the early acquisition of gender agreement in the Spanish NP by monolingual children. The production of 4 children under the age of 3 was analyzed by means of an oral task and an elicitation task. Findings showed that the acquisition of gender agreement is a complex process which is acquired progressively as the child becomes aware of phonological, distributional and functional features. Children usually start producing elements similar to Det (declined with gender) during the two word period before the age of 2 . There was no evidence of masculine or feminine default in the children's production. Besides, the author remarked the absence of gender agreement errors between the adjective and the noun in frequent non-prototypical nouns, such as mano, a feminine noun ending in -o.

\subsubsection{L1 English}

In the case of L1 English monolinguals, little research has been conducted on the early acquisition of possessive adjectives. However, this research indicates that the acquisition of gender can be late (Corbett, 1991). Children at the age of 4 are not able to use he and she as in adult speech. Besides, experimental work has shown that monolingual German children performed more accurately at pronoun selection than 
monolingual English children of the same age (Mills, 1986). As English children get older they continue having difficulties with the use of he and she even though their use of pronouns increasingly approximates to that of adults (Corbett, 1991). When the basic rule is established, around age 10, children have to learn the use of he and she for personification in appropriate contexts (Mills, 1986).

\subsubsection{Evidence from early bilingual children}

Research conducted with Basque/Spanish and English/Spanish early bilinguals ${ }^{7}$ reflects the similarities in the assignment of gender by both groups of bilinguals. Unlike Spanish, Basque and English do not have grammatical gender. Mixed DPs containing a Spanish Det represent a problem for Basque/Spanish and English/Spanish bilinguals, since the child has to assign the value for gender to the Det as in (16).
a. El etxe- $a_{[\text {-gender] }}$ Vs. la etxe- $a_{\text {[-gender }]}$.
b. El house [-gender] Vs. la house [-gender].

The Spanish Det should share Gender and Number features with its N, which coming from either Basque or English cannot be specified for Gender. Although there are some noticeable differences between Basque and English (i.e. Basque is right-headed whereas English is left-headed), early bilinguals seem to behave similarly with respect to gender assignment in mixed DPs.

\subsubsection{English/Spanish bilinguals}

Liceras, Spradlin and Fernández-Fuertes (2005) and Liceras et al. (2008a) investigated the production of mixed DPs by early Spanish/English bilinguals and native and nonnative Spanish speakers. The bilingual children in these studies acquired both languages, English and Spanish, as L1a. Two major tendencies were found in production. Firstly, child mixed utterances reflected a preference for the production of morphemes that evidenced the projection of abstract features: Spanish Det + English NP. As predicted by the Grammatical Features Spell-Out Hypothesis ${ }^{8}$ (Liceras, 2002; Liceras, Spradlin, Senn, Sikorska, Fernández-Fuertes, de la Fuente, 2003; Liceras et al. 2005, 2008a; Spradlin et al. 2003b), the Spanish determiner bears the uninterpretable $n$

\footnotetext{
${ }^{7}$ Children in these studies acquire both languages (Basque and Spanish or English and Spanish) as L1s.

${ }^{8}$ The Grammatical Features Spell-Out Hypothesis states that in code-mixing choices, speakers will favor the functional categories containing the largest array of uninterpretable features (Liceras et al. 2008a)
} 
Gender feature and the intrinsic Gender Agreement $\Phi$-feature, which is responsible for the operation Agree $^{9}$. In the case of English/Spanish mixed DPs, the unvalued features Person, Number and Gender in the Spanish Det can be valued via Agree with the English N because the latter only bears Person and Number features (17) (Moro, 2001). But in the case of English Det + Spanish N, the Gender feature of the Spanish N cannot be valued on the English Det in (17). Thus, Spanish/English bilingual children systematically choose the Spanish Det because they have to specify the agreement features.
a. $L a_{\text {[Person Number Gender] }}$ house [Person Number]
b. The [Person Number] $\operatorname{cas} a_{\text {[Person Number Gender] }}$

Secondly, two kinds of gender assignment were found in mixed DPs:

a) the use of the masculine form as a default form, as shown in (18):
a. en el plane
in the.m plane $(\text { masc })^{10}$
'In the plane'
b. para el church for the.m church (fem)
'For the church'

b) the analogical criterion (Liceras et al. 2008a), which consisted of assigning the gender of the Spanish translation equivalent to the English noun, as shown in (19):
a. El (masc) piggy (masc)
b. El (masc) king (masc)

L1 Spanish speakers (experimental data) favor mixings where Spanish provides the functional category, the Determiner, over mixings where English does.

\footnotetext{
${ }^{9} \Phi$-features are assumed to be inherently valued and interpretable on N/D but not in Agr heads. The uninterpretable $\Phi$ must be eliminated in the Agree relation (Bejar, 2003).

${ }^{10}$ The gender of the Spanish equivalent.
} 


\subsubsection{Basque/Spanish bilinguals}

In the case of Basque/Spanish early bilinguals, Manterola and Ezeizabarrena (2004) and Ezeizabarrena (2005) examined the development of the acquisition of mixed DPs by two Basque/Spanish early bilinguals. Similar to the case of Spanish/English bilinguals, these children acquired Basque and Spanish as their L1s. Ezeizabarrena's (2005) findings were consistent with Liceras et al. (2005, 2008a) with regard to the use of the Spanish determiner followed by a Basque noun. The child did not use a default gender value, that is, no preference for masculine or feminine form was attested. In many mixed DPs, gender assignment matched the Gender value of the Spanish translation of the inserted Basque N, as illustrated in (20).
a. El
tellatu
D.MASC.SG roof.SG
'the roof'
b. Yo cojo con la esku-a
I take-1SG with D.FEM.SG hand-Det.SG
'I take (it) with the hand'

More recently, Larrañaga and Guijarro-Fuentes (2013) examined the acquisition of the gender feature by two Basque/Spanish bilingual children and one Spanish monolingual child. Findings revealed that the three children used the correct gender from the outset as the correct determiner choice and they also overgeneralized masculine and feminine forms over a period of time. However, the acquisition of bilingual and monolingual children shows differences. On the one hand, there is not an early stage where all the children use the masculine determiner for nouns of both classes. Monolinguals prefer to overgeneralize the masculine form over the entire period of the study (15 months), whereas bilingual children overgeneralize both genders but preferably the feminine form over a limited period of time. On the other hand, another major difference lies on the fact that assignment errors in monolingual children disappear at the age of 2;05, whereas bilingual children make gender errors at all stages ${ }^{11}$. The overgeneralization of the masculine form may be indicative of the fact that bilinguals assume Spanish has a sort of default gender, in this case the authors claimed it was the masculine.

\footnotetext{
${ }^{11}$ Data collection ends at the age of $2 ; 10$.
} 
Nevertheless, at very late stages of the data collection, errors by the bilinguals were less frequent, but they never disappeared. On the basis of these results, gender acquisition seems to be more challenging for bilinguals than monolingual children.

Parafita Couto, Munarriz, Epelde, Deuchar and Oyharçabal (2015) investigated gender assignment strategies that Basque/Spanish bilinguals use in mixed nominal constructions. Evidence from naturalistic data and semi-experimental data by means of an elicitation task and an auditory judgment task was collected with especial focus on analyzing the role of the gender of the Spanish equivalent and canonicity (i.e. word ending). Findings from 26 L1 Spanish speakersand 4 simultaneous Basque/Spanish bilinguals in naturalistic observations indicated a preference for a feminine gender in Spanish-Basque mixed DPs. Moreover, these results were corroborated by semiexperimental data. Parafita Couto et al. (2015) claimed that the feminine default may have originated from the morphophonological property of the Basque determiner $(-a)$ suffixed to Basque nouns, which gave rise to a tranfer effect. Due to its homophony with the feminine gender marker in Spanish, the Basque determiner may have been reinterpreted as a feminine marker. This crosslinguistic effect seems to be extended to other environments since it is observed even when the $-a$ ending is not present. Findings seem to indicate that special gender assignment rules applying only to mixed combinations are in operation.

Imaz Agirre (under review) examined the gender assignment in Spanish by 33 Basque native speakers and their outcomes were compared to 32 Spanish monolingual speakers in order to determine whether native speakers of Basque would exhibit a gender assignment pattern similar to Spanish monolingual speakers. Participants assigned gender to inanimate nouns with canonical word endings $(-o,-a)$ and with non-canonical word endings (-e, -consonant). Findings from an online and offline gender assignment task revealed that Basque native speakers performed at ceiling in the online and offline tasks. Results seemed to indicate that early language experience with Spanish may have a positive impact on assigning grammatical gender to inanimate nouns. Nonetheless, results seem to indicate different patterns in both groups in terms of canonicity effects and preferences for a default form in the online task. Accuracy rates and response delays in the Spansih group revealed slower responses in nouns with non-canonical ending as well as a preference for masculine default forms. In contrast, native speakers of Basque seem to have automatized gender assignment in canonical and non-canonical 
word endings. Regarding the preferences of a default form native speakers of Spanish were more accurate and faster in masculine nouns, whereas Basque spakers were faster in assigning gender in feminine inanimate nouns.

\subsection{Gender agreement in non-native systems}

\subsubsection{Evidence from the acquisition of gender agreement in L2 Romance languages}

Up to very recently, most studies investigating the acquisition of gender agreement in L2 have used offline measurements of grammatical knowledge of gender (Dewaele and Véronique, 1999; Montrul et al. 2008; White et al. 2004). This literature has drawn upon a wide range of theoretical views in terms of access to UG. However, more recently, online methods have been used to compare native and non-native sentence processing (Hopp, 2007; Keating, 2009). The comparison of reading times in grammatical and ungrammatical contexts can indicate whether grammatical gender or gender agreement violations can be tapped.

In the last decade, there has been a substantial body of L2 studies on gender processing. Current psycholinguistic research on adult L2 Spanish gender employs online techniques (i.e. eye-tracking, moving-window tasks and Event-related potential (ERP) measurements) to examine implicit grammatical knowledge and its computation. For example, shorter RTs or reading delays suggest effortless access, retrieval and use of implicit knowledge (Alarcón, 2014). These online tasks have been designed to assess underlying competence during real time processing (Field, 2004). Both online and offline measurements have been combined in recent research to shed some light on L2 feature availability accounts (Grüter, Lew-Williams and Fernald, 2012; Montrul et al. 2013; VanPatten et al. 2012).

Most of the current psycholinguistic research on gender is framed within UG-based approaches, including representational deficit accounts (i.e. FFFH) and full access accounts (i.e. MSIH). For example, Foote (2011), using a moving window task, investigated whether early and late English/Spanish bilinguals displayed integrated gender knowledge in Spanish and whether age of acquisition played a role. Her findings revealed that the age of acquisition did not affect the participants' automatic competence of gender: both early and late bilinguals were sensitive to noun adjective 
agreement and all participants, showed longer reading times in ungrammatical sentences than ungrammatical ones.

Alternative approaches to L2 processing include the Shallow Surface Hypothesis (SSC) (Clashen and Felser, 2006), which claims that sentence processing in L2 is more shallow and less detailed than for adult L1 speakers, since the former heavily relies on semantic and pragmatic cues as opposed to morphosyntactic aspects, as L1 learners do. Hence, L1 and L2 grammatical processing during comprehension seem to be qualitatively different (Keating, 2009, 2010). On the other hand, the Fundamental Identity Hypothesis (Hopp, 2009) argues that native-like attainment of L2 inflection is possible and suggests that L1 and L2 grammatical representation and processing are qualitatively similar, especially in comprehension (Sagarra and Herschensohn, 2010). In fact, any difference should be due to performance or L1 transfer effects rather than maturational constraints.

Most recent online comprehension studies have focused on the acquisition of gender agreement in L2 Spanish and the findings have shown different patterns. Using a moving window task Sagarra and Herschensohn (2010, 2011) analyzed whether beginner and intermediate learners of L2 Spanish were sensitive to noun-adjective agreement. Findings revealed that intermediate learners and monolingual learners read faster congruent contexts than incongruent ones. However, beginner learners did not show any sensitivity to gender violations. Besides, regarding noun animacy, both intermediate learners and monolinguals were faster with inanimate nouns than animate ones. However, beginner did not display any significant difference between the two animacy conditions. Hence, proficiency seems to be an important variable in L2 gender acquisition (cf. White et al. 2004). Animacy effects found in the beginners' group rebut previous L1 and L2 behavioral and psycholinguistic studies showing a strong facilitative effect of animate nouns on both accuracy and processing rates at all proficiency levels.

Besides, Grüter et al. (2012) examined the acquisition of grammatical gender by 19 highly proficient L1 English learners of L2 Spanish when completing offline comprehension and production tasks as well as online tasks. Participants completed a sentence-picture matching comprehension task, an elicited production task as well as 
looking while listening task ${ }^{12}$. Findings indicated that L2 learners’ performance did not differ from that of the natives. L2 learners performed at ceiling in offline comprehension task, supporting White et al.'s (2004) and Montrul et al.'s (2008) findings. In the oral production task differences were found between the L1 speakers and L2 learners. These agreement errors in the L2 group were confined to gender assignment errors. On the other hand, gender agreement errors were rare for these highly proficient learners. For the eye-tracking task, results revealed no differences between native speakers and L2 learners. However, comparisons within each group indicated that L2 participants did not process gender agreement as effectively as native speakers do.

Experimentally crossed production/comprehension and online/offline designs with highly proficient L2 learners reveal that L2 learners performed at ceiling in comprehension tasks, made persistent errors in production tasks and displayed weaknesses in the online processing when compared to native speakers.

\subsubsection{Evidence from the acquisition of gender agreement in L2/L3 English}

There has been limited research on the acquisition of gender agreement by learners of English as a non-native language. This research has mainly focused on Catalan/Spanish bilingual learners and French learners of L2 English. Even though these studies have not been framed within the generative perspective section 3.2.3.1 presents evidence from Catalan/Spanish bilinguals, section 3.2.3.2 summarizes the main findings for French learners and section 3.2.3.3 illustrated previous findings for Basque/Spanish bilinguals, one of the experimental groups in the present study.

\footnotetext{
${ }^{12}$ In the looking-while-listening task, participants are shown two pictures on each trial and hear speech naming one of the pictures as their gaze patterns in response to the speech signal are recorded.
} 


\subsubsection{L1 Catalan/Spanish bilinguals}

Regarding the acquisition of gender in possessive adjectives by Catalan/Spanish bilinguals in L2 English, Muñoz $(1991,1994)$ analyzed the production of pronominal forms of 10 intermediate to advanced learners of English whose L1s were Catalan and Spanish. The participants were asked to complete four oral tasks (a task with dolls, picture description, story narration and spontaneous production). Results indicated that subject and possessive pronouns ${ }^{13}$ were biased towards the masculine gender and this tendency was independent of the gender the possessee had in Spanish. Muñoz (1991) argues that the phonological properties of the words (he and she or his and her are similar sounding words) may have an influence on production.

In a further study, Muñoz (1994) tested 55 Spanish learners of English from different proficiency levels (18 low intermediate students, 22 intermediate students and 15 high intermediate students) in order to analyze their performance on pronominal production. Participants completed an oral and a written narration task. Results indicated that errors were found in the third person masculine and feminine pronominal forms, and particularly in the possessive forms. The tendency of the bias to the masculine possessee pronous confirmed the results of the previous study (Muñoz, 1991). Besides, regardless of case (subject, object or possessive), the direction of the error was the same. Regarding the influence of proficiency level, an increase in the production of pronouns is reflected as a consequence of an increase in fluency, length of sentences and number of words produced. Unexpectedly, there was a parallel increase in the number of errors produced. Muñoz (1994) suggests that the effect of proficiency on the production of pronominal forms should be further analyzed. The influence of the task on performance was also examined in this study. She found that the tendency of errors in the oral and written tasks was similar and consequently [...] "the tendency observed is characteristic of spontaneous language, independently of the medium used." In other words, Muñoz (1994) concluded that both oral and written production shared the characteristics of spontaneous language.

\footnotetext{
${ }^{13}$ Object pronouns were very scarce ( 3 incorrect forms out of 47 ), and therefore, the direction of the error could not be generalized.
} 
Muñoz (1994) explained the results of her studies in terms of markedness. The bias seems to be based on an asymmetrical opposition between the two forms. The masculine would be the unmarked form (the more frequent and general) (Zobl, 1985), whereas the feminine pronoun would be the marked one (more specific and restricted). According to Muñoz (1994), markedness can satisfactorily explain the earlier acquisition and overgeneralization of the masculine form. However, it fails to account for the difference between subject and object forms. This difference is explained on the basis of the incongruence between the Spanish and English functional systems. On the one hand, in Spanish, as opposed to English, pronominal forms are only used in case of emphasis or contrast. On the other hand, possession is expressed differently in Spanish and in English, as we have seen above (Section 2.2). This incongruence between the two systems may influence the acquisition process and may enhance the effects of markedness. Nevertheless, Muñoz (1994) claims that more cross-linguistic data would be needed in order to pursue this hypothesis.

\subsubsection{L1 French speakers}

Zobl (1984) examined the effect of input in the production of English possessive adjectives by 18 L1 French speakers with a low proficiency level. Participants completed three elicited production tasks with a pre-test/posttest design. Learners were divided in two groups, a [+ human] group and a [-human] group. Students received intensive exposure on the third person possessive adjective forms (his and her) in each experimental context. Each group was only exposed to possessive forms either in [+human] or [-human] contexts. Findings revealed that no matter the input learners received ([+human] or [-human]), they improved in their own input domain but also in the domain they had received no input. Nevertheless, findings indicated that learners who were exposed to the marked domain (i.e. [+human]) correlated with a tendency to overgeneralize her whereas exposure to the unmarked domain (i.e. [-human]) correlated with a tendency to overgeneralize his.

In a follow up study, Zobl (1985) investigated the acquisition of the third person pronouns his and her by 162 low level adult French learners of English. The experiment consisted of 20 oral questions designed to elicit responses containing his and her with human (i.e. kinship terms) and nonhuman entities (i.e. body parts and inanimate entities). The results showed that [+human] entities pose problems for gender 
assignment. Hence, Zobl (1985) proposes [+human] as the marked form and [-human] as the unmarked term. Similarly, it is suggested that her is the marked term and his the unmarked form of the gender opposition. In sum, Zobl (1985) proposes that markedness conditions represent the abstract structuring principles of the input. The marked values represent more specific forms, while the unmarked value is more frequent. Thus, any learner demonstrating categorical control of gender the marking rule with possessed kinship entities (i.e. her brother, his sister) will also have categorical control of the rule with possessed inanimate entities (i.e. his house, her hand).

J. White and Ranta (2002) analyzed the IL of 59 L1 French learners of English. The learners' oral production was elicited using a picture description task and a passage correction task. For both tasks, learners were assigned to different groups on the basis of developmental stages the authors had classified based on the emergence of possessive forms. Therefore, errors were classified in terms of pre-emergence, emergence and postemergence stages. As illustrated in Table 3, in the pre-emergence stage, learners avoided his or her forms (Stage 1) or used one form, typically your, for all persons, genders, and numbers (Stage 2). In the emergence stages, a few instances of his and her are produced (Stage 3) accompanied by a preference for one of the forms (Stage 4). Post-emergence stages (Stages 5-8) are characterized by a gradual development in the ability to distinguish his and her, even when the gender of the possessor is different from the grammatical and natural gender of the possessed entity. 
Table 3. Developmental sequence in the acquisition of the English agreement rule for his/her (J. White, 2008: 197)

\begin{tabular}{|l|l|}
\hline Pre-emergence \\
\hline Stage 1 & $\begin{array}{l}\text { Avoidance of his and her and/or use of definite article. } \\
\text { The little boy play with bicycle }\end{array}$ \\
Stage 2 & $\begin{array}{l}\text { He have band-aid on the arm, the leg, the stomach } \\
\text { Use of your for all persons, genders and numbers. } \\
\text { This boy cry in the arm of your mother. } \\
\text { There's one girl that talk with your dad. }\end{array}$ \\
\hline
\end{tabular}

Emergence

\begin{tabular}{l|l} 
Stage 3 & Emergence of either or both his/her.
\end{tabular}

A little boy do a cycle ride and he fall. He have a pain on back. He said the situation to her mom.

Stage 4 Preference for his or her.

The mother is dressing her little boy, and she put her clothes, her pant, her coat, and then she finish.

The girl making hisself beautiful. She put the make-up on his hand, on his head, and his father is surprise.

Post-emergence

\begin{tabular}{l|l} 
Stage 5 & Differentiated use of his and her, but not in kin-different contexts.
\end{tabular}

The girl fell on her bicycle. She look *his father and cry.

The dad put *her little girl on his shoulder, and after, on his back.

Stage 6 Differentiated use of his and her; agreement rule applied to kindifferent gender for either his or her.

The mother dress her boy. She put his pants and his sweater. He's all dressed and he say at *her mother he go to the bathroom.

\begin{tabular}{l|l} 
Stage 7 & Differentiated use of his and her to criterion; agreement rule applied
\end{tabular} to kin-different gender for both his or her.

The little girl fell the floor, after she go see for her father, and he pick up his girl in the arms.

\begin{tabular}{l|l} 
Stage 8 & Error-free application of agreement rule to his and her in all
\end{tabular} contexts, including body parts.

The little girl with her dad play together. And the dad take his girl on his arms.

In a similar study, J. White et al. (2007) analyzed the acquisition of possessive determiners by French monolinguals and Catalan/Spanish bilinguals in a minimal input setting. The study aimed at expanding the validity of the developmental framework, originally created to account for the acquisition of gender by francophone learners ( $\mathrm{J}$. White and Ranta, 2002), to other L2 populations. The participants performed a passage correction task, which included kin-different contexts that are crucial for determining post-emergence stages, an oral production task and a meta-comment task. In metacomment task, the teacher asked about some predetermined section on the of the 
passage correction task in order to analyze each student's meta-comments. Results validated the developmental acquisition framework for the acquisition of English possessive determiners. In other words, Catalan/Spanish learners followed a developmental pattern similar to francophone students. However, the L1s examined in these studies are Romance languages (i.e. French, Spanish and Catalan). The authors of the study claim that in order to determine whether the developmental stages are a universal phenomenon of L2 English learners, evidence from a larger variety of L1s is needed.

Furthermore, Collins, Trofimovich, White, Cardoso and Horst (2009) analyzed an 110,000-word corpus with the transcriptions of 40 hours of output by 6 Grade English classes at French-speaking schools in Quebec. Factors identifying different degrees of ease or difficulty were analyzed for the progressive, simple past and the possessive determiner. Type/token distribution of the forms, their lexical properties and their perceptual salience were analyzed. Findings revealed that the factors influencing the acquisition of these constructions were type of frequency, semantic scope and perceptual salience. However, these three factors made the progressive form more available and accessible in the input than either the past simple or the possessive determiner. In other words, the early-acquired progressive and the later acquired simple past and possessive determiners seem to be influenced by input factors.

\subsubsection{Basque/Spanish bilinguals}

In a previous (preliminary) study on the acquisition of gender agreement by Basque/Spanish bilinguals, Imaz Agirre and García Mayo (2013) examined the IL of 34 intermediate and advanced Basque/Spanish bilingual learners of L3 English when completing two oral tasks (an oral production task and a picture description task). Although learners showed high accuracy rates in both tasks, errors fell into clear patterns. In fact, animacy and gender attraction had a clear and significant impact on learners' productions. Besides, proficiency was another variable that showed significant effects since significant differences were found between intermediate and advanced learners. 
Summarizing, gender agreement has been widely investigated in native and non-native language acquisition with several language combinations. Evidence from early bilingual acquisition data from code-mixing utterances revealed that Basque/Spanish and English/Spanish bilinguals showed a similar pattern in establishing gender agreement. Early bilinguals followed an analogical criterion to assign gender which consisted of assigning the gender of the Spanish equivalent to the English or Basque noun. Nonetheless, children differed in the preferences of default forms. On the one hand, Spanish/English bilinguals showed preferences for the masculine form, indicating preferences similar to monolingual Spanish children (Liceras et al., 2005; Liceras et al. 2008a; Mariscal, 2008). On the other hand, variability was found in the preference of either the masculine or the feminine form as default among Basque/Spanish children but in cases in which learners were consisted with one form they preferred the feminine one.

Regarding the acquisition of gender agreement in L2 acquisition, Romance languages have been widely studied using both online and offline techniques. Most current research on this topic has been framed within UG accessibility models: representational deficit models (Franceschina, 2005) and the FT/FA accounts (White et al. 2004). Purely psycholinguistic approaches queried whether L2 processing could be similar to L1 processing (Grüter et al. 2012; Hopp, 2007) or whether they are qualitatively different phenomena (Keating, 2009, 2010). Moreover, research on the acquisition of gender agreement in English reported that Catalan/Spanish, French and Basque/Spanish learners produced incorrect gender forms in possessive adjectives at various stages of proficiency level. In fact, a preliminary study on the acquisition of gender agreement by Basque/Spanish bilinguals showed animacy and gender attraction effects in the intermediate and advanced learner groups.

\subsection{Summary of the chapter}

This chapter has recapitulated the research conducted on gender agreement within the generative framework. The first section summarizes the information on the acquisition of the gender feature by native speakers of the three languages involved in the present dissertation. Evidence has been reported from both early monolingual as well as early bilingual children. These findings have shown that in native languages the gender feature as well as gender agreement is acquired without problems. A second section 
compiles the most recent studies on the acquisition of gender agreement by non-native learners. This research has shown the difficulties L2/L3 learners from different proficiency levels and linguistic backgrouds find when establishing gender agreement in different target languages.

The present study focuses on the acquisition of gender agreement in L3 English by Basque/Spanish bilinguals. Preliminary study indicated that Basque/Spanish bilinguals show difficulties in establishing gender agreement with specific problems with gender attraction effects. Against this backdrop, this dissertation makes four important contributions:

o First, it addresses the question of whether Basque/Spanish bilinguals can acquire the gender feature or even whether these learners could reassemble/remap features in English. Most research studies to date have investigated the acquisition of uninterpretable gender (agreement) feature in numerous language combinations. But the acquisition of gender agreement in English has been an under-researched topic within the generative SLA field.

o Second, it examines whether errors reflect an underlying deficient syntax or whether errors are caused by communication pressure. In order to analyze nonnative learners' deficient syntax, evidence from comprehension (offline vs. online) and production (written vs. oral) is triangulated.

o Third, it fouses on identifying the role of proficiency in developing IL in order to describe the different stages these learners may go through from elementary levels to advanced ones.

o Fourth, it concentrates on the role of transfer from the previously acquired systems. Research in the field of L3 acquisition has primarily focused on the initial stages, whereas little attention has been paid to developing grammars especially at the intermediate and advanced levels.

The following chapter, Chapter 4, presents the research questions as well as the hypotheses and the methodology used in this dissertation. 


\section{CHAPTER 4. THE PRESENT STUDY}

This chapter details the methodology followed in the experimental study. It will first present the research questions and hypotheses entertained on the basis of previous research. Section 4.2 describes the participants, Section 4.3 the steps followed for the item design are reported and in Section 4.4 information on test material validity is provided. Section 4.5 presents the instruments used for the data collection and Section 4.6 the test admimistration procedure. Finally, Section 4.7 explains the decisions made for data codification.

\subsection{Research questions and hypotheses}

The objective of this study is to investigate the acquisition of gender agreement in L3 English third person singular possessive adjectives (his/her) by Basque-Spanish bilinguals. The following research questions are entertained:

i) Does the internal structure of the DP play a role? More specifically, does the grammatical gender of the Spanish equivalent $\mathbf{N}$ and animacy have an effect on the acquisition of gender agreement in L3 English?

ii) Does task-type (comprehension vs. production) influence the performance of participants? Are there significant differences between comprehension and production tasks?

iii) Is there a correlation between proficiency and number of errors? That is, does the number of errors increase as proficiency increases?

iv) What is the role of transfer in establishing gender agreement in L3 English beyond the initial stages and in the ultimate stages?

In light of the findings in L2 and L3 acquisition research, the following hypotheses are entertained:

- Hypothesis 1: regarding animacy effects, it is hypothesized that learners will make more errors in establishing gender agreement in DPs containing an animate possessee than an inanimate one. Previous studies with L2 English (Antón-Méndez, 2010) and with L2 Spanish (Sagarra and Herschensohn, 
2011) participants completing online comprehension tasks have also reported this finding. Concerning the effect of the grammatical gender of the Spanish equivalent noun or 'gender attraction effects', previous research found these effects in the production of L2 and L3 English possessives (Imaz Agirre and García Mayo, 2013; Santesteban et al. 2010).

- Hypothesis 2: the RDH claims that there should not be any task effect for L2 learners (when acquiring an uninterpretable feature that is available from the L1). On the contrary, computational approaches suggest that, due to communication pressure, learners will have problems in oral production (McCarthy, 2008; White et al. 2004). But these claims are made only for uninterpretable features whereas interpretable features (i.e. gender in English) are claimed to be fully acquirable. On the other hand, the FRH advocates that all features are acquirable in an L2. Hence, although for different underlying reasons, $\mathrm{RDH}$ and computational hypotheses claim that learners should not have any problem in either task type (comprehension and production) whereas the FRH posits production to be more demanding for feature reassembly. Table 4 provides a summary of the different outcomes expected on the basis of the different hypotheses discussed in Section 2.4. 
Table 4. Task effects on the basis of the different hypotheses

\begin{tabular}{|c|c|c|c|}
\hline & FFFH/IH & MSIH & FRH \\
\hline Comprehension & $\begin{array}{l}\text { [+interpretable] } \\
\text { features are } \\
\text { expected to be fully } \\
\text { acquirable by } \\
\text { nonnative learners }\end{array}$ & $\begin{array}{c}\text { [+interpretable] } \\
\text { features are } \\
\text { expected to be fully } \\
\text { acquirable by } \\
\text { nonnative learners }\end{array}$ & $\begin{array}{c}\text { Feature re-assembly } \\
\text { may cause } \\
\text { difficulties in } \\
\text { establishing } \\
\text { agreement }\end{array}$ \\
\hline $\begin{array}{l}\text { Written } \\
\text { production }\end{array}$ & $\begin{array}{l}\text { [+interpretable] } \\
\text { features are } \\
\text { expected to be fully } \\
\text { acquirable by } \\
\text { nonnative learners }\end{array}$ & $\begin{array}{l}\text { [+interpretable] } \\
\text { features are } \\
\text { expected to be fully } \\
\text { acquirable by } \\
\text { nonnative learners }\end{array}$ & $\begin{array}{l}\text { Feature re-assembly } \\
\text { may cause } \\
\text { difficulties in } \\
\text { establishing } \\
\text { agreement and } \\
\text { difficulties could be } \\
\text { enhanced in } \\
\text { production tasks }\end{array}$ \\
\hline Oral production & $\begin{array}{l}\text { [+interpretable] } \\
\text { features are } \\
\text { expected to be fully } \\
\text { acquirable by } \\
\text { nonnative learners }\end{array}$ & $\begin{array}{c}\text { [+interpretable] } \\
\text { features are } \\
\text { expected to be fully } \\
\text { acquirable by } \\
\text { nonnative learners. } \\
\text { But if predictions } \\
\text { for } \\
\text { [+uninterpretable] } \\
\text { features were } \\
\text { extended to } \\
\text { [+interpretable] } \\
\text { ones, errors could } \\
\text { be expected due to } \\
\text { communication } \\
\text { pressure }\end{array}$ & $\begin{array}{l}\text { Feature re-assembly } \\
\text { may cause } \\
\text { difficulties in } \\
\text { establishing } \\
\text { agreement and } \\
\text { difficulties could be } \\
\text { enhanced in } \\
\text { production tasks }\end{array}$ \\
\hline
\end{tabular}

- Hypothesis 3: The influence of proficiency may be relevant in minimal input contexts (White et al., 2004), like the one these learners are in (see section 4.2 below). We expect advanced learners to outperform intermediate and elementary learners in establishing correct gender agreement. Besides, participants are expected to adjust to the developmental sequence for the acquisition of third person singular possessive adjectives reported in previous research of Table 3 in Chapter 3 (White and Ranta, 2002; White et al. 2007). 
- Hypothesis 4: Neither Basque nor Spanish display gender features in third person singular possessive adjectives. However, in Basque, like in English, gender is represented in animate nouns and possession is established with the possessor. Among the L3 models, the CEM predicts positive transfer from Basque for Basque/Spanish bilinguals learning L3 English. On the other hand, based on four cues for perceiving language distance, the TPM advocates for the need of (psycho-)typology in order for transfer to occur though this may not be always beneficial. Based on economical reasons, Basque/Spanish bilingual learners are expected to perceive Spanish as being closer to English than to Basque. Therefore, transfer from Spanish is expected to be holistic (and not structure dependent) and thus, facilitative transfer in the initial stages of L3 acquisition when the proximity relation is established. Moreover, previous research has found evidence in favor of holistic facilitative transfer, in this case from Spanish.

In order to collect the data addressing the research questions, a battery of both comprehension and productions tasks were designed targeted at third person possessive adjectives. The following section describes the methodology used in the study.

\subsection{Participants}

A total of 219 participants that were divided in one experimental group (122 participants) and two control groups (73 participants and 24 participants) were recruited for this study. In the experimental group, 122 Basque-Spanish bilinguals initially participated in this study. All Basque/Spanish bilinguals were early bilinguals who were exposed to both Basque and Spanish in early childhood. According to the selfassessment ratings, the majority of learners felt more comfortable speaking Basque than Spanish. However, they were equally proficient in Basque and Spanish (see Appendices 1, 2, 3 for individual information of age of acquisition and self-assessed proficiency in Basque and Spanish in the three proficiency groups). Regarding the use of Basque and of Spanish, learners overall indicated they tended to speak Basque more frequently than Spanish whereas the use of both languages was more similarly balanced in reading and writing (see Appendices 4, 5, 6 for individual information in the use of Basque and Spanish in daily life). In the case of the participants in the two lower proficiency learner groups, dominance in the use of Basque was more prominent than in the university 
students' (henceforth, UNI) group. A reason for this could be that the former groups were recruited in an area where Basque is predominantly spoken whereas learners in the latter group studied in Vitoria-Gasteiz, a Spanish speaking area.

Participants were divided into three groups: in the first group, there were 41 students enrolled in the first year of compulsory secondary education (Derrigorrezko Bigarren Hezkuntza, henceforth DBH group) in a school in Beasain (the Basque Country) (mean age $=12.33$ ). Four students were excluded from the analyses. One of the participants was not in class when the tasks were administered, there were two participants whose L1 was Arabic and in addition their proficiency level in English was too low compared to the class and a fourth student was Spanish dominant and his self-rating proficiency in Basque was low. The second group was comprised of 41 learners studying in the first year of optional secondary education (henceforth BATXI group) in the same school as the previous group (mean age $=16.15$ ). In this group one participant was excluded from the analysis since this student did not attend class when the tests were administered. In the third group, there were 40 undergraduate students from the University of the Basque/Country (UPV/EHU) (UNI group) (mean age = 20.82). In the third group, participants were undergraduate students of the English Studies, Modern Languages or Translation degrees at the UPV/EHU and these learners were paid 20 euros for participating in the study. Both in the DBH and the BATXI group, two intact classes, each one with approximately 20 learners, were selected by the school to participate in the study. Even though there were two groups of learners for the DBH and the BATXI level, conditions were the same for both subgroups. Analyses of variance were conducted between the groups in order to consider both as one group. All participants were enrolled in model $\mathrm{D}$. This is a total immersion programme for those students whose L1 is Spanish and a maintenance programme for L1 speakers of Basque. Participants received their formal instruction through the medium of Basque and Spanish and English are taught as compulsory subjects for about three and four hours per week (Lasagabaster, 2001). These learners were Basque/Spanish bilinguals who were learning or who had learnt English in an instructional or minimal input setting. In this context, learners were exposed to English through formal instruction (approximately) 3 hours of English lessons per week. In minimal input settings, the opportunieties to use the language outside school are scarce (García Mayo \& García 
Lecumberri, 2003). Table 5 displays the distribution of the participants in the Basque/Spanish group.

Table 5. Distribution of the participants in the experimental groups

\begin{tabular}{|c|c|c|}
\hline & \multicolumn{2}{|c|}{ Basque-Spanish bilinguals } \\
\hline DBH = 37 & Group 1 (n = 17) & Group 2(n=20) \\
\hline BATXI $=40$ & Group 1(n = 19) & Group 2(n=21) \\
\hline $\mathrm{UNI}=\mathbf{4 0}$ & \multicolumn{2}{|c|}{ Group $1(n=40)$} \\
\hline \multicolumn{3}{|c|}{ TOTAL = 117} \\
\hline
\end{tabular}

Regarding the linguistic background of participants, none of them in the DBH group and the BATXI group had any knowledge of other languages. Learners in both groups started learning English at the age of 5 and receive 3 hours of English per week. As for the extra-English classes, the majority of the participants in both groups received English lessons from private tuition. More specifically, 83.79\% of the DBH group and 82.5\% of the BATXI learners attended extra-curricular English lessons a trend, that can easily be documented in our EFL context in recent years (Pérez-Vidal, 2014; Sanz, 2014).

In the case of the UNI group, all learners had some knowledge of other languages (i.e. French, German, Catalan, etc. $)^{14}$. However, their self-rated proficiency was low. None of the participants in this group attended private tuition classes at the moment of data collection. Besides, the majority of them had spent over 2 months in an Englishspeaking country. Table 6 summarizes the characteristics of the participants in the three experimental groups. This information was obtained from a background questionnaire that the participants completed (see more on this issue in section 4.5.1 below).

\footnotetext{
${ }^{14}$ It is compulsory for undergraduate students to choose at least one additional language as an optional course in the first year of their degree.
} 
Table 6. Characteristics of the participants in the Basque/Spanish bilingual groups

\begin{tabular}{|c|c|c|c|c|c|c|}
\hline & \multicolumn{2}{|c|}{$\begin{array}{l}\text { DBH group } \\
(\mathbf{n}=37)\end{array}$} & \multicolumn{2}{|c|}{$\begin{array}{l}\text { BATXI group } \\
\quad(n=40)\end{array}$} & \multicolumn{2}{|c|}{$\begin{array}{l}\text { UNI group } \\
(\mathrm{n}=40)\end{array}$} \\
\hline & Range & Mean & Range & Mean & Range & Mean \\
\hline Age of testing & $12-13$ & 12.33 & $16-17$ & 16.15 & $18-28$ & 20.82 \\
\hline $\begin{array}{l}\text { Age of first exposure to } \\
\text { English }\end{array}$ & $3-8$ & 5.07 & $3-7$ & 5.2 & $4-10$ & 6.12 \\
\hline Years studying English & $4-10$ & 7.25 & $8-13$ & 10.85 & $9-20$ & 14.70 \\
\hline $\begin{array}{l}\text { Hours of school } \\
\text { instruction per week }\end{array}$ & 3 & 3 & 3 & 3 & - & - \\
\hline $\begin{array}{l}\text { Private instruction per } \\
\text { week }\end{array}$ & $0-5$ & 2.28 & $0-5$ & 2.47 & - & - \\
\hline $\begin{array}{l}\text { Approx. use of English } \\
\text { p/w in minutes }(\%)\end{array}$ & $0-60$ & 11.15 & $10-180$ & 42.75 & $\begin{array}{l}150- \\
3840\end{array}$ & 52.71 \\
\hline $\begin{array}{l}\text { Age of acquisition of } \\
\text { Basque }\end{array}$ & $0-3$ & 0.31 & $0-3$ & 0.35 & $0-3$ & 0.70 \\
\hline $\begin{array}{l}\text { Daily use of Basque } \\
(\%)\end{array}$ & $60-95$ & 82.38 & $75-100$ & 87.5 & $25-94$ & 64.56 \\
\hline $\begin{array}{l}\text { Age of acquisition of } \\
\text { Spanish }\end{array}$ & $0-7$ & 3.13 & $0-6$ & 1.97 & $0-8$ & 2.38 \\
\hline $\begin{array}{l}\text { Daily use of Spanish } \\
\text { (\%) }\end{array}$ & $5-40$ & 17.61 & $0-25$ & 12.5 & $4-80$ & 35.35 \\
\hline
\end{tabular}

In order to assess the participants' English proficiency level, they all completed the Oxford Placement Test (OPT) (Syndicate, 2001). The test revealed that the participants of the DBH group had an elementary proficiency level whereas the BATXI group featured a lower intermediate proficiency level and learners in the UNI group had advanced level of English (see Appendix 7 for individual information of OPT scores in the Basque/Spanish bilingual group). Table 7 displays the proficiency levels of the three experimental groups. 
Table 7. Mean scores of each Basque/Spanish bilingual group in the OPT test

\begin{tabular}{|l|c|c|c|}
\cline { 2 - 4 } \multicolumn{1}{c|}{} & Mean & Range & SD \\
\hline DBH group & $17.94 / 60$ & $13-23$ & 3.27 \\
\hline BATXI group & $24.85 / 60$ & $21-30$ & 2.59 \\
\hline UNI group & $50.83 / 60$ & $48-57$ & 2.57 \\
\hline
\end{tabular}

Furthermore, as in the experimental groups, L1 Spanish learners of English as an L2 with three different proficiency levels were also tested as control groups. In the first group, 24 students (mean age $=12.22$ ) in the first year of compulsory secondary education (DBH group) were included. However, two participants were excluded from the analysis because they had a different L1 background. The second group was comprised of 25 learners of English (mean age $=16.20$ ) studying in the first year of optional secondary education (BATXI group) but one of the participants was excluded from the analysis since this student could not take all the tasks. DBH and BATXI learners were recruited in Burgos, a Spanish monolingual community in northern Spain. In the third group, data from 24 undergraduate students (mean age $=20.25$ ) enrolled at the University of the Basque Country (UPV/EHU) and the University of Navarre in Spain (UNI group) were gathered. In order to compare the effects of both Basque and Spanish, these control groups of learners without any knowledge of Basque were included in the experimental design in order to assess the effects of Spanish in the acquisition of gender agreement. See Appendices 8, 9, 10 for individual information about the three groups).

Information gathered in the background questionnaire indicated that none of the learners in the DBH and BATXI groups had any knowledge of any languages other than Spanish and English. Learners in both groups started learning English at the age of 5.5-6. Regarding amount of instruction in English, learners in both groups received 3 hours of formal instruction in English per week. Besides, almost all participants in the BATXI group attended extra-curricular English lessons whereas none of the learners in the DBH group received private tuition. In the UNI group, only a few participants had knowledge of other languages (i.e. French and German). None of them attended private tuition classes at the time of the data collection. Moreover, only half of the participants stayed over two months in an English-speaking country. Table 8 summarizes the linguistic profile of L1 Spanish learners. 
Table 8. Characteristics of the participants in the L1 Spanish groups

\begin{tabular}{|c|c|c|c|c|c|c|}
\hline & \multicolumn{2}{|c|}{$\begin{array}{l}\text { DBH group } \\
(\mathbf{n}=22)\end{array}$} & \multicolumn{2}{|c|}{$\begin{array}{l}\text { BATXI group } \\
(\mathrm{n}=24)\end{array}$} & \multicolumn{2}{|c|}{$\begin{array}{l}\text { UNI group } \\
(\mathbf{n}=24)\end{array}$} \\
\hline & Range & Mean & Range & Mean & Range & Mean \\
\hline Age of testing & $12-13$ & 12.22 & $16-17$ & 16.20 & $18-25$ & 20.25 \\
\hline $\begin{array}{l}\text { Age at first instruction } \\
\text { of English }\end{array}$ & $4-6$ & 5.36 & $5-7$ & 6.20 & $5-8$ & 7.29 \\
\hline $\begin{array}{l}\text { Years of studying } \\
\text { English }\end{array}$ & $6-8$ & 6.86 & $9-11$ & 10.00 & $10-17$ & 12.95 \\
\hline $\begin{array}{l}\text { Hours of school } \\
\text { instruction per week }\end{array}$ & 3 & 3 & 3 & 3 & - & - \\
\hline $\begin{array}{l}\text { Private instruction per } \\
\text { week }\end{array}$ & $0-2$ & 0.31 & $0-3$ & 1.70 & - & - \\
\hline $\begin{array}{l}\text { Use of English } p / w \text { in } \\
\text { minutes }(\%)\end{array}$ & $10-90$ & 39.16 & $25-624$ & 46.29 & $\begin{array}{l}435- \\
3420\end{array}$ & 73.04 \\
\hline
\end{tabular}

The L1 Spanish groups also completed the OPT test in order to assess the English level in Basque/Spanish bilingual groups and L1 Spanish groups. Thus, learners in the DBH group had an elementary level, participants in the BATXI group showed intermediate level whereas UNI learners had advanced proficiency level (see Appendix 11 for individual information of OPT scores in the L1 Spanish groups). Table 9 displays the proficiency level of the L1 Spanish groups.

Table 9. Mean scores of each L1 Spanish group in the OPT test

\begin{tabular}{|l|c|c|c|}
\cline { 2 - 4 } \multicolumn{1}{c|}{} & Mean & Range & SD \\
\hline DBH group & $16.52 / 60$ & $14-20$ & 1.32 \\
\hline BATXI group & $24.07 / 60$ & $22-26$ & 1.28 \\
\hline UNI group & $49.80 / 60$ & $48-53$ & 1.26 \\
\hline
\end{tabular}

In addition, the study included 24 American English native-speakers (mean age = 25.45) as a control group. All native speakers were conversation assistants in the Basque Country but none of them had any training in linguistics. Participants were remunerated for participating in the experiment. As a summary, Table 10 displays the general distribution of the nonnative and native participants in the present study. 
Table 10. Distribution of participants in the study

\begin{tabular}{|c|c|c|c|c|}
\cline { 2 - 3 } \multicolumn{1}{c|}{} & $\begin{array}{c}\text { Basque/Spanish } \\
\text { bilinguals }\end{array}$ & $\begin{array}{c}\text { L1 Spanish } \\
\text { speakers }\end{array}$ & $\begin{array}{c}\text { L1 English } \\
\text { speakers }\end{array}$ & TOTAL \\
\hline DBH & 37 & 22 & & $\mathbf{5 7}$ \\
\cline { 1 - 3 } BATXI & 40 & 24 & & $\mathbf{6 4}$ \\
\hline UNI & 40 & 24 & $\mathbf{6 4}$ \\
\hline TOTAL & $\mathbf{1 1 7}$ & $\mathbf{7 0}$ & $\mathbf{2 4}$ & $\mathbf{2 1 1}$ \\
\hline
\end{tabular}

\subsection{Item design}

In each task, items were distributed in terms of the animacy condition and mismatch condition. In the former, items were divided in three conditions: animate condition, inanimate condition and body part condition ${ }^{15}$. Items were designed taking into account the gender of the possessee. In the case of animate possessees, the natural gender of the noun was considered. However, neither animals nor plants (although they are considered animate entities) were included in the design. In inanimate and body part contexts, the (grammatical) gender of the Spanish equivalent was taken into account. In the latter, experimental items were classified in terms of gender-matched and gendermismatched conditions in order to account for all the logical possibilities regarding noun animacy and gender attraction effects. Table 11 summarizes the experimental conditions created for this study.

\footnotetext{
${ }^{15}$ Inanimate and body part sentences were designed separately in order to account for the differences between Basque and Spanish in contrast to English in terms of establishing possession relationships with both types of nouns.
} 
Table 11. Distribution of the experimental conditions

\begin{tabular}{|c|c|c|c|}
\hline Condition & POSSESSOR & POSSESSEE & Example \\
\hline $\begin{array}{l}\text { Gender-matched } \\
\text { animate }\end{array}$ & Masculine & Masculine & $\begin{array}{l}\text { Peter is having dinner with } \\
\text { his brother. }\end{array}$ \\
\hline $\begin{array}{l}\text { Gender-matched } \\
\text { inanimate }\end{array}$ & Masculine & Masculine & $\begin{array}{l}\text { He finished his speech with } \\
\text { applause. }\end{array}$ \\
\hline $\begin{array}{l}\text { Gender-matched } \\
\text { body parts }\end{array}$ & Masculine & Masculine & $\begin{array}{l}\text { Tom is } 6 \text { and he lost his } \\
\text { tooth last night. }\end{array}$ \\
\hline $\begin{array}{l}\text { Gender-matched } \\
\text { animate }\end{array}$ & Feminine & Feminine & $\begin{array}{l}\text { She is having tea with her } \\
\text { grandma. }\end{array}$ \\
\hline $\begin{array}{l}\text { Gender-matched } \\
\text { inanimate }\end{array}$ & Feminine & Feminine & $\begin{array}{l}\text { She covers her terrace with } \\
\text { flowers every spring. }\end{array}$ \\
\hline $\begin{array}{l}\text { Gender-matched } \\
\text { body parts }\end{array}$ & Feminine & Feminine & $\begin{array}{l}\text { She bit her tongue while } \\
\text { eating. }\end{array}$ \\
\hline $\begin{array}{l}\text { Gender- } \\
\text { mismatched } \\
\text { animate }\end{array}$ & Masculine & Feminine & $\begin{array}{l}\text { He is giving a teddy bear to } \\
\text { his daughter. }\end{array}$ \\
\hline $\begin{array}{l}\text { Gender- } \\
\text { mismatched } \\
\text { inanimate }\end{array}$ & Masculine & Feminine & $\begin{array}{l}\text { The farmer is driving his } \\
\operatorname{van}^{16} \text {. }\end{array}$ \\
\hline $\begin{array}{l}\text { Gender- } \\
\text { mismatched body } \\
\text { parts }\end{array}$ & Masculine & Feminine & $\begin{array}{l}\text { He cleaned his throat } \\
\text { before speaking. }\end{array}$ \\
\hline $\begin{array}{l}\text { Gender- } \\
\text { mismatched } \\
\text { animate }\end{array}$ & Feminine & Masculine & $\begin{array}{l}\text { She is giving an ice cream } \\
\text { to her brother. }\end{array}$ \\
\hline $\begin{array}{l}\text { Gender- } \\
\text { mismatched } \\
\text { inanimate }\end{array}$ & Feminine & Masculine & $\begin{array}{l}\text { She donated her piano to } \\
\text { the conservatory. }\end{array}$ \\
\hline $\begin{array}{l}\text { Gender- } \\
\text { mismatched body } \\
\text { parts }\end{array}$ & Feminine & Masculine & $\begin{array}{l}\text { She was wearing a diamond } \\
\text { in her finger during the } \\
\text { party. }\end{array}$ \\
\hline
\end{tabular}

Furthermore, 7 tasks were designed to target third person singular possessive adjectives (see section 4.5 for more details). More specifically, besides completing a background questionnaire, participants completed three comprehension tasks (a picture selection task, a grammaticality judgment task and a moving window task), two written production tasks (a fill-in the gap task and a written description task) and two oral production tasks (an elicitation task and an oral production task). Each task will be described in more detail below. Figure 1 shows the instruments used for data collection in this dissertation.

\footnotetext{
${ }^{16}$ In the picture that targets this sentence, the farmer is a male character.
} 
Figure 1. Tasks used in the experimental design

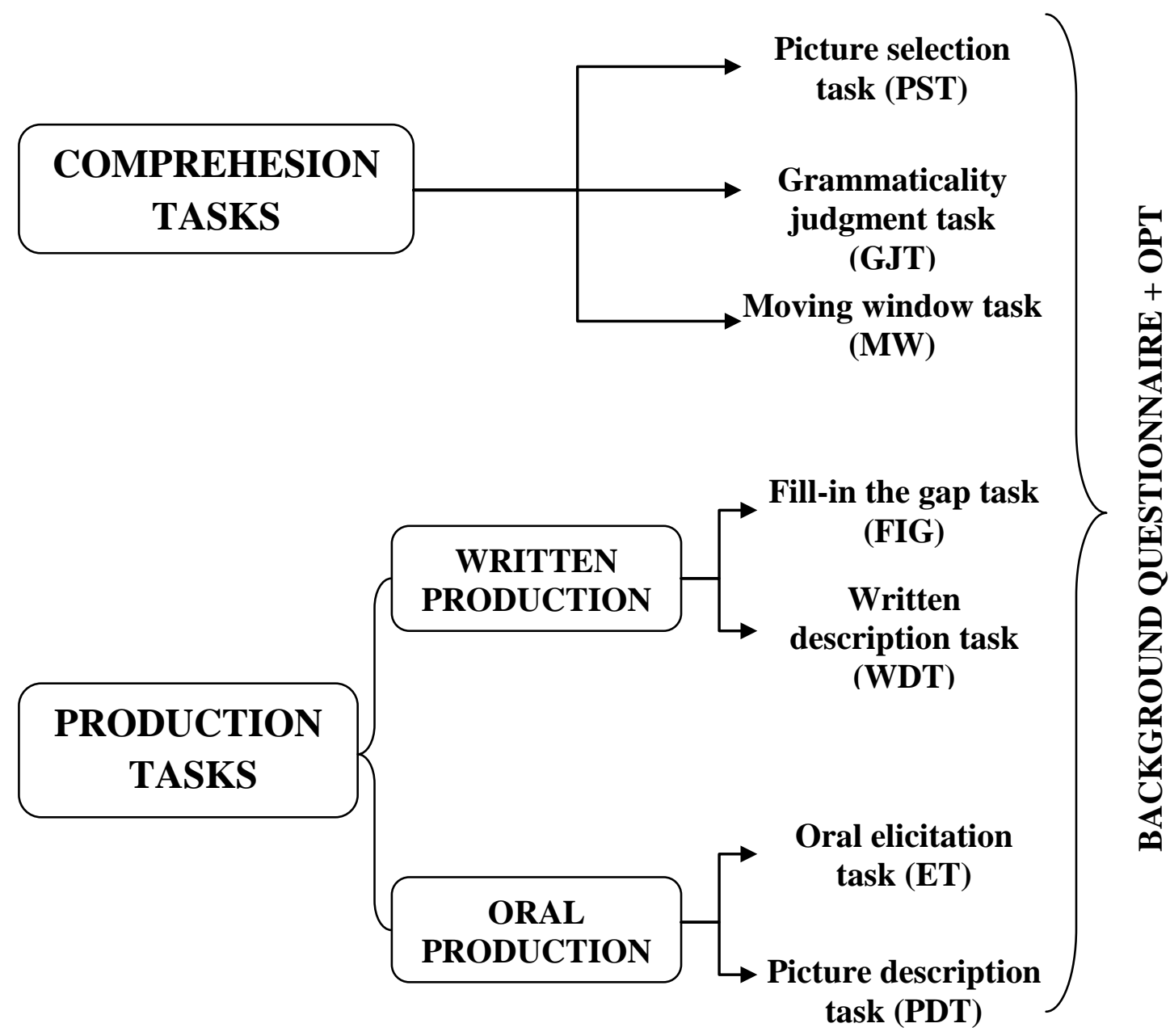

In order to obtain reliable data and to avoid repetition and fatigue effects, the items of the twelve experimental conditions were distributed in lists in each task. Hence, each participant only completed one list in each task. Since the WDT and the PDT were spontaneous description tasks, no experimental items were included in these tasks. Table 12 indicates the distribution of items in each task: 
Table 12. Distribution of items in lists and in each task

\begin{tabular}{lccccc}
\hline Task & $\begin{array}{c}\text { Total } \\
\text { target }\end{array}$ & $\begin{array}{c}\text { Total } \\
\text { fillers }\end{array}$ & $\begin{array}{c}\text { Distribution } \\
\text { (target }+ \\
\text { filler) }\end{array}$ & $\begin{array}{c}\text { Number } \\
\text { of lists }\end{array}$ & $\begin{array}{c}\text { Items per } \\
\text { lists }\end{array}$ \\
\hline $\begin{array}{l}\text { Picture } \\
\text { selection task }\end{array}$ & 144 & 144 & $3+3$ & 4 & 72 \\
$\begin{array}{l}\text { Grammaticality } \\
\text { judgment task }\end{array}$ & 144 & 288 & $2+4$ & 6 & 72 \\
$\begin{array}{l}\text { Moving } \\
\text { window task }\end{array}$ & 96 & 192 & $1+2$ & 4 & 72 \\
$\begin{array}{l}\text { Fill-in the gap } \\
\text { task }\end{array}$ & 96 & 96 & $2+4$ & 4 & 48 \\
$\begin{array}{l}\text { Oral elicitation } \\
\text { task }\end{array}$ & 144 & 144 & $3+3$ & 4 & 72 \\
\hline
\end{tabular}

\subsection{Test material validity}

The experimental items were piloted with 7 English native speakers to validate the (un)grammaticality of the test items and to guarantee an adequate possessive-antecedent relationship. An acceptance rating of at least $85 \%$ was adopted for the acceptability of each test item (i.e. six out of the seven native speakers gave the same judgment) (see Appendices 12-16 for native judgments).

Concerning animate contexts, nouns denoting family relationships (i.e. mother- father; brother-sister, etc.) were used. Family nouns were not repeated in each list. In inanimate nouns, following the CELEX database (Baayen, Piepenbrock and Gulikers, 1995), high frequency nouns were included in the design in order to avoid problems with lexical items. The translations and frequencies of inanimate nouns are reported in Appendices 17-21. Besides, the frequency of each item was controlled for the variance in the lists of each task so that there were no statistically significant differences between nouns in each task. A multivariate ANOVA showed that there were no significant differences either among the lists of each task or between experimental tasks, as shown in Table 13. Besides, Appendices 22-26 provide the post-hoc tests for the frequencies of inanimate

\footnotetext{
${ }^{17}$ The number of target items indicates the number of sentences from each condition that was included in each list.
} 
nouns between experimental lists. Moreover, all the target items were singular in order to avoid the possible effects of number mismatch.

Table 13. Comparison of the lists in each task

\begin{tabular}{|l|c|c|c|c|}
\cline { 2 - 5 } \multicolumn{1}{c|}{} & MEAN & SD & F-value & P-value \\
\hline PST lists & 1.66 & 0.005 & .115 & .951 \\
\hline GJT lists & 1.22 & 0.004 & .607 & .695 \\
\hline MW lists & 1.12 & 0.002 & .583 & .530 \\
\hline FIG lists & 1.60 & 0.04 & 1.216 & .322 \\
\hline ET lists & 1.37 & 0.04 & 2.962 & .204 \\
\hline TOTAL tasks & 1.39 & 0.23 & 5.423 & .109 \\
\hline
\end{tabular}

Furthermore, in order to control for the validity of inanimate nouns in the analyses, 10 native Spanish speakers highly proficient in English were asked to translate these nouns from English to Spanish so that all nouns had a single translation into Spanish. In case nouns had two possible translations, both translations should have the same gender (either feminine or masculine) in order for them to be included in the experimental design. For the translation, speakers were asked to indicate both the equivalent noun in Spanish preceded by the definite article (either masculine or feminine). An acceptability rating of $90 \%$ was adopted for the acceptability of each noun (i.e. nine out of ten native speakers gave the same judgment). This test was performed because all participants were Basque/Spanish bilinguals and they could provide an equivalent noun in Spanish with its corresponding gender feature. Appendix 27 shows the translations of the target possessee nouns by native speakers of Spanish.

\subsection{Instruments}

\subsubsection{Background questionnaire}

A detailed background questionnaire was constructed so as to gather information about the linguistic background of participants (knowledge and use of Basque and Spanish), experience with English learning (i.e. place, years of studying, attending private classes, etc). The questionnaire was given in Basque so that participants did not have any problem in understanding the questions. The complete questionnaire for Basque/Spanish bilinguals is provided in Appendix 28 (with the corresponding 
translation into English in Appendix 29), the one for L1 Spanish learners in Appendix 30 (and its translation into English in Appendix 31) and the questionnaire for native speakers of English in Appendix 32.

\subsubsection{Comprehension tasks}

\subsubsection{Picture selection task}

The findings obtained from this task seek to complement a general panorama on the acquisition of gender agreement with both offline and online tasks in order to tap the learners’ implicit knowledge. The picture selection task aims at testing learners’ implicit knowledge in the acquisition of gender agreement (Mackey and Gass, 2012). This task could suggest whether the abstract gender features are appropriately valued and whether gender agreement is established correctly in comprehension.

\subsection{Materials}

A total of 288 items were designed, which consisted of 144 target items and 144 fillers. The target items were designed on the basis of the experimental conditions shown above. Twelve (12) items were used for each condition (Appendix 33 - for a complete list of target items). All the items were distributed in 4 lists. Each list was comprised of 3 target items from each of the 12 conditions, which made a total of 36 target items (bearing third person singular possessive adjectives) and 36 fillers that were randomized for each list. Besides, the frequencies of the possessee nouns were controlled for so that the differences among lists were not statistically significant.

In this task, 3 pictures were presented in a computer screen and below there appeared a sentence. Slides were shown one at a time for each participant. Sentences consisted of a DP (containing a third person singular possessive adjective) followed by a verb and an adjective. One of the pictures described the meaning of the sentence, another picture described an opposite gender relationship between the possessor and the possessee, whereas the third image was a distractor. The location of the target item was randomized in each slide (see Appendix 34 for a sample of experimental items). Figure 2 shows an example of the stimulus. 
Figure 2. An example of one of the target sentences in the picture selection task
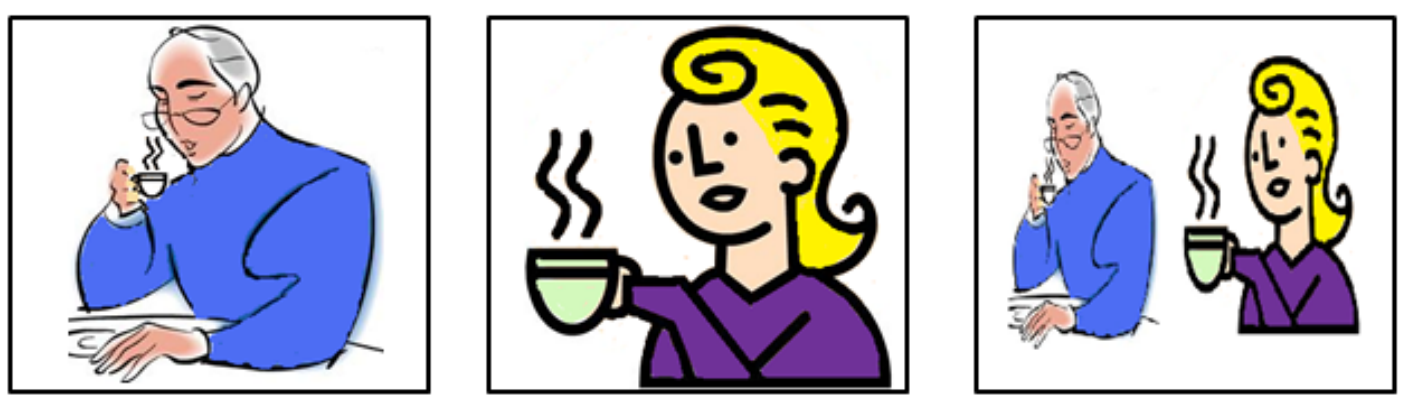

His tea is hot.

\subsection{Procedure}

Participants were presented the task with a Power Point presentation in a computer screen. Instructions were given in Basque for Basque/Spanish leaners and in Spanish for L1 Spanish learners on the first slide of the presentation and in the following slide the participants were given an example. Participants were instructed to read the sentence appearing on the screen and to match it to the picture that described it best (see Appendix 35 for the instructions). Besides, learners were given an answer sheet (see Appendix 36) in which they had to mark their responses as well as a vocabulary list for any query learners had about vocabulary (see Appendix 37). For the DBH group and the BATXI group, participants from each natural group of each proficiency level completed the task the same day. Each participant completed the task individually on a computer so that they could advance to the next slide at their own pace. The completion of the task lasted 20 minutes for each participant in each group. 


\subsubsection{Grammaticality judgment task}

The goal of the off-line grammaticality judgment task was to establish whether L3 English learners were sensitive to gender agreement violations. Performance on grammatical and ungrammatical items may give evidence of whether learners could discriminate between possible and impossible conditions (White, 2003a). In addition, this task would allow the researcher to examine the interaction of the L1s in the underlying grammar of gender agreement in English (Loewen, 2005).

\subsection{Materials}

A total of 432 items were included in this task. Participants were asked to judge whether the sentences were possible or impossible in English. Besides, they were asked to correct these sentences they thought were impossible. Items consisted of 144 target items and 288 fillers, which were designed in terms of the experimental conditions described in section 2. Items were divided in 6 lists which were randomized to avoid the use of strategies. Each list was comprised of 2 target items for each condition, that is, 24 target items. In the case of target items, one of the items was grammatical and the other one was ungrammatical. Regarding the fillers, following the psycholinguistic bases in research (Mackey and Gass, 2012), 1/3 of the items were ungrammatical, that is, 5 filler sentences were ungrammatical and 43 sentences were grammatical, as illustrated in example (21):

\section{a. Mary is wearing a red ribbon on her forehead. \\ b. *George gave me her hand to climb the rock.}

The grammatical and ungrammatical sentences used in this task were 9-14 words and shared a similar syntactic structure. All sentences were randomized in each list and the frequencies of inanimate nouns were controlled for so that there were no differences among lists. See Appendix 38 for a list of target items.

\subsection{Procedure}

Participants were given a sheet of paper with the items and they were asked to judge whether the sentence sounded 'possible' or 'impossible' in English. In addition, learners were asked to correct the ungrammatical sentences. Hence, participants were required to do some degree of conscious analysis by correcting the sentences (Ellis, 1991). Before starting the task, participants were provided with some examples of both grammatical 
and ungrammatical sentences. All the instructions were given either in Basque or in Spanish to the three experimental groups (see Appendix 39). Besides, learners were provided with vocabulary lists (see Appendix 40). The task was completed in 30 minutes ${ }^{18}$.

\subsubsection{Moving window task}

The aim of using an online moving window task was twofold. On the one hand, the online moving window task allows the researcher to compare the results of this task with the offline grammaticality judgment task. On the other hand, the comparison of the reaction times in particular interest areas may indicate whether learners are sensitive to agreement violations (Hopp, 2007; Keating, 2009; VanPatten et al. 2012) in general and more specifically, whether they are sensitive to specific linguistic features such as animacy and grammatical gender. An untimed online design rather than a timed one was preferred for two reasons. First, a timed online task could be too demanding for learners especially at the lower proficiency groups. Second, a self-paced reading task could indicate the response delays in each interest area.

\subsection{Materials}

For the moving window task, 96 target items were selected from the GJT. Items were distributed in 4 lists so that participants did not judge the sentences twice in both the offline and the online tasks. Each list consisted of 72 items, 2 items (one grammatical and one ungrammatical) from each 12 conditions were selected for each list. Participants completed a self-paced reading task in which sentences were presented on a computer screen, word-by-word and answered in yes/no questions. Half of the experimental items required "yes” answers and half of them "no" answers.

All sentences (experimental and fillers) were similar in length (9-14 words) and in syntactic structure. All sentences were similar consisting of a proper name, a verb and a possessive adjective followed by a noun (followed by context). The frequencies of possessee nouns were also controlled for. Besides, sentences were randomized to avoid having two experimental sentences appearing consecutively. Appendix 41 presents a complete list of test items.

\footnotetext{
${ }^{18}$ Participants were not given any time limitation to complete the task.
} 


\subsection{Procedure}

The moving window task was completed individually using the software LINGER. Each learner had one computer in which they completed the task. Data were gathered using a noncumulative center presentation technique (Marinis, 2003). The stimulus sentences were presented on a 17-inch monitor in black bold letters (22 point Courier new font) against a white background. Each sentence began with a fixation marker '+' that appeared in the center of the screen. Each trial was introduced by a fixation marker in order for learners to know a new sentence was going to appear. Words appeared one by one in the center of the screen when participants pressed the space bar key, the first word of the sentence appeared. By pressing the space bar key each time, the previous word was removed and the subsequent word was revealed. Pressing the key on the last word of the sentence prompted a question mark, in which participants should answer 'yes' (key ' $F$ ' in the keyboard) if they believed the sentence was grammatical or 'no' (key ' $\mathrm{J}$ ' in the keyboard) if it was ungrammatical. At the bottom of the screen the answer keys were indicated in all sentences.

The administration of the experimental lists was carefully controlled for so that participants did not judge the same sentence twice in the grammaticality judgment task and in the moving window task. The task included a practice section in which participants were explained how the task worked and they were also presented with 4 practice sentences. Instructions (in Basque and Spanish for nonnative groups) were presented on the screen before participants began performing the task (see Appendix 42). Nevertheless, the researcher explained the procedure and showed the response keys to the participants again. Afterwards, participants completed the training session. In this session, the sentences were combined with instructions in Basque in order to clarify the procedure of the task for the participant. Each block had a break in the middle of the test. Participants completed the task in about 35 minutes.

The experimental sentences were divided in four regions of interest. The sentences testing gender agreement were divided as indicated in (22): 


$\begin{array}{llll}1 & 2 & 3 & 4\end{array}$

(22) a. Kate / broke / her / promise / of not telling the truth.

b. *Kate / broke / his / promise / of not telling the truth.

The reading times (or reaction times) were examined in three key interest areas: region 1 (the possessor), region 3 (the possessive) and region 4 (the possessee). Figure 3 displays an example of the procedure of this task.

Figure 3. Example of the moving window task.

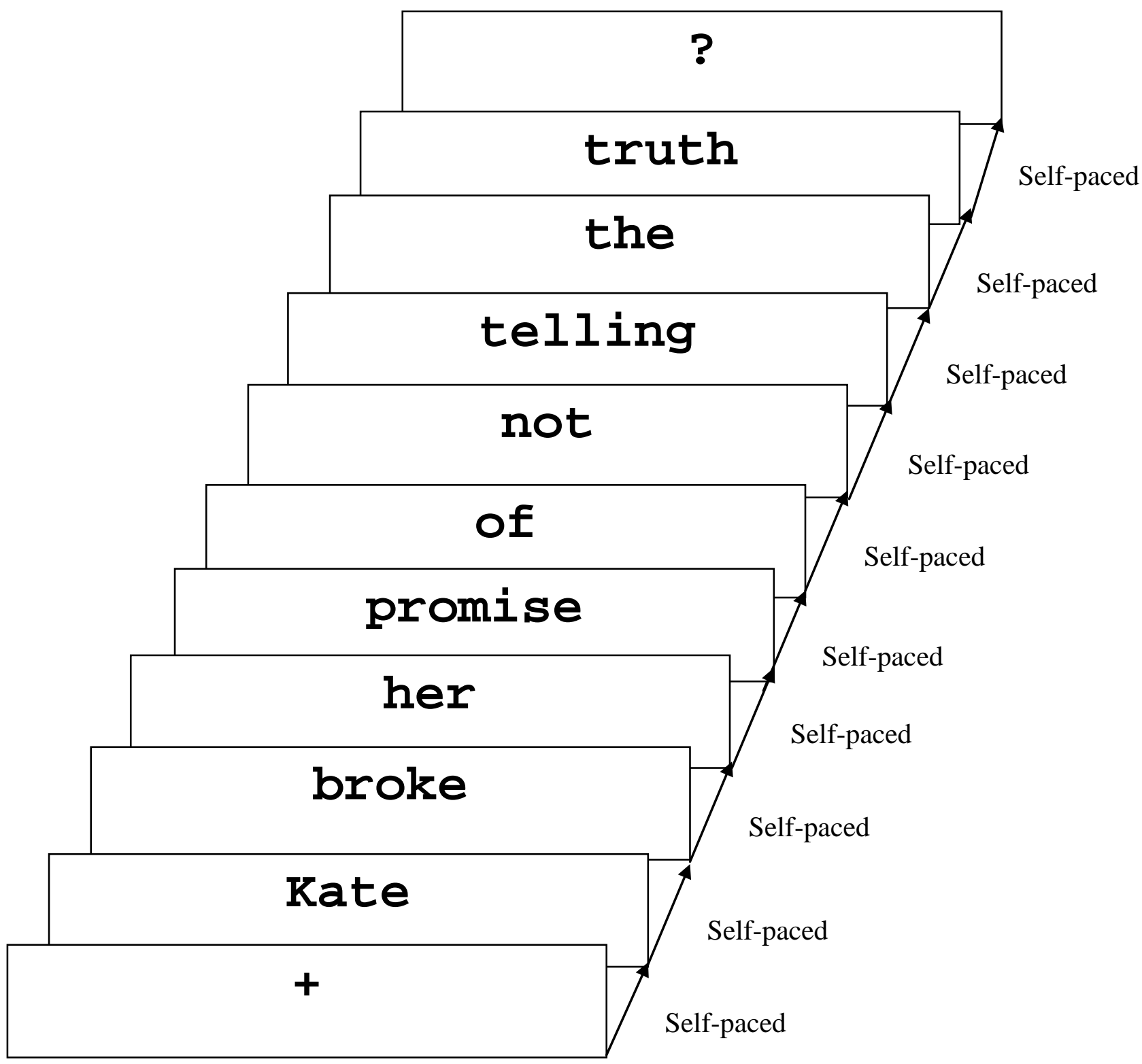




\subsubsection{Production tasks}

\subsubsection{Written production tasks}

\subsection{Fill-in the gap task}

The fill-in-the-gap task aimed at tapping the learners' explicit knowledge in written production (Ellis, 2005). This task, combined with the spontaneous written description task, would measure participants' accuracy in gender agreement in writing. The focus of the fill-in the gap task was to concentrate on learners' written production and to compare it to comprehension data as well as oral production data. More precisely, the aim of using this task was to contrast the use of possessive adjectives in a controlled task in order to compare with a more spontaneous description task.

\subsection{Materials}

One hundred and ninety two (192) items were designed for inclusion in this task, 96 of them were target items and 96 were fillers. Items were distributed in 4 lists so that each list was comprised of 2 target items from each condition. The total number of items each participant completed was of 24 target items and 48 fillers. Example (23) shows an example of the experimental items, which were randomized. Appendix 43 shows the lists of items.

Mike is a very bad student, but son is brilliant.

\subsection{Procedure}

Each participant was given one list in which they had to fill in the blank with an appropriate word. Instructions were given in Basque or in Spanish so that participants did not have any problem in understanding the task (see Appendix 44). Moreover, participants were provided a basic vocabulary list for each list (see Appendix 45). Besides, the items of each list were randomized to avoid the use of strategies. Learners were not given any time limits. 


\subsection{Written description task}

The goal of the written description task was to examine whether these gender agreement errors were attested in written production. More specifically, the written description task would provide information about spontaneous written production. This task would complement the production in the fill-in the gap task.

\subsection{Materials}

For the written description task, participants described 'The dog story', a story consisting of 6 pictures which was adapted from Heaton (1966). This task was previously used by Muñoz (2006) in a study targeting third person singular possessives. In this story, there appeared two characters (a boy and a girl) in all the pictures and their mother appeared in two of them. However, the 6 vignettes did not tell the complete story and therefore, each participant should provide an ending to it. The picture was colored in order for participants to give a more detailed description of the story (see Appendix 46).

\subsection{Procedure}

The instructions were given in Basque for the Basque/Spanish group so that the task was clear for the participants. Learners were instructed to describe the story of one of the characters either the boy or the girl (this was randomized) as precisely as they could (see Appendix 47 for the instructions). In addition, learners were explicitly instructed that they could only use proper names just once to encourage participants use third person pronouns. In order to obtain a complete description, participants were also provided with a basic vocabulary list (see Appendix 48).

\subsubsection{Oral production tasks}

\subsection{Oral elicitation task}

The aim of the oral elicitation task was to assess third person singular possessive adjectives in oral production. The objective of introducing a semi-guided oral task in the experimental design was to elicit items for the experimental conditions included in the experiment in a "naturalistic" context. In addition, oral data enables to triangulate these data with comprehension and written production data. 


\subsection{Materials}

The target items were designed on the basis of the experimental conditions shown above. A total of 288 items was created for this task, which consisted of 144 target items and 144 fillers. Twelve (12) items were created for each condition but due to the inconveniences such a large number of items would create in terms of time and subject 'tiredness', items were divided in 4 different lists. Therefore, each list consisted of 3 target items per condition, which makes a total amount of 36 target items targeting the production of third person singular possessives. Thirty six (36) fillers were also included in the task. The items of each list were randomized. In the case of inanimate items, the frequencies were controlled so that there were no differences between the four lists.

The structure of target sentences as follows: masculine/feminine Subject + (aux) $+V+$ DP + PP. The possessive adjective was expected to be produced either in the DP or in the PP. Appendix 49 shows a complete list of target items.

\subsection{Procedure}

Each participant was interviewed individually. They were shown all 72 images, one at a time, in a random order on a computer screen. Participants were given instructions in such a way that they had to give a complete answer, that is, sentences should have a subject, a verb and at least one object (see Appendix 50 for a more detailed view of the instructions). Afterwards, the researcher presented each character appearing in the images to the participants and they were asked a single question, example (24) describes a target item (Appendix 51 shows a sample of pictures used in this task). 
(24)

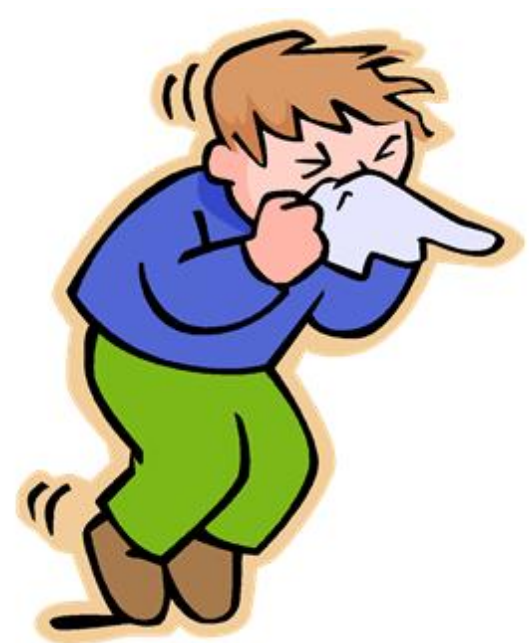

INV: What is the boy doing?

CHI: He is blowing his nose

There were no time constraints for participants to give an answer. Once the participant provided a response, the researcher moved on to the next item. Learners were provided with some basic vocabulary lists (see Appendix 52) although they could also ask for help with lexical items to the researcher. Interviews were audio recorded.

\subsection{Oral picture description task}

The goal of the oral picture description task was to collect data in a naturalistic and spontaneous context. The choice of this specific description task would provide learners numerous opportunities to produce gender agreement spontaneously. This production could evidence the strategies used by Basque-Spanish bilinguals when narrating a story orally in L3 English.

\subsection{Materials}

A picture from Holderness and Hughes (1997) was used for the picture description task. The picture represented a family with 11 members and one of the characters, either Susan or Tom, was introduced to the participants (see Appendix 53 for the male version and Appendix 54 for the female version). Each participant had to describe the family, which consisted of 5 male characters and 6 female characters. The picture was colored in order to elicit more detailed descriptions. 


\subsection{Procedure}

Participants had to describe the family of one of the characters either of the male character or of the female one. The description of either of the characters was randomized, that is, half of the learners described the male version whereas the other half completed the female version). Learners were instructed in such a way that they could not use any proper name except of Susan and Tom in Basque or Spanish (see Appendix 55 for the instructions). In this task, participants were also provided with a basic vocabulary list (see Appendix 56).

\subsection{Test administration}

In all tasks, instructions were given in Basque to all the participants in the three Basque/Spanish experimental groups in order to avoid any problem comprehending the experimental tasks. Even though the instructions were given in Basque, all experimental items as well as the interviews in the oral production tasks were fully conducted in English. Besides, participants were provided with a basic vocabulary list that was adapted to each list for each task. In contrast, instructions for the L1 Spanish groups were given in Spanish.

Regarding test administration, the same procedure was followed for both the Basque/Spanish bilingual groups and the L1 Spanish groups. In the DBH groups and BATXI groups participants completed all the tasks during their English lessons (three times a week). Data collection lasted 17-18 sessions with each one of the two DBH and BATXI groups. In both groups, data from the background questionnaire and the OPT were gathered in the first session. In the following two days, comprehension data were collected and in the next lesson participants completed the written production tasks. All these sessions were done in groups. From the fifth lesson onwards, participants completed the two oral production tasks individually. The group sessions lasted for 1 hour each whereas the individual sessions with each participant took approximately 20 minutes. The length of each group session varied among participants and all the tasks (except for the moving window task) were untimed. The procedure was repeated for the L1 Spanish DBH and BATXI learners. The data collection in this group lasted for 12-13 sessions. 
On the other hand, the data of the UNI participants in both nonnative groups as well as the one of the native speakers were collected in two individual appointments (approximately one hour each). In the first session, participants filled the background questionnaire, the OPT and two comprehension and a written production task. In the next session, participants completed the moving window task as well as the production tasks. The reason for collecting data in two different sessions (1 hour each) was to avoid developing strategies when doing the tasks. Table 14 describes the procedure of the task administration.

Table 14. Chronological distribution of test administration of the non-native learner groups

\begin{tabular}{|c|c|c|c|c|c|}
\hline & DAY 1 & DAY 2 & DAY 3 & DAY 4 & DAY 5/... \\
\hline 兽 & $\begin{array}{l}\text { BQ + OPT } \\
\text { (in groups) }\end{array}$ & $\begin{array}{l}\text { PST + GJT } \\
\text { (in groups) }\end{array}$ & $\begin{array}{c}\text { MW } \\
\text { (in groups) }\end{array}$ & $\begin{array}{c}\text { FIG + WDT } \\
\text { (in groups) }\end{array}$ & $\begin{array}{c}\text { ET + PDT } \\
\text { (individually) }\end{array}$ \\
\hline$\underset{\infty}{x}$ & $\begin{array}{l}\text { BQ + OPT } \\
\text { (in groups) }\end{array}$ & $\begin{array}{l}\text { PST + GJT } \\
\text { (in groups) }\end{array}$ & $\begin{array}{c}\text { MW } \\
\text { (in groups) }\end{array}$ & $\begin{array}{c}\text { FIG + WDT } \\
\text { (in groups) }\end{array}$ & $\begin{array}{c}\text { ET + PDT } \\
\text { (individually) }\end{array}$ \\
\hline 竞 & $\begin{array}{c}\text { BQ + OPT + } \\
\text { PST + GJT + } \\
\text { FIG } \\
\text { (individually) }\end{array}$ & $\begin{array}{c}\text { MW + WDT } \\
+ \text { ET + PDT } \\
\text { (individually) }\end{array}$ & & & \\
\hline
\end{tabular}

\subsection{Data codification and analysis}

\subsubsection{Coding}

The data coming from comprehension and the fill-in the gap task were coded for the experimental conditions. The written description data were transcribed and coded using CHILDES (MacWhinney, 2000) (see Appendix 57 for an example of a transcription and codification of the written production task). Finally, oral production tasks were audiorecorded, transcribed and coded in CHILDES as well (see Appendix 58 and Appendix 59 for an example of the transcriptions and codifications in both the oral elicitation task and the oral production tasks). As for the codification of doubtful contexts in terms of the use of possessive adjectives or other forms in obligatory context, two native 
speakers of English were asked to evaluate these experimental items. Besides, for the use of inanimate possessee nouns that were not included in the first experimental design, gender assignment was checked with two native speakers of Spanish. Concerning the hours of recordings, for the DBH group 8 hours were recorded in the oral elicitation task whereas 7 hours were recorded for the BATXI group. In the oral picture description task, 4, 5 hours were recorded for the DBH group and 5 hours for the BATXI group.

The participants' label has been formed as follows: first, the letters BS or SP encode the L1 group each participant belongs to, the number encodes the participants' number, the following letters encode the proficiency level of each participant and the final letters encode the experimental task. Table 15 summarizes the conventions used when labelling the participants.

Table 15. Labelling system

\begin{tabular}{|c|c|l|}
\hline Order of the symbols & Symbols used & \multicolumn{1}{|c|}{ Meaning of the symbols } \\
\hline \multirow{2}{*}{ First code } & BS & Basque/Spanish bilinguals \\
\cline { 2 - 3 } Number & SP & L1 Spanish speakers \\
\hline \multirow{4}{*}{ Second code } & $\mathbf{1 - 4 0}$ & Participants' number \\
\cline { 2 - 3 } & DBH & Elementary learners \\
\cline { 2 - 3 } & BATXI & Intermediate learners \\
\hline \multirow{5}{*}{ Final code } & UNI & Advanced learners \\
\cline { 2 - 3 } & PST & Picture selection task \\
\cline { 2 - 3 } & GJT & Grammaticality judgment tasks \\
\cline { 2 - 3 } & MW & Moving window task \\
\cline { 2 - 3 } & FIG & Fill-in the gap task \\
\cline { 2 - 3 } & WDT & Written description task \\
\cline { 2 - 3 } & ET & Elicitation task \\
\cline { 2 - 3 } & PDT & Picture description task \\
\hline
\end{tabular}

In all the tasks, data were coded for gender-matched animate, inanimate and body part conditions as well as gender-mismatched animate, inanimate and body part conditions. Table 16 shows the codes and an example of each. 
Table 16. Coding criteria for the experimental conditions

\begin{tabular}{|c|c|c|}
\hline CODE & CONDITION & EXAMPLE \\
\hline [gman] & Gender-matched animate & $\begin{array}{l}\text { She help her } \\
\text { [BS_09_BATXI_WDT] }\end{array}$ \\
\hline [gmin] & Gender-matched inanimate & $\begin{array}{l}\text { The boy is taking something from the } \\
\text { pocket.[BS_02_DBH_ET] }\end{array}$ \\
\hline [gmbp] & Gender-matched body parts & $\begin{array}{l}\text { She has a baby in her hand. } \\
\text { [BS_04_BATXI_PDT] }\end{array}$ \\
\hline [gmman] & Gender-mismatched animate & $\begin{array}{l}\text { Susan is catching a butterfly with her } \\
\text { brother. [BS_02_DBH_PDT] }\end{array}$ \\
\hline [gmmin] & Gender-mismatched inanimate & $\begin{array}{l}\text { He has some flowers in his baske.t } \\
\text { [BS_18_BATXI_FIG] }\end{array}$ \\
\hline [gmmbp] & Gender-mismatched body parts & $\begin{array}{l}\text { Jake had a bump of his head after } \\
\text { crashing against a } \\
\text { [BS_20_DBH_GJT] }\end{array}$ \\
\hline
\end{tabular}

In addition, learners produced other (incorrect) forms rather than third person possessive adjectives in obligatory context. Table 17 shows the codes and an example of each case is provided. 
Table 17. Coding criteria of other errors in obligatory contexts

\begin{tabular}{|c|c|c|}
\hline CODE & CONDITION & EXAMPLE \\
\hline [posspl] & $\begin{array}{l}\text { Possessive adjective } \\
\text { plural }\end{array}$ & $\begin{array}{l}\text { John is looking to their aunts. } \\
\text { [BS_06_DBH_PDT] }\end{array}$ \\
\hline [dao] & Definite article overuse & She brush the hair. [BS_01_DBH_ET] \\
\hline [omi] & Omission & $\begin{array}{l}\text { A crayfish bit a boy in leg. } \\
\text { [BS_05_DBH_ET] }\end{array}$ \\
\hline [case] & Case mismatches & $\begin{array}{l}\text { Can you give me him address? } \\
\text { [BS_23_BATXI_FIG] }\end{array}$ \\
\hline [myo] & My overuse & $\begin{array}{l}\text { She realized my dog is in the box. } \\
\text { [17_BATXI_WDT] }\end{array}$ \\
\hline [yo] & 'Your' overuse & $\begin{array}{l}\text { He are speaking for your brother. } \\
\text { [BS_15_DBH_PDT] }\end{array}$ \\
\hline [tda] & Two determiners & $\begin{array}{l}\text { He is washing the his cloth. } \\
\text { [BS_07_BATXI_ET] }\end{array}$ \\
\hline [genS] & $\begin{array}{l}\text { Use of the Saxon } \\
\text { genitive 's }\end{array}$ & $\begin{array}{l}\text { She is walking with she's mother. } \\
\text { [BS_11_DBH_ET] }\end{array}$ \\
\hline [hir] & & $\begin{array}{l}\text { Hir brother are catching a butterfly. } \\
\text { [BS_19_DBH_PDT] }\end{array}$ \\
\hline [placeholder] & & $\begin{array}{l}\mathrm{He} \text { is his cut \#\# a grass. } \\
\text { [BS_18_BATXI_ET] }\end{array}$ \\
\hline [tp] & Two pronouns & $\begin{array}{l}\text { Next to \# there is his she mother with } \\
\text { camera. [BS_18_BATXI_PDT] }\end{array}$ \\
\hline
\end{tabular}

\subsubsection{Decisions for data-coding}

When coding the data, not all instances of possessive adjective use could be submitted to statistical analyses. In order to establish some conventions for the data analysis, some examples of data that was included and excluded from the analysis will be provided. 
The following decisions were taken as correct production when codifying:

* Self-repairs of possessives were coded as correct (if the last choice was correct) even if an incorrect possessive form was used.

(25) Tom is playing his... *her.... his brother. [BS_26_BEG_PDT]

The use of possessive adjectives was not included in the analysis:

Even though the possessive adjective was correctly used, gender assignment of the antecedent was inaccurate.

$$
\text { She } \boldsymbol{e}_{\boldsymbol{i}} \text { fells and *he } \boldsymbol{e}_{\boldsymbol{i}} \text { brokes her feet. [BS_10_BEG_ET] }
$$

Possessive adjectives without a clear antecedent were not tallied for the analyses.

$$
\text { is watching eeee her daughter. [BS_02_INT_PDT] }
$$

Inanimate possessees with two translation possibilities each with different gender assignment in Spanish.

$$
\text { *She is looking to his bracelet. [BS_23_BEG_ET] }
$$

As example (28) shows 'bracelet' could be translated as 'la pulsera' (feminine) or 'el brazalete' (masculine).

Developmental errors (i.e. the overuse of the expletive 'there' in obligatory context) if their use was not robust enough.

$$
\text { He is speaking with there friend with the telephone. [BS_18_INT_ET] }
$$

\subsubsection{Procedures for data analyses}

Data was submitted to quantitative statistical analysis using SPSS 20 statistical package. Variances in the use of possessive adjectives were computed for each subject in each list. This analysis indicated that two participants in the DBH group were performing as outliers in all the tasks therefore they were excluded from the statistical analyses. Variances in each task were also computed in order to analyze whether differences were found between experimental lists. No variances were found between experimental lists so that items in each list were comparable. Moreover, variances in each list were 
computed in order to control for the difficulty of the experimental items. The analysis of variances showed that in any list all participants made gender agreement errors. Instead, those items in which all participants used possessive adjectives correctly were considered as indicative of their developing IL rather than task easiness.

\subsection{Summary of the chapter}

This chapter has presented the participants in this study: three experimental groups of Basque/Spanish bilinguals with different levels of proficiency (elementary, intermediate and advanced) and three L1 Spanish control groups with different proficiency level as well as a control group of L1 English speakers. Participants completed three comprehension tasks (a picture selection task, a grammaticality judgment task and a self-paced reading task), two written production tasks (a fill-in the gap task and a written description task) and two oral production tasks (an oral elicitation task and an oral picture description task).

In the next chapter, Chapter 5, the results obtained from the seven experimental tasks will be presented. Results will be considered and commented on in terms of the analysis of linguistic conditions, the analysis between experimental tasks, the comparison between proficiency groups and the contrasts between the native and non-native groups. 


\section{CHAPTER 5. RESULTS}

This section presents the results of both comprehension and production tasks targeting L3 English possessive adjectives (his/her) as completed by Basque-Spanish bilinguals, L1 Spanish speakers and L1 English speakers. More specifically, in section 5.1 findings for the general use of possessive adjectives is reported. Section 5.2 analyzes the results of animacy and gender attraction effects. In section 5.3, the findings from the seven experimental tasks are compared. Section 5.4, reports the comparison between different proficiency levels and in Section 5.5 differences between experimental and control groups are presented. Section 5.6 provides an overview of the main findings. Significance was set at $\alpha=.05$ for all analyses.

\subsection{Overall use of possessive adjectives}

The total production of subject and object pronouns together with third person singular possessive adjectives was computed. The contrast between third person singular subject and object pronouns, on the one hand, and third person singular possessive adjectives, on the other, provides an overall picture of the participants' developing IL and allows us to see that there is a significant difference between the use of the former and the latter. The interaction between third person subject, object and possessives pronouns showed statistically significant differences both in the Basque/Spanish bilingual group ( $F$ $(2,690)=2.288 ; p<.0001)$ and in the L1 Spanish group $(F(2,214)=243.332 ; p<.0001)$, as illustrated in Table 18. A follow up pairwise analysis revealed that significant differences were only found when possessive adjectives were compared to subject and object pronouns (both $p$-values $<.0001$ ). In the natives group, no differences between subject, object and possessives pronouns were found. 
Table 18. Third person singular subject and object pronouns vs. third person singular possessive adjectives

\begin{tabular}{|c|c|c|c|c|c|c|c|}
\hline & \multicolumn{3}{|c|}{ CORRECT } & \multicolumn{3}{|c|}{ INCORRECT } \\
\hline & & $\mathbf{N}$ & $\%$ & SD & $\mathbf{N}$ & $\%$ & SD \\
\hline \multirow{3}{*}{ 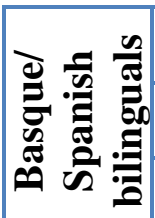 } & Subject & $2434 / 2535$ & 96.01 & 5.20 & $101 / 2535$ & 3.98 & 0.77 \\
\hline & Object & $81 / 93$ & 87.09 & 0.56 & $12 / 93$ & 12.90 & 0.11 \\
\hline & Possessive & $6867 / 11727$ & 58.59 & 3.28 & $4860 / 11727$ & $41.41 *$ & 3.82 \\
\hline \multirow{3}{*}{ 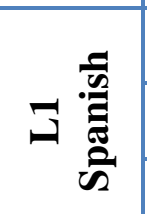 } & Subject & 3072/3183 & 96.5 & 1.10 & 111/3183 & 3.49 & 0.24 \\
\hline & Object & $50 / 50$ & 100 & 0.15 & $0 / 0$ & 0 & 0 \\
\hline & Possessive & $7645 / 10527$ & 72.62 & 1.36 & $2882 / 10527$ & $27.37 *$ & 1.00 \\
\hline \multirow{3}{*}{ 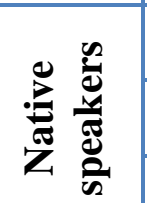 } & Subject & $1218 / 1218$ & 100 & 1.10 & $0 / 1218$ & 0 & 0 \\
\hline & Object & $126 / 126$ & 100 & 0.51 & $0 / 126$ & 0 & 0 \\
\hline & Possessive & 3905/3909 & 99.89 & 0.02 & $4 / 3909$ & 0.10 & 0.02 \\
\hline
\end{tabular}

Thus, gender agreement seems to pose specific problems with third person singular possessive adjectives since the percentage of agreement errors is above $40 \%$ for Basque/Spanish bilinguals in all tasks. However, the analyses of possessive adjectives seem to indicate differences between the three proficiency groups. Lower proficiency groups show a higher percentage of both incorrect gender agreement and the use of other forms in obligatory contexts.

The production of third person singular possessive adjectives was computed and possessives were classified in terms of correct production, incorrect production, the non-use of possessive adjectives in obligatory context (i.e. first/second person singular pronoun, definite article overuse, etc.) and non-analyzable items. Table 19 summarizes the correct and incorrect third person singular possessive adjectives as well as the use of other forms in obligatory context. 
Table 19. Correct and incorrect third person singular possessive adjectives vs. other errors in obligatory contexts across groups

\begin{tabular}{|c|c|c|c|c|c|c|c|c|c|c|}
\hline & \multicolumn{3}{|c|}{ CORRECT } & \multicolumn{3}{|c|}{ INCORRECT } & \multicolumn{3}{|c|}{ OTHER ERRORS } \\
\hline & & $\mathbf{N}$ & $\%$ & SD & $\mathbf{N}$ & $\%$ & SD & $\mathbf{N}$ & $\%$ & SD \\
\hline \multirow{3}{*}{ 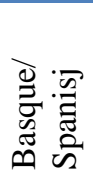 } & $\mathrm{DBH}$ & $2916 / 5696$ & 51.19 & 3.40 & $1648 / 5696$ & 28.93 & 1.40 & $1136 / 5696$ & 19.87 & 1.63 \\
\hline & BATXI & $3944 / 6014$ & 65.58 & 3.17 & $1359 / 6014$ & 22.59 & 1.24 & $711 / 6014$ & 11.82 & 1.10 \\
\hline & UNI & $5624 / 6296$ & 89.33 & 2.75 & $465 / 6296$ & 7.38 & 1.62 & $207 / 6296$ & 3.28 & 0.94 \\
\hline \multirow{3}{*}{ ت泀 } & $\mathrm{DBH}$ & $1851 / 3382$ & 54.73 & 1.08 & $1135 / 3382$ & 33.56 & 1.00 & $396 / 3382$ & 11.70 & 0.63 \\
\hline & BATXI & $1980 / 3304$ & 59.92 & 1.15 & $1163 / 3304$ & 35.19 & 1.00 & $161 / 3304$ & 4.87 & 0.50 \\
\hline & UNI & $3461 / 3779$ & 91.58 & 1.05 & 288/3779 & 7.62 & 0.51 & $30 / 3779$ & 0.79 & 0.13 \\
\hline \multicolumn{2}{|c|}{ English natives } & $3105 / 3109$ & 99.87 & 0.02 & $4 / 3109$ & 0.13 & 0.02 & $0 / 3105$ & 0 & 0 \\
\hline
\end{tabular}

n.p. $=$ not produced or not analyzed

Findings in the Basque/Spanish bilingual group indicated that for the DBH group 51.1\% of possessive adjectives were correctly used, whereas almost $30 \%$ and $20 \%$ of the possessives were incorrect gender agreement instances and inaccurate uses in obligatory context, respectively. Regarding the BATXI group, results showed a higher percentage of accurate use (65\%) in gender agreement. However, the percentage of incorrect gender agreement is still over $20 \%$ and other errors present more than $10 \%$. In the UNI group, the percentage of accurate gender agreement reaches almost $90 \%$. However, the use of incorrect gender agreement and the use of other forms in obligatory contexts is slightly over $10 \%$. In fact, statistical analysis revealed significant differences between incorrect agreement and the use of other forms $(F(2,392)=283.288 ; p<.0001)$.

Data in all tasks were trimmed, some datapoints were excluded from the analysis for various reasons (i.e. unintelligible writing/production, non-target form, ...). From the data set $4.40 \%$ of data points were excluded from the analysis in the picture selection task, $7.08 \%$ in the grammaticality judgment task, 3.19\% in the moving window task, $1.82 \%$ in the fill-in the gap task, $4.53 \%$ in the elicitation task. Regarding RTs in the moving window task, reaction delays faster than three SDs below the mean and slower than three SDs bove the mean were discarded from the statistical analysis. This affected the $3.50 \%$ of the data.

This section has provided evidence that English learners both Basque/Spanish bilingual learners and L1 Spanish learners have problems in using third person singular possessive adjectives accurately. The following sections will provide a more fine- 
grained analysis in order to identify the effect of animacy and gender attraction effects in gender agreement errors as well as the role of proficiency, linguistic background and task type.

\subsection{Animacy and gender attraction effects in gender agreement errors}

This section presents the data gathered from Basque/Spanish bilinguals, L1 Spanish spekaers and native speakers of English in order to answer the first research question of the present study, which is repeated here for the reader's convenience:

RQ 1: Does the internal structure of the DP play a role? More specifically, does animacy and the grammatical gender of the Spanish equivalent $\mathrm{N}$ have an effect on the acquisition of gender agreement in L3 English?

The statistical analysis in this section was conducted only with gender agreement errors. Data from each task was submitted to a mixed model ANOVA analysis with animacy (animate, inanimate, body part) and attraction (gender-matched, gender-mismatched) as within-subject variables and group (Basque/Spanish, L1 Spanish, native speakers) and proficiency (elementary, intermediate, advanced) as between subject variables in the bysubject analysis and with group and proficiency as within-item variables and animacy and attraction as between-item variables in the by-item analysis. Animacy and gender attraction effects in each task will be presented in a separate section, starting with comprehension tasks (picture selection task in Section 5.2.1, grammaticality judgment task in Section 5.2.2 and moving window task in Section 5.2.3), written production tasks (fill-in the gap task in Section 5.2.4 and written description task in Section 5.2.5) and oral production tasks (elicitation task in Section 5.2.6 and picture description task in Section 5.2.7). In each subsection, animacy effects will be described first and then, the outcome from attraction effects will be reported.

\subsubsection{Animacy and gender attraction effects in the picture selection task}

No main effect of animacy was found in the picture selection task. This finding indicated that overall participants in all groups and proficiency levels produced similar error percentages. 
In contrast, a main significant effect was found for attraction $(F(1,205)=30.453$; $\left.p<.0001 ; \boldsymbol{\eta}_{p}{ }^{2}=.13\right)$. Post hoc tests with Bonferroni correction indicated that Basque/Spanish bilinguals showed more gender agreement errors when compared to L1 Spanish speakers and native speakers (all $p$-values $<.0001$ ). Figure 4 displays the percentages of inconrrect gender agreement in gender-mismatched conditions.

Figure 4. Percentages of incorrect gender agreement in the mismatched conditions in the picture selection task

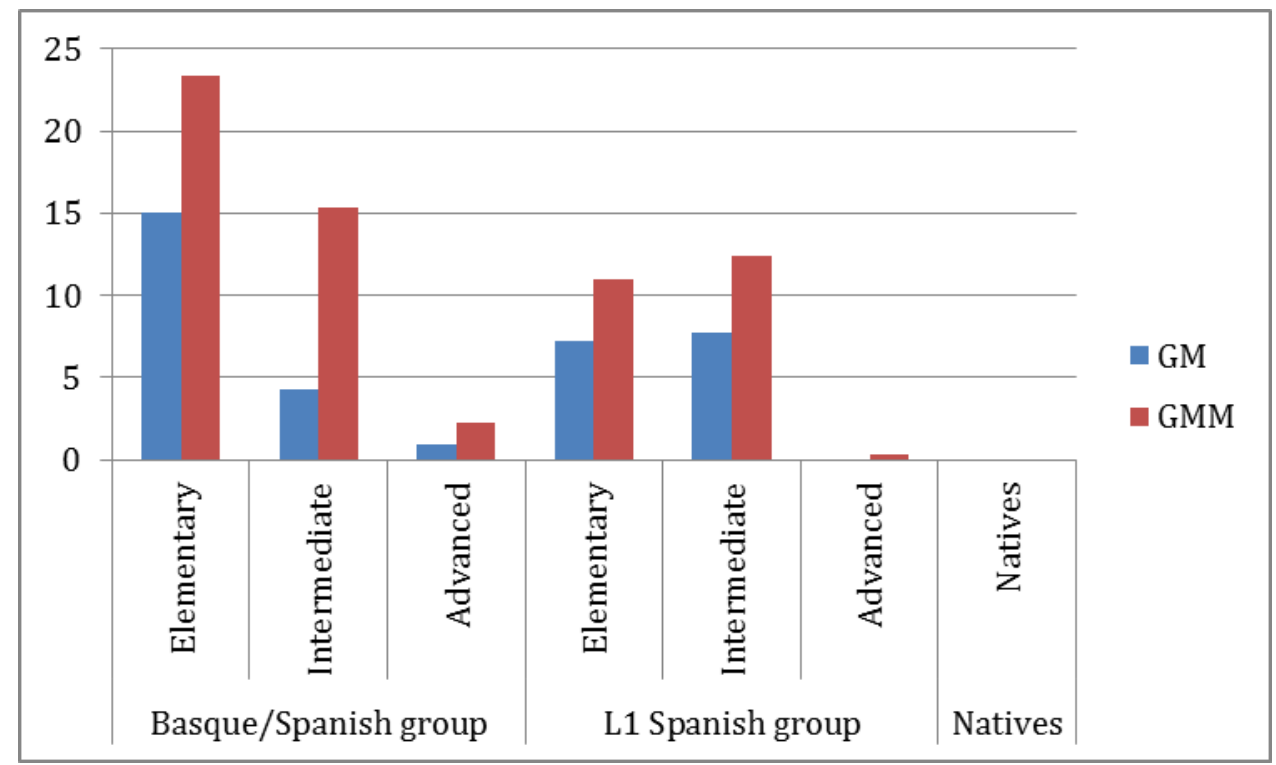

Although error rates were significantly higher in gender-mismatched contexts, pairwise analyses were conducted in each group in order to examine whether learners adopted a preference for a default form. Figure 5 shows inaccurate gender agreement percentages in the three proficiency levels of both non-native groups and in the native group.

Figure 5. Percentages of incorrect gender agreement in gender-matched conditions in the picture selection task

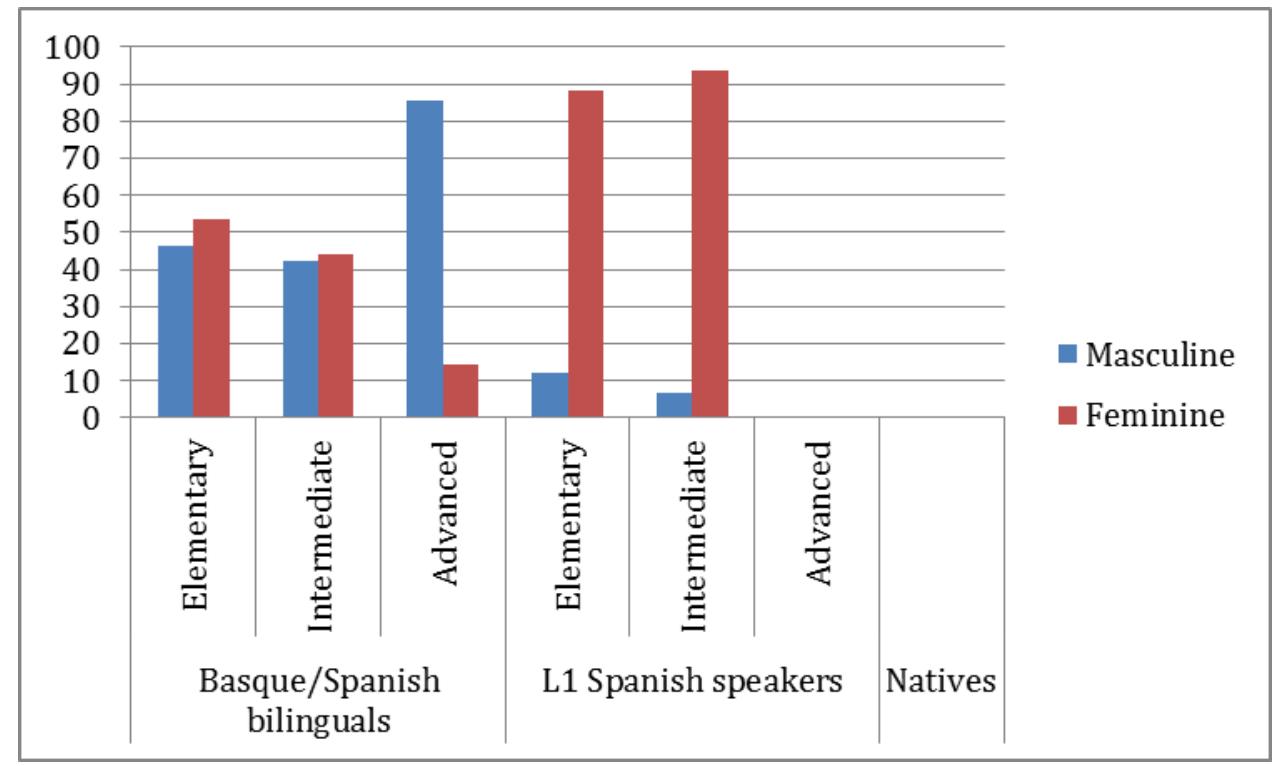


The post-hoc analyses revealed that L1 Spanish learners showed preferences for a masculine default form (over feminine forms) in the elementary and intermediate proficiency level ( $p$-values<.0001).

\subsubsection{Animacy and gender attraction effects in the grammaticality judgment task}

Statistical analyses revealed main effects of attraction $(F(1,154)=71.511 ; p<.0001$; $\left.\boldsymbol{\eta}_{\boldsymbol{p}}{ }^{2}=.32\right)$ and grammaticality $\left(F(1,154)=232.649 ; p<.0001 ; \boldsymbol{\eta}_{\boldsymbol{p}}{ }^{2}=.40\right)$. Post hoc tests with Bonferroni corrections indicated that participants overall showed higher gender agreement error percentages in gender-mismatched conditions than in gender-matched ones $(p<.0001)$. Figure 6 displays gender agreement errors in gender-mismatched conditions in the grammaticality judgment task.

Figure 6. Percentages of incorrect gender agreement in gender-matched conditions in the grammaticality judgment task

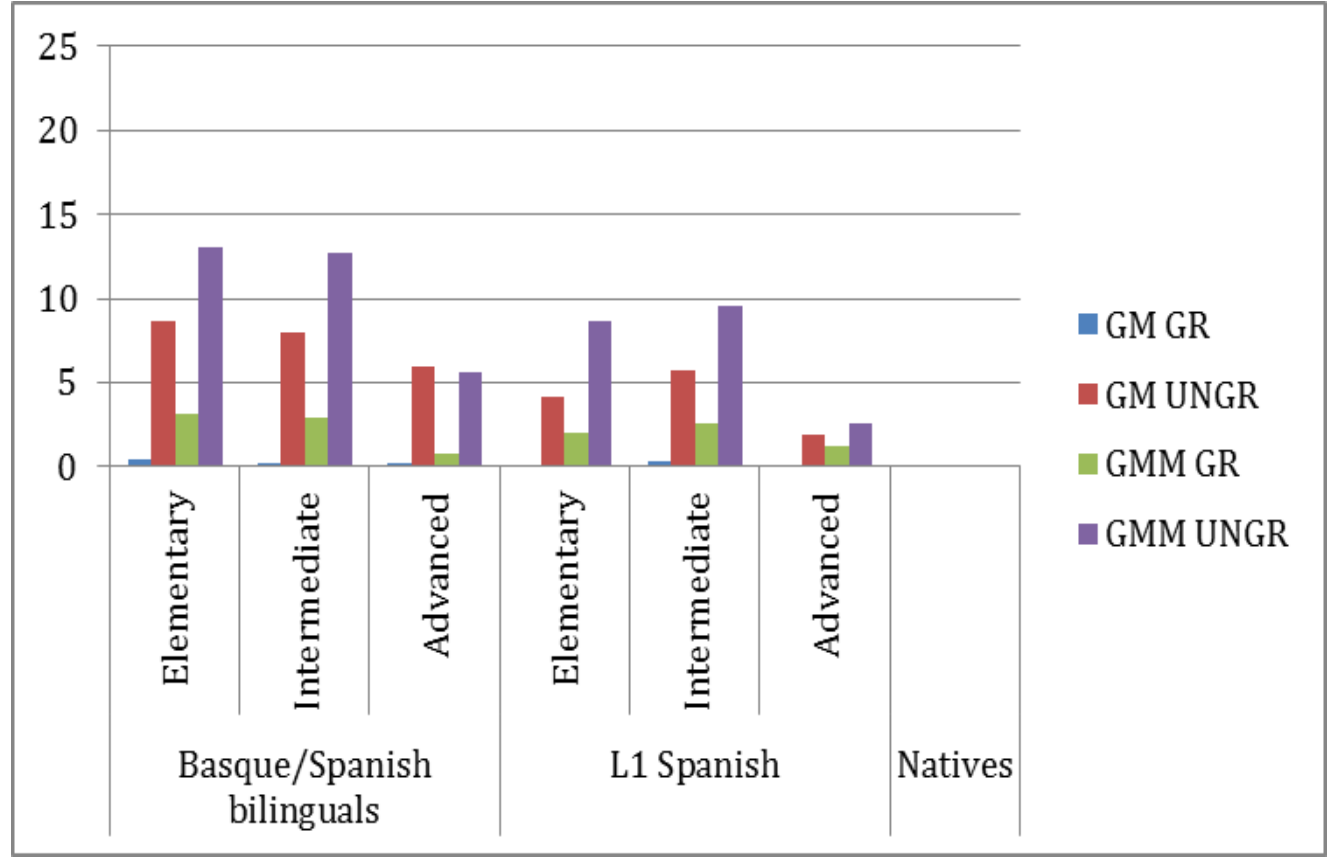

A more detailed pairwise comparison in gender-matched contexts displayed a preference for a masculine default form in the L1 Spanish group in the elementary $(p<.0001)$, intermediate $(p<.0001)$ and advanced $(p=.031)$, as displayed in Figure 7 . 
Figure 7. Percentages of incorrect gender agreement in gender-matched conditions in the grammaticality judgment task

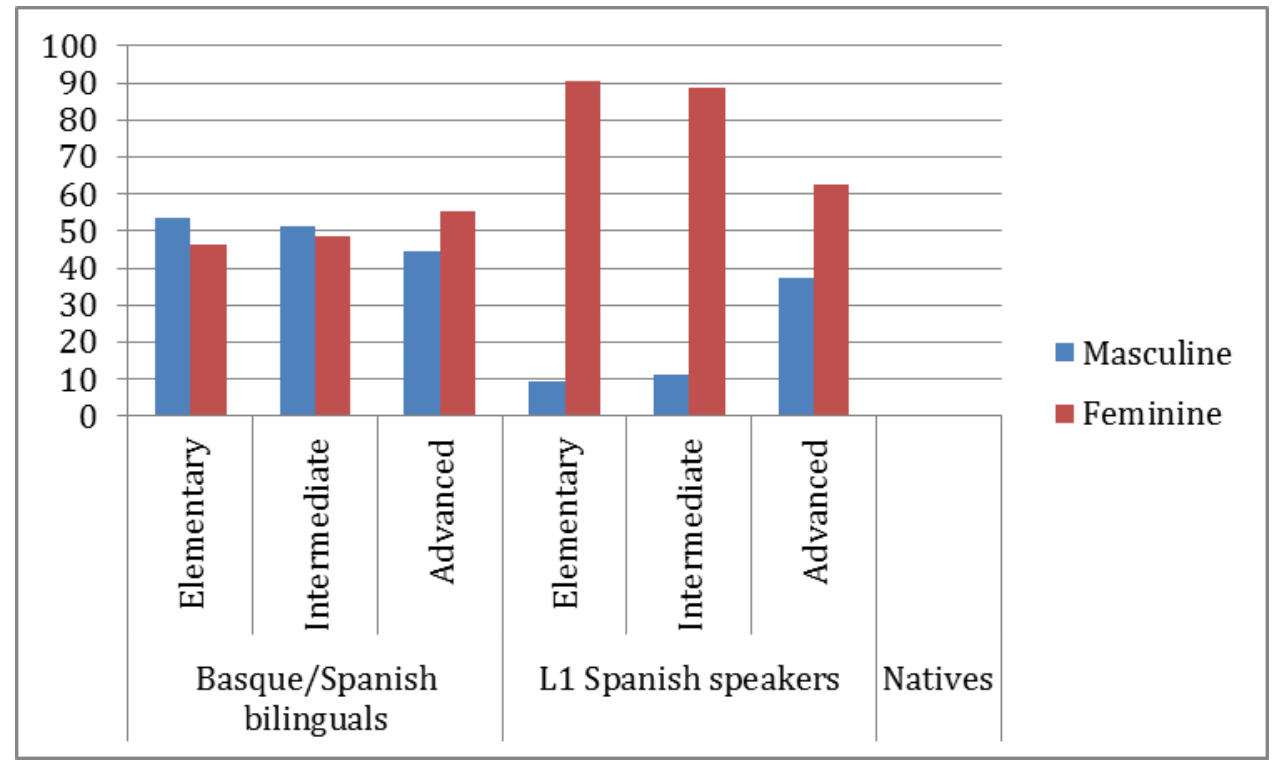

Regarding grammaticality, participants revealed more difficulties in identifying sentences with ungrammatical gender agreement $(p<.0001)$. Moreover, statistically significant interaction effects were found between attraction x proficiency $(F(2,154)=$ 28.220; $\left.p<.0001 ; \boldsymbol{\eta}_{p}{ }^{2}=.29\right)$ indicating that lower proficiency learners had more difficulties in gender-mismatched contexts.

\subsubsection{Animacy and gender attraction effects in the moving window task}

Results in the moving window task were analyzed in terms of accuracy data and RT data. Moreover, in the analyses of reaction delays, data in four interest areas (i.e. the possessive, the possessee, the final context and the response) were specifically examined in order to analyze whether participants revealed processing difficulties in any of these areas.

\subsubsection{Animacy and gender attraction effects in accuracy}

Regarding accuracy data, statistical analyses revealed a main effect of animacy ( $F$ (2, 196) $\left.=6.060 ; p=.003 ; \boldsymbol{\eta}_{p}{ }^{2}=.06\right)$ and grammaticality $\left(F(2,98)=10.083 ; p=.002 ; \boldsymbol{\eta}_{p}{ }^{2}\right.$ $=$.09). Post-hoc Bonferroni analyses showed statistically significant differences between animate and body part conditions $(p<.0001)$ and between inanimate and body part contexts $(p=.042)$. Figure 8 presents the gender agreement errors in animacy conditions in the moving window task. 
Figure 8. Percentages of incorrect gender agreement in animacy conditions in the moving window task

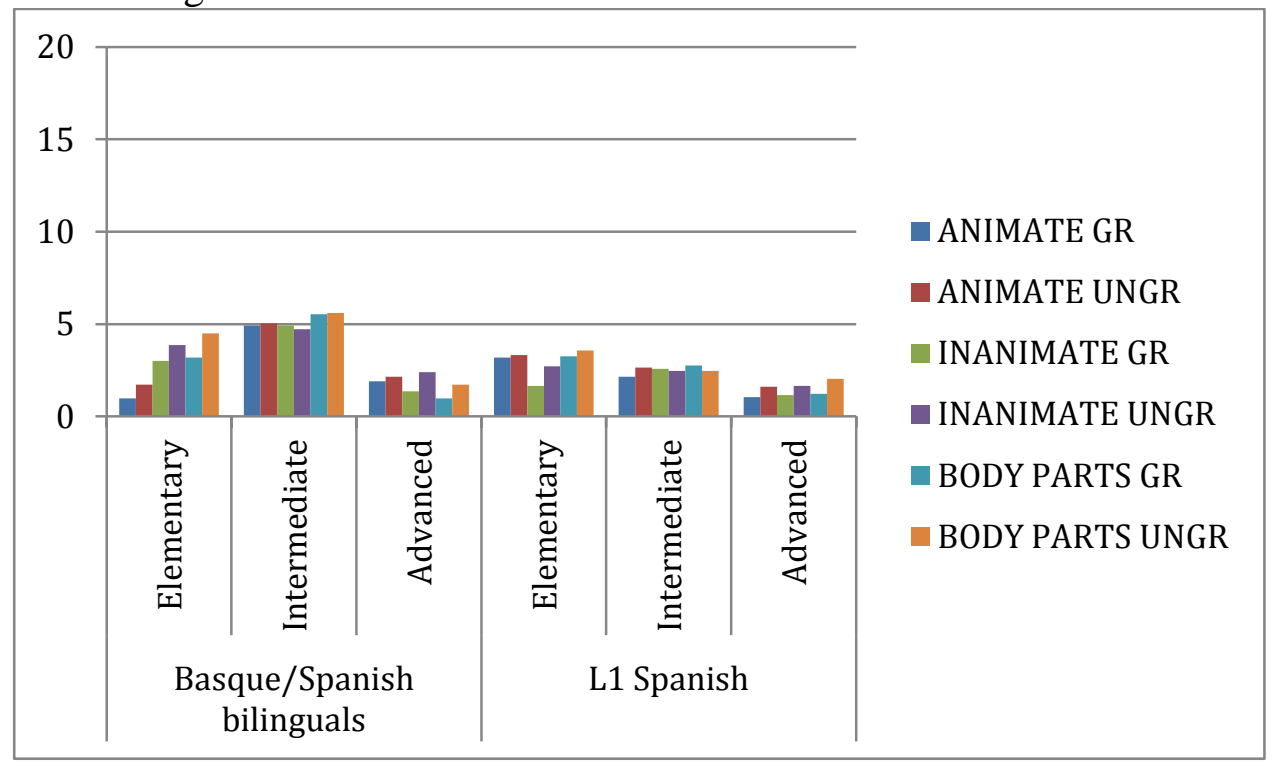

In terms of grammaticality, learners showed persistent difficulties in evaluating ungrammatical sentences accurately in comparison to grammatical trials $(p<.0001)$. Contrasts indicated significant interaction effects between animacy x group $(F(2,196)$ $\left.=7.308 ; p=.001 ; \boldsymbol{\eta}_{p}{ }^{2}=.07\right)$ and between animacy x proficiency $(F(4,196)=7.365$; $\left.p<.0001 ; \boldsymbol{\eta}_{\boldsymbol{p}}{ }^{2}=.13\right)$. Moreover, animacy x group x proficiency exhibited statistically significant differences $\left(F(4,196)=14.990 ; p<.0001 ; \boldsymbol{\eta}_{p}{ }^{2}=.23\right)$ indicating that Basque/Spanish bilingual group with intermediate proficiency level showed most difficulties.

A main effect was also found for attraction $\left(F(1,96)=8.263 ; p=.005 ; \boldsymbol{\eta}_{p}{ }^{2}=.07\right)$. Higher accuracy rates were found in the gender-mismatched condition in comparison to gender-matched contexts $(p<.0001)$, as shown in Figure 9. 
Figure 9. Percentages of incorrect gender agreement in gender-mismatched conditions in the moving window task

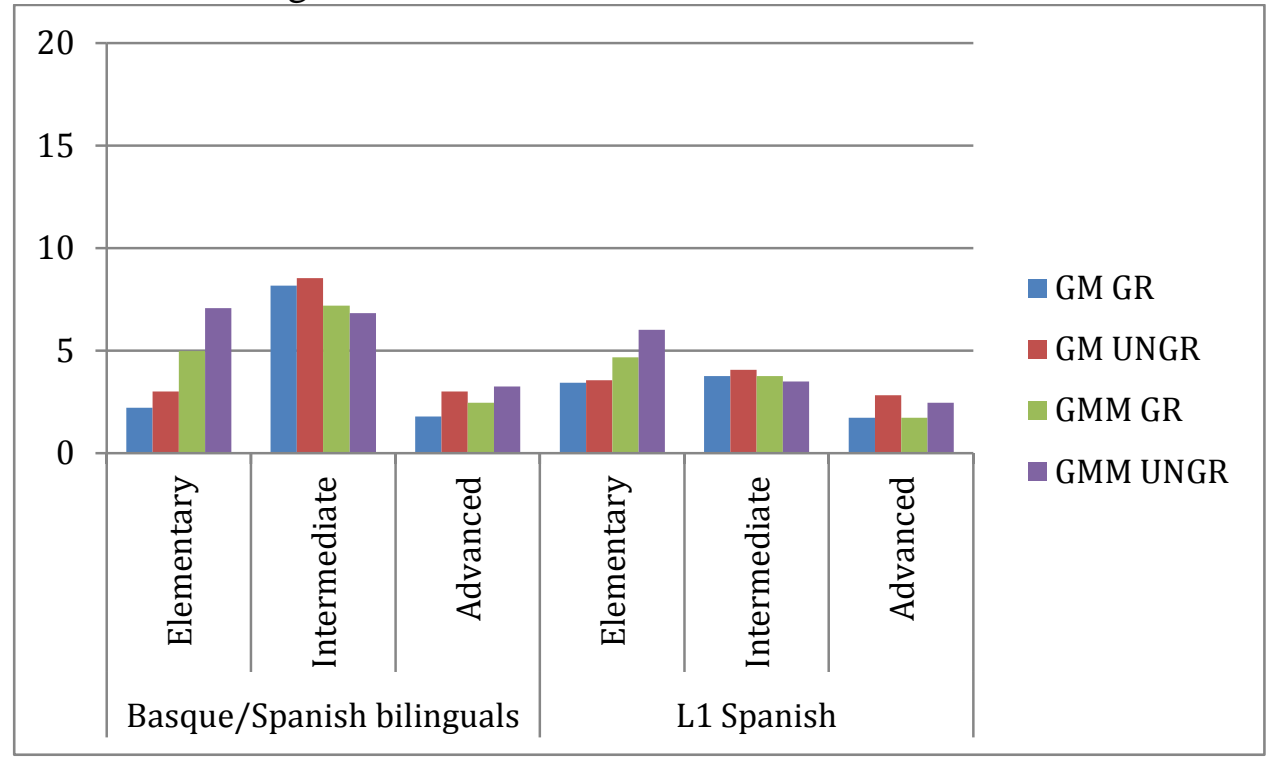

Contrasts also revealed significant interaction effects between attraction x proficiency $\left(F(2,98)=34.265 ; p<.0001 ; \boldsymbol{\eta}_{p}{ }^{2}=.41\right)$ and attraction $\mathrm{x}$ group $\mathrm{x}$ proficiency $(F(2,98)$ $\left.=4.880 ; p=.010 ; \boldsymbol{\eta}_{p}{ }^{2}=.09\right)$. Participants in the intermediate Basque/Spanish bilingual group had more agreement errors in gender-mismatched conditions.

Contrasts revealed significant interaction effects for animacy $\mathrm{x}$ attraction $(F(2,196)=$ 4.329; $\left.p=.015 ; \eta_{p}^{2}=.04\right)$, animacy $\mathrm{x}$ attraction $\mathrm{x}$ group $(F(2,196)=7.621 ; p=.001$; $\left.\eta_{p}{ }^{2}=.07\right)$ and animacy $\mathrm{x}$ attraction $\mathrm{x}$ group x proficiency $(F(4,196)=7.001 ; p<.0001$; $\left.\eta_{p}{ }^{2}=.12\right)$. These interactions revealed that intermediate learners in the Basque/Spanish bilingual group had more agreement errors in animate gender-mismatched conditions.

\subsubsection{Animacy and gender attraction effects in RTs}

Concerning the RTs, reading time analyses in the possessive revealed a main effect of attraction $\left(F(1,830)=26.111 ; p<.0001 ; \eta_{p}{ }^{2}=.03\right)$ in the by-item analysis. Post-hoc Bonferroni tests indicated that longer reaction delays were found in the gendermismatched condition in comparison to gender-matched contexts $(p<.0001)$, as shown in Figure 10. 
Figure 10. Mean RTs in gender-mismatched conditions in the possessive interest area

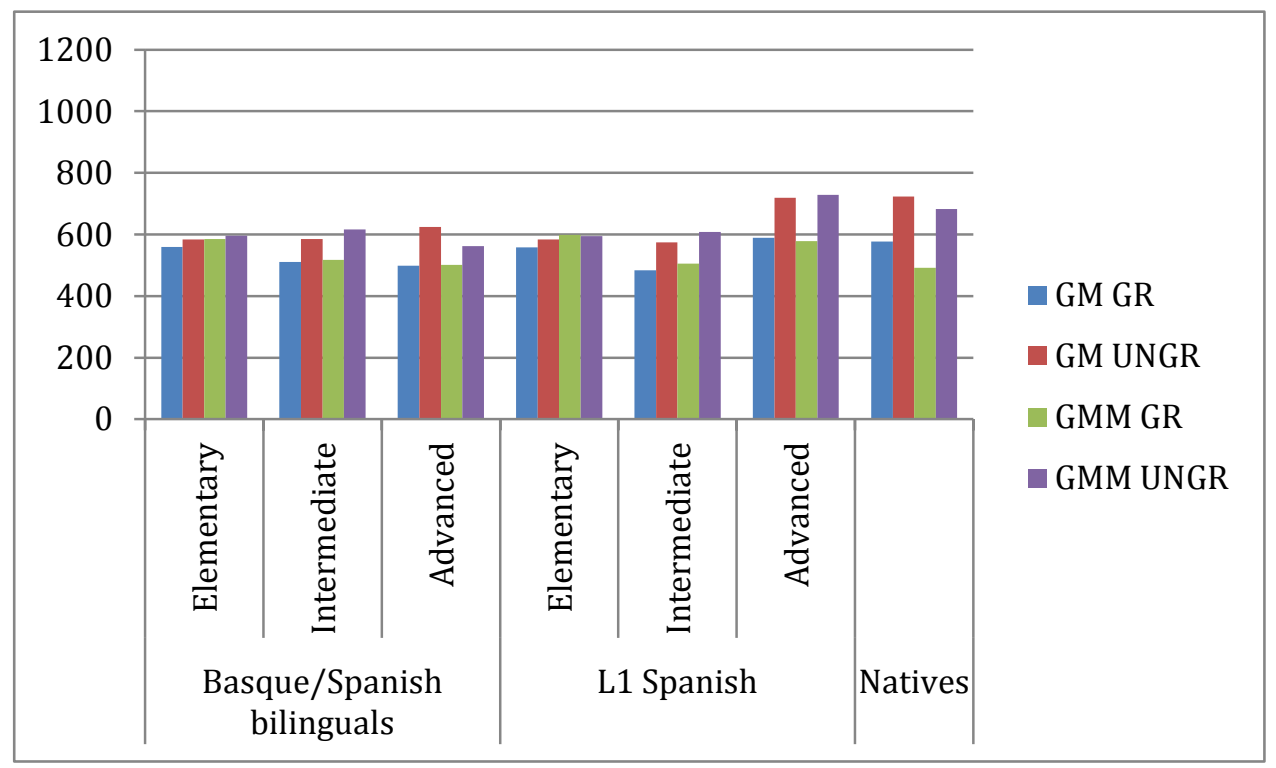

In the possessee interest area, a main effect of attraction $(F(1,830)=8.407 ; p=.004$; $\eta_{p}{ }^{2}=.01$ ) was found in the by-item analysis. Post-hoc Bonferroni analyses exhibited statistically significant differences where gender-mismatched conditions were the more problematic items in comparison to gender-matched contexts $(p=.026)$. Figure 11 exhibits the mean RTs in gender-mismatched condition in the possessee interest area.

Figure 11. Mean RTs in gender-mismatched conditions in the possessee interest area

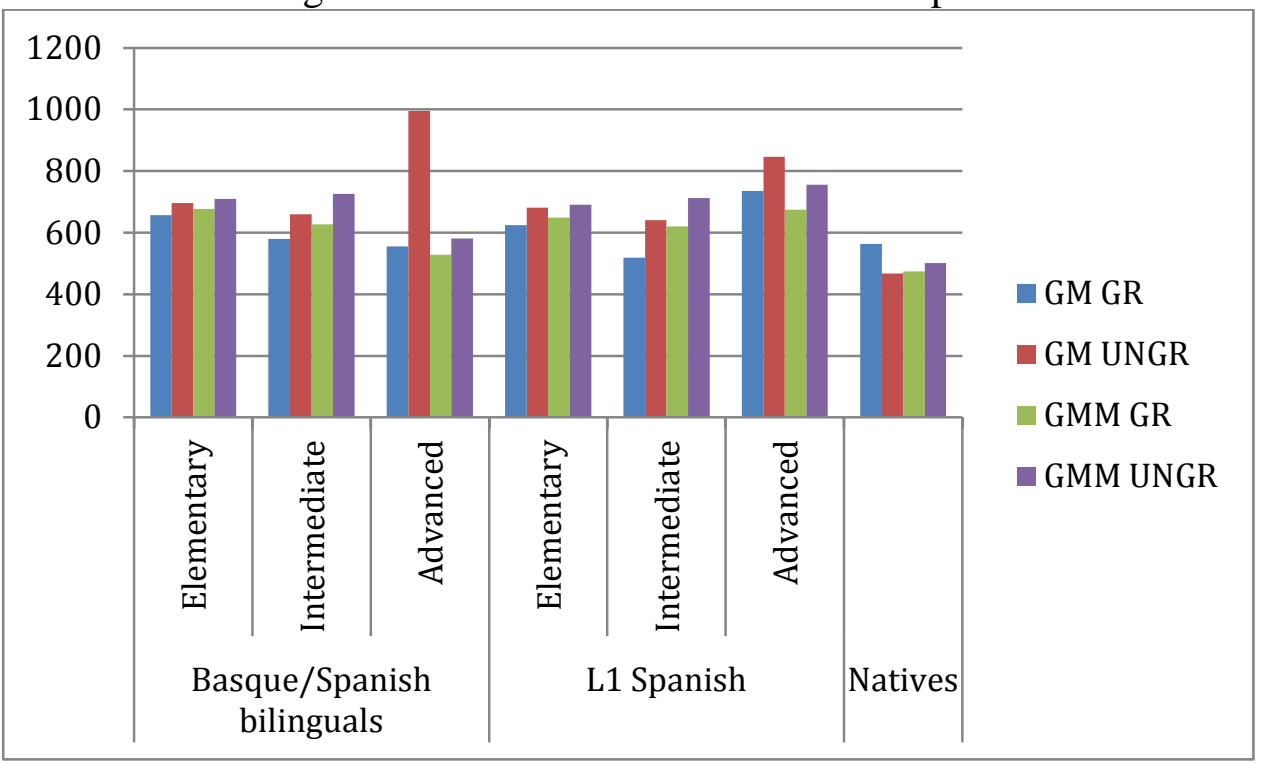


Contrasts indicated statistically significant interaction effects between attraction $\mathrm{x}$ proficiency $\left(F(2,830)=12.267 ; p<.0001 ; \boldsymbol{\eta}_{\boldsymbol{p}}{ }^{2}=.03\right)$ and attraction $\mathrm{x}$ grammaticality $(F$ $\left.(1,830)=3.792 ; p=.050 ; \boldsymbol{\eta}_{p}{ }^{2}=.07\right)$. L1 Spanish learners displayed longer reaction delays in gender-mismatched conditions, more specifically, in ungrammatical sentences.

Reaction delays were measured in the final contextual interest area in order to examine whether spill over effects were found in this area. Statistical analyses revealed a main effect of attraction $\left(F(1,830)=14.546 ; p<.0001 ; \boldsymbol{\eta}_{p}{ }^{2}=.11\right)$. Post-hoc Bonferroni analysis revealed significant differences between gender-mismatched and gendermatched conditions ( $p<.0001)$, as displayed in Figure 12.

Figure 12. Mean RTs in gender-mismatched conditions in the context interest area

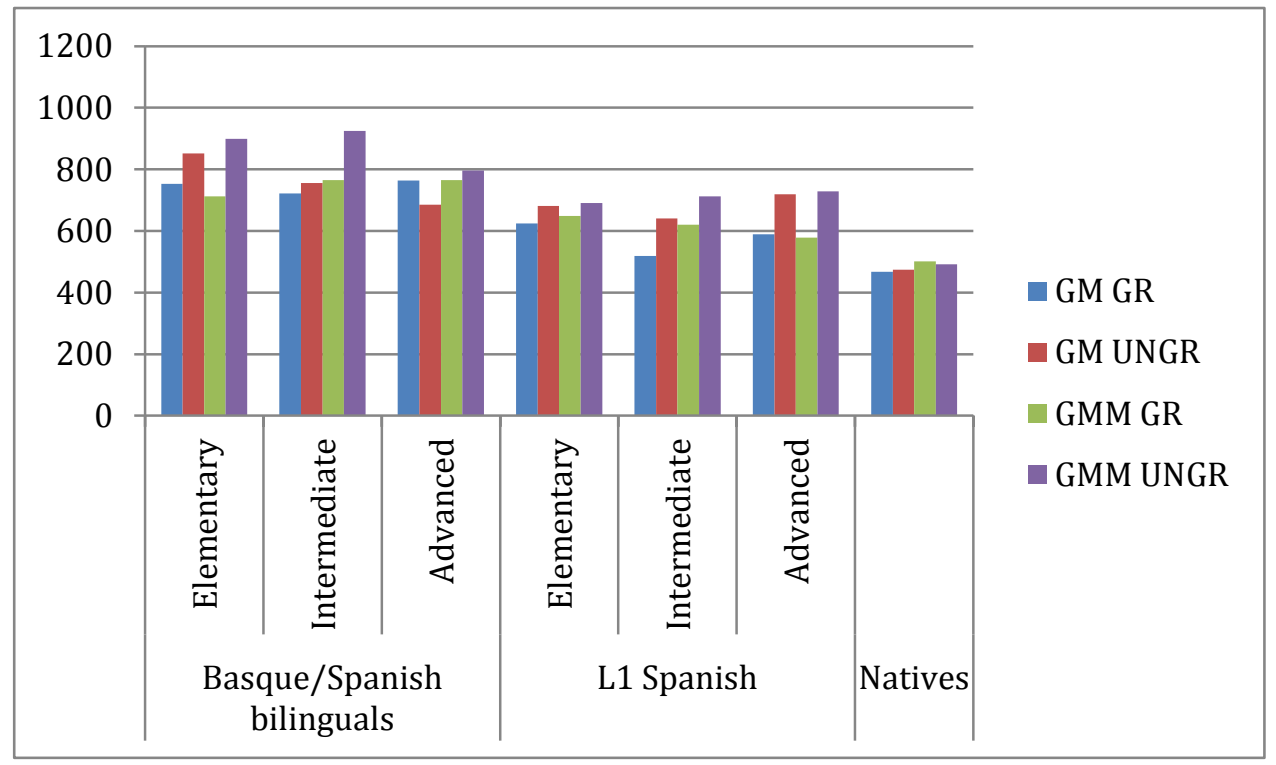

The attraction x grammaticality $\left(F(2,830)=5.928 ; p=.027 ; \boldsymbol{\eta}_{p}{ }^{2}=.17\right)$ interaction also indicated significant differences. Participants showed longer reading times in ungrammatical and gender-mismatched contexts.

Finally, in the response interest area main effect of animacy $(F(2,1660)=14.812$; $p<.0001 ; \boldsymbol{\eta}_{p}{ }^{2}=.01$ ) was found. Post-hoc Bonferroni analyses indicated that differences were found between animate and inanimate conditions $(p=.005)$, as shown in Figure 13. 
Figure 13. Mean RTs in animacy conditions in the response interest area

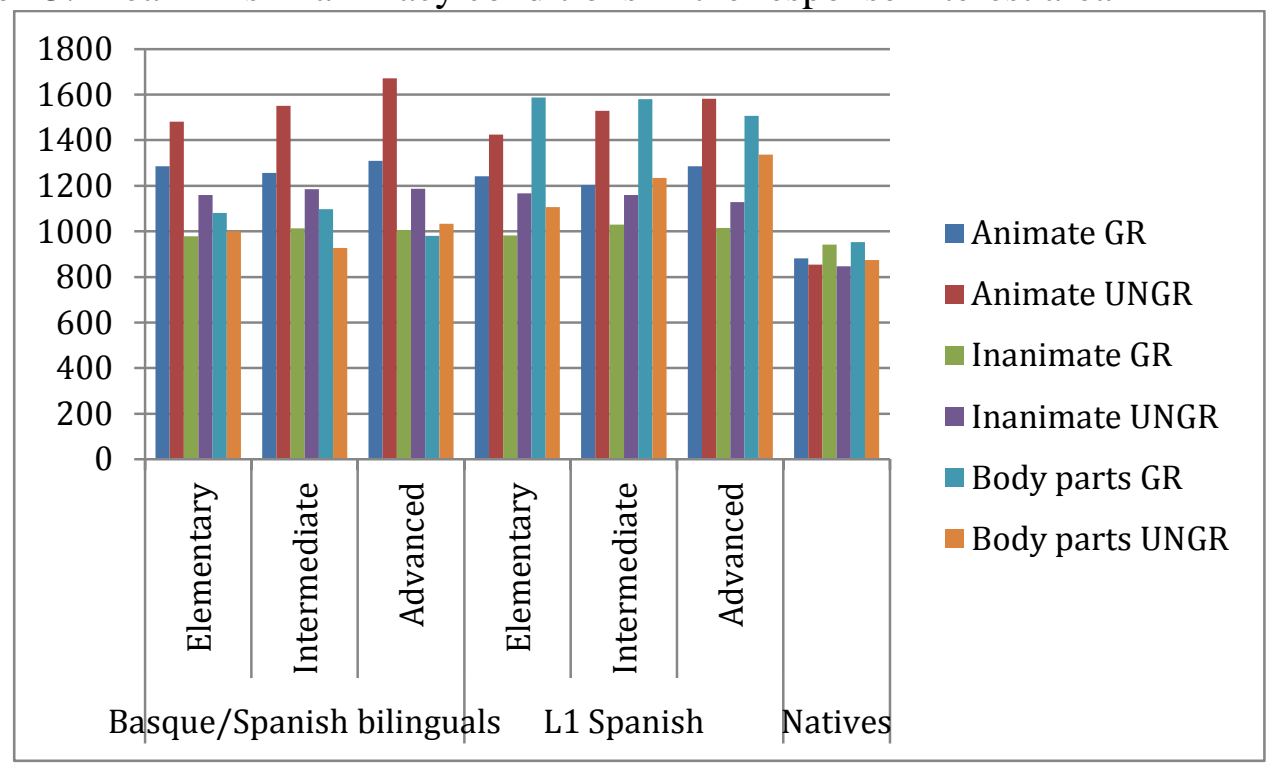

Contrasts revealed interaction effects between animacy $\mathrm{x}$ grammaticality $(F(2,1660)=$ 16.654; $\left.p<.0001 ; \boldsymbol{\eta}_{p}{ }^{2}=.02\right)$. Participants showed more difficulties in ungrammatical animate conditions.

Regarding gender attraction effects, a main attraction effect $(F(1,830)=2.873 ; p=$ $\left..050 ; \boldsymbol{\eta}_{p}{ }^{2}=.13\right)$ was found. Bonferroni pairwise comparison showed longer RTs in gender-mismatched conditions $(p=.010)$. Figure 14 describes the mean RTs in gendermismatched conditions in the response interest area.

Figure 14. Mean RTs in gender-mismatched conditions in the response interest area

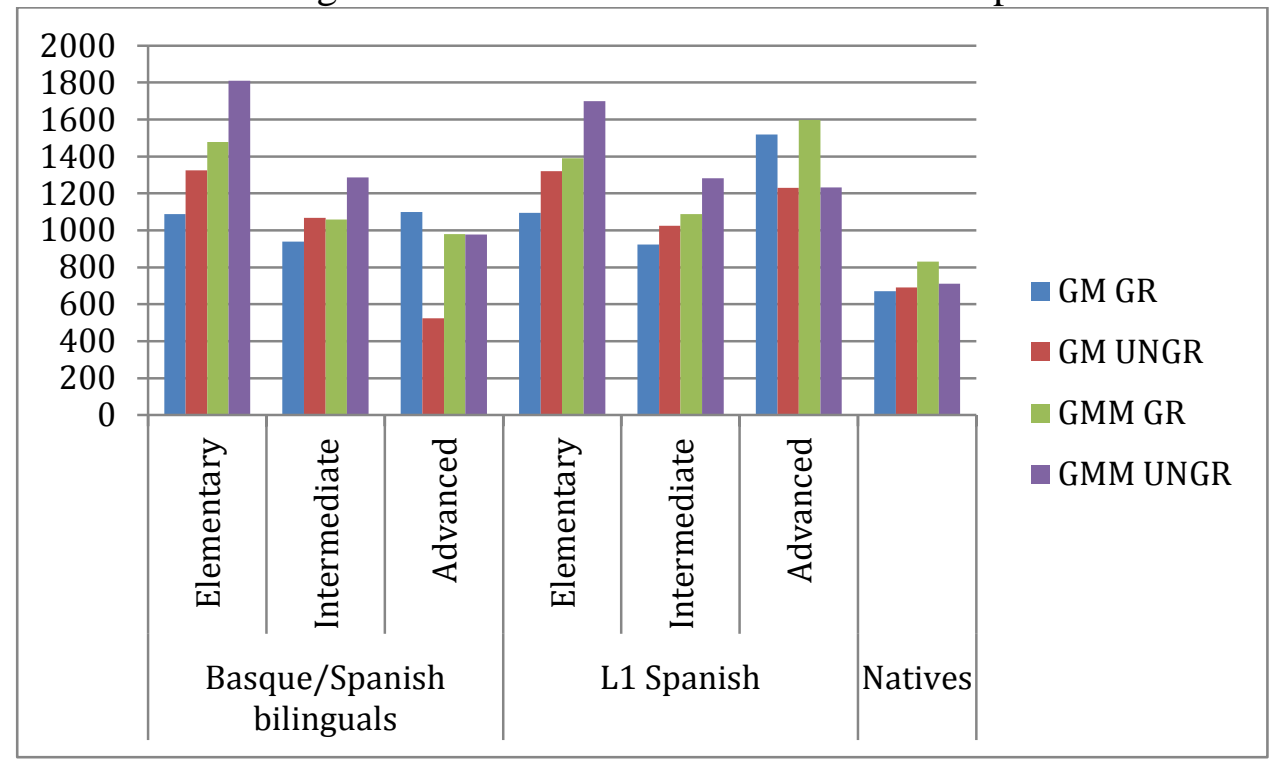


Contrasts displayed interaction effects between attraction x proficiency $(F(2,830)=$ $\left.7.420 ; p=.001 ; \eta_{p}{ }^{2}=.18\right)$ and between attraction $\mathrm{x}$ grammaticality $(F(1,830)=$ 51.748; $p$ <.0001; $\left.\boldsymbol{\eta}_{p}{ }^{2}=.06\right)$. Ungrammatical gender-mismatched conditions posed most difficulties in reading delays to participants with elementary and intermediate proficiency levels. Moreover, statistically significant interaction effects were also found for animacy $\mathrm{x}$ attraction $\left(F(2,1660)=23.797 ; p<.0001 ; \boldsymbol{\eta}_{p}{ }^{2}=.03\right)$ and animacy $\mathrm{x}$ attraction x grammaticality $\left(F(2,1660)=9.590 ; p<.0001 ; \eta_{p}{ }^{2}=.11\right)$. Longer reaction delays were found in ungrammatical sentences in animate gender-mismatched conditions.

\subsubsection{Animacy and gender attraction effects in the fill-in the gap task}

Statistically significant main effects were found for animacy $(F(2,410)=27.292$; $\left.p<.0001 ; \boldsymbol{\eta}_{\boldsymbol{p}}{ }^{2}=.46\right)$. Post-hoc comparisons with Bonferroni corrections revealed that inanimate conditions seem to pose more difficulties than animate and body part contexts (all $p$-values<.0001). Figure 15 displays the percentages of gender agreement in animacy condition in the fill-in the gap task.

Figure 15. Percentages of incorrect gender agreement in animacy conditions in the fillin the gap task

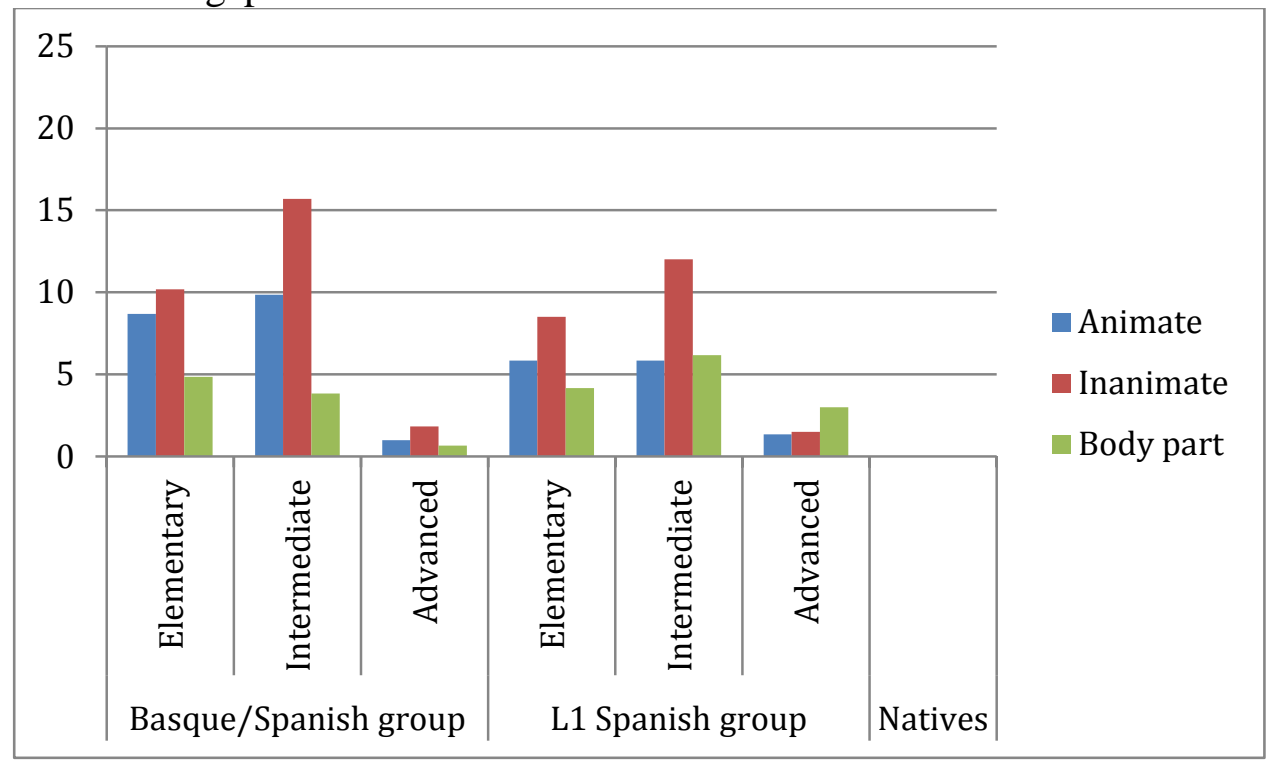

Main attraction effects $\left(F(1,205)=106.139 ; p<.0001 ; \boldsymbol{\eta}_{p}{ }^{2}=.40\right)$ were also found. Post-hoc Bonferroni analyses exhibited that more errors were found in the gendermismatched conditions $(p<.0001)$ in comparison to the gender-matched condition. Figure 16 shows the percentages of incorrect gender agreement in gender-mismatched conditions in the fill-in the gap task. 
Figure 16. Percentages of incorrect gender agreement in gender-mismatched conditions in the fill-in the gap task

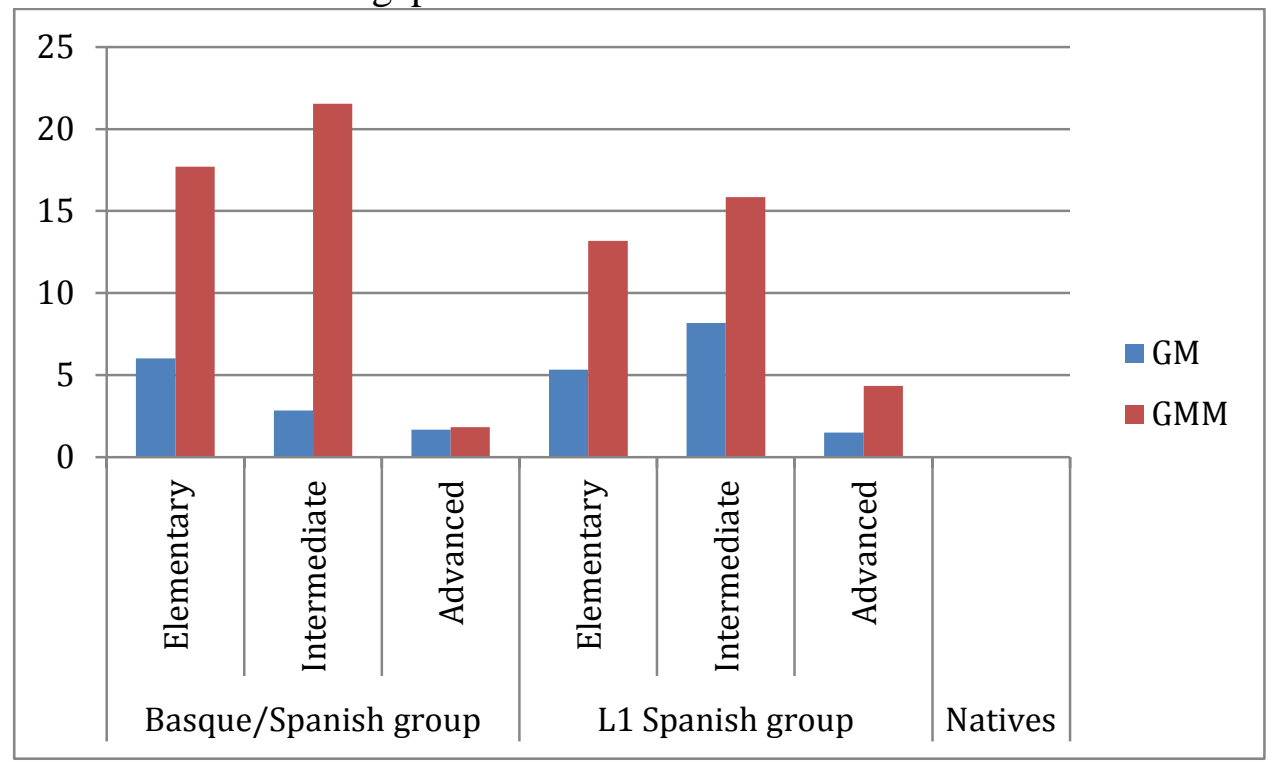

The post-hoc Bonferroni tests in gender-matched conditions revealed that L1 Spanish elementary learners showed preferences for masculine default forms in comparison to feminine forms $(p<.0001)$, as illustrated in Figure 17:

Figure 17. Percentages of incorrect gender agreement in gender-matched conditions in the fill-in the gap task

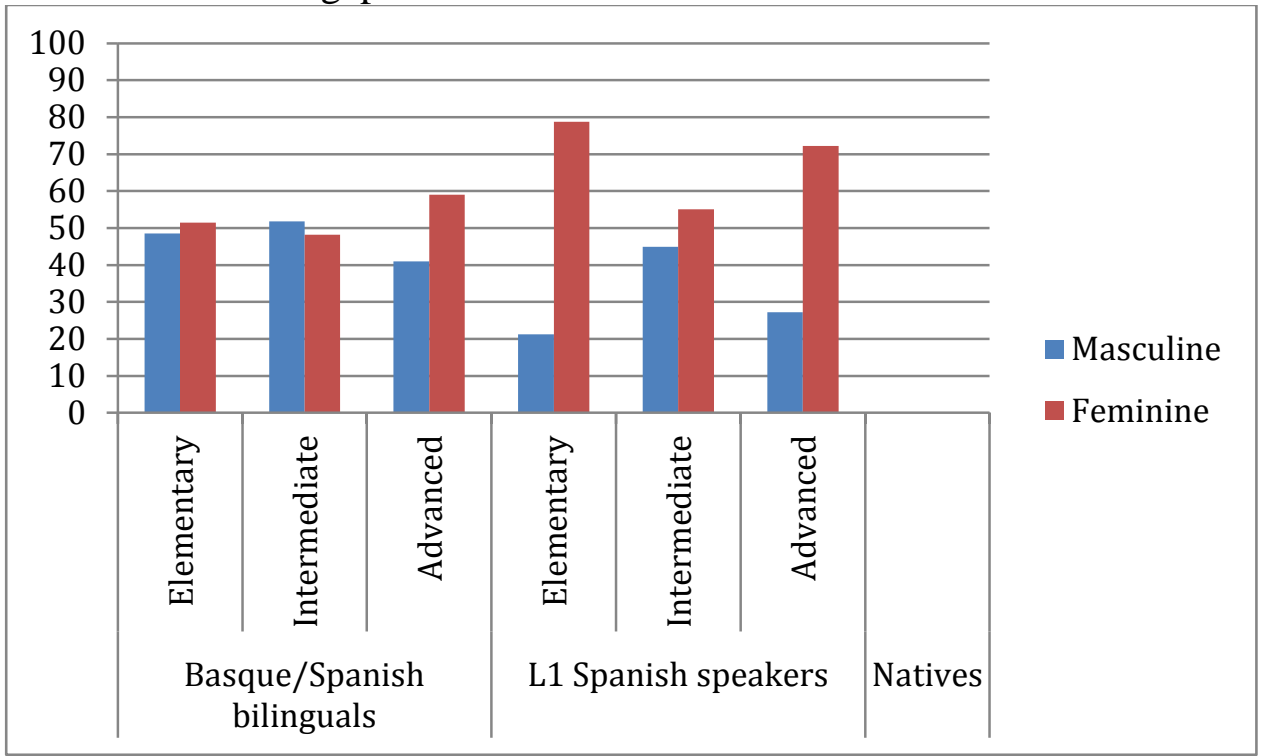

In the by-subject analysis, a significant interaction was found between animacy $\mathrm{x}$ attraction $\left(F(2,410)=13.840 ; p<.0001 ; \eta_{p}{ }^{2}=.56\right)$ so that inanimate gendermismatched conditions were the most difficult contexts for participants. 


\subsubsection{Animacy and gender attraction effects in the written description task}

There was a main effect of animacy $\left(F(2,410)=79.475 ; p<.0001 ; \eta_{p}{ }^{2}=.31\right)$ and attraction. Post-hoc tests with Bonferroni adjustments indicated that there were higher incorrect gender agreement rates in animate contexts when compared to inanimate and body part conditions as well as in inanimate conditions when compared to body part items (all $p$-values<.0001). Figure 18 shows the percentages of incorrect gender agreement in animacy conditions in the written description task.

Figure 18. Percentages of incorrect gender agreement in animacy conditions in the written description task

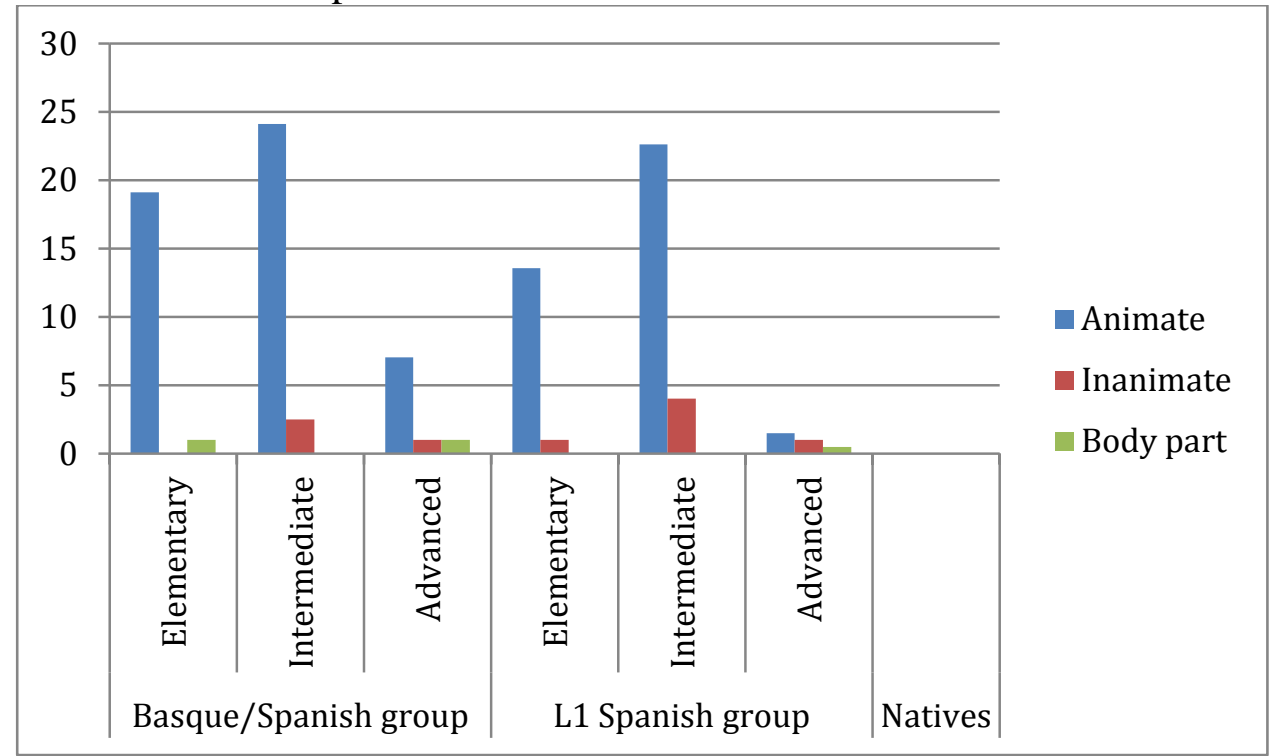

In addition, contrasts between animacy x proficiency $\left(F(4,410)=24.797 ; p<.0001 ; \eta_{p}{ }^{2}\right.$ $=.40$ ) revealed statistically significant differences. Individual repeated measures analyses indicated that more agreement errors were found in animate conditions across proficiency levels as well as in gender-mismatched conditions (all $p$-values $<.0001$ ). Contrasts also revealed significant interaction effects between animacy $\mathrm{x}$ attraction $\mathrm{x}$ proficiency $\left(F(4,410)=15.185 ; p<.0001 ; \eta_{p}{ }^{2}=.40\right)$ indicating that intermediate level learners showed the highest agreement error rates in animate gender-mismatched conditions although differences were found in all pairwise comparisons (all $p$ values $<.0001)$.

A main effect of attraction $\left(F(1,205)=55.827 ; p<.0001 ; \eta_{p}{ }^{2}=.39\right)$ was found in this task. Higher error rates were found in gender-mismatched items in comparison to gender-matched contexts. Figure 19 displays the percentages of incorrect gender agreement in gender-mismatched conditions in the written description task. 
Figure 19. Percentages of incorrect gender agreement in gender-mismatched conditions in the written description task

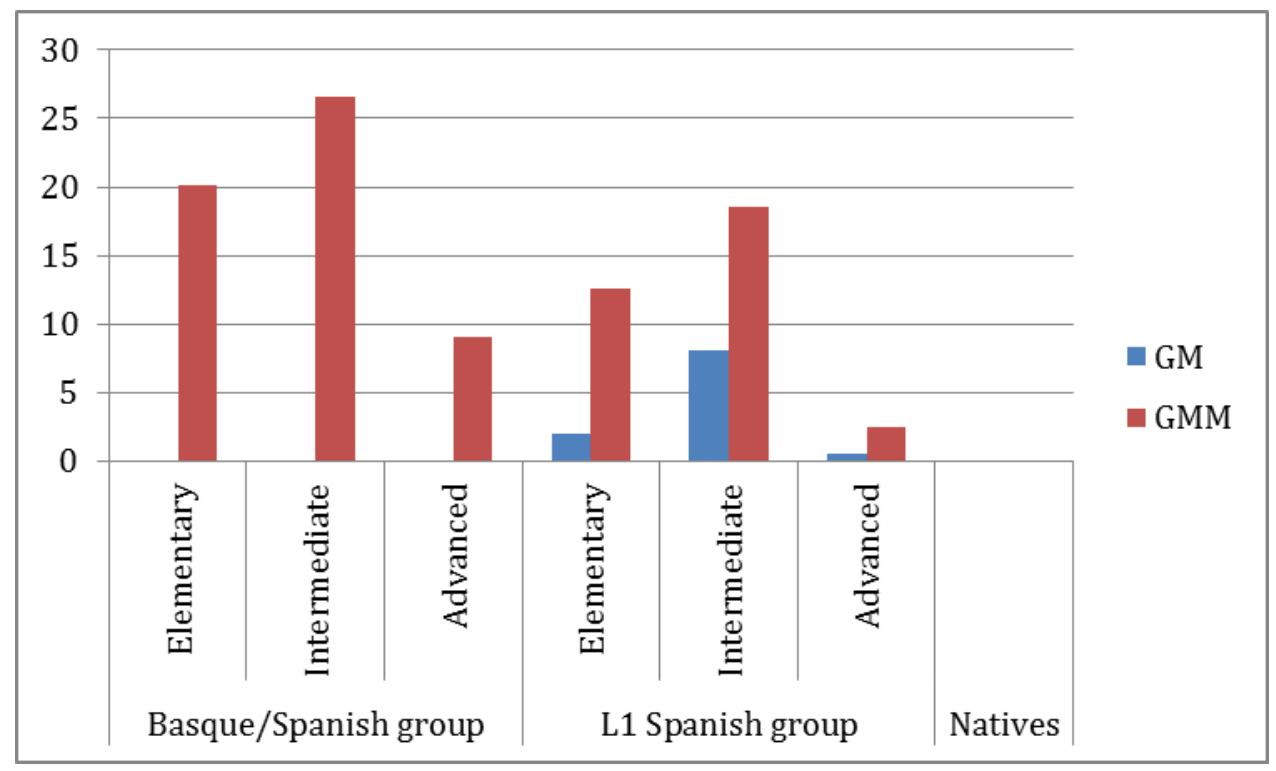

Moreover, a more detailed analysis of gender-matched contexts indicated that participants used the masculine and feminine form to a similar extent in both non-native groups. Attraction x proficiency $\left(F(2,205)=9.767 ; p<.0001 ; \eta_{p}{ }^{2}=.50\right)$ showed significant interaction effects.

\subsubsection{Animacy and gender attraction effects in the elicitation task}

There was a main effect of animacy $\left(F(2,410)=54.145 ; p<.0001 ; \boldsymbol{\eta}_{\boldsymbol{p}}{ }^{2}=.33\right)$ in the elicitation task. Post-hoc pairwise comparisons with Bonferroni corrections on animacy indicated that more gender agreement errors were found in animate conditions in comparison to inanimate and body part contexts. Besides, inaccuracy rates were higher in body part conditions than in inanimate items (all $p$-values $<.0001$ ), as illustrated in Figure 20. 
Figure 20. Percentages of incorrect gender agreement in animacy conditions in the elicitation task

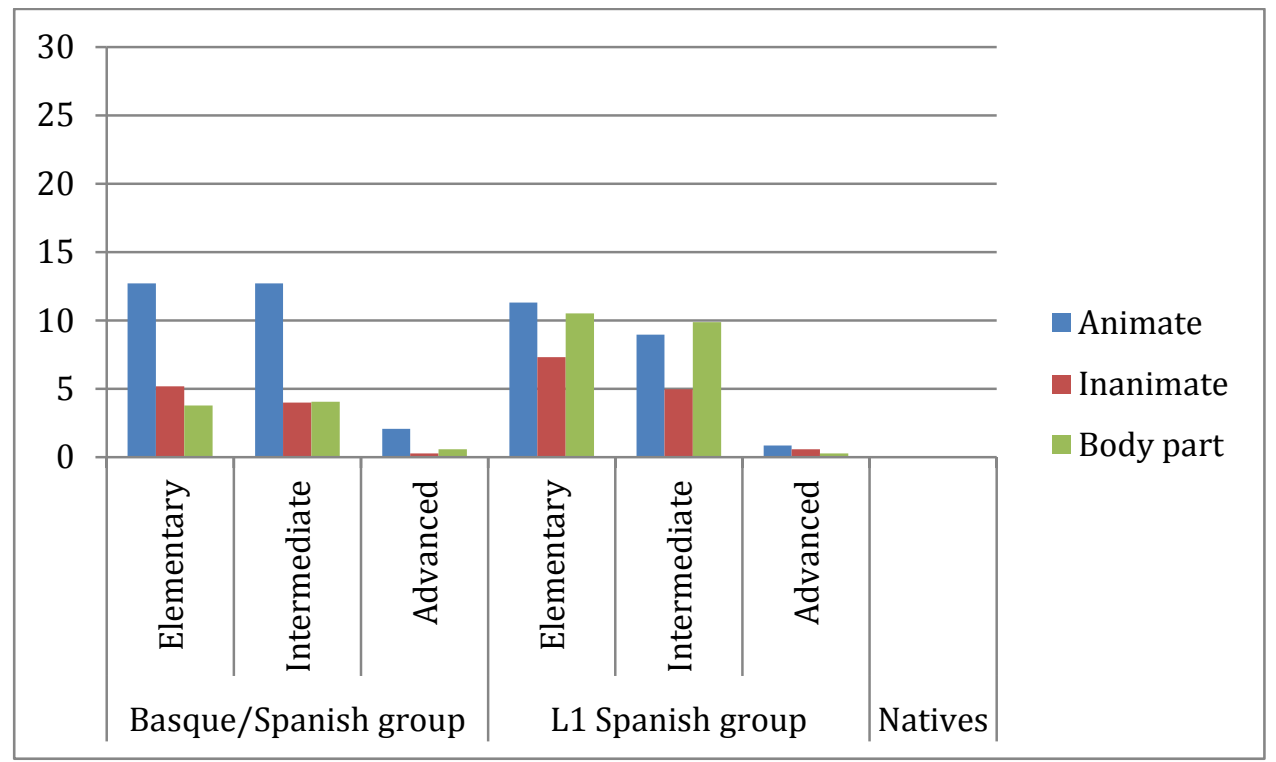

A main effects were also found for attraction $\left(F(1,205)=52.352 ; p<.0001 ; \boldsymbol{\eta}_{\boldsymbol{p}}{ }^{2}=.35\right)$. The post-hoc tests on attraction showed that participants had more difficulties in gender-mismatched contexts when compared to gender-matched ones. Figure 21 displays the gender agreement errors in gender-mismatched conditions in the elicitation task.

Figure 21. Percentages of incorrect gender agreement in gender-mismatched conditions in the elicitation task

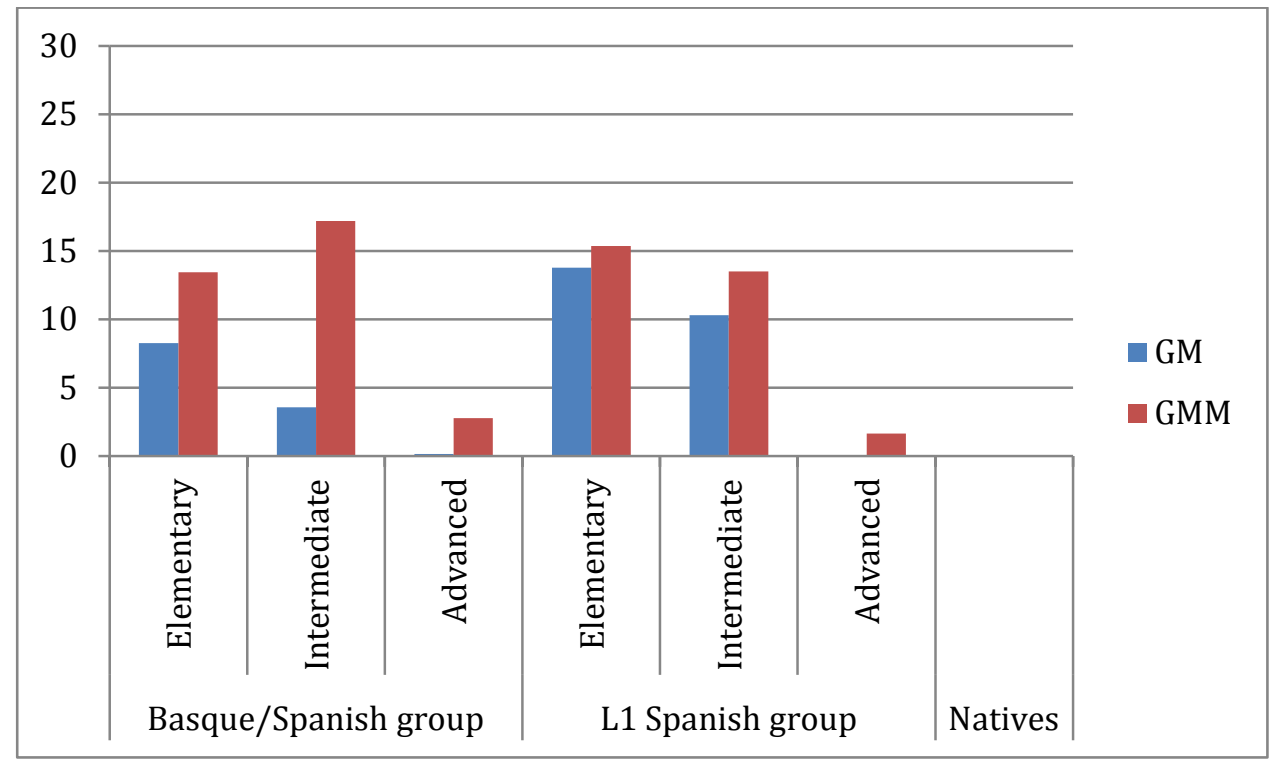


The pairwise comparison for the preference of a default form indicated that lower proficiency learners in the L1 Spanish group tended to use the masculine possessive form more frequently than the feminine form $(\mathrm{p}<.0001)$, as shown in Figure 22:

Figure 22. Percentages of incorrect gender agreement in gender-matched conditions in the elicitation task

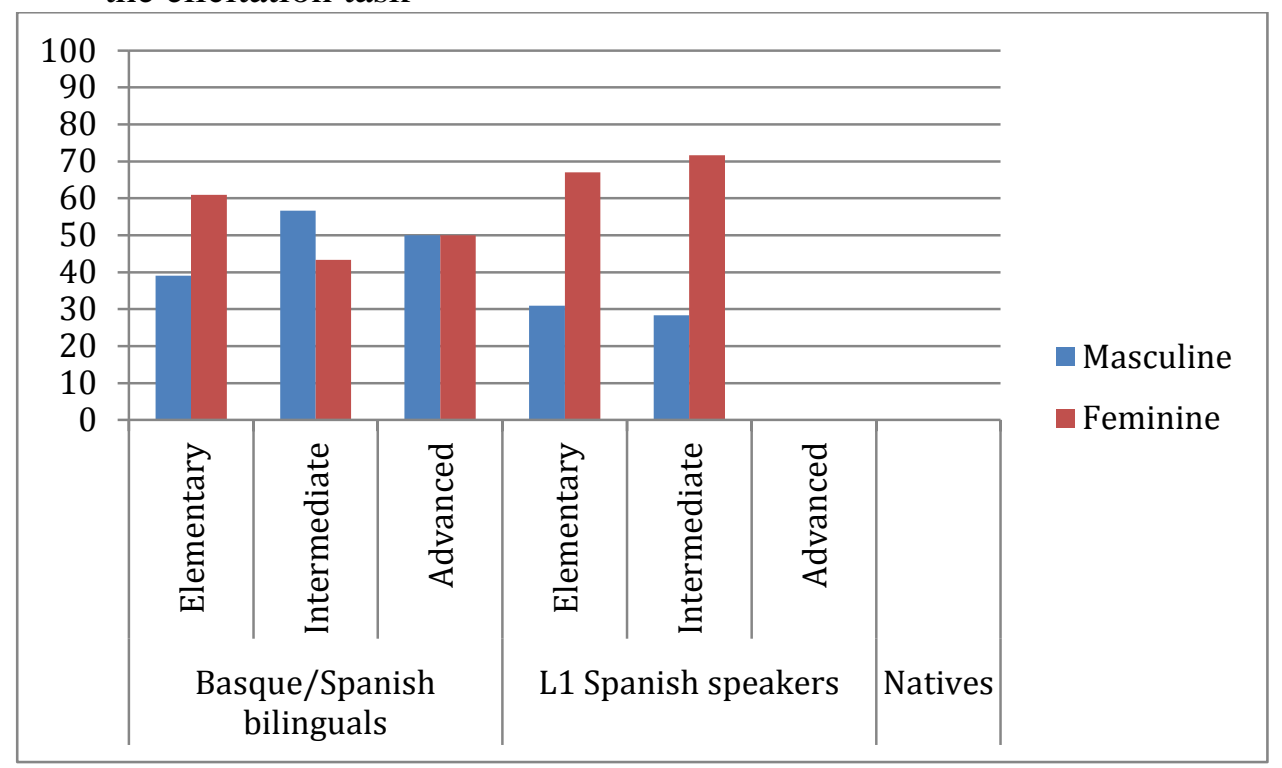

In the by-subject analyses, significant interaction effects were found between animacy $\mathrm{x}$ attraction $\left(F(2,410)=17.801 ; p<.0001 ; \boldsymbol{\eta}^{2}=.21\right)$.

\subsubsection{Animacy and gender attraction effects in the picture description task}

Findings revealed main effects of animacy $\left(F(2,410)=125.081 ; p<.0001 ; \boldsymbol{\eta}_{p}{ }^{2}=.15\right)$. Post-hoc tests with Bonferroni adjustments indicated that more gender agreement errors were found in animate conditions in comparison to inanimate and body part contexts (all $p$-values<.0001). Figure 23 shows the percentages of incorrect gender agreement in animacy conditions in the picture description task. 
Figure 23. Percentages of incorrect gender agreement in animacy conditions in the picture description task

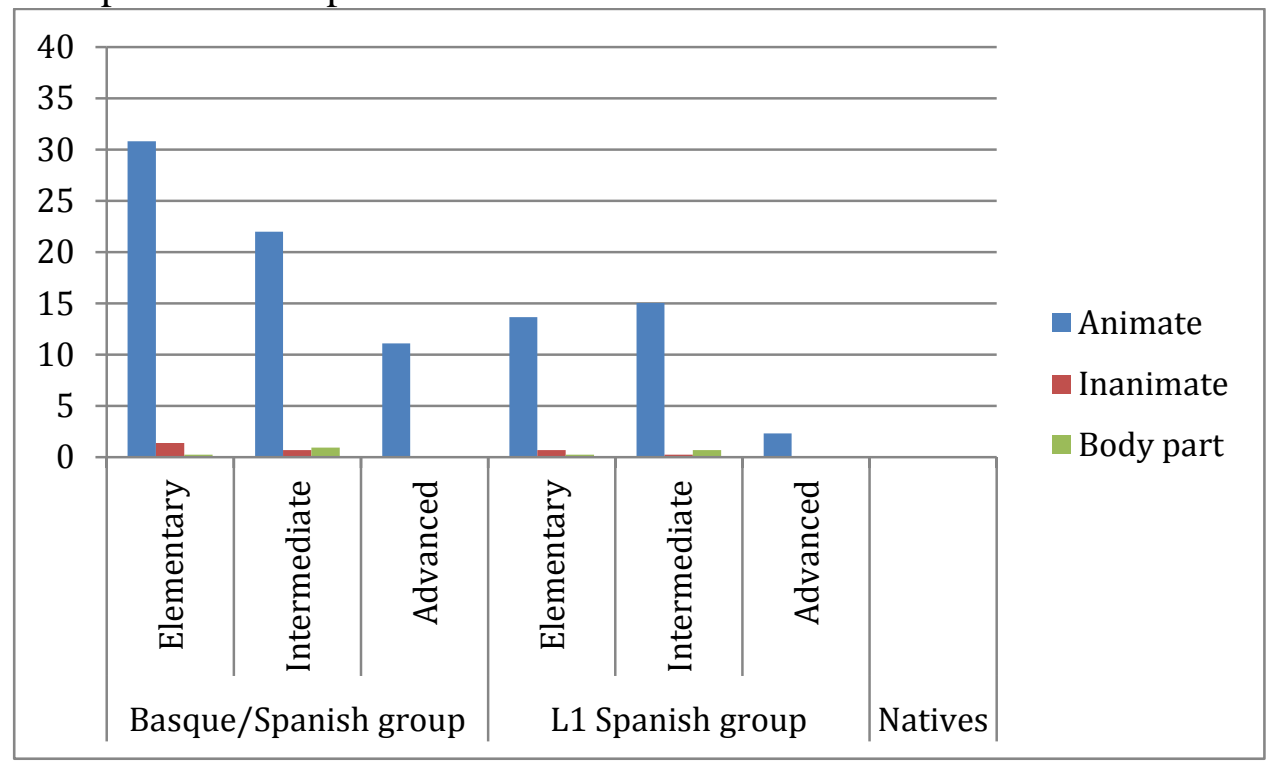

Contrasts showed significant interaction effects between animacy x proficiency ( $F$ (4, 410) $=22.857 ; p<.0001 ; \boldsymbol{\eta}_{p}{ }^{2}=.21$ ). Individual repeated measures analysis indicated animate conditions were more difficult than inanimate and body part ones across proficiency levels (all p-vales $<.0001$ ).

A main effect of attraction was found for attraction effects $(F(1,205)=61.140$; $\left.p<.0001 ; \boldsymbol{\eta}_{p}{ }^{2}=.21\right)$. In fact, more difficulties were found in gender-mismatched conditions $(p=.034)$ than in gender-matched conditions, as displayed in Figure 24:

Figure 24. Percentages of incorrect gender agreement in gender-mismatched conditions in the picture description task

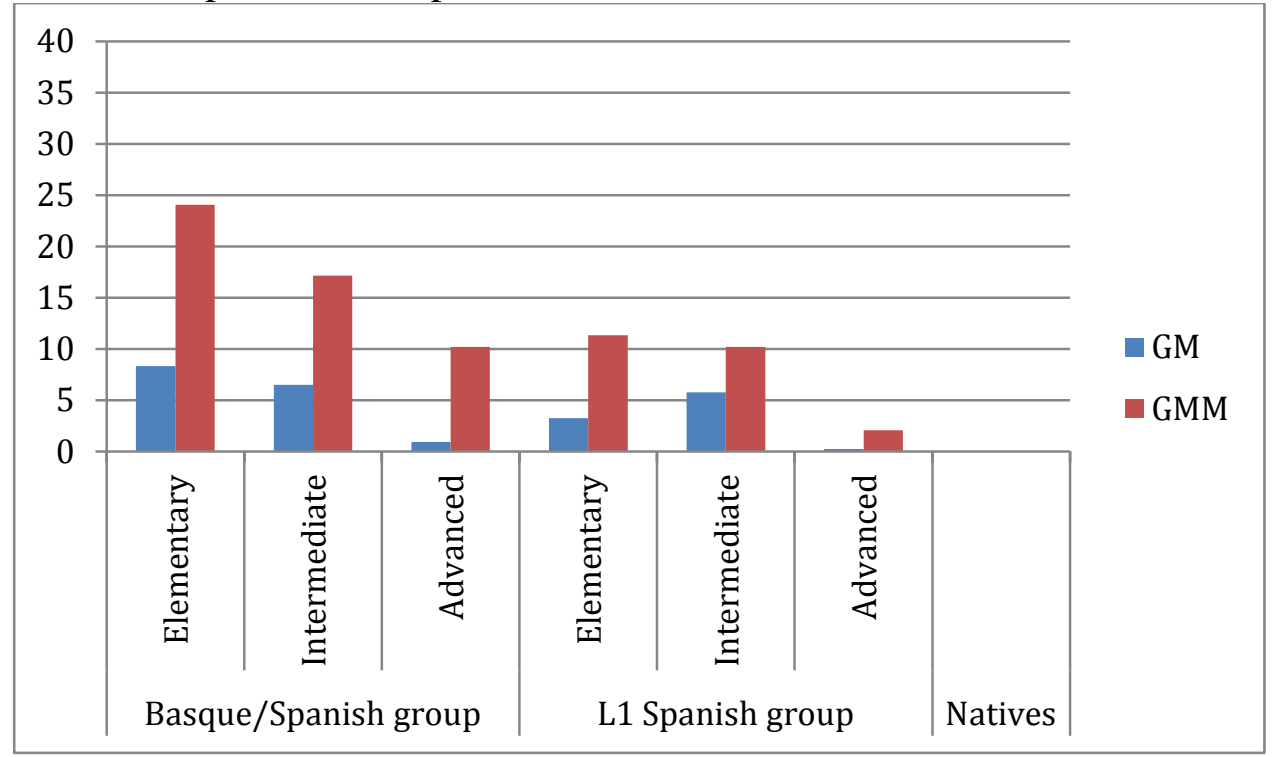


Regarding the preferences for a default form, post-hoc Bonferroni comparisons in gender-matched conditions indicated that Basque/Spanish bilinguals in the elementary and intermediate proficiency levels overused a feminine default form $(p<.0001)$. In contrast, L1 Spanish learners in the same proficiency levels preferred a masculine default form $(p<.0001)$. Figure 25 displays the percentages of incorrect gender agreement in gender-matched conditions in the picture description task.

Figure 25. Percentages of incorrect gender agreement in gender-matched conditions in the picture description task

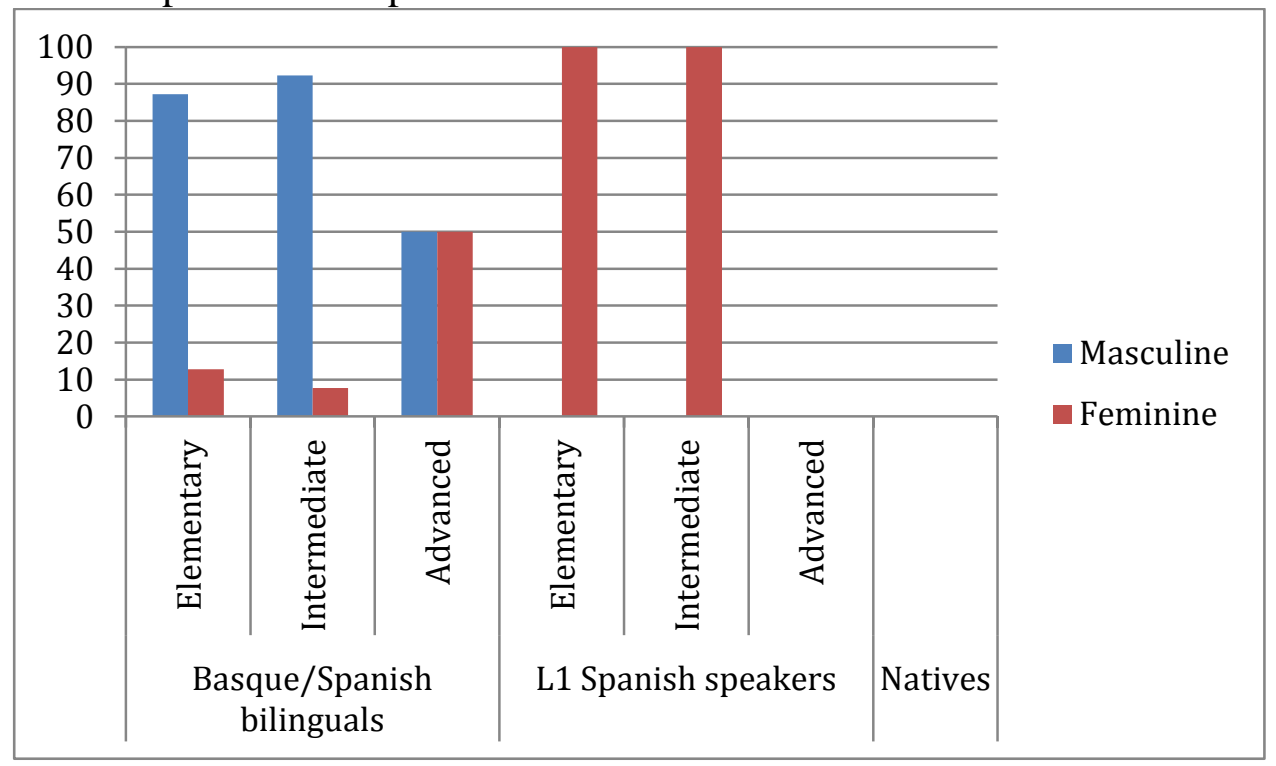

Contrasts revealed that the interactions between attraction $\mathrm{x}$ group $(F(1,205)=4.600$; $\left.p=.033 ; \boldsymbol{\eta}_{p}{ }^{2}=.63\right)$ and attraction x proficiency $\left(F(2,205)=9.049 ; p<.0001 ; \boldsymbol{\eta}_{p}{ }^{2}=.55\right)$ were significant. Higher inaccuracy rates were found in gender-mismatched contexts across proficiency levels (all $p$-values $<.0001$ ). Regarding group, Basque/Spanish bilinguals produced more gender agreement errors than L1 Spanish speakers ( $p=.033$ ). Furthermore, two more contrasts revealed statistically significant interaction effects: animacy x attraction x proficiency $\left(F(4,410)=13.377 ; p<.0001 ; \boldsymbol{\eta}_{p}{ }^{2}=.37\right)$ and animacy x attraction x group $\left(F(2,410)=4.139 ; p=.017 ; \boldsymbol{\eta}_{p}{ }^{2}=.59\right)$. These contrasts indicated that proficiency level in English and language group were significant predictors on the production of gender agreement in animate gender-mismatched conditions. 


\subsubsection{Summary of the main findings in animacy and gender attraction effects}

Overall, the statistical analyses have shown animacy and gender attraction effects. Animacy effects were found in the fill-in the gap task, written description task, elicitation task and picture description task. Learners experiencd more difficulties in establishing gender agreement in animate conditions in the spontaneous production tasks. However, in the fill-in the gap task, difficulties were found in establishing gender agreement in body part conditions in the moving window task and in inanimate conditions in the fill-in the gap task. Moreover, longer RTs were found in animate conditions in the response interest area, indicating that learners needed more time when evaluating sentences containing an animate possessee.

The analysis of gender-matched conditions revealed the preferences for either a masculine or a feminine default form. In the Basque/Spanish bilingual groups, a preference for a feminine default form was found in the picture description task. Error percentages from masculine and feminine remained similar in the other tasks in this group. In contrast, findings in the L1 Spanish speaker groups pointed to a clear evidence in favor of a masculine default form since higher error percentages were found in the feminine contexts.

On the other hand, gender-mismatched conditions were examined to test gender attraction effects. Findings revealed problems in establishing gender agreement in gender-mismatched conditions in all tasks indicating gender attraction effects. In fact, errors were found with an animate possessee but also with an inanimate possessee (i.e. fill-in the gap task). This finding indicated that learners established gender agreement with the grammatical gender of the Spanish equivalent noun. 


\subsection{Task effects}

In this section, differences among tasks are reported in order to address our second research question (RQ 2):

RQ 2: Does task-type (comprehension vs. production) influence the performance of participants? In other words, are there significant differences between comprehension and production tasks?

In this section, errors made by the participants were submitted to multivariate ANOVA analyses. Due to the fact that error rates were different in each nonnative group, the output of each nonnative group will be reported in a separate section. Section 5.3.1 presents the comparison between tasks in the Basque/Spanish bilingual group and Section 5.3.2 analyzes these findings in the L1 Spanish group.

\subsubsection{Task differences in Basque/Spanish bilingual groups}

When gender agreement errors were compared for incorrect gender agreement production (fill-in the gap task, written description task, oral elicitation task and oral picture description task) and incorrect comprehension (picture selection task, grammaticality judgment task and moving window task), a multivariate ANOVA test showed statistically significant differences between production and comprehension tasks in both the DBH group $(F(1,257)=4.102 ; p=.044)$, the BATXI group $(F(1$, $278)=6.657 ; p=.010)$ and even in the UNI group $(F(1,78)=27.228 ; p<.0001)$, as shown in Figure 26: 
Figure 26. Percentages of incorrect gender agreement in comprehension and production task

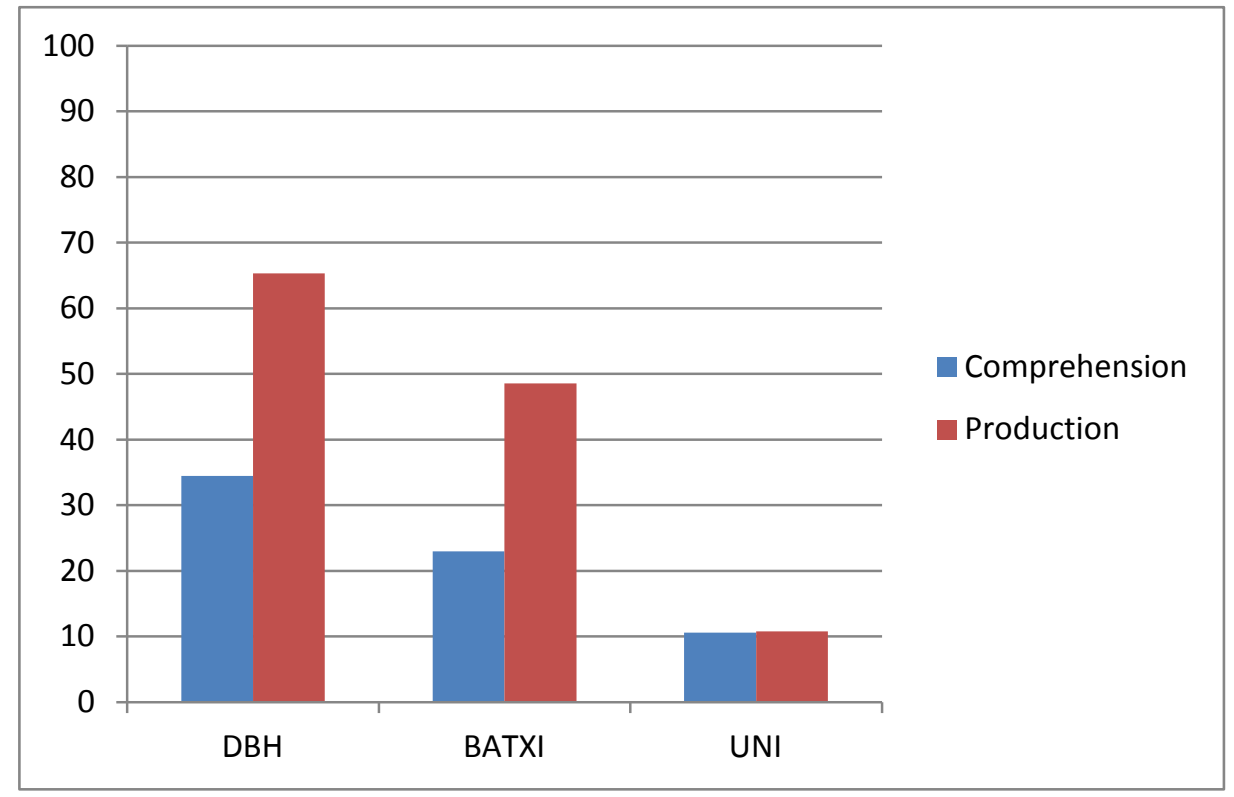

Besides, recall that production tasks were divided into oral and written production. When both types of production tasks were compared to comprehension tasks, a post-hoc analysis showed statistically significant differences among the three task types, as illustrated in Table 20:

Table 20. Number of gender agreement errors in comprehension and production tasks in the Basque/Spanish bilingual group

\begin{tabular}{|c|c|c|c|c|}
\cline { 3 - 5 } \multicolumn{2}{c|}{} & $\mathbf{N}$ & $\mathbf{\%}$ & SD \\
\hline \multirow{3}{*}{ DBH } & Comprehension & $1603 / 3085$ & $34.45 *$ & 4.61 \\
\cline { 2 - 5 } & Written production & $548 / 1041$ & $52.64 * * *$ & 6.49 \\
\cline { 2 - 5 } & Oral production & $1135 / 1536$ & $73.89 * / * * *$ & 8.32 \\
\hline \multirow{3}{*}{ BATXI } & Comprehension & $772 / 3360$ & $22.97 *$ & 3.97 \\
\cline { 2 - 5 } & Written production & $486 / 1126$ & $43.16^{* * *}$ & 5.48 \\
\cline { 2 - 5 } & Oral production & $800 / 1523$ & $52.52 * / * * *$ & 5.62 \\
\hline \multirow{3}{*}{ UNI } & Comprehension & $356 / 3360$ & $10.59 * / * *$ & 5.49 \\
\cline { 2 - 5 } & Written production & $179 / 1245$ & $14.37 * *$ & 1.68 \\
\cline { 2 - 5 } & Oral production & $137 / 1691$ & $8.10^{*}$ & 2.05 \\
\hline
\end{tabular}

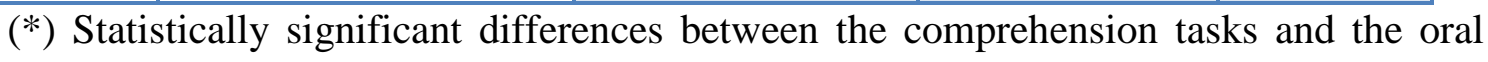
production tasks.

$\left({ }^{* *}\right)$ Statistically significant differences between comprehension and written production tasks.

$(* * *)$ Statistically significant differences between written production tasks and oral production tasks. 
In the DBH group, there were statistically significant differences for the interaction of task types $(F(2,256)=30.939 ; p<.0001)$. Post-hoc analyses revealed statistically significant differences between the comprehension tasks and oral production tasks $(p<.0001)$ as well as differences between written production and oral production tasks $(p<.0001)$. In the BATXI group, statistically significant differences were also found for the interaction of task types $(F(2,277)=16.257 ; p<.0001)$. Besides, pairwise analysis showed significant differences between comprehension and oral production tasks $(p<.0001)$ as well as written production and oral production tasks $(p<.0001)$. Nevertheless, differences between comprehension and written production tasks were neither found in the DBH group ( $p=.063$ ) nor in the BATXI group ( $p=.870)$. In the UNI group, statistically significant differences were found for the interaction of task types $(F(1,117)=51.243 ; p<.0001)$. The post-hoc Tuckey test analysis indicated differences between comprehension and both written production tasks $(p<.0001)$ and oral production tasks $(p<.0001)$. However, no differences were found between oral and written production tasks. Figure 27 shows the percentages of incorrect gender agreement in comprehension and both oral and written production.

Figure 27. Percentages of incorrect gender agreement between comprehension and written and oral production task in the Basque/Spanish bilingual groups

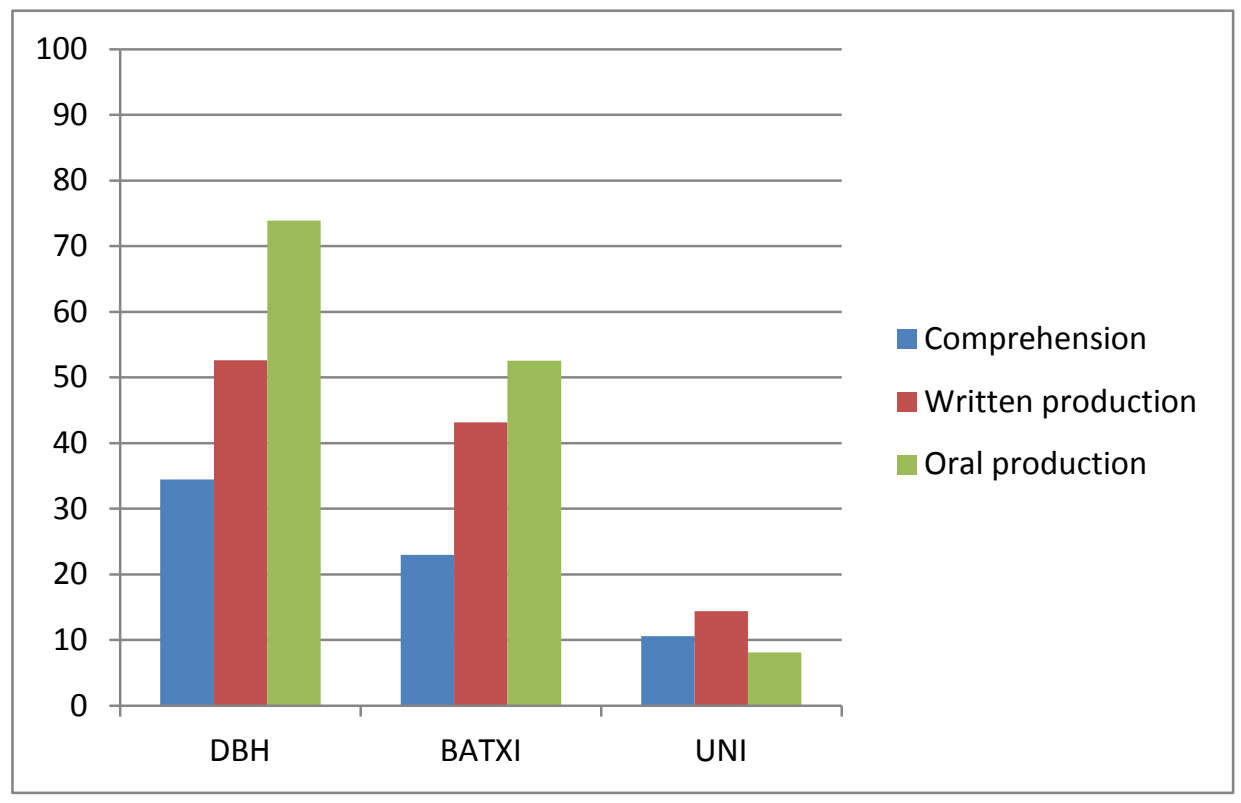


An across-task comparison provided a more detailed analysis of gender agreement errors in each task. For the DBH group, statistical analyses indicated between-task significant differences $(F(4,187)=6.689 ; p<.0001)$. A post-hoc analysis showed that there were no significant differences between the picture selection task- grammaticality judgment task, the grammaticality judgment task - the fill-in the gap task and between the grammaticality judgment task - the picture description pairs. Table 21 shows the pvalues of the comparison between tasks:

Table 21. $p$-values of the comparison between tasks in the Basque/Spanish bilingual DBH group

\begin{tabular}{|c|c|c|c|c|c|c|c|}
\hline & PST & GJT & MW & FIG & WDT & ET & PDT \\
\hline PST & & .155 & $<.0001$ & $<.0001$ & $<.0001$ & $<.0001$ & .037 \\
\hline GJT & .155 & & $<.0001$ & $<.0001$ & $<.0001$ & $<.0001$ & .243 \\
\hline MW & $<.0001$ & $<.0001$ & & .211 & $<.0001$ & $<.0001$ & $<.0001$ \\
\hline FIG & $<.0001$ & $<.0001$ & .211 & & $<.0001$ & $<.0001$ & .003 \\
\hline WDT & $<.0001$ & $<.0001$ & $<.0001$ & $<.0001$ & & $<.0001$ & $<.0001$ \\
\hline ET & $<.0001$ & $<.0001$ & $<.0001$ & $<.0001$ & $<.0001$ & & $<.0001$ \\
\hline PDT & .037 & .243 & $<.0001$ & .003 & $<.0001$ & $<.0001$ & \\
\hline
\end{tabular}

PST = picture selection task; GJT = grammaticality judgment task; $\mathrm{MW}=$ moving window; FIG = fill-in the gap; WDT = written description task; ET = elicitation task; PDT $=$ picture description task.

The findings in the DBH group could be classified into three patterns. The use of gender agreement in the picture selection task and the grammaticality judgment task seems to be the most accurate among the experimental tasks; in fact the percentage of correct gender agreement is over $60 \%$. Secondly, in the moving window task and in both written production tasks, accuracy percentages are lower (less than 50\%). Moreover, the figures for incorrect gender agreement use and the use of other errors are similar, except for the online task ${ }^{19}$. In the third group, the elicitation task and the picture description task high percentages of errors were found in the use of other forms in obligatory context, whereas the percentages of correct and incorrect use of possessive adjectives

\footnotetext{
${ }^{19}$ In the moving window task learners had to evaluate whether the sentence was possible or not for English. Thus, other forms could not be used in this task.
} 
were similar. Thus, oral production tasks seem to be more problematic for $\mathrm{DBH}$ learners.

For the BATXI group, statistical analyses indicated that there were statistically significant differences among tasks $(F(6,273)=4.553 ; p<.0001)$. Post-hoc Tuckey tests showed that there were statistically significant differences for all tasks (see Table 22) except for the picture selection task - the written description task, the grammaticality judgment task - fill-in the gap task and the grammaticality judgment task - the picture description task.

Table 22. $p$-values of the comparison between tasks in the Basque/Spanish bilingual

\begin{tabular}{|c|l|l|l|l|l|l|l|}
\multicolumn{1}{c|}{ BATXI group } \\
\cline { 2 - 8 } \multicolumn{1}{c|}{ PST } & GJT & MW & FIG & WDT & ET & PDT \\
\hline PST & & $<.0001$ & $<.0001$ & $<.0001$ & .054 & $<.0001$ & $<.0001$ \\
\hline GJT & $<.0001$ & & $<.0001$ & $<.0001$ & $<.0001$ & $<.0001$ & .659 \\
\hline MW & $<.0001$ & $<.0001$ & & .655 & $<.0001$ & .002 & .001 \\
\hline FIG & $<.0001$ & $<.0001$ & .655 & & $<.0001$ & .011 & .004 \\
\hline WDT & .054 & $<.0001$ & $<.0001$ & $<.0001$ & & $<.0001$ & $<.0001$ \\
\hline ET & $<.0001$ & $<.0001$ & .002 & .011 & $<.0001$ & & $<.0001$ \\
\hline PDT & $<.0001$ & .659 & .001 & .004 & $<.0001$ & $<.0001$ & \\
\hline
\end{tabular}

PST = picture selection task; GJT = grammaticality judgment task; $\mathrm{MW}=$ moving window; FIG = fill-in the gap; WDT = written description task; ET = elicitation task; $\mathrm{PDT}=$ picture description task.

The (non-)use of possessive adjectives in obligatory context indicates that, like in the DBH group, results could be classified into three groups. Firstly, participants show a high percentage in the accurate use of gender agreement in the picture selection task and the grammaticality judgment task (especially in the former accuracy reaches over 90\%). Secondly, learners show a similar percentage of accuracy in both the moving window task and the fill-in the gap task. Finally, production tasks revealed similar percentages of accuracy in the written description task, the elicitation task and the picture description task. As for the inaccurate use of possessive adjectives, percentages of incorrect gender agreement and the use of other forms in obligatory context are similar. However, compared to the DBH group, BATXI learners seem to use fewer developmental errors. 
In the UNI group, a multivariate ANOVA test indicated that there were statistically significant differences among tasks $(F(6,273)=29.519 ; p<.0001)$. A post-hoc Bonferroni test revealed that statistically significant differences were found when the grammaticality judgment task and the moving window task were compared to the rest of the tasks, as illustrated in Table 23:

Table 23. $p$-values of the comparison between tasks in the Basque/Spanish bilingual

\begin{tabular}{|c|c|c|c|c|c|c|c|}
\multicolumn{1}{c|}{ UNI group } & PST & GJT & MW & FIG & WDT & ET & PDT \\
\hline PST & & $<.0001$ & $<.0001$ & & & & \\
\hline GJT & $<.0001$ & & & $<.0001$ & $<.0001$ & $<.0001$ & $<.0001$ \\
\hline MW & $<.0001$ & & & $<.0001$ & $<.0001$ & $<.0001$ & $<.0001$ \\
\hline FIG & & $<.0001$ & $<.0001$ & & & & \\
\hline WDT & & $<.0001$ & $<.0001$ & & & & \\
\hline ET & & $<.0001$ & $<.0001$ & & & & \\
\hline PDT & & $<.0001$ & $<.0001$ & & & & \\
\hline
\end{tabular}

PST = picture selection task; GJT = grammaticality judgment task; $\mathrm{MW}=$ moving window; FIG = fill-in the gap; WDT = written description task; ET = elicitation task; PDT $=$ picture description task.

Findings in the UNI group indicate high percentages of accuracy in the use of gender agreement. In fact, percentages in all tasks are over $80 \%$. For instance, accuracy was extremely high in the picture selection task and in the elicitation task, 98\% and 94\% respectively. However, some tasks (i.e. the grammaticality judgment task, the moving window task and the picture selection task) show traces of incorrect gender agreement use and other tasks (i.e. the fill-in the gap task) of the use of other forms.

\subsubsection{Task differences in L1 Spanish groups}

Inaccurate possessive adjective forms in production tasks were compared to the incorrect use in comprehension tasks. A multivariate ANOVA analysis showed statistically significant differences only in the UNI group $(F(1,167)=21.635$; $p<.0001)$. However, no differences were found in the DBH and the BATXI groups. Percentages of incorrect gender agreement in comprehension and production tasks are displayed in Figure 28: 
Figure 28. Percentages of incorrect gender agreement in comprehension and production tasks in the L1 Spanish groups

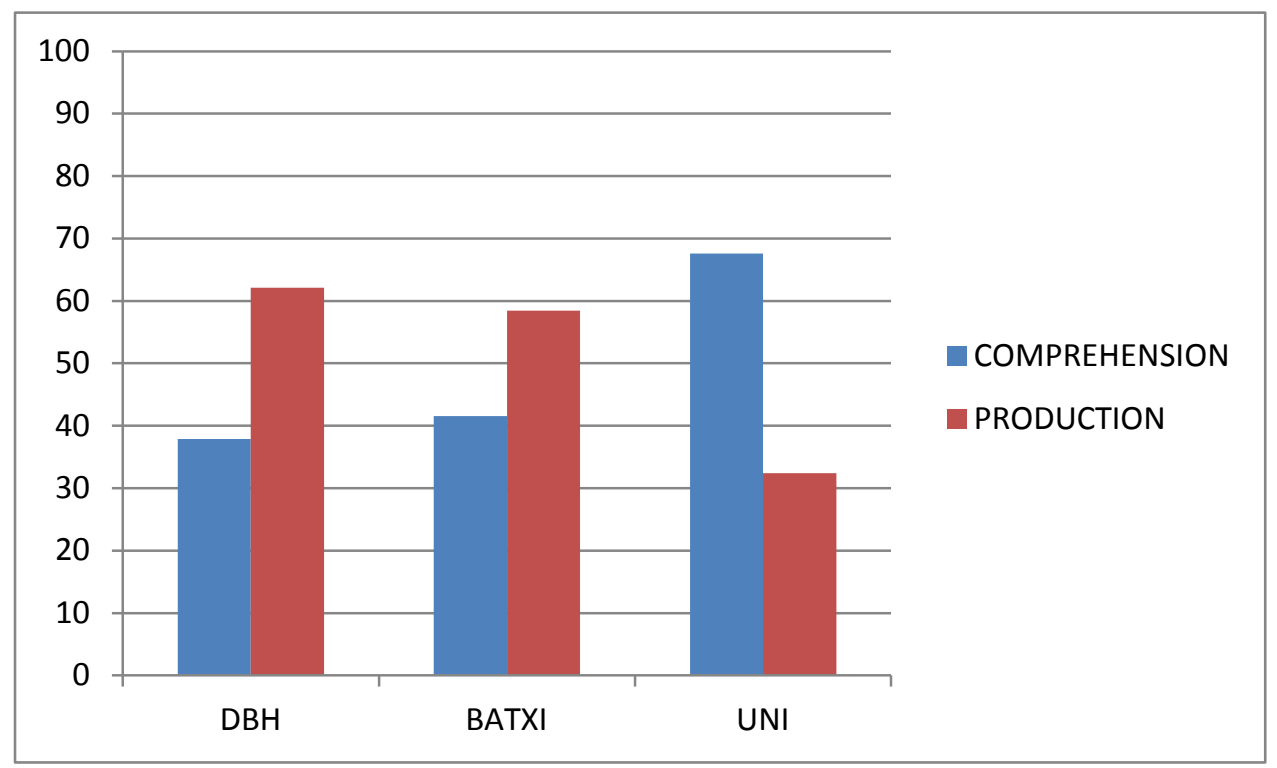

Furthermore, findings in production tasks were divided into written and oral production in order to examine the differences between the two production types. Thus, written and oral production types were compared to comprehension tasks. An ANOVA analysis revealed statistically significant differences in the interaction of comprehension and written and oral production tasks in the DBH $(F(2,151)=14.428 ; p<.0001)$, BATXI $(F$ $(2,165)=6.925 ; p=.001)$ and UNI groups $(F(2,165)=6.925 ; p=.001)$. Table 24 illustrates the percentages of incorrect gender agreement in each task type. 
Table 24. Number of gender agreement errors in comprehension and production tasks in the L1 Spanish group

\begin{tabular}{|c|c|c|c|c|}
\cline { 3 - 5 } \multicolumn{1}{c|}{} & $\mathbf{N}$ & $\mathbf{\%}$ & SD \\
\hline \multirow{3}{*}{ DBH } & Comprehension & $596 / 1843$ & $32.33^{*}$ & 3.81 \\
\cline { 2 - 5 } & Written production & $331 / 655$ & $50.92^{* * *}$ & 5.51 \\
\cline { 2 - 5 } & Oral production & $645 / 926$ & $69.65 * / * * *$ & 1.17 \\
\hline \multirow{3}{*}{ BATXI } & Comprehension & $587 / 2016$ & $29.11^{*}$ & 3.72 \\
\cline { 2 - 5 } & Written production & $323 / 745$ & $43.35^{* * *}$ & 3.85 \\
\cline { 2 - 5 } & Oral production & $503 / 952$ & $52.83^{*} / * * *$ & 7.19 \\
\hline \multirow{3}{*}{ UNI } & Comprehension & $215 / 2016$ & $10.66^{*}$ & 3.62 \\
\cline { 2 - 5 } & Written production & $68 / 754$ & $9.01^{* * *}$ & 1.83 \\
\cline { 2 - 5 } & Oral production & $35 / 1009$ & $3.46 * / * * *$ & 1.06 \\
\hline
\end{tabular}

(*) Statistically significant differences between the comprehension tasks and the oral production tasks.

$(* * *)$ Statistically significant differences between written production tasks and oral production tasks.

A post-hoc Tuckey analysis showed statistically significant differences between comprehension and oral production tasks as well as between written and oral production tasks in the DBH $(p<.0001)$, the BATXI $(p=.036 ; p=.001)$ and the UNI $(p=.036 ; p=$ .001) groups. Figure 29 depicts the percentages of inaccurate gender agreement use in comprehension and both written and oral production tasks.

Figure 29. Percentages of incorrect gender agreement in comprehension and written and oral production tasks in the three L1 Spanish control groups

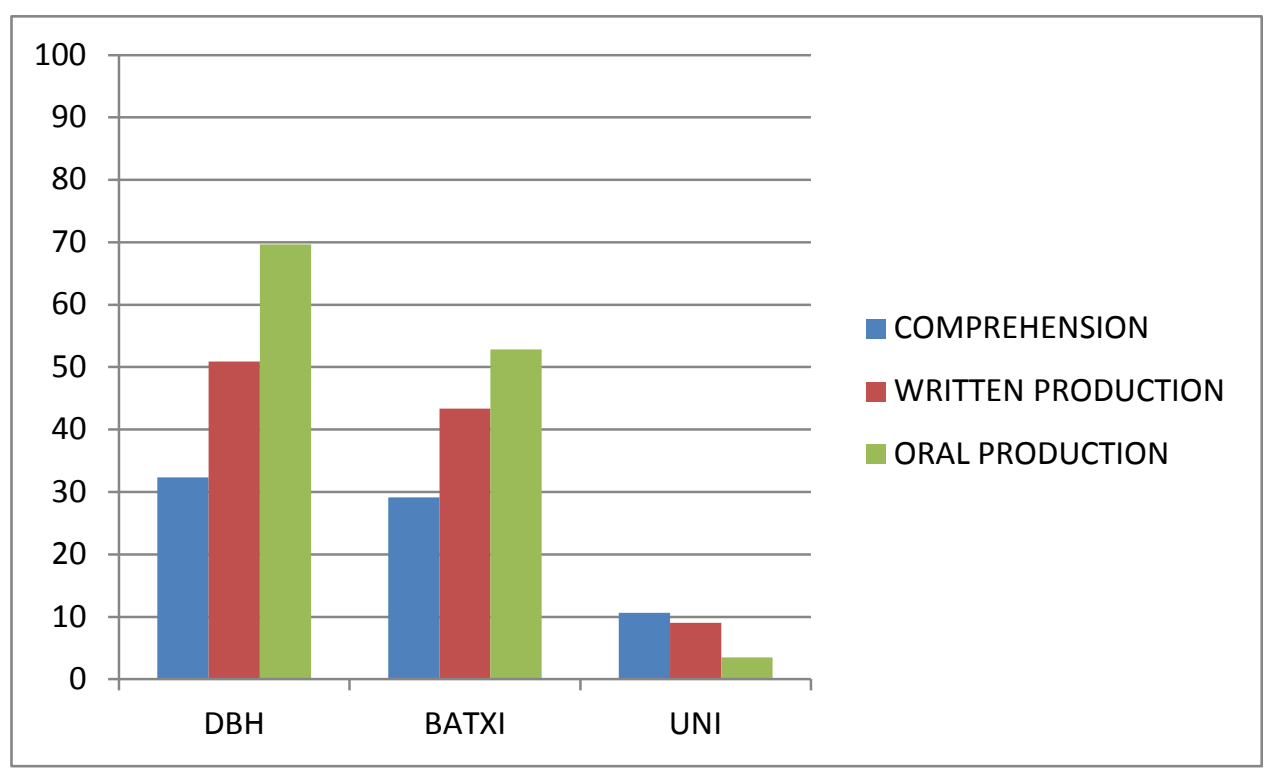


Errors were also submitted to an across task comparison in order to compare the results in each task. The one-way ANOVA analysis revealed statistically significant differences between experimental tasks $(F(6,153)=111.174 ; p<.0001)$ in the DBH group. Task comparison in the DBH group showed that learners exhibited high percentages of accuracy in gender agreement in the comprehension tasks. In written production, although percentages of correct agreement were higher, these learners also showed high percentages of incorrect gender agreement. The post-hoc Tuckey analyses between experimental tasks are reported in Table 25:

Table 25. $p$-values of the comparison between tasks in the L1 Spanish DBH group

\begin{tabular}{|c|c|c|c|c|c|c|c|}
\cline { 2 - 8 } \multicolumn{1}{c|}{} & PST & GJT & MW & FIG & WDT & ET & PDT \\
\hline PST & & .029 & $<.0001$ & $<.0001$ & .294 & $<.0001$ & .999 \\
\hline GJT & .029 & & $<.0001$ & .034 & $<.0001$ & $<.0001$ & .007 \\
\hline MW & $<.0001$ & $<.0001$ & & $<.0001$ & $<.0001$ & $<.0001$ & $<.0001$ \\
\hline FIG & $<.0001$ & .034 & $<.0001$ & & $<.0001$ & $<.0001$ & $<.0001$ \\
\hline WDT & .294 & $<.0001$ & $<.0001$ & $<.0001$ & & $<.0001$ & .563 \\
\hline ET & $<.0001$ & $<.0001$ & $<.0001$ & $<.0001$ & $<.0001$ & & $<.0001$ \\
\hline PDT & .999 & .007 & $<.0001$ & $<.0001$ & .563 & $<.0001$ & \\
\hline
\end{tabular}

PST = picture selection task; GJT = grammaticality judgment task; $\mathrm{MW}=$ moving window; FIG = fill-in the gap; WDT = written description task; ET = elicitation task; PDT $=$ picture description task.

In the BATXI group, one-way ANOVA analyses showed significant differences between tasks $(F(6,167)=53.857 ; p<.0001)$. Learners in the BATXI group featured a pattern similar to the previous group. BATXI learners showed higher percentages than the DBH group across-tasks, mainly in comprehension tasks. However, these learners showed lower rates of the use of other forms in obligatory context. In order to provide a more detailed view of the differences between experimental tasks, the significance values are reported in Table 26: 
Table 26. $p$-values of the comparison between tasks in the L1 Spanish BATXI group

\begin{tabular}{|c|c|c|c|c|c|c|c|}
\cline { 2 - 8 } \multicolumn{1}{c|}{} & PST & GJT & MW & FIG & WDT & ET & PDT \\
\hline PST & & $<.0001$ & $<.0001$ & $<.0001$ & .915 & $<.0001$ & .898 \\
\hline GJT & $<.0001$ & & .837 & 1.000 & $<.0001$ & $<.0001$ & $<.0001$ \\
\hline MW & $<.0001$ & .837 & & .942 & $<.0001$ & $<.0001$ & $<.0001$ \\
\hline FIG & $<.0001$ & 1.000 & .942 & & $<.0001$ & $<.0001$ & $<.0001$ \\
\hline WDT & .915 & $<.0001$ & $<.0001$ & $<.0001$ & & $<.0001$ & 1.000 \\
\hline ET & $<.0001$ & $<.0001$ & $<.0001$ & $<.0001$ & $<.0001$ & & $<.0001$ \\
\hline PDT & .898 & $<.0001$ & $<.0001$ & $<.0001$ & 1.000 & $<.0001$ & \\
\hline
\end{tabular}

PST = picture selection task; GJT = grammaticality judgment task; $\mathrm{MW}=$ moving window; FIG = fill-in the gap; WDT = written description task; ET = elicitation task; PDT $=$ picture description task.

In the UNI group, an ANOVA analysis revealed statistically significant differences between experimental tasks $(F(6,161)=20.356$; $p<.0001)$. Findings in the UNI group show high percentages of accuracy in the use of gender agreement, percentages are almost above 90\% (except for the moving window task). Nevertheless, some traces of gender agreement errors are still found in the moving window task or the fill-in the gap task. However, a post-hoc Tuckey test indicated statistically significant differences were found especially when the moving window task was compared to the other experimental tasks, as shown in Table 27: 
Table 27. $p$-values of the comparison between tasks in the L1 Spanish UNI group

\begin{tabular}{|c|c|c|c|c|c|c|c|}
\cline { 2 - 8 } \multicolumn{1}{c|}{} & PST & GJT & MW & FIG & WDT & ET & PDT \\
\hline PST & & .077 & $<.0001$ & .045 & .997 & .998 & 1.000 \\
\hline GJT & .077 & & $<.0001$ & 1.000 & .013 & .258 & .031 \\
\hline MW & $<.0001$ & $<.0001$ & & $<.0001$ & $<.0001$ & $<.0001$ & $<.0001$ \\
\hline FIG & .045 & 1.000 & $<.0001$ & & .007 & .171 & .017 \\
\hline WDT & .997 & .013 & $<.0001$ & .007 & & .914 & 1.000 \\
\hline EDT & .998 & .258 & $<.0001$ & .171 & .914 & & .976 \\
\hline
\end{tabular}

PST = picture selection task; GJT = grammaticality judgment task; $\mathrm{MW}=$ moving window; FIG = fill-in the gap; WDT $=$ written description task; ET = elicitation task; PDT $=$ picture description task.

\subsubsection{Summary of the main findings for task effects}

In the Basque/Spanish bilingual group, more errors were found in production tasks than in comprehension tasks. In the lower proficiency groups, learners showed higher accuracy percentages in the comprehension and written production tasks when compared to oral production tasks. However, in the most advanced proficiency group, higher accuracy rates were found in comprehension tasks but gender agreement errors increased in written and oral production tasks. Across task analyses indicated that learners made agreement errors in the lower proficiency groups. However, higher proficiency learners seem to overcome difficulties and reach an accuracy rate of over $80 \%$ in all the tasks. Findings in the L1 Spanish group revealed more errors in obligatory context in production tasks whereas in the most proficient group participants showed difficulties in the comprehension tasks. In the advanced group, accuracy rates were over $90 \%$ in all tasks except for comprehension tasks. A higher error percentage in comprehension tasks could be due to the difficulties in the moving window task. 


\subsection{Proficiency effects}

In this section proficiency effects will be analyzed in order to answer the third research question (RQ 3):

RQ 3: Is there a correlation between proficiency and number of errors? That is, does the number of errors decrease as proficiency increases?

Section 5.4.1 features the differences between the three proficiency groups in the use of gender agreement errors. In section 5.4.2, the developmental sequence in the acquisition of gender agreement in English is described with a detailed analysis of the use of other errors in obligatory context in each nonnative group.

\subsubsection{Proficiency effects in gender agreement errors}

The statistical analysis in this section was conducted only with gender agreement errors. Data from each task was submitted to a mixed model ANOVA analysis with animacy (animate, inanimate, body part) and attraction (gender-matched, gender-mismatched) as within-subject variables and group (Basque/Spanish, L1 Spanish, native speakers) and proficiency (elementary, intermediate, advanced) as between subject variables in the bysubject analysis and with group and proficiency as within-item variables and animacy and attraction as between-item variables in the by-item analysis.

A main effect of proficiency $\left(F(2,276)=181.458 ; p<.0001 ; \boldsymbol{\eta}_{p}{ }^{2}=.57\right)$ was found in the picture selection task. Post hoc tests with Bonferroni adjutsments indicated that advanced learners made fewer gender agreement errors in comparison to elementary $(p<.0001)$ and intermediate $(p<.0001)$ participants. Moreover, in the Basque/Spanish bilingual group elementary learners showed higher percentages of inaccurate gender agreement in comparison to intermediate learners $(p<.0001)$, as shown in Figure 30: 
Figure 30. Percentages of errors in the three proficiency levels in the picture selection task

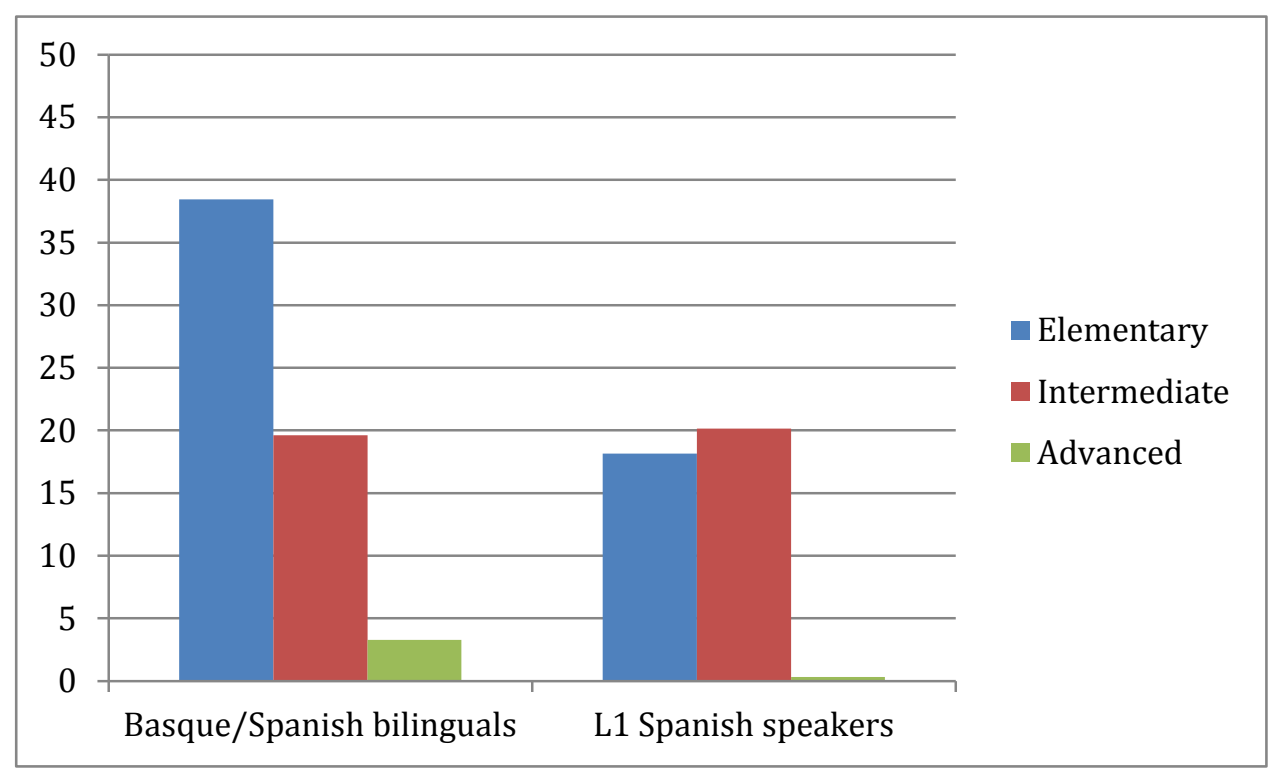

Additionally, contrasts revealed significant interaction effects between attraction $\mathrm{x}$ proficiency in the by-subject analysis $\left(F(2,205)=6.495 ; p=.002 ; \boldsymbol{\eta}_{p}{ }^{2}=.60\right)$ and in the by-item $\left(F(2,276)=10.227 ; p<.0001 ; \boldsymbol{\eta}_{p}{ }^{2}=.69\right)$ analysis, indicating that participants in all proficiency levels showed more gender agreement errors in mismatched contexts. Moreover, statistically significant interaction effects were found for proficiency $\mathrm{x}$ attraction x animacy $\left(F(4,276)=2.666 ; p=.033 ; \eta_{p}{ }^{2}=.37\right)$. More gender agreement errors were found in the Basque/Spanish bilingual group, more specifically in the elementary and intermediate proficiency level in the animate gender-mismatched condition.

In the grammaticality judgment task main effect was also found for proficiency ( $F(1$, 154) $\left.=47.466 ; p<.0001 ; \eta_{p}{ }^{2}=.40\right)$. Participants in the advanced proficiency group evaluated sentences more accurately than elementary and intermediate proficiency learners $(p<.0001)$. However, no differences were found between elementary and intermediate groups, as shown in Figure 31: 
Figure 31. Percentages of errors in the three proficiency levels in the grammaticality judgment task

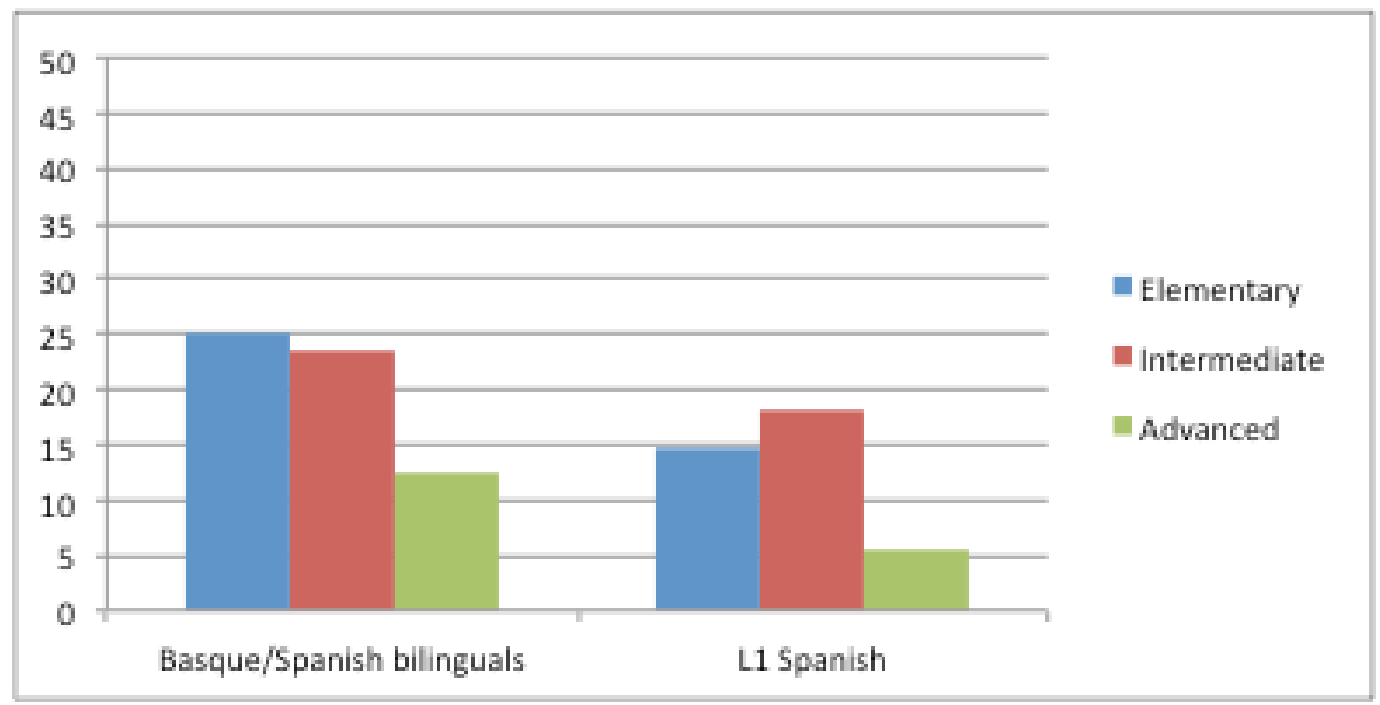

Contrast revealed significant interaction effects between proficiency x grammaticality $\left(F(2,154)=11.516 ; p<.0001 ; \boldsymbol{\eta}_{p}{ }^{2}=.13\right)$. Learners in lower proficiency groups were the least accurate groups in ungrammatical sentences.

In the moving window task, proficiency analysis was conducted with accuracy data as well as RTs in each interest area. Statistical analyses revealed a main effect of proficiency $\left(F(2,98)=130.534 ; p<.0001 ; \boldsymbol{\eta}_{p}{ }^{2}=.73\right)$ in accuracy data. This finding indicated that participants in the intermediate group showed the lowest accuracy rates in comparison to elementary and advanced level participants ( $p$-values $<.0001)$. Figure 32 illustrates proficiency effects in the moving window task. 
Figure 32. Percentages of errors in the three proficiency levels in the moving window task

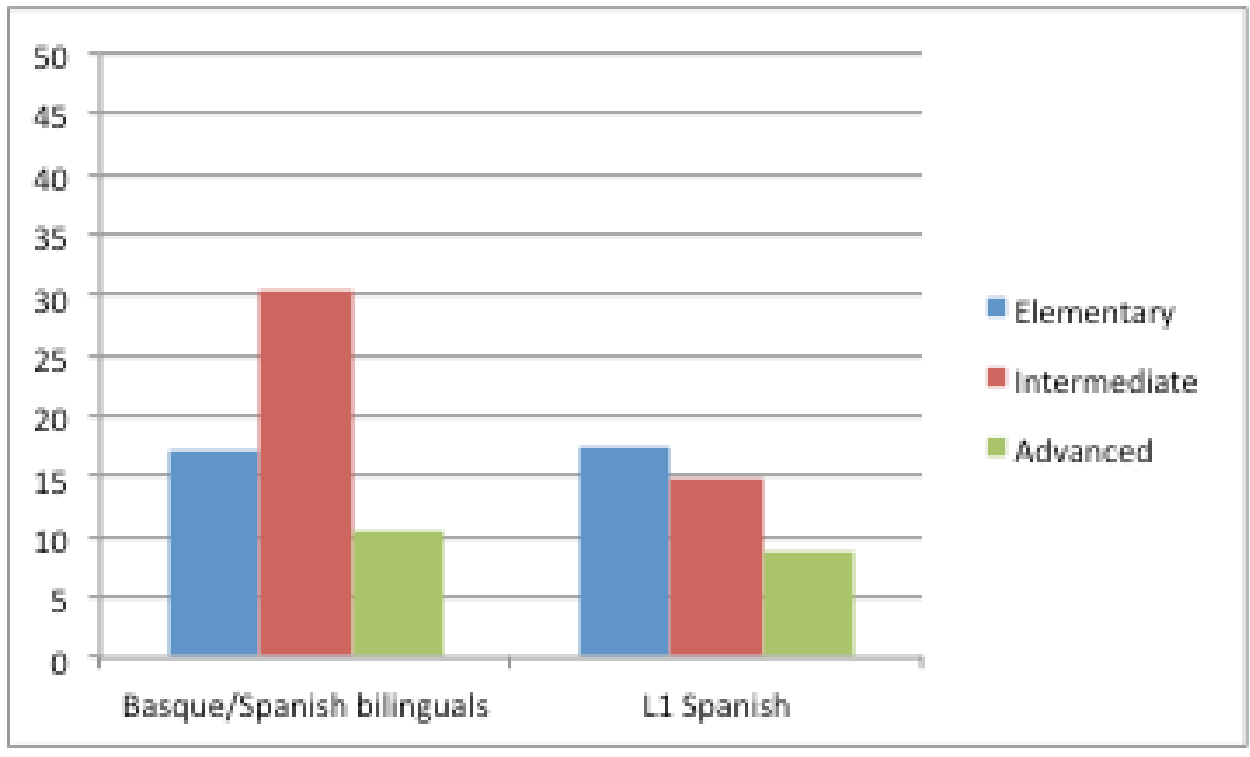

The proficiency $\mathrm{x}$ grammaticality contrast also revealed statistically significant differences $\left(F(2,98)=4.061 ; p=.020 ; \eta_{p}{ }^{2}=.08\right)$ indicating that lower proficiency level participants showed more difficulties in ungrammatical sentences.

Regarding RTs, no a main effect of proficiency was found in any of the interest areas.

In the fill-in the gap task, statistically significant main effects were found for proficiency $\left(F(2,184)=108.705 ; p<.0001 ; \boldsymbol{\eta}_{p}{ }^{2}=.54\right)$. Pairwise comparisons between proficiency levels revealed that intermediate learners established more instances of inaccurate gender agreement than elementary and advanced learners, being the most advanced learners the most accurate speakers (all $p$-values $<.0001$ ), as illustrated in Figure 33: 
Figure 33. Percentages of errors in the three proficiency levels in the fill-in the gap task

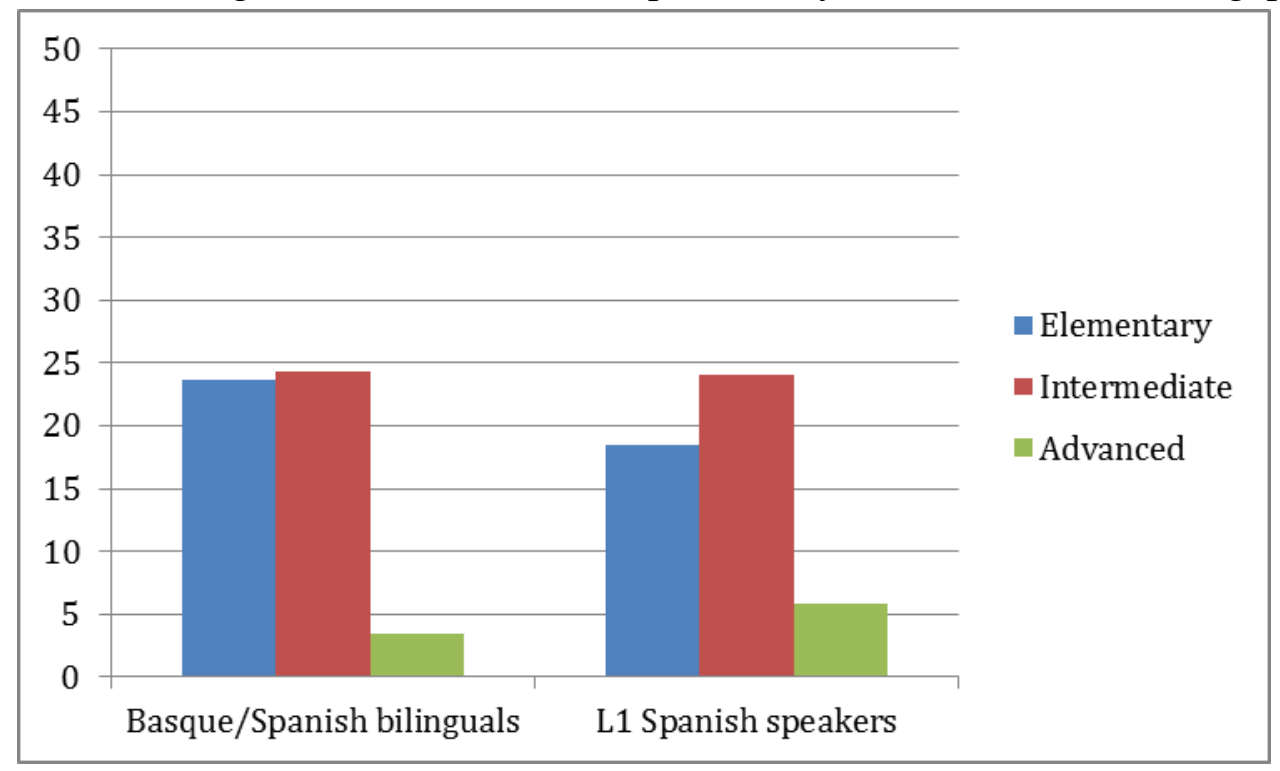

Contrasts revealed significant interaction effects between proficiency $\mathrm{x}$ animacy in the by-subject $\left(F(4,410)=19.860 ; p<.0001 ; \eta_{p}{ }^{2}=.46\right)$ and in the by-item $(F(2,184)=$ 13.979; $\left.p<.0001 ; \boldsymbol{\eta}_{p}{ }^{2}=.13\right)$ analyses, indicating that learners had more difficulties in inanimate contexts across proficiency levels. Similarly, significant interaction effects were found for attraction $x$ proficiency in the by-subject analysis $(F(2,205)=29.185$; $\left.p<.0001 ; \boldsymbol{\eta}_{p}{ }^{2}=.55\right)$ and in the by-item analysis $\left(F(4,184)=6.140 ; p<.0001 ; \boldsymbol{\eta}_{p}{ }^{2}=.12\right)$ indicating that gender-mismatched contexts were the most problematic conditions. Moreover, the contrast between animacy $\mathrm{x}$ attraction $\mathrm{x}$ proficiency were statistically significant $\left(F(4,410)=4.151 ; p<.0001 ; \eta_{p}{ }^{2}=.66\right)$ indicating inanimate gendermismatched conditions were the most problematic conditions for the lowest proficiency level learners.

In the written description task, a main effect of proficiency $(F(2,205)=26.182$; $p<.0001 ; \boldsymbol{\eta}_{p}{ }^{2}=.10$ ) was found. Post-hoc pairwise comparisons indicated significant differences between elementary and intermediate learners $(p=.032)$ as well as between these two groups and the advanced groups (all $p$-values<.0001). Figure 34 displays the error rates in the three proficiency levels in the written description task. 
Figure 34. Percentages of errors in the three proficiency levels in the picture description task

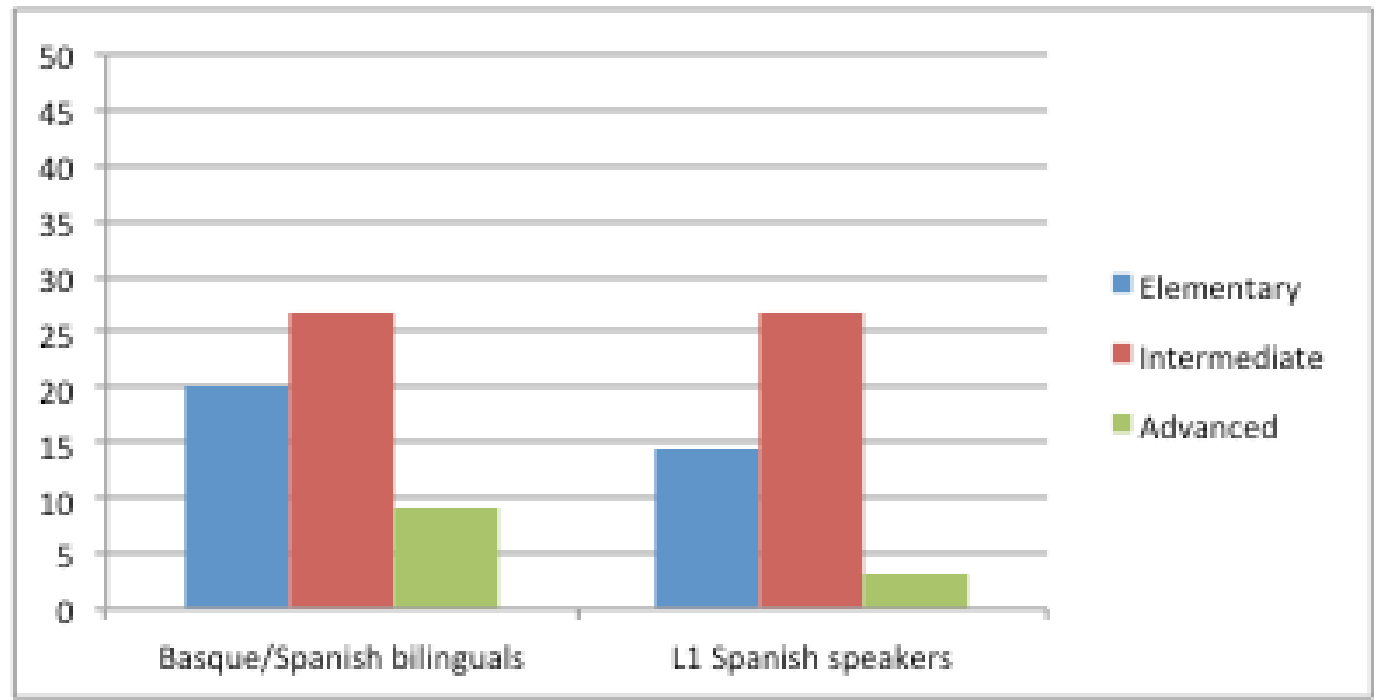

Significant main effects of proficiency $\left(F(2,276)=420.035 ; p<.0001 ; \boldsymbol{\eta}_{p}{ }^{2}=.75\right)$ were found in the elicitation task. Post-hoc tests with Bonferroni corrections indicated that lower level learners more gender agreement errors in comparison to intermediate and advanced learners (all $p$-values $<.0001$ ), as shown in Figure 35:

Figure 35. Percentages of errors in the three proficiency levels in the elicitation task

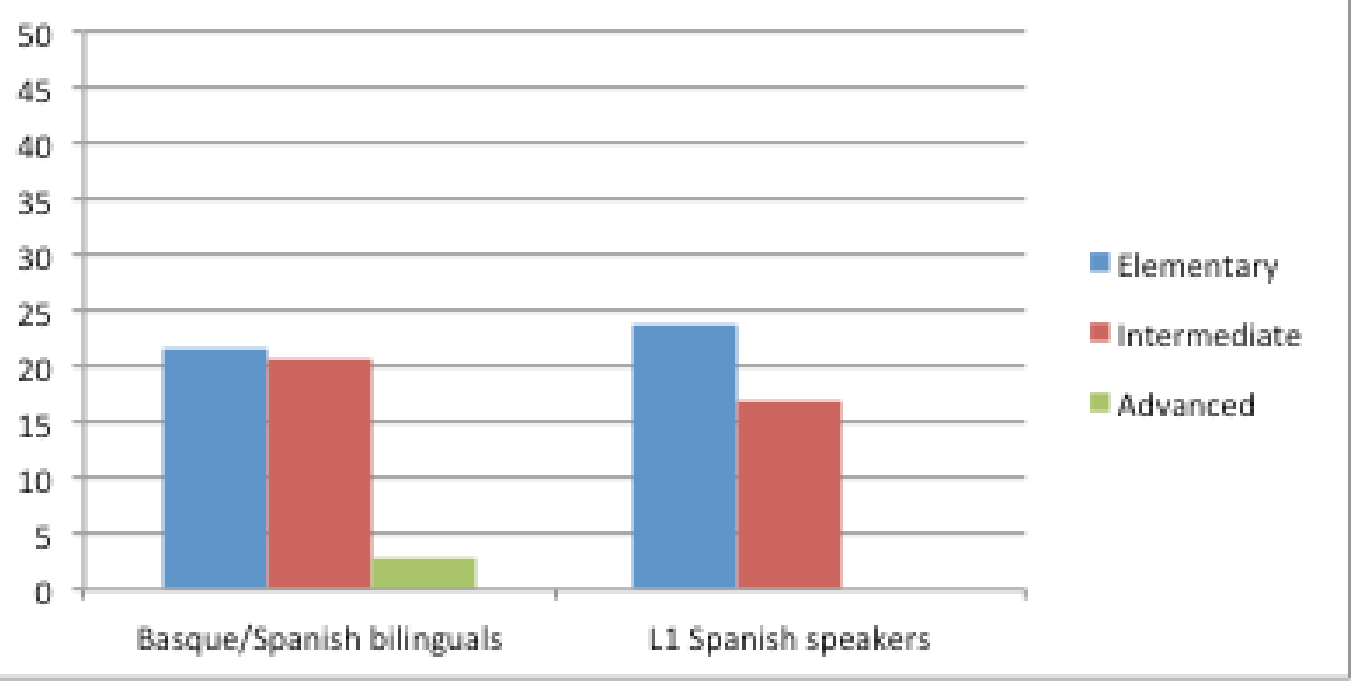

Contrasts showed significant interaction effects between proficiency x attraction ( $F$ (2, $\left.\left.205)=13.356 ; p<.0001 ; \boldsymbol{\eta}_{\boldsymbol{p}}{ }^{2}=.49\right) ;\left(F(4,276)=15.397 ; p<.0001 ; \boldsymbol{\eta}_{\boldsymbol{p}}{ }^{2}=.19\right)\right)$ in the bysubject and by-item analyses. Moreover, in the by-subject analysis significant interaction effects between animacy x proficiency $\left(F(4,410)=16.165 ; p<.0001 ; \boldsymbol{\eta}_{p}{ }^{2}=\right.$ 
.20). Regarding proficiency differences, individual repeated measures analyses showed that low proficiency learners experienced difficulties when establishing gender in animate and gender-mismatched conditions (all $p$-values<.0001). In addition, contrasts in the by-subject analyses revealed significant interaction effects between animacy $\mathrm{x}$ attraction x proficiency $\left(\mathrm{F}(4,410)=3.865 ; \mathrm{p}=.004 ; \boldsymbol{\eta}_{p}{ }^{2}=.39\right)$.

In the picture description task, a statistically significant effect was found for proficiency $\left(F(2,205)=26.616 ; p<.0001 ; \boldsymbol{\eta}_{p}{ }^{2}=.34\right)$. Post-hoc analyses with Bonferroni corrections revealed differences between advanced learners and elementary and intermediate speakers (all $p$-values $<.0001$ ), as displayed in Figure 36:

Figure 36. Percentages of errors in the three proficiency levels in the picture description task

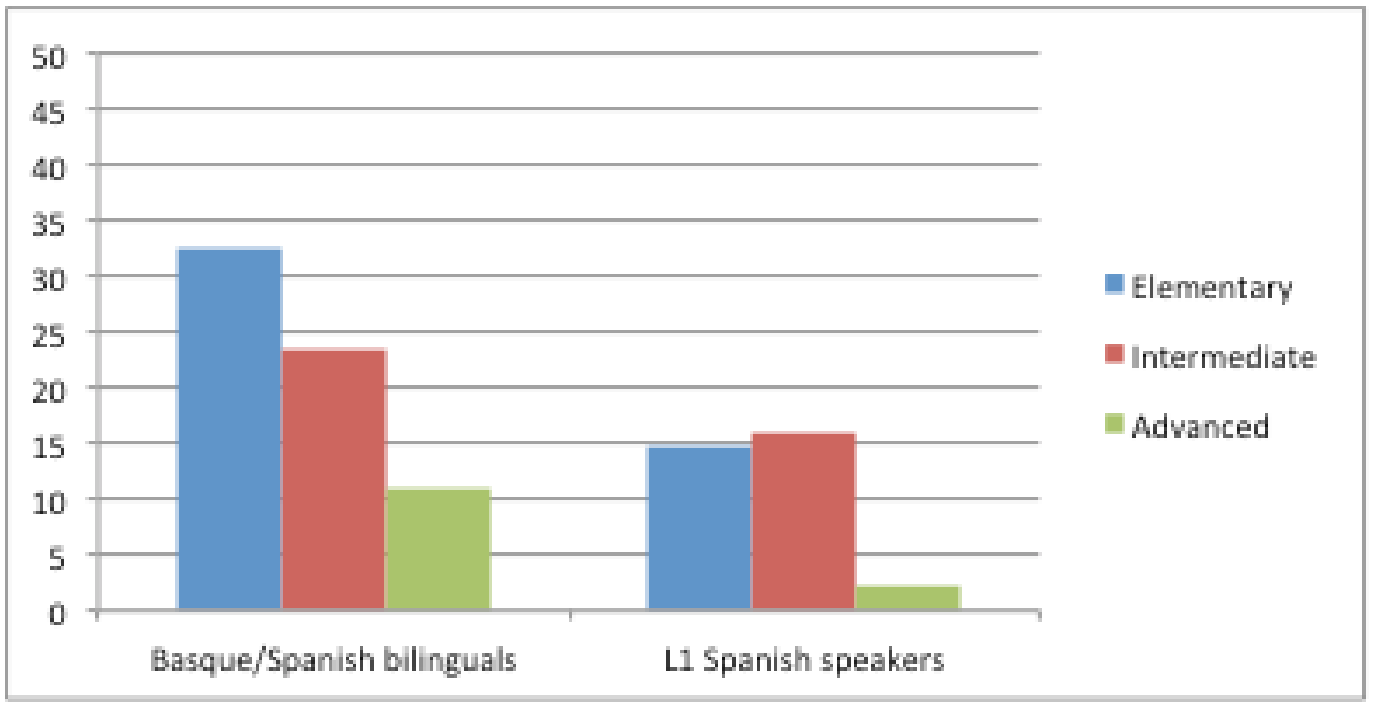

In sum, the comparison between proficiency levels revealed that intermediate learners showed difficulties in the grammaticality judgment task, moving window task and fillin the gap task. In contrast, elementary learners made more gender agreement errors in the picture selection task and the three spontaneous tasks.

\subsubsection{The use of other forms in obligatory context}

The use of other errors in obligatory context would be indicative of the developmental sequence in third person singular possessive adjectives followed by nonnative learners. Errors that were consistent across learners in the non-native groups were considered as developmental errors. In order to analyze whether Basque/Spanish bilinguals and L1 Spanish speakers showed a similar developmental pattern, findings were submitted to 
an independent simple t-test in each proficiency level. Statistical analyses revealed significant differences between Basque/Spanish bilinguals and L1 Spanish speakers in the elementary $(t(172)=8.883 ; p<.0001)$ and intermediate $(t(172)=6.466 ; p<.0001)$ groups indicating that speakers in each group followed a different developmental pattern. Therefore, the analyses of other errors in obligatory context will be reported in each section for Basque/Spanish bilinguals and L1 Spanish speakers.

\subsubsection{Analysis of other forms in obligatory contexts for Basque/Spanish bilingual groups}

Gender agreement errors and the use of other forms rather than third person singular possessive adjectives in obligatory contexts were analyzed. The analysis of the errors in obligatory context would be indicative of the developmental sequence in third person singular possessive adjectives.

An ANOVA analysis indicated that statistically significant differences were found in the interaction of the use of other forms rather than possessive adjectives in obligatory contexts $(F(2,114)=82.798 ; p<.0001)$ for the experimental groups. In fact, a post-hoc analysis between groups showed statistically significant differences for all pairwise comparisons (all $p$-values <.0001).

The use of third person possessive adjectives seems to increase as proficiency level increases. In fact, a paired t-test analysis of the gender agreement errors and the use of other forms in each proficiency group indicated that there were statistically significant differences for the BATXI $(t(39)=5.551 ; p<.0001)$ and the UNI group $(t(39)=4.858$; $p<.0001$ ), as shown in Figure 37. However, no differences were found for the DBH group. 
Figure 37. Comparison of the percentages in gender agreement errors and other errors in the experimental groups

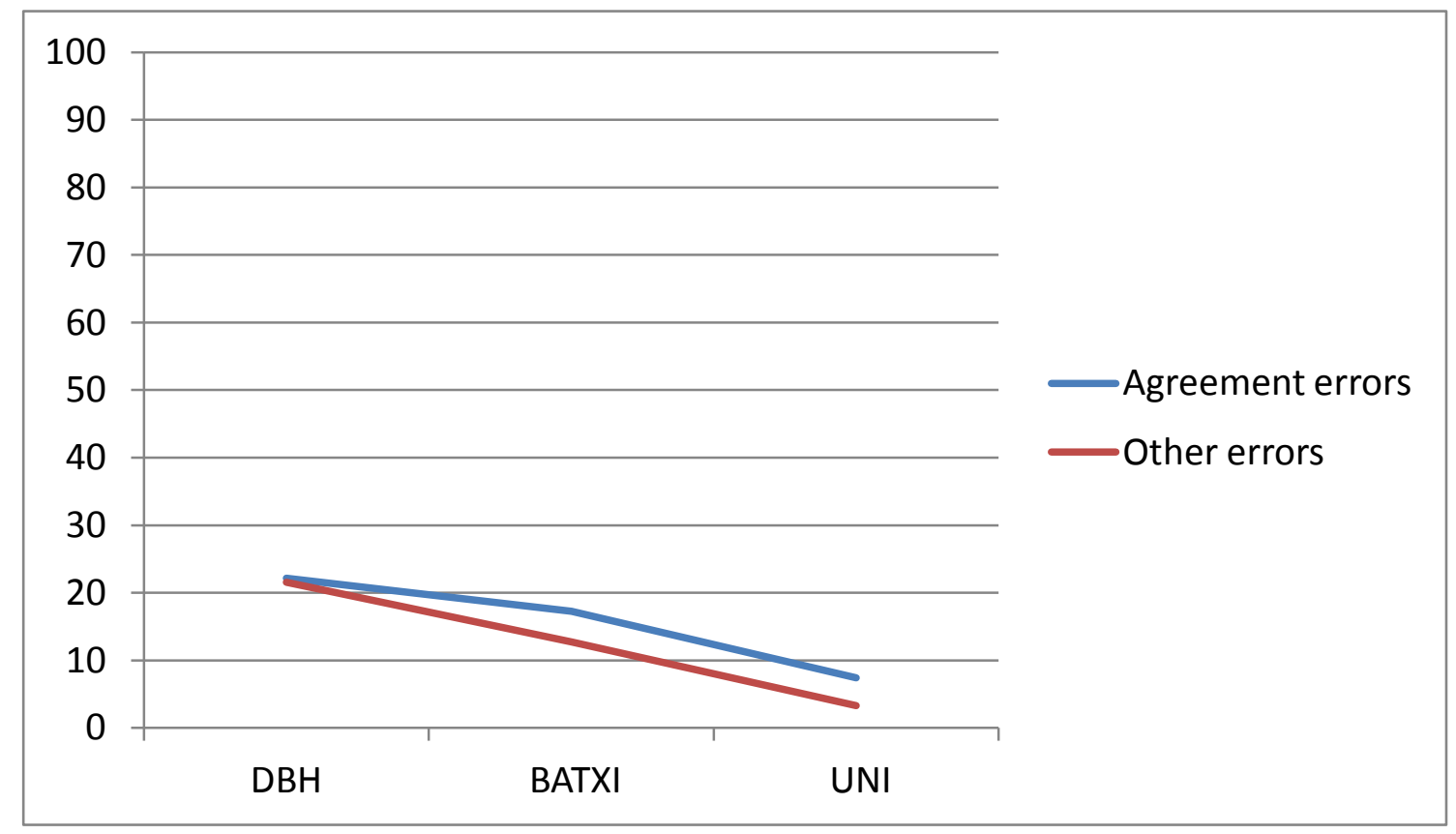

Thus, the lack of differences between agreement errors and other errors in the DBH group would be indicative of the use of other developmental forms in the lowest stages of proficiency. However, as proficiency increases, the use of other errors decreases rapidly, whereas gender agreement errors are still found in both the BATXI and the UNI group (though percentages could be low).

The use of other forms is considered to be representative of the developmental sequence in the use of third person possessive adjectives. After running a multivariate ANOVA analysis on the use of other forms in obligatory contexts, the following forms were identified to have a statistically significant interaction effect (examples are provided for the reader's convenience).

- Number errors: John is looking to their aunts. [BS_15_INT_PDT]

- Overuse of the definite article 'the': She brush the hair. [BS_22_ADV_FIG]

- Overuse of the first person singular possessive adjective 'my': She realized my dog is in the box. [BS_20_BEG_GJT] 
- Overuse of the second person singular possessive adjective 'your': $\mathbf{H e}$ are speaking for your brother. [BS_04_BEG_ET]

- Case mismatched errors: Can you give me him address? [BS_10_INT_WDT]

- Omission errors: A crayfish bit a boy in ø leg. [BS_08_BEG_WDT]

- The use of the definite article 'the' + the use of the third person singular possessive adjective: $\mathbf{H e}$ is washing the his $\boldsymbol{c l o t h}$.[BS_03_BEG_PDT]

- The use of the form 'HIR': Hir brother are catching a butterfly. [BS_27_BEG_PDT]

- The use of a third person singular possessive adjective + third person singular pronoun: Next to there is his she mother with camera. [BS_39_BEG_PDT]

In order to describe a possible developmental sequence in the use of these errors, the differences between experimental groups were analyzed individually. A multivariate ANOVA analysis indicated a statistically significant interaction for number errors ( $F(2$, $114)=9.517 ; p<.0001)$ and for the overuse of the definite article 'the' $(F(2,114)=$ $44.360 ; p<.0001)$. A post-hoc Tukey analysis of the differences between experimental groups indicated that there were statistically significant differences between DBH and UNI learners $(p<.0001)$ as well as BATXI and UNI groups $(p=.008)$. However, for both error types no differences were found between DBH and BATXI groups.

A multivariate ANOVA analysis indicated that the interaction for the overuse of the second person possessive adjective was statistically significant $(F(2,114)=15.814$; $p<.0001)$. Similarly, statistically significant differences were found for the interaction of omission errors $(F(2,114)=18.407 ; p<.0001)$, for the use of the form 'HIR' $(F(2,114)$ $=7.973 ; p=.001$ ) as well as for the use of the third person singular possessive adjective followed by a third person singular pronoun $(F(2,114)=6.291 ; p=.003)$. The posthoc pairwise Tuckey analysis showed that there were statistically significant differences between the DBH and the BATXI groups as well as the DBH and the UNI learners in each task, as is indicated in Table 28: 
Table 28. The number of other forms in obligatory context in the three Basque/Spanish experimental groups

\begin{tabular}{|c|c|c|c|c|c|c|c|c|c|c|c|c|c|}
\hline & \multicolumn{2}{|c|}{ PST } & \multicolumn{2}{|c|}{ GJT } & \multicolumn{2}{|c|}{ FIG } & \multicolumn{2}{|c|}{ WDT } & \multicolumn{2}{|c|}{ ET } & \multicolumn{2}{|c|}{ PDT } \\
\hline & & $\mathbf{N}$ & $\%$ & $\mathbf{N}$ & $\%$ & $\mathbf{N}$ & $\%$ & $\mathbf{N}$ & $\%$ & $\mathbf{N}$ & $\%$ & $\mathbf{N}$ & $\%$ \\
\hline \multirow{9}{*}{ 窝 } & $\begin{array}{c}\text { Number } \\
\text { errors }\end{array}$ & $23 / 235$ & 9.79 & $0 / 317$ & 0 & $0 / 466$ & 0 & $3 / 82$ & 3.66 & $0 / 784$ & 0 & $0 / 351$ & 0 \\
\hline & $\begin{array}{c}\text { THE + } \\
\text { possessive }\end{array}$ & - & - & $0 / 317$ & 0 & $0 / 466$ & 0 & $0 / 82$ & 0 & $28 / 784$ & 3.57 & $15 / 351$ & 4.27 \\
\hline & $\begin{array}{c}\text { YOUR } \\
\text { overuse }\end{array}$ & - & - & $0 / 317$ & 0 & $0 / 466$ & 0 & $1 / 82$ & 1.22 & $41 / 784$ & 5.23 & $20 / 351$ & 5.70 \\
\hline & Omission & - & - & $0 / 317$ & 0 & $0 / 466$ & 0 & $5 / 82$ & 6.10 & 93/784 & 11.86 & $57 / 351$ & 16.24 \\
\hline & HIR & - & - & $0 / 317$ & 0 & $0 / 466$ & 0 & $0 / 82$ & 0 & $15 / 784$ & 1.91 & $5 / 351$ & 1.42 \\
\hline & $\begin{array}{c}\text { Possessive } \\
+ \\
\text { pronoun }\end{array}$ & - & - & $0 / 317$ & 0 & $0 / 466$ & 0 & $0 / 82$ & 0 & $0 / 784$ & 0 & $11 / 351$ & 3.13 \\
\hline & $\begin{array}{c}\text { THE } \\
\text { overuse }\end{array}$ & - & - & $30 / 317$ & 9.46 & $220 / 466$ & 47.21 & $13 / 82$ & 15.85 & $209 / 784$ & 26.66 & $59 / 351$ & 16.81 \\
\hline & $\begin{array}{c}\text { MY } \\
\text { overuse }\end{array}$ & - & - & $8 / 317$ & 2.52 & 28/466 & 6.01 & $5 / 82$ & 6.10 & 29/784 & 3.70 & $0 / 351$ & 0 \\
\hline & $\begin{array}{c}\text { Case } \\
\text { errors }\end{array}$ & - & - & $0 / 317$ & 0 & $10 / 466$ & 2.15 & $9 / 82$ & 10.98 & $51 / 784$ & 6.51 & $17 / 351$ & 4.84 \\
\hline \multirow{5}{*}{ 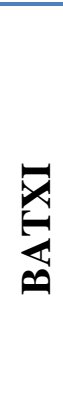 } & $\begin{array}{l}\text { Number } \\
\text { errors }\end{array}$ & $7 / 120$ & 5.83 & $0 / 266$ & 0 & $0 / 400$ & 0 & $5 / 86$ & 5.81 & $0 / 522$ & 0 & $0 / 278$ & 0 \\
\hline & $\begin{array}{c}\text { THE + } \\
\text { possessive }\end{array}$ & - & - & $0 / 266$ & 0 & $0 / 400$ & 0 & $0 / 86$ & 0 & $10 / 522$ & 1.92 & $20 / 278$ & 7.19 \\
\hline & $\begin{array}{c}\text { YOUR } \\
\text { overuse }\end{array}$ & - & - & $0 / 266$ & 0 & $0 / 400$ & 0 & $0 / 86$ & 0 & $0 / 522$ & 0 & $4 / 278$ & 1.44 \\
\hline & Omission & - & - & $0 / 266$ & 0 & $0 / 400$ & 0 & $5 / 86$ & 5.81 & $8 / 522$ & 1.53 & $40 / 278$ & 14.39 \\
\hline & HIR & - & - & $0 / 266$ & 0 & $0 / 400$ & 0 & $0 / 86$ & 0 & $1 / 522$ & 0.19 & $4 / 278$ & 1.44 \\
\hline
\end{tabular}




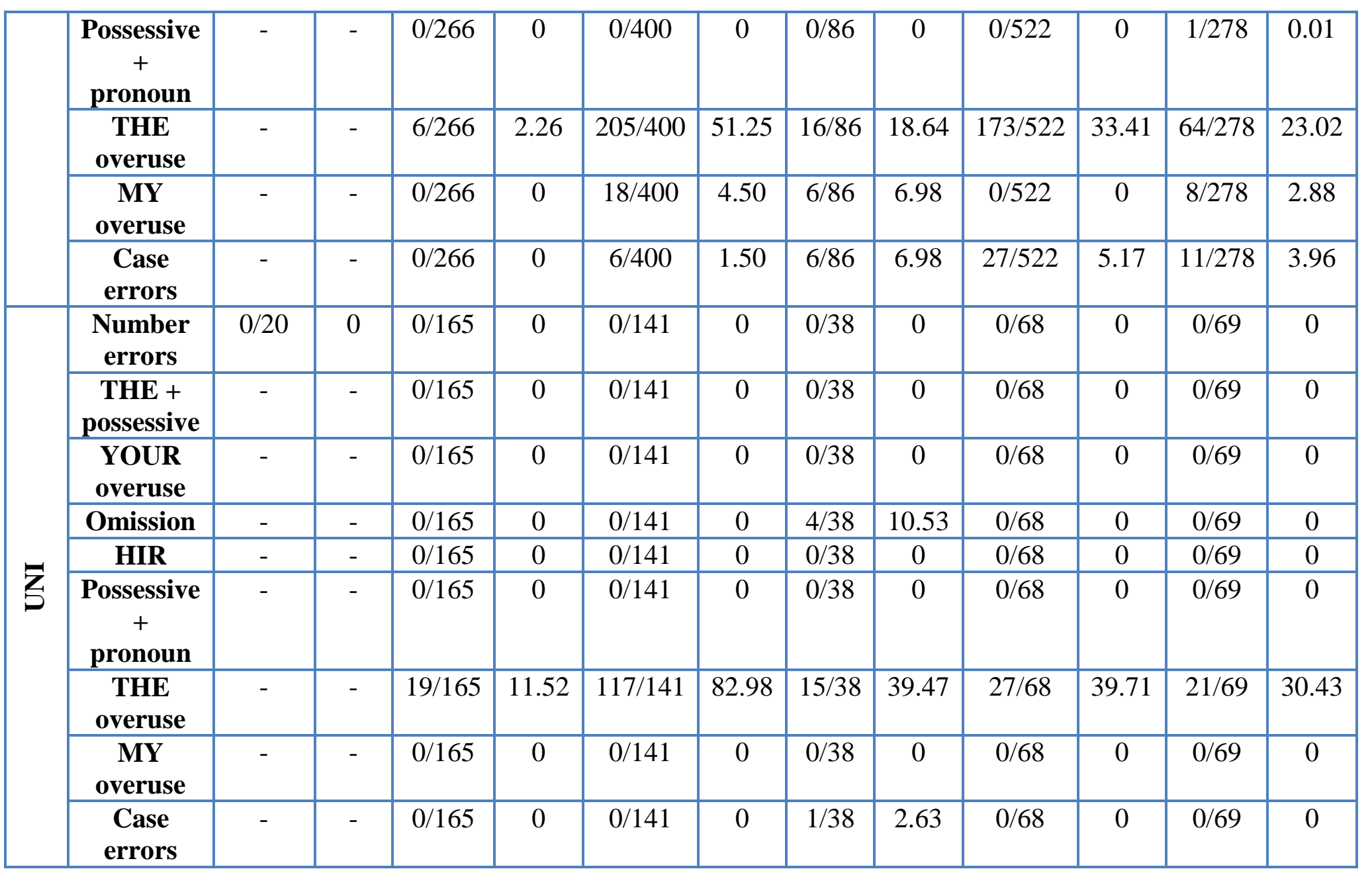

Number errors = number agreement errors; THE + possessive = definite Det 'the' followed by a third person singular possessive adjective; YOUR overuse = use of the second person singular pronoun in obligatory context; omission = omission errors in obligatory context; HIR = the of the form HIR in obligatory context; possessive + pronoun = third person singular possessive adjective followed by a personal pronoun; THE overuse = overuse of the definite Det in obligatory context; MY overuse = overuse of the first singular pronoun in obligatory context; case errors = case agreement errors in obligatory context. 
Statistical analysis showed that there were significant differences for the interaction of the definite article 'THE' $(F(2,114)=44.360 ; p<.0001)$ in obligatory contexts. Similar findings were observed for the overuse of the first person singular possessive adjective ' $\mathrm{MY}$ ' $(F(2,114)=17.672 ; p<.0001)$ as well as for the errors in case mismatched conditions $(F(2,114)=18.540 ; p<.0001)$. A post-hoc Tuckey test showed statistically significant differences between the three group pairs for definite article 'THE' overuse, for the overuse of the first person singular possessive pronoun ' $M Y$ ' and for case mismatch errors, as illustrated in Table 29.

Table 29. Summary of the $p$-values in the experimental groups in the use of other forms in obligatory contexts

\begin{tabular}{|c|c|c|c|}
\cline { 2 - 4 } \multicolumn{1}{c|}{} & DBH - BATXI & DBH - UNI & BATXI - UNI \\
\hline Number errors & & $<.0001$ & .008 \\
\hline THE + possessive & & $<.0001$ & $<.0001$ \\
\hline YOUR overuse & $<.0001$ & $<.0001$ & \\
\hline Omission & $<.0001$ & $<.0001$ & \\
\hline HIR & .011 & .001 & \\
\hline Possessive + pronoun & .011 & .005 & \\
\hline THE overuse & .027 & $<.0001$ & $<.0001$ \\
\hline MY overuse & .002 & $<.0001$ & .040 \\
\hline Case errors & .019 & $<.0001$ & .003 \\
\hline
\end{tabular}

In sum, proficiency seems to play an important role in the acquisition of gender agreement in third person singular possessive adjectives. The statistical analysis conducted for gender agreement errors shows differences among the experimental groups. Thus, an increasing trend in the number of gender agreement errors is found as proficiency level decreases since higher proficiency learners made fewer errors.

Regarding the developmental sequence, there seems to be a decreasing pattern in the use of both gender agreement errors and the use of other forms in obligatory context as proficiency increases. In fact, in the DBH group, learners made a similar number of errors types. However, for more proficient learners differences were found between gender agreement and the use of other forms. Moreover, the differences between the 
experimental groups in the use of other forms would be indicative of the stages learners represent throughout the developmental sequence.

\subsubsection{Analysis of other forms in obligatory contexts for L1 Spanish learner groups}

In order to examine the developmental sequence in third person singular possessive adjectives, the use of other forms in obligatory context rather than the target forms was analyzed. An ANOVA analysis showed statistically significant differences in the use of gender agreement forms and the use of other forms in obligatory context in the DBH ( $F$ $(2,439)=60.781 ; p<.0001)$, the BATXI $(F(2,479)=151.851 ; p<.0001)$ and the UNI $(F(2,479)=456.589 ; p<.0001)$ group. Regarding gender agreement errors, inaccuracy percentages seem to be quite similar for both DBH and BATXI groups. However, an important decrease is found as proficiency reaches a high level. The use of other forms in obligatory context reflects a progressive decrease as proficiency level increases. Figure 38 shows the percentages of gender agreement errors and other errors in obligatory contexts.

Figure 38. Percentages of incorrect gender agreement and other forms in the L1 Spanish groups

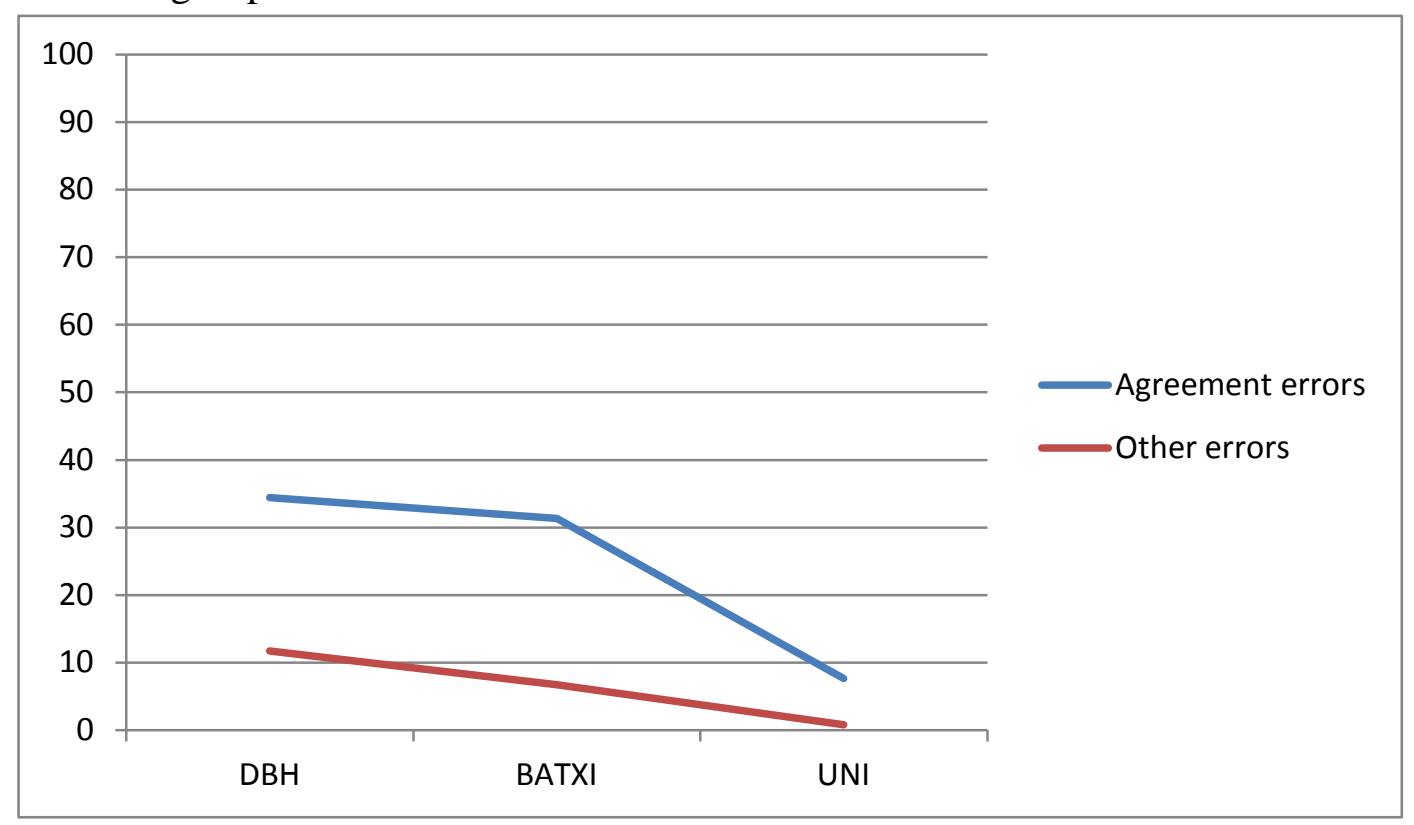

Therefore the differences between agreement errors and developmental errors were significant in the three proficiency groups. In the DBH group, the percentage of other errors in obligatory context was over $10 \%$ whereas agreement errors were more than 
$35 \%$ of the use of this form. Besides, as proficiency increases developmental errors also disappear completely but this is not the case with agreement errors.

Even though the percentage of developmental errors was only over $10 \%$ in DBH (lower in the higher proficiency groups), in this section these forms will be identified and analyzed. In the DBH group, the overuse of the second person possessive adjective, definite article overuse or number errors were found in both comprehension and production tasks, as shown in the following examples:

- Overuse of the second person possessive adjective: *Henry is talking to your brother during lunch time. [SP_12_BEG_GJT]

- Overuse of the definite article 'the': Allison is wearing a big diamond in the finger.[SP_18_BEG_FIG]

- Number mismatches: the mother is helping to their sons with the food. [SP_05_BEG_WDT]

Besides, instances of omission, overuse of the first person singular possessive or case mismatches were found only in production, as illustrated in these examples:

- Omission: *She is taking photos to grandmother. [SP_01_BEG_PDT]

- First person singular possessive: *Tom is fighting with my brother. [SP_02_BEG_ET]

- Case mismatches: *He is giving a flower to him mother. [SP_10_BEG_ET]

Table 30 displays the developmental errors produced by L1 Spanish speakers in the DBH group. 
Table 30. Developmental errors in the L1 Spanish DBH group

\begin{tabular}{|c|c|c|c|c|c|c|c|c|c|}
\cline { 2 - 10 } \multicolumn{1}{c|}{} & \multicolumn{3}{c}{ TOTAL } & \multicolumn{3}{c|}{ COMPREHENSION } & \multicolumn{3}{c|}{ PRODUCTION } \\
\cline { 2 - 10 } \multicolumn{1}{c|}{} & N & \% & SD & N & \% & SD & N & $\%$ & SD \\
\hline $\begin{array}{c}\text { Number } \\
\text { errors }\end{array}$ & $18 / 2864$ & 0.54 & 0.73 & $12 / 1315$ & 0.12 & 0.81 & $6 / 1549$ & 0.38 & 0.23 \\
\hline THE & $118 / 2864$ & 3.55 & 2.71 & $13 / 1315$ & 1.41 & 4.40 & $105 / 1549$ & 70.46 & 1.56 \\
\hline YOUR & $96 / 2864$ & 2.89 & 1.64 & $15 / 1315$ & 0.30 & 0.58 & $81 / 1549$ & 5.22 & 0.69 \\
\hline Omission & $94 / 2864$ & 2.83 & 2.33 & $0 / 1315$ & 0 & 0.41 & $94 / 1549$ & 6.06 & 1.02 \\
\hline MY & $23 / 2864$ & 0.69 & 1.04 & $0 / 1315$ & 0 & 0.41 & $23 / 1549$ & 1.48 & 0.52 \\
\hline Case & $34 / 2864$ & 1.02 & 1.22 & $0 / 1315$ & 0 & 0.64 & $34 / 1549$ & 2.19 & 0.26 \\
\hline
\end{tabular}

Number errors $=$ number agreement errors; THE overuse $=$ overuse of the definite Det in obligatory context; YOUR overuse = use of the second person singular pronoun in obligatory context; omission = omission errors in obligatory context; $\mathrm{MY}$ overuse = overuse of the first singular pronoun in obligatory context; case errors $=$ case agreement errors in obligatory context.

In the BATXI group, the use of other forms in obligatory context showed an overuse of the definite article 'the' in comprehension tasks. In contrast, similar forms to the previous group were used in target conditions in production tasks, as illustrated in the following examples.

- Number errors: *Jane is in the park with their two daughters. [SP_17_INT_ET]

- Overuse of the definite article 'the': *The boy is finding the keys in the pocket. [SP_23_INT_ET]

- Overuse of the second person singular possessive: *Mark is doing a dance with your wife. [SP_08_INT_ET]

- Omission errors: *She is putting money in piggy. [SP_11_INT_ET]

- Overuse of the first person singular possessive: Her dog and her mum are looking them and my mum say her that they have to see the map. [SP_07_INT_WDT]

- Case mismatches: *Susan is collecting butterflies with him grandfather. [SP_24_INT_PDT] 
Nonetheless, the number of non-target-like forms decreased in this proficiency group, as illustrated in Table 31:

Table 31. Developmental errors in the L1 Spanish BATXI group

\begin{tabular}{|c|c|c|c|c|c|c|c|c|c|}
\cline { 2 - 10 } \multicolumn{1}{c|}{} & \multicolumn{3}{c}{ TOTAL } & \multicolumn{3}{c|}{ COMPREHENSION } & \multicolumn{3}{c|}{ PRODUCTION } \\
\cline { 2 - 10 } \multicolumn{1}{c|}{} & $\mathbf{N}$ & $\%$ & SD & $\mathbf{N}$ & $\%$ & SD & $\mathbf{N}$ & $\%$ & SD \\
\hline $\begin{array}{c}\text { Number } \\
\text { errors }\end{array}$ & $16 / 3137$ & 0.51 & 0.81 & $0 / 1440$ & 0 & 0 & $16 / 1697$ & 0.94 & 0.85 \\
\hline Dao & $195 / 3137$ & 6.21 & 4.40 & $25 / 1440$ & 1.73 & 1.06 & $170 / 1697$ & 10.01 & 1.62 \\
\hline YO & $4 / 3137$ & 0.12 & 0.38 & $0 / 1440$ & 0 & 0 & $4 / 1697$ & 0.23 & 0.14 \\
\hline Omi & $5 / 3137$ & 0.15 & 0.41 & $0 / 1440$ & 0 & 0 & $5 / 1697$ & 0.29 & 0.82 \\
\hline MYO & $5 / 3137$ & 0.15 & 0.41 & $0 / 1440$ & 0 & 0 & $5 / 1697$ & 0.29 & 0.26 \\
\hline Case & $9 / 3137$ & 0.28 & 0.64 & $0 / 1440$ & 0 & 0 & $9 / 1697$ & 0.53 & 0.06 \\
\hline
\end{tabular}

Number errors $=$ number agreement errors; THE overuse $=$ overuse of the definite Det in obligatory context; YOUR overuse = use of the second person singular pronoun in obligatory context; omission = omission errors in obligatory context; $\mathrm{MY}$ overuse = overuse of the first singular pronoun in obligatory context; case errors = case agreement errors in obligatory context.

In the highest proficiency group, almost no use of other forms was attested. Participants only showed a low percentage of overuse of the definite article 'the' (*Jake was sticking the mouth out [SP_13_ADV_FIG]), as displayed in Table 32: 
Table 32. Developmental errors in the L1 Spanish UNI group

\begin{tabular}{|c|c|c|c|c|c|c|c|c|c|}
\cline { 2 - 10 } \multicolumn{1}{c|}{} & \multicolumn{3}{c}{ TOTAL } & \multicolumn{3}{c|}{ COMPREHENSION } & \multicolumn{3}{c|}{ PRODUCTION } \\
\cline { 2 - 10 } \multicolumn{1}{c|}{} & $\mathbf{N}$ & $\%$ & SD & N & $\%$ & SD & N & $\%$ & SD \\
\hline $\begin{array}{c}\text { Number } \\
\text { errors }\end{array}$ & $2 / 3203$ & 0.06 & 0.28 & $1 / 1440$ & 0.06 & 0.12 & $1 / 1763$ & 0.05 & 0.02 \\
\hline Dao & $26 / 3203$ & 0.81 & 1.41 & $1 / 1440$ & 0.06 & 0.12 & $25 / 1763$ & 1.41 & 0.16 \\
\hline YO & $0 / 3203$ & 0 & 0 & $0 / 1440$ & 0 & 0 & $0 / 1763$ & 0 & 0 \\
\hline Omi & $0 / 3203$ & 0 & 0 & $0 / 1440$ & 0 & 0 & $0 / 1763$ & 0 & 0 \\
\hline MYO & $0 / 3203$ & 0 & 0 & $0 / 1440$ & 0 & 0 & $0 / 1763$ & 0 & 0 \\
\hline Case & $0 / 3203$ & 0 & 0 & $0 / 1440$ & 0 & 0 & $0 / 1763$ & 0 & 0 \\
\hline
\end{tabular}

Number errors $=$ number agreement errors; THE overuse $=$ overuse of the definite Det in obligatory context; YOUR overuse = use of the second person singular pronoun in obligatory context; omission = omission errors in obligatory context; $\mathrm{MY}$ overuse = overuse of the first singular pronoun in obligatory context; case errors = case agreement errors in obligatory context.

Univariate ANOVA analyses showed statistically significant effects for the interaction of the three proficiency groups in omission errors $(F(2,69)=71.685 ; p<.0001)$, the overuse of the second person singular possessive adjective $(F(2,69)=153.416$; $p<.0001)$, the overuse of the first person singular possessive adjective $(F(2,69)=$ $17.286 ; p<.0001)$ and in case mismatches $(F(2,69)=24.062 ; p<.0001)$. Post hoc Tuckey analyses revealed significant differences only when elementary learners were compared to intermediate and advanced groups, as shown in

33. For number mismatches, the ANOVA analysis revealed significant differences between the proficiency groups $(F(2,69)=8.300 ; p=.001)$. However, the post-hoc analyses indicated differences between advanced learners when compared to elementary as well as intermediate learners. Whereas, in the overuse of the definite article 'the' significant interaction effects were found for proficiency $(F(2,69)=31.233 ; p<.0001)$. 
Table 33. Summary of the $p$-values in the use of other forms in the L1 Spanish groups

\begin{tabular}{|c|c|c|c|}
\hline & DBH-BATXI & DBH-UNI & BATXI-UNI \\
\hline Number errors & & .001 & .008 \\
\hline THE overuse & .010 & $<.0001$ & $<.0001$ \\
\hline YOUR overuse & $<.0001$ & $<.0001$ & \\
\hline Omission & $<.0001$ & $<.0001$ & \\
\hline MY overuse & $<.0001$ & $<.0001$ & \\
\hline Case & $<.0001$ & $<.0001$ & \\
\hline
\end{tabular}

Number errors $=$ number agreement errors; THE overuse $=$ overuse of the definite Det in obligatory context; YOUR overuse $=$ use of the second person singular pronoun in obligatory context; omission = omission errors in obligatory context; $\mathrm{MY}$ overuse = overuse of the first singular pronoun in obligatory context; case errors = case agreement errors in obligatory context.

Summarizing, proficiency seems to have a clear impact on the inaccurate use of third person singular possessive adjectives. Regarding gender agreement errors, although elementary and intermediate learners showed similar problems in both linguistic conditions examined in the present study, the advanced group did show proficiency benefits. On the other hand, the use of other forms in obligatory context may display L1 Spanish learners' developmental sequence in the acquisition of third person singular possessive adjectives. These errors are mainly represented in production tasks but low proficiency learners also use these forms in comprehension tasks as well. Nevertheless, the use of developmental errors seems to be overcome by proficiency benefits.

\subsubsection{Summary of the main findings for proficiency effects}

Higher proficiency learners were more accurate in gender agreement in almost all the tasks. Intermediate learners outperformed elementary learners across tasks, except for the grammaticality judgment task, moving window task and fill-in the gap task and advanced learners also had better accuracy rates than the previous two groups. Regarding the developmental sequence in the acquisition of gender agreement, Basque/Spanish bilinguals and L1 Spanish speakers seem to follow a different sequence. Basque/Spanish bilingual learners in the elementary and intermediate group showed some evidence of developmental/transfer errors (i.e. overgeneralization of first or second person possessive forms or the use of two pronouns). Nevertheless, developmental errors decreased as proficiency level increased since advanced learners 
did not show evidence of this type of error. In the L1 Spanish group, developmental errors decreased gradually as proficiency increased. Although L1 Spanish learners in the elementary group produced omission errors, overuse of the first and second person possessive forms, overuse of the definite article 'the' and case mismatches, error rates were significantly lower in this group in comparison to the Basque/Spanish bilingual group.

\subsection{Group effects}

The statistical analysis in this section was conducted only with gender agreement errors. Data from each task was submitted to a mixed model ANOVA analysis with animacy (animate, inanimate, body part) and attraction (gender-matched, gender-mismatched) as within-subject variables and group (Basque/Spanish, L1 Spanish, native speakers) and proficiency (elementary, intermediate, advanced) as between subject variables in the bysubject analysis and with group and proficiency as within-item variables and animacy and attraction as between-item variables in the by-item analysis.

\subsubsection{Group effects in the picture selection task}

There was a main effect of group $\left(F(1,138)=28.261 ; p<.0001 ; \boldsymbol{\eta}_{p}{ }^{2}=.17\right)$. Post-hoc Bonferroni comparisons revealed significant differences between native and non-native speakers $(p<.0001)$ indicating that Basque/Spanish bilinguals had more agreement errors than L1 Spanish and native speakers, as shown in Figure 39:

Figure 39. Percentages of errors in the native and non-native groups in the picture selection task

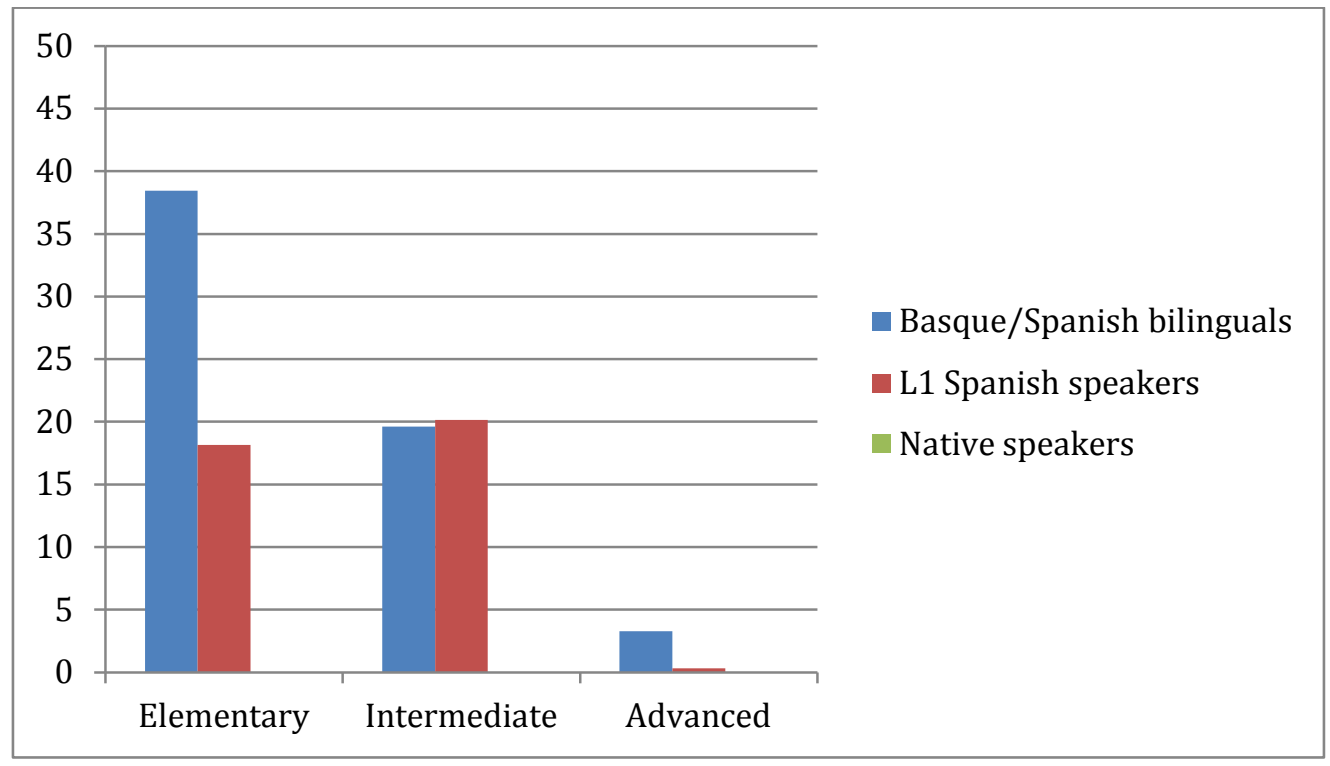


Contrast displayed statistically significant interactions between group $\mathrm{x}$ animacy ( $F(1$, $\left.138)=4.792 ; p=.030 ; \boldsymbol{\eta}_{p}{ }^{2}=.34\right)$ and between group $\mathrm{x}$ attraction $(F(2,138)=3.091 ; p$ $\left.=.049 ; \boldsymbol{\eta}_{p}{ }^{2}=.43\right)$ in the by-item analysis. Individual repeated measures comparison indicated that Basque/Spanish bilingual learners showed more difficulties in inanimate conditions as well as in gender-mismatched contexts. In fact, statistically significant interaction effects were found for group $\mathrm{x}$ attraction $\mathrm{x}$ animacy $(F(2,138)=3.774 ; p$ $\left.=.025 ; \eta_{p}{ }^{2}=.52\right)$.

\subsubsection{Group effects in the grammaticality judgment task}

Statistically significant main effects were also found for group $(F(1,154)=28.685 ; p$ $\left.<.0001 ; \boldsymbol{\eta}_{p}{ }^{2}=.16\right)$. Post hoc Bonferroni tests indicated that Basque/Spanish bilingual learners showed the highest error rates in comparison to L1 Spanish speakers and the native speaker group (all $p$-values $<.0001$ ), as illustrated in Figure 40:

Figure 40. Percentages of errors in the native and non-native groups in the grammaticality judgment task

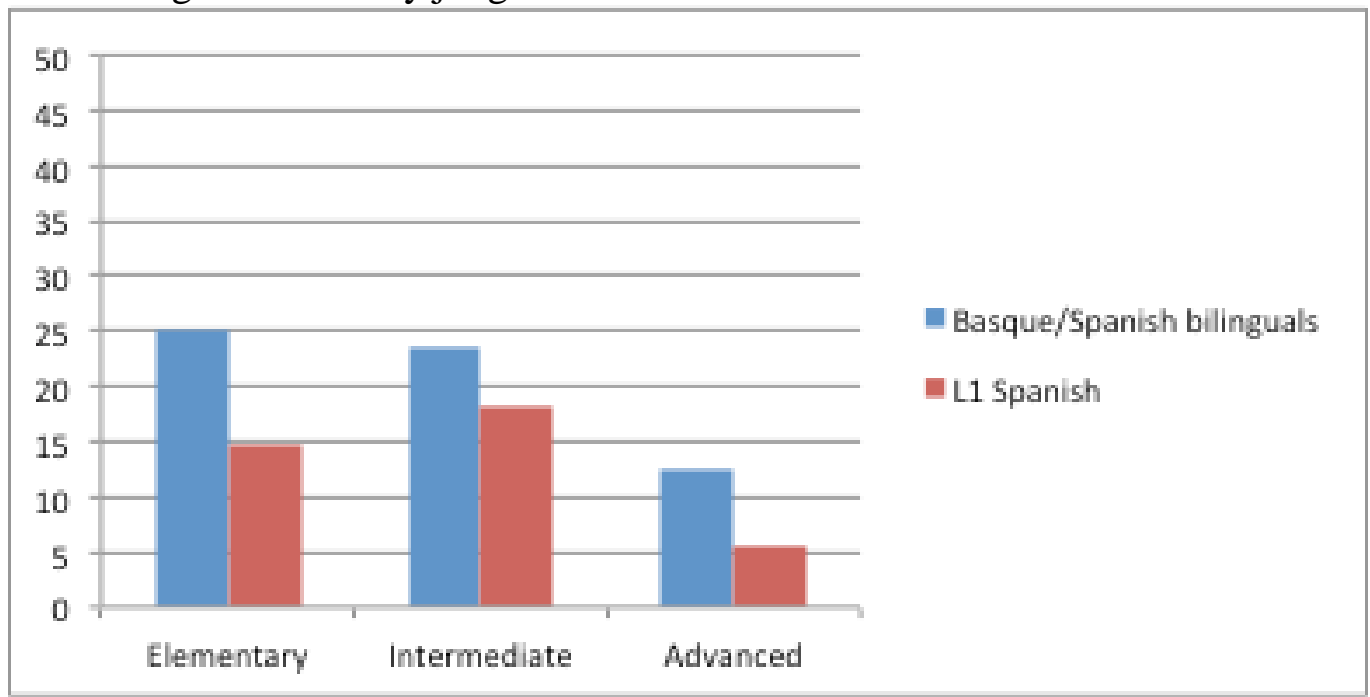

Moreover, significant interaction effects were found between group x grammaticality ( $F$ $\left.(2,154)=61.788 ; p<.0001 ; \eta_{p}{ }^{2}=.29\right)$. These results indicated that Basque/Spanish bilingual learners showed more difficulties in identifying ungrammatical sentences. The interaction between group $\mathrm{x}$ proficiency $\mathrm{x}$ grammaticality also resulted in significant interaction effects $\left(F(2,154)=3.136 ; p=.046 ; \boldsymbol{\eta}_{p}{ }^{2}=.04\right)$. Participants in the Basque/Spanish elementary and intermediate group had difficulties in correcting accurately sentences containing an ungrammatical gender agreement relationship. 


\subsubsection{Group effects in the moving window task}

\subsubsection{Accuracy data}

A main effect of group was found $\left(F(2,98)=70.749 ; p<.0001 ; \boldsymbol{\eta}_{p}{ }^{2}=.42\right)$. Post-hoc tests indicated that error percentages were higher for the Basque/Spanish bilingual groups, especially in the intermediate group, in comparison to L1 Spanish speakers and natives speakers of English ( $p$-values<.0001). Figure 41 shows the error percentages in experimental and control groups in the moving window task.

Figure 41. Percentages of errors in the native and non-native groups in the moving window task

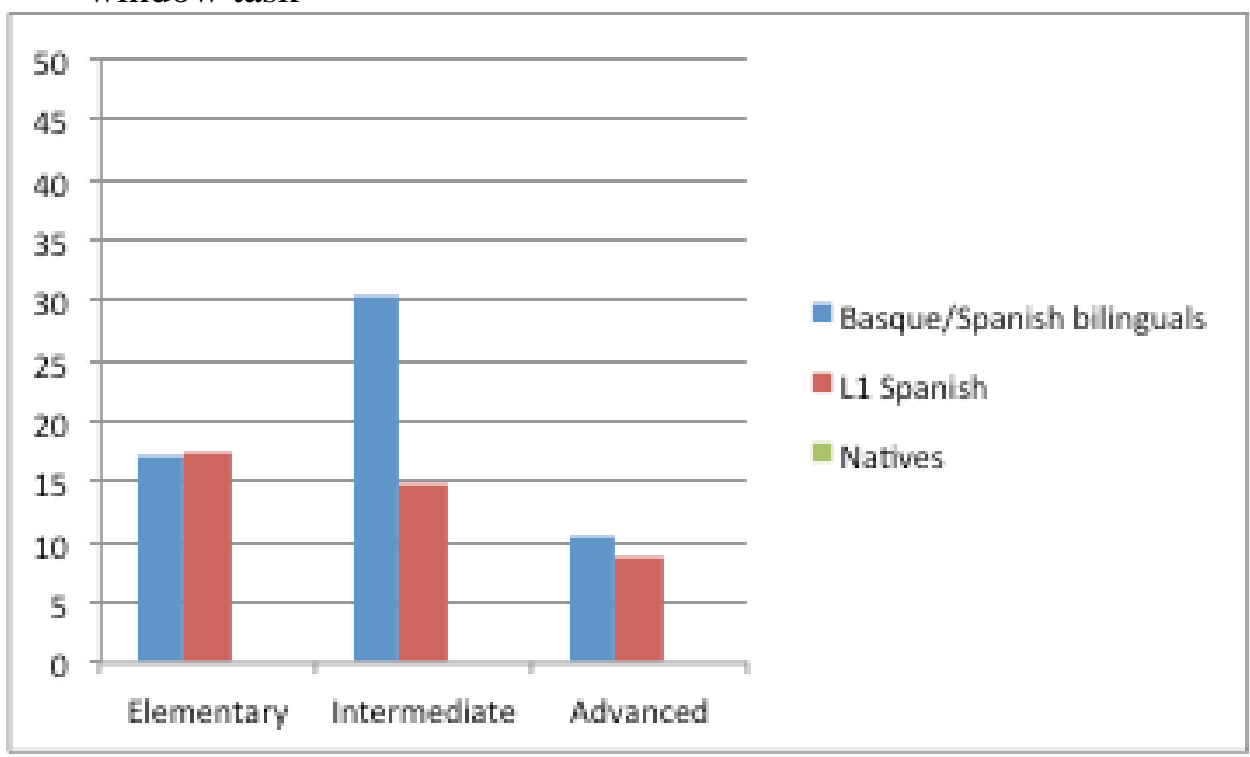

Moreover, the group x proficiency interaction was also significant $(F(2,196)=55.792$; $\left.p<.0001 ; \boldsymbol{\eta}_{p}{ }^{2}=.53\right)$. This interaction indicated that the participants that showed greatest difficulties were Basque/Spanish bilinguals at lower proficiency levels.

\subsubsection{RT data}

In the possessive interest area, a main effect of group $\left(F(1,830)=11.563 ; p=.001 ; \boldsymbol{\eta}_{\boldsymbol{p}}{ }^{2}\right.$ $=.16)$ and grammaticality $\left(F(1,830)=5.785 ; p=.016 ; \eta_{p}{ }^{2}=.07\right)$ were found. Post-hoc tests with Bonferroni adjustments revealed that L1 Spanish speakers showed longer reaction delays in comparison to Basque/Spanish bilinguals $(p=.002)$ and native speakers of English $(p<.0001)$, as illustrated in Figure 42: 
Figure 42. Mean RTs in the native and non-native groups in the possessive interest area

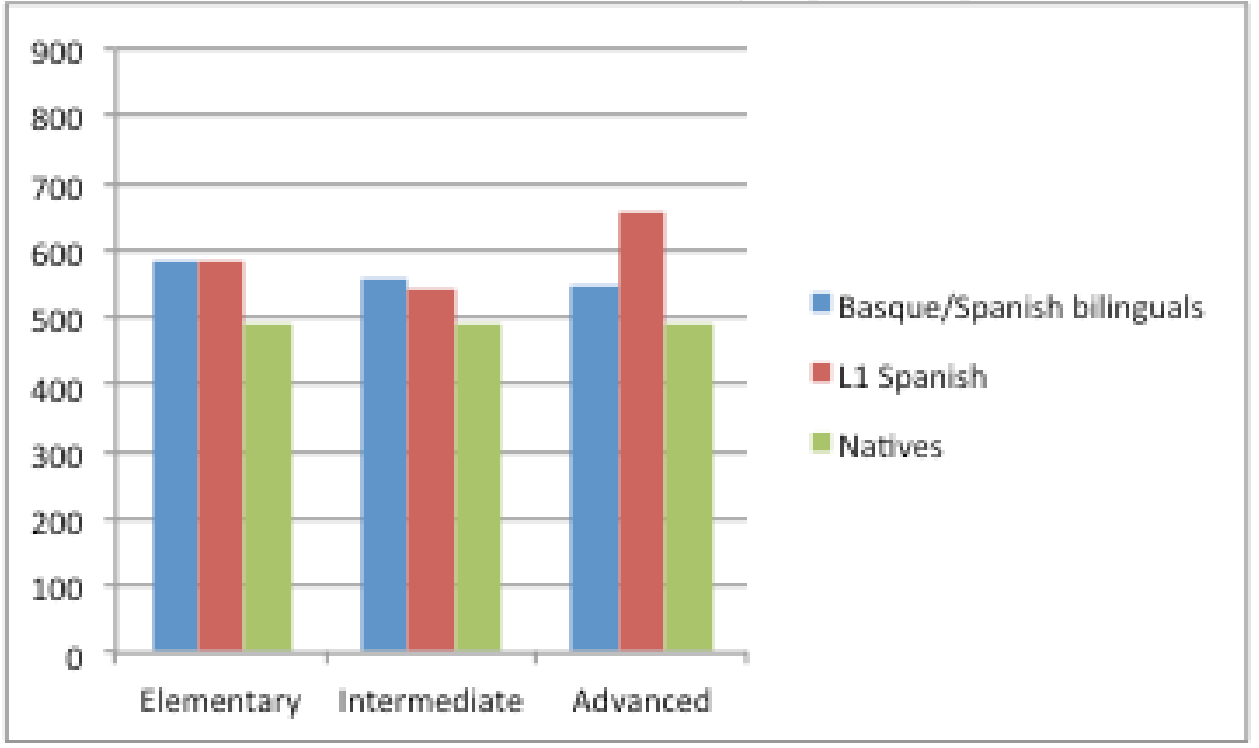

Regarding grammaticality, participants showed longer RTs in ungrammatical sentences than in grammatical ones $(p<.0001)$. Moreover, contrasts indicated statistically significant effects for group x proficiency $\left(F(2,830)=15.296 ; p<.0001 ; \boldsymbol{\eta}_{p}{ }^{2}=.04\right)$ and proficiency x grammaticality $\left(F(2,830)=3.498 ; p=.031 ; \boldsymbol{\eta}_{p}{ }^{2}=.08\right)$. These contrasts showed that L1 Spanish learners in lower proficiency level groups displayed longer RTs and, in fact, these elementary and intermediate learners showed more difficulties in ungrammatical sentences.

In the posseessee interest area, a main effect of group $\left(F(1,830)=6.866 ; p=.009 ; \boldsymbol{\eta}_{\boldsymbol{p}}{ }^{2}\right.$ $=.08)$ and grammaticality $\left(F(1,830)=5.807 ; p=.016 ; \eta_{p}{ }^{2}=.07\right)$ were found. Pairwise comparison with Bonferroni adjustments between groups revealed L1 Spanish learners showed longer reaction delays in comparison to Basque/Spanish bilinguals $(p=.027)$ and the native speaker group ( $p<.0001)$, as shown in Figure 43. 
Figure 43. Mean RTs in the native and non-native groups in the possessee interest area

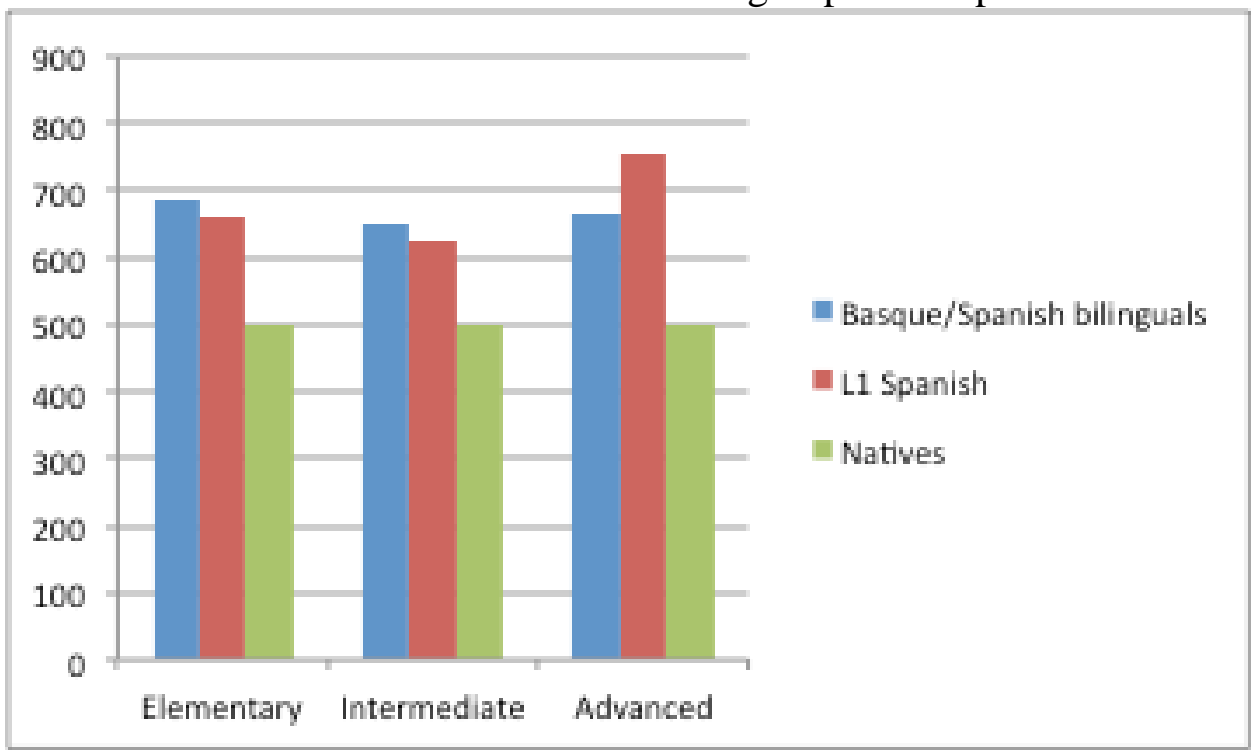

In terms of grammaticality, participants were more accurate in evaluating grammatical sentences $(p=.001)$. The group $\mathrm{x}$ proficiency interaction displayed statistically significant effects $\left(F(2,830)=15.871 ; p<.0001 ; \boldsymbol{\eta}_{p}{ }^{2}=.04\right)$. L1 Spanish learners in lower proficiency level groups displayed longer RTs.

Furthermore, RTs were analyzed in the context interest area. A main effects were found for group $\left(F(2,830)=32.452 ; p=.018 ; \eta_{p}{ }^{2}=.16\right)$ and grammaticality $(F(2,830)=$ 8.382; $\left.p<.0001 ; \boldsymbol{\eta}_{p}{ }^{2}=.47\right)$. Pairwise comparisons with Bonferroni adjustments displayed that Basque/Spanish learners had longer RTs than L1 Spanish bilinguals $(p=.023)$ and native speakers of English ( $p<.0001)$, as shown in Figure 44:

Figure 44. Mean RTs in the native and non-native groups in the contextual interest area

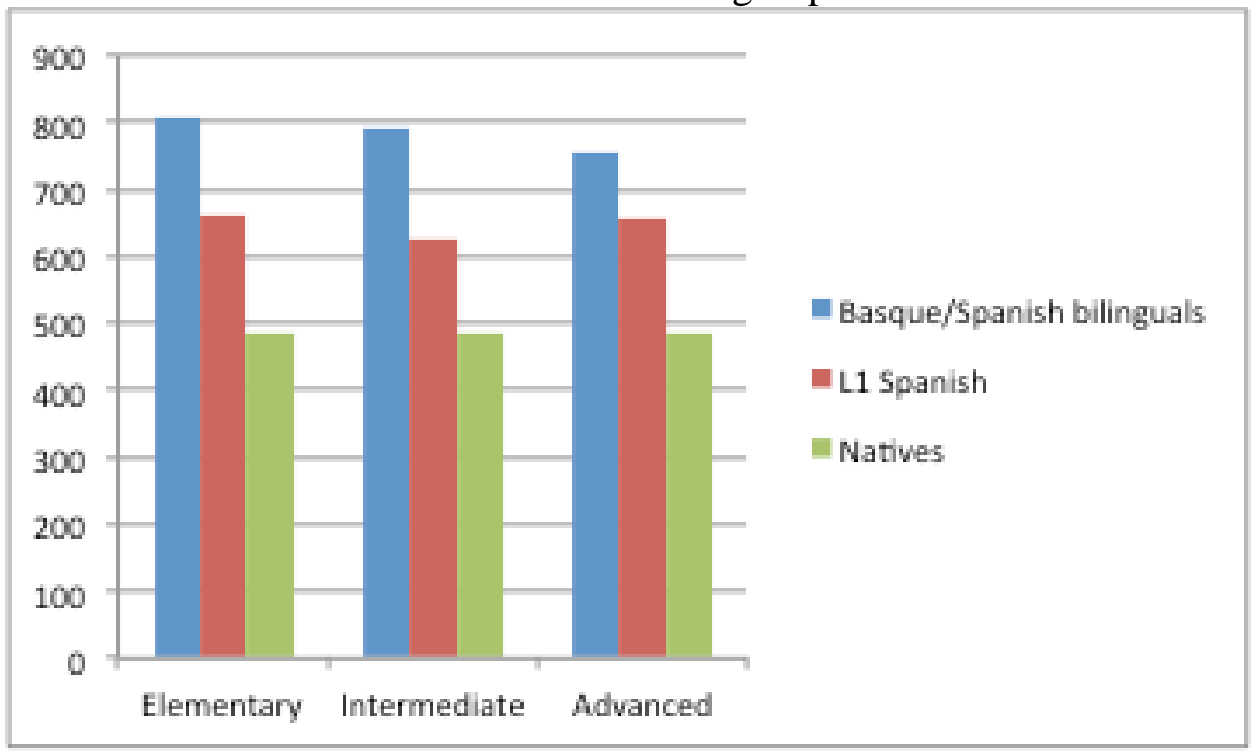


Concerning grammaticality, participants were slower in ungrammatical sentences than in grammatical contexts $(p<.0001)$. Contrasts displayed statistically significant interaction effects between group x grammaticality $\left(F(2,830)=36.641 ; p=.036 ; \boldsymbol{\eta}_{p}{ }^{2}=\right.$ .19) indicating that L1 Spanish learners needed longer RTs in ungrammatical sentences.

In the response area, main effects of group $\left(F(1,830)=5.276 ; p=.022 ; \boldsymbol{\eta}_{p}^{2}=.06\right)$, proficiency $\left(F(2,830)=14.881 ; p<.0001 ; \boldsymbol{\eta}_{p}{ }^{2}=.35\right)$ and grammaticality $(F(1,830)=$ 6.218; $p=.013 ; \eta_{p}{ }^{2}=.07$ ) were found. Post-hoc analyses with Bonferroni adjustments indicated that L1 Spanish speakers had longer reaction delays than Basque/Spanish bilinguals $(p=.050)$ and native speakers $(p<.0001)$, as illustrated in Figure 45:

Figure 45. Mean RTs in the native and non-native groups in the response interest area

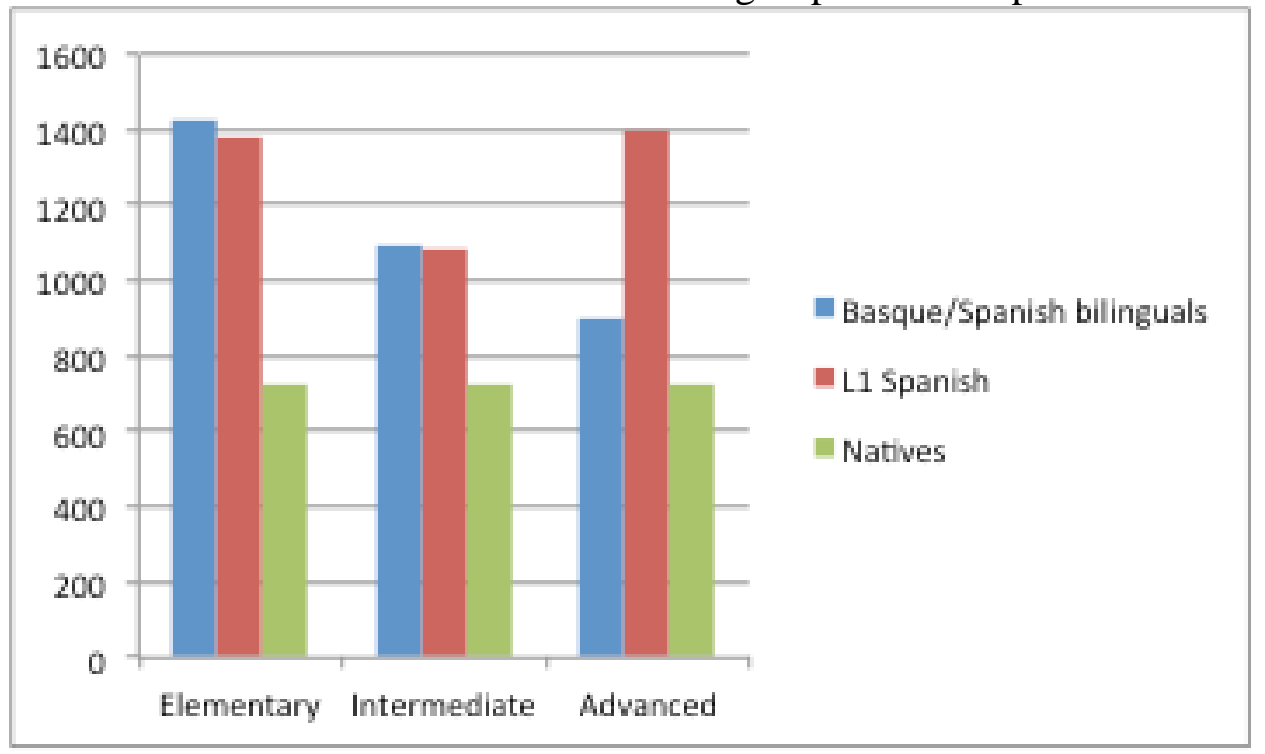

Moreover, elementary learners were significantly slower than higher proficiency learners (all $p$-values<.0001). Regarding grammaticality, participants needed longer delays in evaluating ungrammatical sentences than grammatical items $(p=.035)$. Contrasts revealed significant interaction effects between group $\mathrm{x}$ proficiency $(F$ (2, $\left.830)=8.475 ; p<.0001 ; \boldsymbol{\eta}_{\boldsymbol{p}}{ }^{2}=.20\right)$ and proficiency $\mathrm{x}$ grammaticality $(F(2,830)=8.968$; $\left.p<.0001 ; \eta_{p}{ }^{2}=.21\right)$. These findings showed that L1 Spanish learners in the lowest proficiency groups find more difficulties for evaluating especially ungrammatical sentences. 


\subsubsection{Group effects in the fill-in the gap task}

A main effect of group $\left(F(1,92)=53.846 ; p<.0001 ; \boldsymbol{\eta}^{2}{ }^{2}=.37\right)$ was found. The comparison between groups showed that Basque/Spanish bilinguals made more gender agreement errors than L1 Spanish speakers and native speakers (all $p$-values<.0001). Figure 46 displays the error rates in experimental and control groups in the fill-in the gap task.

Figure 46. Percentages of errors in the native and non-native groups in the fill-in the gap task

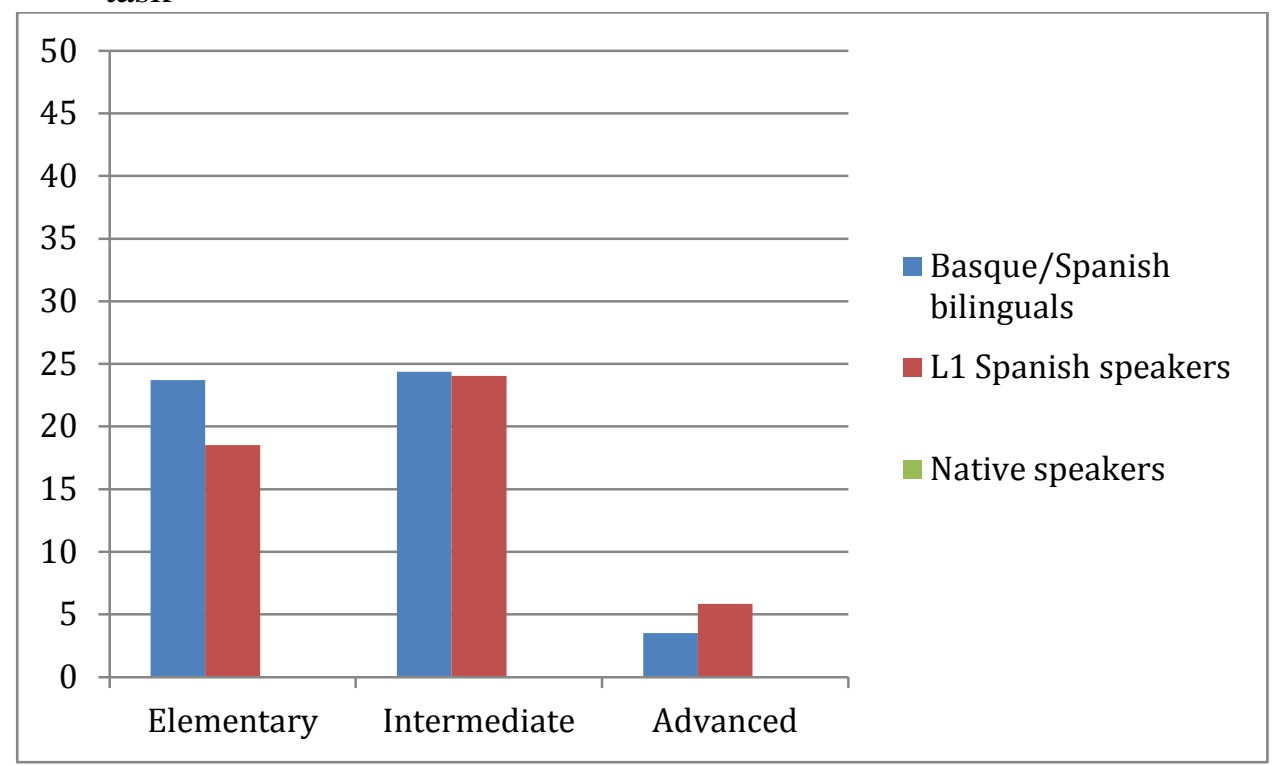

In the by-item analyses, the group $\mathrm{x}$ attraction interaction also revealed significant interaction effects $\left(F(2,92)=3.375 ; p=.039 ; \eta_{p}{ }^{2}=.68\right)$. The individual repeated measures analysis showed that non-native groups had more gender agreement errors in gender-mismatched conditions (all $p$-values $<.0001$ ), whereas no differences were found for the native speaker group. Additionally, statistically significant interactions were found between attraction x group x proficiency $\left(F(2,205)=4.220 ; p=.016 ; \eta_{p}{ }^{2}=.63\right)$. Therefore, this contrast showed that intermediate Basque/Spanish bilinguals made more errors in establishing gender agreement in inanimate gender-mismatched conditions (all $p$-values $<.0001)$. 


\subsubsection{Group effects in the written description task}

A main effect of group $\left(F(1,205)=3.536 ; p=.049 ; \boldsymbol{\eta}_{\boldsymbol{p}}{ }^{2}=.06\right)$ was found. Post-hoc Bonferroni tests revealed that Basque/Spanish bilinguals made more errors in comparison to L1 Spanish speakers and native speakers (all $p$-values $<.0001$ ). Figure 47 illustrates the error percentages in the native and non-native groups in the written description task.

Figure 47. Percentages of errors in the native and non-native groups in the written description task

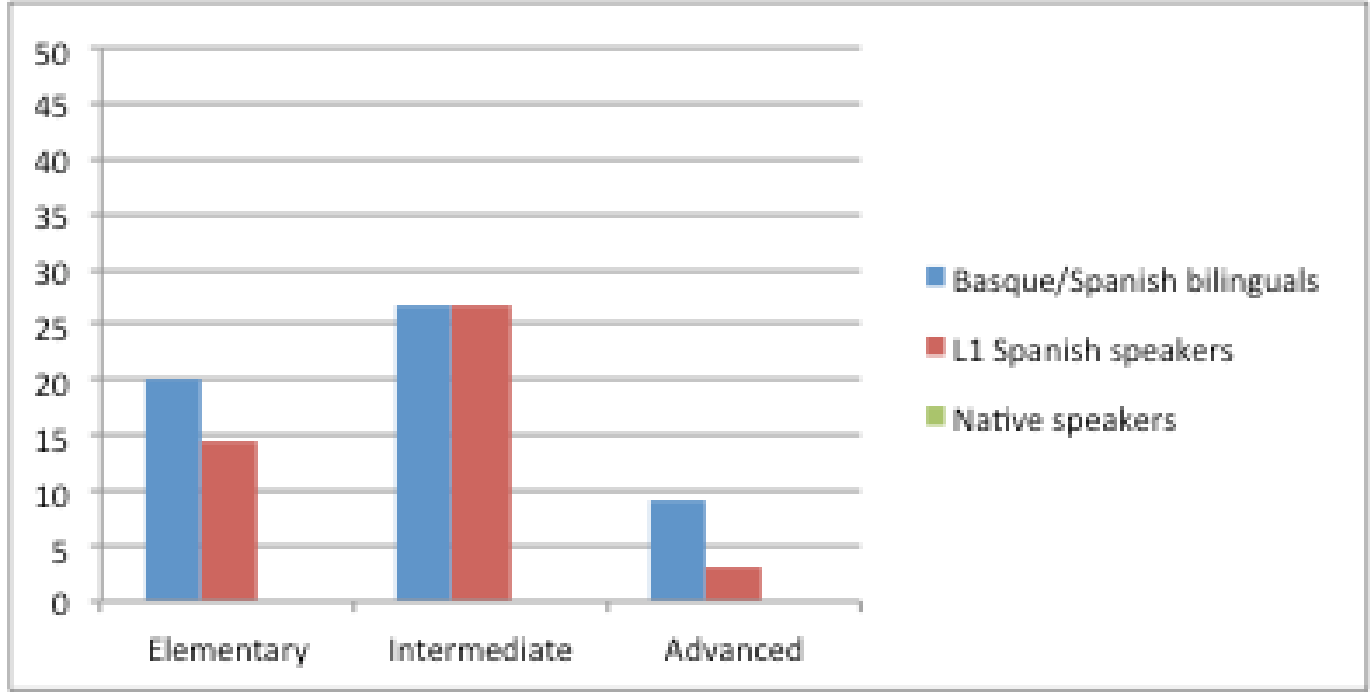

\subsubsection{Group effects in the elicitation task}

Statistically significant main effects were found for group $(F(1,138)=506.124$; $p<.0001 ; \eta_{p}{ }^{2}=.79$ ). Pairwise comparison between experimental groups and the native speaker group indicated that Basque/Spanish bilinguals showed more difficulties than L1 Spanish learners and native speakers in establishing gender agreement (all $p$ values<.0001), as shown in Figure 48: 
Figure 48. Percentages of errors in the three proficiency levels in the elicitation task

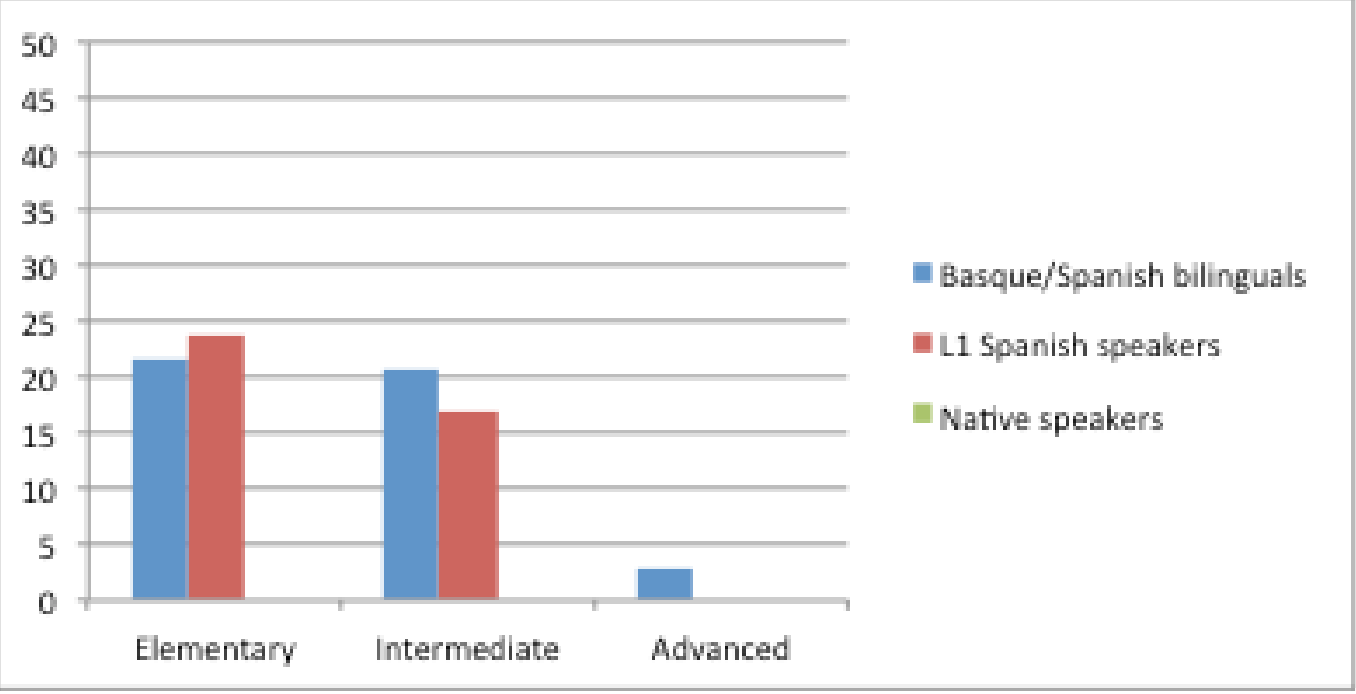

Contrasts revealed statistically significant interaction effects for group x animacy ( $F(2$, 410) $\left.\left.=33.180 ; p<.0001 ; \boldsymbol{\eta}_{p}{ }^{2}=.33\right) ;\left(F(1,138)=9.959 ; p=.002 ; \boldsymbol{\eta}_{p}{ }^{2}=.67\right)\right)$, group $\mathrm{x}$ attraction $\left(\left(F(1,205)=10.559 ; p=.001 ; \eta_{p}{ }^{2}=.58\right) ;\left(F(1,138)=20.101 ; p<.0001 ; \eta_{p}{ }^{2}\right.\right.$ $=.23)$ ) in the by-subject and by-item analyses. Individual repeated measures analyses on each contrast revealed that Basque/Spanish bilinguals had more difficulties in animate conditions in comparison to control groups (all $p$-values $<.0001$ ). Additionally, there were significant interaction effects between attraction $\mathrm{x}$ group $\mathrm{x}$ proficiency $((F$ $\left.\left.(2,205)=4.625 ; p=.011 ; \eta_{p}{ }^{2}=.63\right) ;\left(F(4,276)=4.063 ; p=.003 ; \boldsymbol{\eta}_{p}{ }^{2}=.56\right)\right)$ and between animacy x attraction x group $\left(\left(F(2,410)=6.632 ; p=.001 ; \boldsymbol{\eta}_{p}{ }^{2}=.20\right) ;(F(1\right.$, 138) $\left.=9.127 ; p<.0001 ; \boldsymbol{\eta}_{\boldsymbol{p}}{ }^{2}=.12\right)$ in the by-subject and by-item analyses indicating agreement error rates were different in animate gender-mismatched conditions depending on the group and the proficiency level these participants had. Moreover, contrasts in the by-subject analyses revealed significant interaction effects between animacy x group x proficiency $\left(F(4,410)=8.647 ; p<.0001 ; \boldsymbol{\eta}_{p}{ }^{2}=.40\right)$. These contrasts indicated that proficiency had a strong impact on establishing accurate gender agreement in animate ( $p$-values $<.0001)$ and animate gender-mismatched contexts (all $p$ values $<.0001)$.

\subsubsection{Group effects in the picture description task}

A main effect of group $\left(F(1,205)=2.831 ; p=.044 ; \eta_{p}{ }^{2}=.18\right)$ was found in this task. Post-hoc Bonferroni comparisons indicated statistically significant differences between Basque/Spanish bilinguals and L1 Spnaish speakers as well as native speakers (all $p$ values $<.0001$ ), as illustrated in Figure 49 . 
Figure 49. Percentages of errors in the three proficiency levels in the picture description task

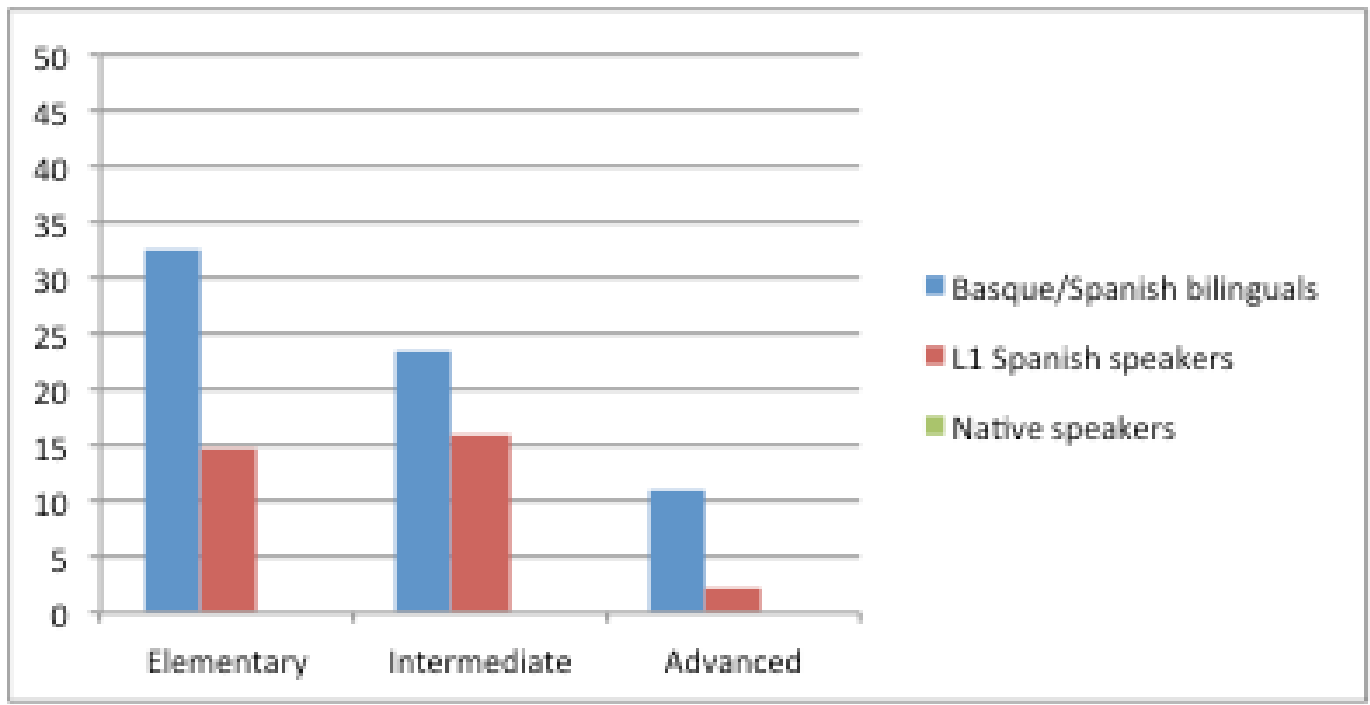

\subsubsection{Summary of the main findings for group effects}

Overall, findings indicated that Basque/Spanish bilinguals displayed higher error rates than L1 Spanish speakers and native speakers across tasks. Even though L1 Spanish speakers showed more errors in some tasks and at a certain proficiency level, overall these learners were more accurate than Basque/Spanish bilingual speakers. Similar results were found in accuracy and RT analyses. In general, Basque/Spanish bilingual learners showed longer reaction delays than L1 Spanish speakers across tasks. However, in the L1 Spanish advanced group, learners showed longer latencies than Basque/Spanish bilinguals. Nonetheless, none of the non-native groups achieved nativelike accuracy in any of the tasks.

\subsection{Summary of the results}

\subsubsection{Main results regarding linguistic conditions}

The comparison of the use of incorrect gender agreement in each linguistic condition assessed whether learners showed difficulties in animacy contexts and whether there were gender attraction effects (Hypothesis 1). What follows is a summary of the main findings in terms of linguistic conditions:

o Learners were less accurate in animate nouns than in inanimate nouns in the three proficiency groups especially in spontaneous production tasks (i.e. written 
description task, oral elicitation task and oral picture description task) in both non-native learner groups.

o However, RT data did not indicate differences between animate and inanimate nouns.

o In gender-mismatched contexts, both non-native groups displayed gender attraction effects in the three proficiency groups.

o In gender-mismatched contexts, Basque/Spanish bilinguals make more gender agreement errors in inanimate nouns in comprehension tasks whereas in production tasks learners were less accurate in establishing gender agreement in animate conditions. In contrast, L1 Spanish learners only showed problems in the inanimate condition across tasks.

o In fact, learners showed slower reaction delays in gender-mismatched conditions than in gender-matched conditions.

o Regarding the preferences of default forms, Basque/Spanish bilinguals showed preferences for the feminine default form but only in the BATXI group whereas L1 Spanish learners showed clear preferences for the masculine form in the three proficiency groups. In the DBH and the UNI Basque/Spanish bilingual groups no preferences for a default form were found.

These findings seem to indicate that animacy and gender attraction effects play a role when Basque/Spanish and Spanish learners of English established gender agreement in English. On the one hand, animacy effects seem to be closely related to spontaneous tasks although these effects are not reflected in RT data. On the other hand, findings in mismatched conditions show different patterns in both non-native groups. Basque/Spanish bilinguals show animacy effects in production tasks whereas in comprehension tasks learners show more difficulties in inanimate nouns across tasks. Besides, these difficulties are also found in the online task. Nevertheless, variability among conditions was found. On the other hand, the L1 Spanish groups also showed gender attraction effects in the three proficiency groups, mainly in the inanimate conditions. In gender-matched conditions, clear preferences for a masculine default form were found in the L1 Spanish group. 


\subsubsection{Main results regarding task effects}

Results obtained in each experimental task were compared in order to examine whether differences were found in the accuracy of gender agreement (Hypothesis 2). In what follows, the most relevant findings are summarized:

o In the three proficiency levels of both non-native groups, learners were more accurate in comprehension and written production tasks than in oral production tasks.

o Error percentages were above $10 \%$ in all tasks for Basque/Spanish bilinguals in the three proficiency groups.

o In contrast, L1 Spanish learners in the advanced group achieved an accuracy rate above $90 \%$ in all tasks.

o The PST and the GJT were the easiest tasks for learners, in the MW and the FIG task participants had some difficulties but the WDT, the ET and the PDT were the most problematic tasks for learners when establishing gender agreement.

Even though all non-native learner groups were more accurate in comprehension tasks than in production tasks, accuracy rates for L1 Spanish are higher than for Basque/Spanish bilinguals. However, task differences do not seem to be explained just by the comprehension vs. production dichotomy.

\subsubsection{Main results regarding proficiency effects}

Data in each proficiency group were compared as to general agreement patterns (Hypothesis 3). The main findings of this comparison are as follows:

o Elementary learners made more errors in obligatory contexts in both non-native groups. However, difficulties in establishing gender agreement seem to be overcome by increasing proficiency.

o Concerning the first stages in the acquisition of third person singular possessive adjectives, the percentage of use of developmental errors and gender agreement errors is similar in elementary learners from both nonnative groups. However, in intermediate and in advanced learners the percentage of developmental errors decreased. 
o Basque/Spanish learners made more developmental errors than L1 Spanish learners.

Strong correlations were found between proficiency and accuracy, mainly in the Basque/Spanish bilingual group, fewer errors were found as proficiency increased. Besides, proficiency seems to have an important (but not unique) role in the use of developmental errors as lower proficiency learners made more gender agreement errors but this difficulty was overcome as proficiency increased.

\subsubsection{Main results regarding transfer effects and developing interlanguage}

Findings in the use of gender agreement in the non-native groups were compared to the use of third person singular possessive adjective by native speakers of English in order to examine whether non-native learners were able to attain native-like accuracy. On the other hand, both non-native groups were contrasted to explore the role of transfer for L2 and for L3 learners. Next, the most relevant findings are outlined:

o Basque/Spanish bilingual learners did not achieve native-like accuracy in any of the three proficiency groups in each of the linguistic condition or across-tasks.

o Overall, Basque/Spanish bilingual learners showed more difficulties then L1 Spanish speakers.

o In terms of transfer effects, Basque/Spanish learners had more difficulties with animate nouns as well as with gender-mismatched contexts. In contrast, L1 Spanish learners had problems in gender-mismatched contexts only.

o Transfer effects were also found in the first stages, Basque/Spanish learners seem to display more developmental errors than L1 Spanish learners.

o RT data indicated that Basque/Spanish bilinguals exhibited longer reaction delays than L1 Spanish speakers, especially in the lower proficiency levels. However, in the advanced group L1 Spanish speakers seem to display longer RTs.

The findings from the comparison between experimental and control groups revealed that Basque/Spanish bilinguals did not achieve native-like accuracy in any of the conditions whereas advanced L1 Spanish learners revealed accuracy levels similar to those of native speakers. Besides, results indicated that Basque/Spanish learners show 
both animacy and gender attraction effects whereas L1 Spanish learners mainly display problems having to do with attraction effects.

In Chapter 6 the results presented in this chapter will be discussed in light of the hypotheses entertained in Chapter 3. 


\section{CHAPTER 6. DISCUSSION}

This chapter summarizes the main findings reported in the previous chapter in the light of the research questions and hypotheses entertained Chapter 4. Thus, in Section 6.1 I will begin by providing a general picture of the use of (in)accurate third person pronouns as well as possessive adjectives by non-native speakers of English. Then the reader will be reminded of the research questions and each of the following sections will concentrate on answearing each of them. Thus, the rest of the chapter is organized as follows: Section 0 outlines the main predictions of the hypotheses (repeated for the reader's convenience). Section 6.3 deals with the hypothesis for RQ1 in terms of animacy and gender attraction effects. Section 6.4 considers the result obtained across tasks under RQ 2. Section 6.5 analyzes the results of RQ 3 for proficiency effects. Section 6.6 discussed the main hypothesis in terms of RQ 4 on transfer effects.

\subsection{Third person pronouns: omission vs. commission errors}

Results regarding the use of third person singular subject and object pronouns as well as of possessive adjectives displayed quite low inaccuracy rates in subject and object pronouns in both nonnative groups. However, in possessive adjectives the error rate was above $40 \%$ for Basque/Spanish bilinguals and above 25\% for L1 Spanish learners. As in previous evidence from Catalan/Spanish (Muñoz, 1991, 1994) and French learners (White and Ranta, 2002; White et al. 2007), variability was found when subject and object pronouns were compared to possessive adjectives. In generative L2 acquisition studies, error rates above $10 \%$ in nonnative speakers are considered to be due to some sort of deficit or failure with gender agreement (Franceschina, 2005; Montrul et al. 2007). Since percentages in gender agreement errors are above $10 \%$ in both nonnative groups, findings seem to point to a problem with the reassembling of features. The nature of this failure does not seem to be either at the representation level (Hawkins and Hattori, 2006) or the computation level (White et al. 2004). Rather findings seem to point to a feature reassembly difficulty (Lardiere, 1998, 2000, 2009). The fact that gender in English is an interpretable feature and that the percentage of agreement errors is over $10 \%$ indicates that nonnative learners had difficulties in acquiring these features. 


\subsection{Summary of research questions and hypotheses}

In this section, the four hypotheses entertained in Chapter 4 will be repeated for the reader's convenience and the main finding from the experimental study will be reported and analyzed.

Hypothesis 1: regarding animacy effects, it was hypothesized that learners would make more errors in establishing gender agreement in DPs containing an animate possessee than an inanimate one. Previous studies with L2 English (Antón-Méndez, 2010) and with L2 Spanish (Sagarra and Herschensohn, 2011) completing online comprehension tasks have also reported this finding. Concerning the effect of the grammatical gender of the Spanish equivalent noun or 'gender attraction effects', previous research found these effects in the production of L2 and L3 English possessives (Imaz Agirre and García Mayo, 2013; Santesteban et al. 2010).

Hypothesis 2: the RDH claims that when acquiring an uninterpretable gender feature that is available from the L1, there should not be any task effect in the comprehension and production to L2 learners. Computational approaches, however, suggest that, due to communication pressure, learners will have problems in oral production (McCarthy, 2008; White et al. 2004). But these claims are made only for uninterpretable features whereas interpretable features (i.e. gender in English) are claimed to be fully acquirable. On the other hand, the FRH advocates that all features are available for L2 learners. Hence, despite for different underlying reasons, RDH and computational hypotheses claim that learners should not have any problem in either task type (comprehension and production) whereas the FRH posits production to be more demanding for feature reassembly.

Hypothesis 3: The influence of proficiency may be relevant in minimal input contexts (White et al., 2004), like the one these learners are in. We expected advanced learners to outperform intermediate and elementary learners in establishing correct gender agreement. Besides, participants were expected to follow the developmental sequence for the acquisition of third person singular possessive adjectives found by previous research (White and Ranta, 2002; White et al. 2007).

Hypothesis 4: Neither Basque nor Spanish display gender features in third person singular possessive adjectives. However, in Basque, like in, English, gender is 
represented in animate nouns and possession is established with the possessor. Among the L3 models, the CEM predicts positive transfer from Basque for Basque/Spanish bilinguals learning L3 English. On the other hand, based on four cues for perceiving language distance, the TPM advocates for the need of (psycho-)typology in order for transfer to occur though this may not be always beneficial. Based on economical reasons, Basque/Spanish bilingual learners are expected to perceive Spanish as being more proximate to English than Basque. Therefore, transfer from Spanish is expected to be holistic (and not structure dependent) and thus, facilitative transfer in the initial stages of L3 acquisition when the proximity relation is established. Moreover, previous research has found evidence in favor of holistic facilitative transfer, in this case from Spanish.

\subsection{Discussing RQ and hypothesis 1: Animacy and attraction effects}

Results obtained in order to provide an answer for the first research question will be discussed in terms of animacy effects (section 6.3.1), gender-mismatched effects (section 6.3.2), the role of transfer in inanimate items (section 0) and the preference of a default form (section 6.3.3).

\subsubsection{Animacy}

Results showed animacy effects in the three Basque/Spanish bilingual proficiency groups. As expected, learners were more accurate in inanimate and body part conditions than in animate conditions, as shown in (30).
a. ${ }^{*}$ Tom $_{\mathbf{i}}$ is giving her daughter $\mathbf{i}$ a toy. [BS_06_DBH_ET] Animate
b. ${ }^{*}$ She $_{\mathbf{i}}$ is picking up his toy $\mathbf{i}$. [BS_22_BATXI_ET] Inanimate
c. ${ }^{*} \mathbf{H e}_{\mathbf{i}}$ is getting up her $\mathbf{a r m}_{\mathbf{i}}$. [BS_35_DBH_ET] Body part

Similar animacy effects have also been attested by Sagarra and Herschensohn (2011) for L2 learners of Spanish in previous research. Results in the three proficiency groups showed that animacy effects were mainly found in production tasks although these effects were not as clear as reported by Hopp (2007). In the moving window task, learners also seem to display difficulties in accuracy and in the RTs of the response areas. Accuracy results in this task indicated that similar error rates were found in 
animate and inanimate conditions in comparison to body part contexts. Moreover, in the fill-in the gap task, more gender agreement errors were found in the inanimate conditions. These findings mainly revealed that animacy effects are found in production tasks as opposed to comprehension tasks, where intermediate learners made a few agreement errors.

Processing studies have showed that language processing is strongly influenced by linguistic cues, which compete for the semantic and syntactic interpretation of the input in both comprehension and production. The present study only reveals animacy effects in the production data but animacy seems to be a strong cue for learners in oral production tasks. The hypothesis about the potential effect animacy may play in establishing appropriate gender agreement is confirmed in one sense since animacy effects were found for Basque/Spanish bilinguals as well as L1 Spanish learners. Previous findings showed animacy effects in online tasks and the present study has shown that those effects can also be found in offline tasks as well (Alarcón, 2010, 2011; Sagarra and Herschensohn, 2011). Nonetheless, results were not corroborated in another sense since learners did not reveal animacy effects in RTs in the moving window task. Although main animacy effects were found in the response interest area, this finding could be a reflection of the acceptability decisions participants should make. But animacy was not an intervening factor in any of the three interest areas that were analyzed. The fact that animacy did not influence reaction delays may indicate that animacy difficulties would be related to computation rather than representation. In nonnative grammars similar to the predictions made by computational accounts (White et al. 2004), learners seem to show difficulties in establishing gender agreement in both comprehension and production tasks. However, the different outcomes in animacy effects across could be indicative of the difficulties in gender agreement at a microlevel. In other words, animacy effects could be likely to emerge depending on the nature of the task.

The evidence gathered in the present study seems to show the relevance of animacy as an important linguistic cue to establish gender agreement with possessive adjectives for the two nonnative groups of learners, thus supporting previous evidence. For the acquisition of grammatical gender (i.e. Spanish as L1 and L2) both animacy and overt morphology have been found to be strong linguistic cues that aid learners in the process (Alarcón, 2010, 2011; Pérez-Pereira, 1991). L1 Spanish learners may use animacy 
and/or morphology as linguistic cues for establishing correct gender agreement. Thus, in nouns such as 'hijo' (son), animacy and overtness work together to reinforce correct gender agreement. Similarly, one might expect L2 learners to use both linguistic cues simultaneously to trigger more accuracy.

Besides, in the Basque/Spanish bilingual BATXI group, an overuse of the definite article 'the' was found in body parts. Even though the highest percentage of definite article overuse was found in this group, elementary and advanced learners also overuse the definite article in body part contexts. This overuse might have influenced the results in showing these animacy effects. A speculative interpretation could be that this finding could be influenced by the use of the definite article in Basque where the alienable/inalienable possession relationship with body parts is encoded with the definite article 'the', as in (31).

$$
\begin{aligned}
& \text { Jon-(e)k hanka hautsi du. } \\
& \text { Jon-ERG leg-DET.ABS broken.PF AUX } \\
& \text { 'John broke his leg.' }
\end{aligned}
$$

This overuse of the definite article 'the' in obligatory contexts could be seen as a transfer error from one of the learners L1s in the experimental group. Nevertheless, transfer errors will be discussed in more detail in Section 6.6.

Regarding animacy, results indicated that, on the one hand, the more spontaneous the task was the more frequent animacy effects were. Establishing gender agreement in animate contexts was more difficult in the written composition task as well as in oral tasks as opposed to comprehension tasks. On the other hand as proficiency increases, the use of inaccurate gender agreement forms in animate conditions decreases. Previous research only showed evidence for animacy effects in online and offline comprehension tasks with L2 learners of Spanish (Sagarra and Herschensohn, 2011). However, the results in the present study did not show any animacy effect in reaction times, as found for L2 Spanish learners. 
The findings indicate that:

- Experimental Basque/Spanish bilingual groups as well as control L1 Spanish speakers showed overall animacy effects.

- Learners in the L3 and in the L2 groups revealed higher accuracy rates in comprehension tasks than in production tasks.

\subsubsection{Gender-mismatched contexts}

Gender attraction effects were found in the three Basque/Spanish bilingual groups as had been previously found by Meyer and Bock (1999) and Santesteban et al. (2010). Gender-attraction effects were found in the three proficiency groups and across tasks. These effects were especially remarkable in the elementary and the intermediate groups. Consider the examples in (32).
a. ${ }^{*} \boldsymbol{J}_{\boldsymbol{H}} \boldsymbol{h}_{\boldsymbol{i}}$ was saying bye to her mother $_{\mathbf{i}}$ [BS_19_DBH_WDT]
b. ${ }^{*} \boldsymbol{H} \boldsymbol{e}_{\boldsymbol{i}}$ starts walking with her sister $_{\boldsymbol{i}}$ to the mountain. [BS_01_BATXI_WDT]

In the most proficient group, however, attraction effects were more often found in production tasks. In fact, as reported for animacy effects, learners in the UNI group showed difficulties in establishing accurate gender agreement when the gender of the possessor and the one of the possessee did not coincide, as shown in (33).

(33) a. The dog gets out very excited from the sack but the girl $_{\boldsymbol{i}}$ and his brother $_{\boldsymbol{i}}$ has nothing to eat. [BS_14_UNI_WDT]

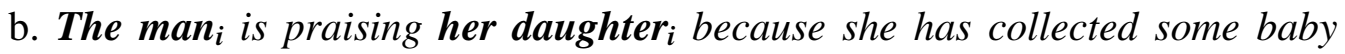
frogs. [BS_15_UNI_PDT]

Data from L1 Spanish control groups corroborated the findings of Basque/Spanish bilinguals since L2 learners also showed difficulties caused by gender-attraction acrosstasks. Besides, lower proficiency groups seem to have more difficulties than higher proficiency learners. However, the L1 Spanish UNI learners had difficulties in the picture selection task and the fill-in the gap task as well as in the oral production tasks.

RT data also illustrated longer latencies in gender-mismatched conditions than in gender-matched contexts indicating learners’ difficulty in identifying ungrammatical 
forms in the former contexts. Nonetheless, the comparison of latencies only showed significant effects in the DBH group. These same effects were also found for L1 Spanish learners. RTs were significantly slower in gender-mismatched conditions indicating clear gender attraction effects in response interest areas.

The findings in the present study seem to go in line with previous data since Basque/Spanish learners seem to feature gender-attraction effects (Santesteban et al. 2010). However, the present study also demonstrates that these effects are found in both comprehension and production tasks, mainly at the lower proficiency levels. At this stage, learners seem to have problems establishing the correct directionality or establishing local agreement with the possessee. In order to identify the nature of the attraction effects animate and inanimate contexts were compared. Findings in the DBH and the BATXI groups of Basque/Spanish bilinguals indicated that they made more agreement errors in comprehension tasks (in the grammaticality judgment task and the moving window task) whereas in production animate conditions posed more difficulties in written and oral tasks. In the L1 Spanish group at the same proficiency level, errors were found in inanimate conditions. Similarly, in the UNI group results indicated that Basque/Spanish learners showed more difficulties in inanimate conditions in the comprehension tasks whereas animacy effects were found in animate contexts. On the other hand, L1 Spanish errors in inanimate errors were found in comprehension, written production as well as oral production.

Hence, Basque/Spanish learners seem to establish incorrect agreement in animate conditions as well as inanimate contexts. This may indicate that bilingual learners transfer the grammatical gender of the Spanish equivalent noun to English.

\subsubsection{Inanimacy effects}

Animacy effects in the gender-mismatched conditions revealed that learners transfer the grammatical gender of the Spanish equivalent noun, as illustrated in (34).

(34) a. Ana preparing the sandwich with his brother $_{i}$ Jon. [BS_01_DBH_WDT]

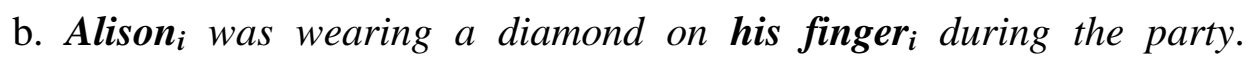
[BS_14_BATXI_FIG]

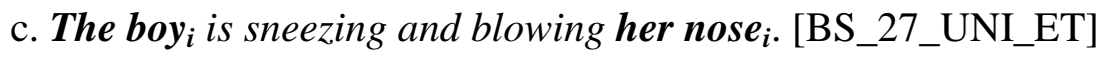


Basque/Spanish bilingual learners in the three proficiency groups showed more gender agreement problems in inanimate contexts in comprehension tasks whereas animacy effects were found in oral production tasks. However, in the L1 Spanish group, learners transferred the grammatical gender of the Spanish equivalent noun in order to establish gender agreement with the possessee. This same effect was found in the general use of possessive adjectives in the three proficiency groups.

Basque/Spanish bilinguals seem to establish gender agreement with the grammatical gender of the Spanish equivalent noun. L1 Spanish learners showed more problems in establishing gender agreement in inanimate nouns no matter the task type. However, L1 Spanish learners transfer the value of the grammatical gender in both comprehension and production tasks. Although in previous research by Antón-Méndez (2011) no evidence for the interaction between inanimate conditions and transfer of the grammatical gender was attested, the findings in the present study seem to show a clear effect of the grammatical gender of the Spanish equivalent noun. In fact, these effects seem to be stronger in L1 Spanish groups since in learners in the three proficiency groups learners made more gender agreement errors in inanimate contexts in the general use.

Basque/Spanish learners showed animacy effects mainly in oral production tasks. Previous findings revealed animacy effects in online comprehension tasks for L2 learners of Spanish (Sagarra and Herschensohn, 2011, 2013). The present results showed a strong relationship between animacy and production for bilingual learners. These effects between animacy and production were not so clear for L1 Spanish learners though. These differences were only found in spontaneous tasks in the lower proficiency groups.

To our knowledge this type of transfer of the grammatical gender of the Spanish equivalent noun has not been attested in the literature of second or third language acquisition of English. Thus, the present dissertation makes an important contribution by identifying the transfer of the grammatical gender of the Spanish equivalent noun into English. Apparently, these agreement errors may be an indication of transfer of the Spanish directionality agreement pattern ('forward agreement') to English as L2 and L3 learners established gender agreement with the possessee instead of with the possessor. Nonetheless, these gender attraction effects may not only be an instance of transfer of 
the Spanish agreement pattern because errors were found in animate conditions but also in inanimate and body part contexts. These findings seem to corroborate previous research by Morales et al (2014) in the sense that learners seem to transfer the gender feature of the equivalent noun from Spanish into English in order to establish gender agreement.

A possible explanation of the data couched in generative terms would be as follows: within the MP (Chomsky, 2000, 2001) agreement relations are said to result from the syntactic operation Agree, which operates on two elements. One of these elements bears a probe (an uninterpretable feature) while the other bears a goal (an interpretable feature counterpart). In order for syntactic structures to be interpreted in the semantic component of the grammar, all uninterpretable features must be eliminated. In order for the morphophonological component to interpret syntactic structure, all uninterpretable features must acquire values. The Agree operation has been claimed to consist of two suboperations: search and value. Search identifies the feature closest to the probe which matches the feature type, where closeness is defined as minimal structural distance. The domain to which search applies is the constituent with which the head bearing the probe undergoes merge. The value suboperation identifies the value of the goal feature as the value of the probe feature.

Assuming the syntactic structure that projects a FP for possessives as in Bernstein and Tortora (2005), the specifier FP position would be the 'goal' and the head F would be the 'probe'. The probe contains the $\Phi$ features in order to establish agreement via operation AGREE. As proposed in current Minimalism, the $\Phi$ features should be checked and deleted. Bernstein and Tortora (2005) proposed that possessives in English project an FP that contains a bundle of $\Phi$ features on the F. We claim that the difficulties learners in the experimental groups show seem to emerge with these two suboperations. When learners should establish the search operation, they undergo the agreement relationship by means of a c-command relationship and value the $\Phi$ features of the $\mathrm{F}$ with the features of the lexical item instead of establishing upward agreement with the possessor. Since the search operation is established via c-command, the participants in the present study value the $\Phi$ features of the $F$ with the features of the possessee. In consequence, learners value the features of the possessive with the features of the animate lexical item. Moreover, as English inanimate nouns are not 
classified in terms of gender, participants seem to transfer or assign the gender features of the Spanish equivalent nouns, as illustrated in Figure 50:

Figure 50. Syntactic representation of gender agreement for the participants

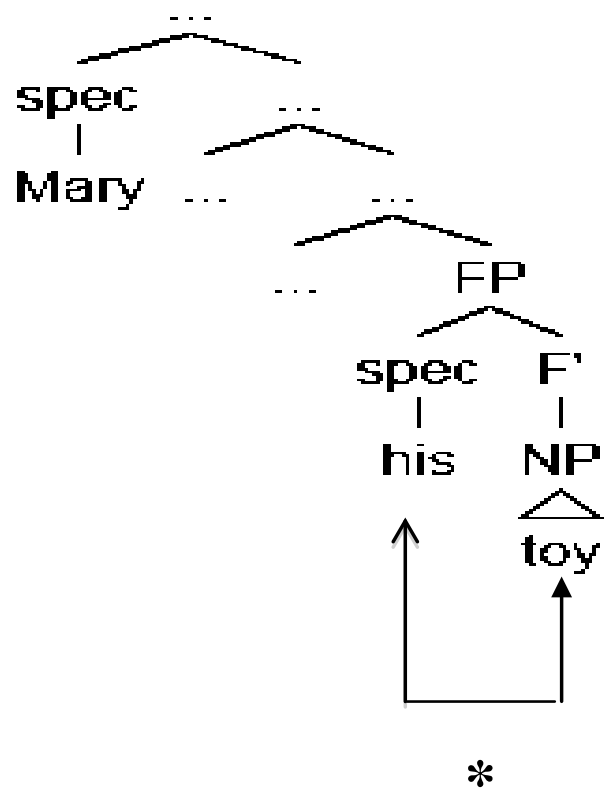

Learners in both nonnative groups needed to assign the features of the Spanish equivalent noun in order to have a lexical item with which the $\Phi$ features could be checked and deleted. The strategy of assigning the phonetically unrelated features, (not phonetically realized) of the Spanish equivalent noun to the genderless language (i.e. Basque or English) has also been a recurrent explanation in mixed DPs by Basque/Spanish and Spanish/English bilingual speakers (Ezeizabarrena, 2004; Liceras et al. 2005; Liceras et al. 2008; Manterola \& Ezeizabarrena, 2004; Parafita Couto et al. 2015; Spradlin et al. 2003). These bilingual speakers establish agreement within the nominal domain, possibly due to either an economical motivation or the influence for Spanish.

In L1 acquisition studies, code-mixing research has also indicated a similar pattern in assigning gender values to the Basque noun preceded by the Spanish determiner with the 'analogical criterion'. This research illustrated that early Basque/Spanish and English/Spanish bilinguals showed a tendency to assign the grammatical gender value 
of the Spanish equivalent noun to Basque nouns in code-mixing (Manterola and Ezeizabarrena, 2005; Larrañaga and Guijarro-Fuentes, 2013; Liceras et al. 2008a).

\subsubsection{Default form}

Regarding the preference of a default form Basque/Spanish bilinguals did not show any preference for either the masculine or the feminine form in the DBH group (only in the picture description task learners showed a preference for a feminine possessive adjective) and in the UNI group. However, in the BATXI group a preference for a feminine default form was found. In contrast, findings of L1 Spanish learners revealed the use of a masculine default form in the three proficiency groups. Besides, the RT data revealed longer latencies in masculine gender-matched conditions in the online tasks that could be indicative of the use of feminine default form. L1 Spanish learners longer reaction times in feminine contexts but differences were not significant.

Previous research on the preferences of default forms had reported that L2 Romance language learners (in various L1-L2 language pairs) used the masculine form as default (cf. J. White and Ranta, 2007 and White et al. 2004). However, the present study provides no evidence for the MUH (McCarthy, 2007, 2008) since Basque/Spanish learners overgeneralized the feminine form instead of the masculine one (as predicted by this hypothesis), at least, in the DBH group (mainly in the PDT) and in the BATXI group, especially in oral production tasks. Besides, RT measurements indicated that bilingual learners showed longer latencies in masculine contexts which could be an indicative of the preference for a feminine default form, as displayed in (35).
a. The $\boldsymbol{m a n}_{\boldsymbol{i}}$ is walking in the street with her son $_{\boldsymbol{i}}$. [BS_11_BATXI_ET]
b. The $\operatorname{man}_{\boldsymbol{i}}$ is walking one place with her umbrella . $_{\text {. }}$ [BS_11_BATXI_ET]

\section{c. The boy is tying her shoe $\boldsymbol{i}_{\boldsymbol{i}}$ [BS_11_BATXI_ET]}

These findings for Basque/Spanish bilinguals seem to confirm previous evidence in Manterola and Ezeizabarrena (2005) and Larrañaga and Guijarro-Fuentes (2012) that showed an absence of a masculine default form in early L1 Basque/Spanish bilinguals. Manterola and Ezeizabarrena (2005) found a preference for a feminine default form whereas Larrañaga and Guijarro-Fuentes (2012) showed that early bilingual learners displayed individual variability in overusing either the feminine or the masculine form 
at the first stages of the occurrence of gender agreement but later on speakers showed preferences for the feminine form.

In contrast, L1 Spanish learners showed clear preferences for masculine default forms in the three proficiency groups supporting previous findings for L1 learners (Mariscal, 2008) as well as for L2 learners (Montrul et al. 2013; White et al. 2004), as shown in (36). Moreover, as found in previous research, RT delays indicated that L1 Spanish learners showed longer latencies in feminine contexts (Sagarra and Herschensohn, 2010, 2011, 2013) when compared to masculine contexts although differences were not statistically significant.

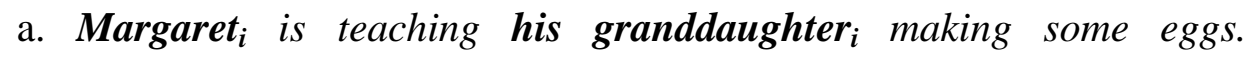
[SP_25_BATXI_ET]

b. She $_{\boldsymbol{i}}$ is celebrating his graduation $_{\boldsymbol{i}}$ [SP_25_BATXI_ET]

c. The girl $_{\boldsymbol{i}}$ handing his hand . [SP_25_BATXI_ET]

Basque/Spanish learners at lower proficiency groups did not show any preference for any of the default forms. It could be the case that learners could need a threshold of proficiency (or metalinguistic knowledge) to be able to use a default form. Besides, the lack of preference in the use of default forms could indicate that increasing proficiency has positive effects at least for Basque/Spanish bilinguals. But the fact that the three proficiency groups in the L1 Spanish group used a masculine default form discards this explanation. This problem could be related to the delay in developmental sequence in the acquisition of gender agreement by Basque/Spanish bilinguals as compared to the L1 Spanish learners. As found by Larrañaga and Guijarro-Fuentes (2012) for the acquisition of the gender feature in early bilinguals, the participants in the present study seem to show preferences for a default form later than L1 Spanish speakers. Besides, as opposed to Basque/Spanish bilinguals, L1 Spanish learners even at the UNI group showed preferences for the masculine default form.

\subsubsection{Summary of the discussion of RQ and hypothesis 1}

Animacy findings discussed under Hypothesis 1 have shown that Basque/Spanish bilingual learners show more gender agreement errors in animate contexts than in inanimate ones partially confirming previous research on this topic. However, findings indicated that animacy effects seem to be closely related to spontaneous tasks since 
more gender agreement errors were found in description tasks. But animacy effects were only found in accuracy whereas RT data did not reveal any difference between animate and inanimate contexts. An important factor that could be affecting statistical analyses could be the overuse of the definite article 'the' in obligatory body part contexts.

Moreover in gender-mismatched contexts, Basque/Spanish bilingual seem to have clear 'gender attraction effects'. In other words, the gender of the possessee noun seems to attract the agreement relationship and hence, the directionality of the agreement relationship is modified. Both non-native groups and at all proficiency levels show similar gender attraction effects. Besides, this attraction effects are also reflected in the RTs. Nonetheless, attraction effects were not only seen as a consequence of the locality effect of the natural gender of the possessee noun but were also found in inanimate and body part conditions. This indicates that learners transfer the grammatical gender of the Spanish equivalent noun to reflect this locality relationship. Moreover, findings seem to indicate clear patters since Basque/Spanish bilinguals show animacy effects in production tasks whereas attraction effects were found in comprehension tasks. In contrast, findings revealed attraction effects for L1 Spanish learners in all tasks.

Regarding the preferences of a default form, Basque/Spanish bilinguals only showed preferences for the feminine default form in the intermediate group whereas L1 Spanish learners overused the masculine default form in the three proficiency groups. Nonetheless, findings across conditions showed great variability among conditions in the three proficiency groups.

To conclude, regarding animacy effects Hypothesis 1 is partially confirmed since difficulties in animate nouns were only found in production task in the three proficiency groups. Nonetheless, Hypothesis 1 was fully confirmed in terms of gender attraction effects since these effects were found in the three proficiency groups across tasks and in every experimental condition (i.e. animate, inanimate and body part contexts). 


\subsection{Discussing RQ and hypothesis 2: Feature availability and task differences}

In this section, findings on gender agreement errors will be analyzed in light of the hypotheses that have been proposed to account for feature availability in L2 acquisition. Section 6.4.1 summarizes the main findings on comprehension and production and each feature availability account is examined. Section 6.4.2 analyzes across-task findings and section 6.4 .3 recapitulates the most relevant findings.

\subsubsection{Comprehension vs. production}

The findings of task effects revealed that Basque/Spanish learners were more accurate in comprehension than in oral production tasks as well as in written production tasks when compared to oral production tasks in the DBH and the BATXI group. Besides, results of the L1 Spanish control groups indicated similar differences in the same proficiency level groups. In the UNI group, Basque/Spanish learners were more accurate in comprehension tasks when compared to written and oral production tasks. However, in the L1 Spanish group learners showed a similar tendency in the lower proficiency groups.

\subsubsection{Representational accounts}

These approaches claims that L2 learners will not able to acquire uninterpretable features not present in their L1 whereas interpretable features are predicted to be fully acquirable. Hence, representational hypotheses (Hawkins and Hattori, 2006) do not expect any task effect when acquiring an interpretable feature, such as the gender feature in English.

Nonetheless, the present findings revealed Basque/Spanish bilinguals show persistent problems in acquiring an interpretable gender feature in L3 English, even at advanced levels of proficiency, learners' inaccuracy rate remains still above 10\%. Besides, contra predictions made by representational accounts (Hawkins and Hattori, 2006, Tsimpli and Dimitrakopoulou, 2007), proficiency and task (comprehension vs. production) seems to play a strong role in learners’ accuracy when using gender agreement appropriately. 


\subsubsection{Computational accounts}

Computational accounts claim that L2 learners will be less accurate under communication pressure situations. Previous studies showed that learners were more accurate in comprehension tasks than in production tasks, especially in oral production tasks (White et al. 2004). Nevertheless, this explanation has been provided for L2 learners acquiring uninterpretable features since interpretable features are claimed to be fully acquirable.

Findings in the present study illustrated that learners had specific problems in oral production tasks when compared to comprehension tasks. Although computational accounts hypothesize that interpretable features are fully acquirable, the acquisition of interpretable features has not been tested under these approaches yet. Results indicate that Basque/Spanish bilinguals at the three proficiency levels were more accurate in comprehension than in production tasks. Moreover, learners showed specific problems (i.e. animacy and gender attraction effects) in oral production tasks. The present data seem to support the predictions posited by computational accounts. In line with White et al. (2004), oral production tasks seem to be more challenging than comprehension tasks for non-native learners. Even though computational accounts were only claimed to account for task variability in uninterpretable features, this task effect seems to be observed for the interpretable gender feature as well.

\subsubsection{Feature Re-assembly hypothesis}

The Feature Reassembly hypothesis (Lardiere, 1998) considered that reassembling or remapping features in the L2 could be difficult for nonnative learners. The findings in the present study seem to corroborate the hypothesis put forward by Lardiere (2000). Although the mapping between semantic gender and pronominal gender in English seems to be a simple one-to-one correspondence, findings seem to corroborate that this agreement process turns out not to be so simple. As Lardiere (2000) suggested, learners seem to show difficulties in achieving the correct phonological form (PF). These problems could be due to three causes. First, syntactic computation since third person pronouns must also be assigned Case marking (apart from gender features). Second, the mapping to morphology since learners must identify an appropriate semantic feature of the corresponding discourse referent. In other words, once the derivational featurechecking occurs (or the syntax licenses case assignment) and maps the output to the 
'genitive' in the morphological component, yet another mapping is required for third person pronouns: conditioning the gender and number features. Third, other features, such as agreement in Spanish, could be conditioning the choice of the spell-out or the use of gender agreement. Hence, if this mapping fails, variability with respect to gender marking should be expected and this could account for L1 transfer. Although the English system seems to be 'simple' in principle, executing the first mapping to Case and the additional mapping to gender required for third person pronouns happens to be a layer further removed from syntactic computation. Thus, under the FRH these mappings from morphology to PF are advocated to show greatest vulnerability to fossilization effects. In this vein, the persistent gender marking errors found in the L3 IL of Basque/Spanish bilinguals seem to be indicative of these mapping difficulties. In fact, Basque/Spanish learners show Case marking problems at the lowest proficiency level. Nonetheless, this seems to be solved with increasing proficiency. In contrast, mapping to morphology and the influence of other features is found in the data in the three nonnative proficiency levels.

The findings in the present study point to the difficulties in the acquisition of the interpretable gender feature in English. Previous research by Grüter et al. (2012) claimed that an error percentage of over $10 \%$ in an advanced group would indicate a fossilization state for L2 learners. On the basis of this finding, the fact that percentages of gender agreement errors by Basque/Spanish bilinguals were $10.71 \%$ would indicate that advanced Basque/Spanish learners could have reached a fossilization stage regarding this particular target language feature. This fossilization state is also found in the most advanced group of L1 Spanish learners. If Basque/Spanish learners were at this fossilization stage, contra computational and representational approaches, this would evidence that interpretable features, similar to uninterpretable features, could undergo availability constraints. Nonetheless, the differences between comprehension and production data provide support for the computational hypothesis as well as for the FRH. Although the former hypotheses were proposed for the acquisition of uninterpretable features, the findings indicated that Basque/Spanish bilinguals in the three proficiency levels showed difficulties in establishing gender agreement in production tasks. Thus, the findings of the present study seem to confirm indirectly the claims made by the MSIH and also confirm the predcitions of the FRH. Lardiere (2009) 
claimed that mapping features in oral production could cause more difficulties than in comprehension tasks.

\subsubsection{Across-task findings}

The experimental tasks in this dissertation were designed so that tasks were organized in three groups: comprehension, written production and oral production. This distribution of tasks aimed at shedding some light on the hypothesis previously discussed in the literature but with a new combination of languages.

Across-tasks findings indicated that agreement errors in all tasks could be classified in three groups. Even though in the experimental design tasks were initially distributed in comprehension, written production and oral production tasks, agreement findings revealed a new organization of tasks for the Basque/Spanish bilingual group. First, the picture selection task and the grammaticality judgment task were the less problematic tasks in the three proficiency groups. Regardless of the proficiency level, learners in all groups obtained the highest scores in these two tasks. The fact that these tasks were untimed task and learners had no communication pressure could have made learners show higher accuracy rates. Second, learners showed similar accuracy rates in the moving window tasks as well as in the fill-in the gap task. Third, the written description task, the oral elicitation task and the picture description task were the most problematic tasks for Basque/Spanish learners. Although these tasks were untimed, the communication pressure of these spontaneous tasks seems to pose difficulties for the bilingual learners. L1 Spanish data seem to partially confirm this distribution of the experimental tasks. In the DBH group, tasks were distributed as shown for bilingual learners. However, for BATXI learners' accuracy in tasks was distributed in terms of whether the task was spontaneous or not. Besides, UNI L1 Spanish learners were highly accurate in all tasks since accuracy percentages were over $75 \%$ in all of them. Findings seem to indicate the following difficulty scale in terms of the difficulties found in the experimental tasks: 
Figure 51. Difficulty scale of the experimental tasks

\begin{tabular}{|c|c|c|}
\hline $\begin{array}{c}\text { Picture selection } \\
\text { task }\end{array}$ & $\begin{array}{c}\text { Moving window } \\
\text { task } \\
\text { Grammaticality } \\
\text { iudgment task }\end{array}$ & $\begin{array}{c}\text { Written } \\
\text { Fill-in the gap } \\
\text { task }\end{array}$ \\
description task
\end{tabular}

\subsubsection{Summary of the discussion of RQ and hypothesis 2}

In conclusion, under the representational and computational hypotheses discussed in this dissertation, no task effects should have been found since gender is an interpretable feature in English and hence, fully acquirable by L2 learners. However, findings seem to indicate that the low percentages of accuracy in the use of gender agreement in third person singular possessives and communication pressure as well as spontaneity are closely linked. Even though computational and representational accounts were posited to explain variability in the acquisition of uninterpretable features, results reported here seem to partially support computational approaches since Basque/Spanish bilinguals showed more difficulties in the two oral production tasks. In contrast, evidence illustrates that the predictions of the FRH are confirmed since difficulties in reassembling features are found in specific conditions (i.e. animacy effects in oral tasks). In fact, not all features seem to pose equal difficulties for all learners as shown by the variability between experimental conditions found in each task. Besides, advanced learners seem to be fossilized at some conditions (i.e. gender-mismatched conditions). Table 34 illustrates the summary of the predictions confirmed by the data in the present study: 
Table 34. Summary of the predictions of feature availability

\begin{tabular}{|c|c|c|c|}
\hline & FFFH/IH & MSIH & FRH \\
\hline Comprehension & $\begin{array}{l}\text { Hypotheses not } \\
\text { confirmed. } \\
\text { Learners had } \\
\text { difficulties in } \\
\text { acquiring a [+ } \\
\text { interpretable] } \\
\text { feature }\end{array}$ & $\begin{array}{l}\text { Hypotheses not } \\
\text { confirmed. } \\
\text { Learners had } \\
\text { difficulties in } \\
\text { acquiring a [+ } \\
\text { interpretable] } \\
\text { feature }\end{array}$ & $\begin{array}{c}\text { Hypotheses } \\
\text { confirmed. } \\
\text { Learners had } \\
\text { difficulties in } \\
\text { acquiring a [+ } \\
\text { interpretable] } \\
\text { feature }\end{array}$ \\
\hline $\begin{array}{c}\text { Written } \\
\text { production }\end{array}$ & $\begin{array}{l}\text { Hypotheses not } \\
\text { confirmed. } \\
\text { Learners had } \\
\text { difficulties in } \\
\text { acquiring a [+ } \\
\text { interpretable] } \\
\text { feature }\end{array}$ & $\begin{array}{l}\text { Hypotheses not } \\
\text { confirmed. } \\
\text { Learners had } \\
\text { difficulties in } \\
\text { acquiring a [+ } \\
\text { interpretable] } \\
\text { feature }\end{array}$ & $\begin{array}{l}\text { Hypotheses } \\
\text { confirmed. } \\
\text { Learners had more } \\
\text { difficulties in } \\
\text { production tasks } \\
\text { than in } \\
\text { comprehension }\end{array}$ \\
\hline Oral production & $\begin{array}{l}\text { Hypotheses not } \\
\text { confirmed. } \\
\text { Learners had } \\
\text { difficulties in } \\
\text { acquiring a [+ } \\
\text { interpretable] } \\
\text { feature }\end{array}$ & $\begin{array}{c}\text { Hypotheses not } \\
\text { confirmed. } \\
\text { Learners had } \\
\text { difficulties in } \\
\text { acquiring a [+ } \\
\text { interpretable] } \\
\text { feature. } \\
\text { Nonetheless, similar } \\
\text { to the predictions } \\
\text { with } \\
\text { [+uninterpretable] } \\
\text { features, learners } \\
\text { showed difficulties } \\
\text { in oral production } \\
\text { tasks }\end{array}$ & $\begin{array}{l}\text { Hypotheses } \\
\text { partially } \\
\text { confirmed. } \\
\text { Learners had more } \\
\text { difficulties in oral } \\
\text { production tasks } \\
\text { than in written ones } \\
\text { (the difference } \\
\text { between written vs. } \\
\text { oral is not } \\
\text { considered in the } \\
\text { FRH) }\end{array}$ \\
\hline
\end{tabular}

On the other hand, on the basis of the results found in this dissertation, the initial distribution of the experimental design was readjusted as indicated by the findings in the Basque/Spanish bilingual groups: a first group would be composed of the least spontaneous tasks (PST and GJT), a second group would be comprised of more spontaneous tasks (MW and the FIG) and a third group included the most spontaneous tasks (WDT, ET and PDT). 


\subsection{Discussing RQ and hypothesis 3: Proficiency effects}

The comparison of the three proficiency groups (i.e. elementary, intermediate and advanced groups) revealed that the level proficiency in English played a significant role in the acquisition of gender agreement in third person singular possessive adjectives. Previous findings with L2 Romance language learners (White et al. 2004) and Catalan/Spanish bilingual (Muñoz, 1991, 1994) as well as L1 French learners of English (White and Ranta, 2002; White et al. 2007) showed that proficiency played a significant role in the acquisition of morphosyntactic structures in minimal input settings. Findings in the present dissertation showed differences between advanced proficiency level learners when compared to elementary and intermediate learners. Moreover, differences between elementary and intermediate proficiency level learners revealed differences only in some tasks.

The results of Basque/Spanish bilinguals seem to confirm previous findings. Problems in establishing gender agreement seem to be overcome by increasing proficiency. However, it should be noted that Basque/Spanish bilingual learners even at the highest proficiency level have an inaccuracy rate of over $10 \%$. As has been mentioned above, according to Grüter et al. (2012), an error rate over 10\% at the higher proficiency level could be an indicative of a fossilization state or some deficient grammar.

Nevertheless, results of L1 Spanish learners did not show such a clear relationship between gender agreement errors and proficiency level. The two lower proficiency groups (i.e. the DBH and the BATXI groups) had a similar agreement error rate and no differences were found between the two groups. Although evidence from Basque/Spanish bilinguals learners did show these proficiency benefits at all stages, findings in the control group did not confirm these results, similar what Antón-Méndez (2010) reported. In order to account for this difference between experimental Basque/Spanish learners and L1 Spanish learners, it could be hypothesized that L2 and L3 learners routes and/or rates in the acquisition of gender agreement. A possible interpretation of the effect of proficiency on agreement errors could be that the developmental sequence of Basque/Spanish bilinguals slows down when compared to L1 Spanish learners. Indeed, proficiency level in English seems to be more explanatory for the Basque/Spanish bilingual groups than for the L1 Spanish learners. 


\subsubsection{First stages in the acquisition of third person singular possessive adjectives}

The use of other forms in obligatory context was considered as instances of the ongoing stages of the developmental sequence in the acquisition of third person singular possessive adjectives following the sequence proposed by J. White and Ranta (2002). The total number of errors in obligatory context as well as the percentages of gender agreement errors revealed similar percentages in both gender agreement and other error types in the $\mathrm{DBH}$ group in the Basque/Spanish bilingual groups. However, as proficiency level increases, gender agreement errors exceeded the percentage of errors in obligatory contexts both in the BATXI and in the UNI groups. These findings indicated that lower proficiency level learners still go through these stages. However, as proficiency increases, learners seem to overcome the use of other forms in obligatory contexts.

The developmental sequence followed by Basque/Spanish bilinguals in the acquisition of gender agreement seems to differ from the one proposed by J. White and Ranta (2002). L1 Spanish learners showed a higher percentage of gender agreement errors than developmental ones in the three groups. In fact, developmental errors decrease as proficiency increases. Basque/Spanish bilinguals seem to show a more gradual or progressive sequence in the developmental acquisition than L1 Spanish learners do. Even though data in the present dissertation confirm some developmental stages previously identified (i.e. omission errors or the overuse of the second person singular form), Basque/Spanish learners seem to display a wider range of developmental errors mainly in the lower proficiency groups. Besides, transfer seems to play an important role in their developmental stages. These transfer errors were only found at the lowest proficiency level and they gradually disappear as proficiency increases (i.e. the use of a definite article followed by a possessive adjective), as shown in example (37):
a. $\mathbf{H e}_{\mathbf{i}}$ is washing the his $\mathbf{s}_{\mathbf{i}}$ cloth [BS_03_BEG_ET].
b. $\mathbf{H e}_{\mathbf{i}}$ is washing his $\mathbf{i}$ cloth [BS_31_INT_ET].

But the percentage in the use of developmental errors is lower in the L1 Spanish group. This could imply that learners go through different stages in the development of the acquisition of possessive adjectives due to the typological differences between Basque and Spanish, i.e. differences in the preference of a default form. Moreover, the fact that 
bilinguals learners had knowledge of two linguistic systems as opposed to L1 learners have just one may make learners go through different stages.

Nevertheless, the developmental sequence of elementary learners in any of the nonnative learner groups may not be a clear indicative of the first stages in the acquisition of gender agreement since these learners have already been studying English for several years in a minimal input setting, although their proficiency level is still low. In order to identify a complete sequence, less proficient learners or initial state learners should have also been included in a further analysis.

\subsubsection{Summary of the discussion of RQ and hypothesis 3}

Findings concerning Hypothesis 3 have fully supported the predictions made. Proficiency is a strong factor affecting accuracy in gender agreement, confirming previous evidence on Catalan/Spanish (Muñoz, 1994) and French (White and Ranta, 2002) learners of English. In other words, fewer gender agreement errors are found as proficiency increases. However, error rates for advanced Basque/Spanish bilinguals were still above $10 \%$ which may indicate bilingual learners might have reached a fossilization stage (along the lines of Grüter et al. 2012).

Moreover, errors in obligatory context considered as developmental errors indicated that Basque/Spanish bilinguals displayed a slower developmental sequence than the one found for L1 Spanish learners because Basque/Spanish bilinguals in the first stages show transfer errors that L1 Spanish learners did not. However, these errors disappeared gradually as proficiency level increased. Basque/Spanish bilinguals at lower proficiency levels produced more other errors in obligatory context than L1 Spanish learners. Findings revealed that L1 Spanish learners followed a developmental sequence similar to the previous findings for L1 French and Catalan/Spanish bilinguals. In contrast, the stages of the Basque/Spanish bilinguals' developmental sequence does not seem to be so clear since transfer could also play a role at lower levels of proficiency.

\subsection{Discussing RQ and hypothesis 4: Transfer effects in developing interlanguages}

The aim of the present section is to discuss how transfer of the previous linguistic systems affects the acquisition of gender agreement in L3 English at different proficiency levels and to describe the acquisition process of the most advanced 
participants among the non-native learners. Thus, Section 6.6.1 examines the role of transfer in animacy and gender attraction contexts. Section 6.6.2 reviews the role of transfer in developing interlanguages.

\subsubsection{Transfer in the linguistic conditions under study: Animacy and attraction effects}

Findings in the present study revealed that Basque/Spanish bilinguals differed significantly from native speakers of English in accuracy as well as in RTs regarding the establishment of agreement in the three proficiency groups. This result provides evidence against both representational and computational accounts since Basque/Spanish bilinguals showed persistent errors even in the advanced group. Thus, it seems that the IL of Basque/Spanish bilingual learners could display some kind of deficient grammar that could not be explained by any of these two approaches. The comparison of the advanced experimental group with the non-native and the native control groups did not show clear evidence in favor or against these accounts. Nonnative learners in the elementary and in the intermediate group showed neither nativelike accuracy nor reaction delays in establishing correct gender agreement relationships. Regarding the advanced learners' group, participants showed non-native accuracy in almost every task as well slower reaction delays in the online task. However, in oral production tasks advanced learners were comparable to native speakers of English regarding accuracy. Therefore contra representational and computational accounts, which predicted native-like acquisition for interpretable features, it seems that Basque/Spanish bilinguals have persistent difficulties in acquiring the interpretable gender feature in English.

Moreover, findings revealed that Basque/Spanish bilinguals showed lower accuracy than L1 Spanish speakers. In the advanced group, L1 Spanish learners were more accurate in production tasks than Basque/Spanish bilingual learners. A tentative explanation at this point would be to suggest that since Basque/Spanish have two different linguistic systems in which gender is encoded differently, feature reassembly could be more demanding. Besides, communication pressure (maybe timing or spontaneity) in production tasks could enhance learners' difficulty in assembling features in a target-like manner in English. Hence, findings seem to support the FRH. This result was also found for the intermediate group in comprehension tasks. In the 
elementary group, L1 Spanish learners were more accurate than bilingual learners. A possible explanation for this difference could be the use of developmental errors or other forms by Basque/Spanish bilingual learners.

\subsubsection{Animacy, attraction and default forms}

Even though general findings displayed differences between non-native learners with native speakers in accuracy and RTs, transfer together with the nature of the task effects in each linguistic construct seem to pose different degrees of difficulties for non-native learners indicating that all features (i.e. linguistic conditions) are not equally problematic for L2 learners (Liceras, 2010).

Regarding animacy conditions, constrasts in the picture selection task, the fill-in the gap task and the elicitation task seem to indicate that learners in each linguistic group behave differently with regard to animacy conditions as well as attraction conditions. In these tasks, Basque/Spanish bilinguals show higher error percentages than L1 Spanish speakers and native speakers. Nonetheless, in other experimental tasks non-native learners seem to show similar interaction effects between the linguistic condition and the linguistic group.

Regarding L3 transfer models, four alternative hypotheses have been proposed in order to account for cross-linguistic influence. Nevertheless, due to the characteristics of our participants, the Absolute L1 Transfer model and the L2 Status Factor could not be considered in the present dissertation since participants in the experimental group are not successive bilinguals. Even though all participants in the Basque/Spanish bilingual group were Basque-dominant speakers, Spanish has always been present (though to a lesser degree) throughout their lives. Therefore rather than describing these participants' type of bilingualism in terms of chronology, they should be classified in terms of language dominance. Nonetheless, the absolute L1 transfer and the L2 Statuts Factor models only make predictions for transfer sources based on a chronological classification of bi-/multilinguals. Thus, only the CEM and the TPM will be discussed in this section. On the one hand, on the basis of the CEM (Flynn et al. 2004) and assuming full transfer, Basque should play a facilitative role in this case since gender is distributed similarly to English in terms of agreement directionality and the semantic/biological nature of the gender feature. However, this hypothesis does not seem to be supported with the empirical data from this study. On the other hand, the 
TPM would claim that learners that establish a typological proximity between two languages could undergo either positive or negative transfer (Rothman, 2010). Assuming this hypothesis, the difficulties these learners have in animate contexts could be explained on the basis of negative transfer. This may indicate that learners establish some kind of proximity between Spanish and English, as predicted by the TPM since both languages are typologically closer (Rothman, 2013). However, the recent version of the TPM (Rothman, 2013, 2014) advocated that transfer is not selective or structuredependent. Our findings do to seem to confirm this prediction.

Attraction effects showed that advanced learners did not reach native-like accuracy in gender-mismatched conditions. Besides, neither intermediate learners nor elementary learners reached native-like accuracy in gender-mismatched conditions. One of the major difficulties posed by transfer was found in gender-mismatched contexts in which participants across proficiency levels did not reach native-like accuracy. This might indicate the influence of Spanish syntax on English since learners seem to transfer the Spanish agreement pattern by checking the gender feature with the possessee instead of with the possessor. Similar to the findings attested by García Mayo and Slabakova (2015) and Slabakova and García Mayo (2015), Spanish seems to be playing a more prevalent role for transfer in both non-native groups.

Furthermore, animacy effects in gender-mismatched conditions could be a clearer indication of learners' transfer. In fact, findings revealed that non-native learners did not achieve native-like accuracy in almost any experimental condition. The percentage of agreement errors in comprehension tasks was above $20 \%$, which may indicate bilingual learners show some persistent fossilization errors with this specific feature. However, the comparison between the two experimental groups illustrates clear transfer patterns. The clearest example of transfer could be the gender attraction effects found with inanimate conditions in the fill-in the gap and the moving window task. Although similar attraction effects were found across tasks, errors in these tasks indicated that participants transfer the grammatical gender of the Spanish equivalent noun, as found by Morales et al. (2014).

The findings of the Basque/Spanish bilingual group on their own seem to provide partial evidence in favor of the TPM (Rothman, 2015). Even though animacy seems to be a strong cue when establishing agreement. Basque/Spanish bilinguals seem to transfer the 
Spanish agreement pattern as well as the grammatical gender of the Spanish equivalent noun. Thus, there seem to be an apparent preference to establish transfer from Spanish. Nevertheless, evidence in the present dissertation seems to indicate that transfer is not holistic but rather selective. Basque and Spanish seem to be sources of transfer for Basque/Spanish bilinguals. Further evidence in favor of selective transfer could be inferred from the comparison between the Basque/Spanish bilingual group and the L1 Spanish group. Logically speaking, Basque/Spanish bilinguals have two plausible sources of transfer, whereas L1 Spanish speakers only have one possibility. Assuming the fact that Spanish and English are the two languages that are typologically closer in this combination and that transfer is predicted to be holistic for the TPM, Spanish should be the only source of transfer for both non-native groups and therefore no differences should be expected. Due to typological distance Basque should not be an option as a source of transfer. However, the comparison between gender agreement errors in the two non-native groups revealed that Basque/Spanish bilinguals showed higher percentages of incorrect gender agreement in comparison to L1 Spanish learners. The differences between the two non-native groups may indicate that subtle typological (dis-)similarities between the three languages may affects the acquition of morphosyntactic properties in L3 irrespectively of the perceived typological distance between languages.

Moreover, proficiency seems to be a relevant factor for transfer to arise, as indicated by the contrasts across tasks between proficiency and group. Elementary and intermediate learners between learners seem to display negative transfer effects as illustrated by the percentages of gender agreement errors whereas advanced learners does not seem to show these transfer effects. The differences between proficiency levels in terms of transfer suggest that some metalinguistic knowledge could be necessary for learners to establish associations between languages.

Regarding the preference of a default form, the influence of the previous linguistic systems is significant. Non-native learners still seem to overgeneralize a default possessive form in the advanced group. In the Basque/Spanish bilingual group variability was found among subjects in comprehension as well as in production tasks. But in the L1 Spanish group learners showed preferences for the masculine default form. Although the feminine form was overused in some cases (and statistical analyses indicated significant differences were found), these preferences were not as consistent 
as for the masculine form. However, lower proficiency learners did not display nativelike accuracy in gender-matched conditions. However, the comparison of both nonnative groups revealed L1 Spanish learners' difficulties in feminine conditions, which would indicate a preference for the masculine default form (White et al. 2004). This partially confirms previous research by Zobl $(1984,1985)$ that claimed the masculine form was the unmarked, default form in English for L2 learners. Nonetheless, the fact that variability appeared in the Basque/Spanish bilingual groups may indicate that preferences for the use of default forms could also be transferred.

RT data in each interest area indicated that non-native learners did not achieve nativelike reading delays. Findings showed a qualitatively different processing pattern in native and non-native speakers. These results seem to go in line with Keating (2009) and do not seem to confirm previous evidence by Hopp (2007) and Sagarra and Herschensohn (2011). In fact, L1 Spanish speakers showed longer reaction delays in comparison to Basque/Spanish bilinguals and native speakers in all interest areas, except for the contextual interest area. Basque/Spanish bilinguals seem to show spillover effects in the contextual interest area. However, since constrasts between group and linguistic constructs were not significant, both non-native groups seem to show similar RTs in animacy and attraction conditions revealing that transfer was not reflected in the RT data.

\subsubsection{Transfer effects in the developmental stages}

Developmental stages in the acquisition of gender agreement in third person singular possessive adjectives seem to differ in organization and rates for Basque/Spanish bilingual learners as opposed to L1 Spanish learners. Basque/Spanish learners seem to follow a different developmental path from Spanish learners. L1 Spanish learners go through omission and second person overuse stages at the lower proficiency group supporting previous evidence on Catalan/Spanish as well as French learners of English (White and Ranta, 2002; White et al. 2007). Basque/Spanish learners also show these agreement errors in addition to other developmental errors that have not been attested in previous research. In fact, Basque/Spanish bilingual learners make more gender agreement errors than L1 Spanish learners. An interesting finding in the developmental errors is the fact that Basque/Spanish bilingual learners tend to overuse the first person singular possessive adjective 'my' as opposed to the L1 Spanish learners' preference to 
overgeneralize the second person possessive 'your'. Besides, Basque/Spanish learners tend to determine the possessee twice by means of a definite article followed by the possessive adjective or by using two pronouns, as shown in (38).

a. She is play with the his bear. [BS_21_DBH_ET] Two definite article

b. Baby is cry in she his mum arms. [BS_01_DBH_PDT]Two pronouns

Bilingual learners seem to be transferring this structure from Basque since possessive adjectives are not in complementary distribution with definite articles, as in Spanish or English. Moreover, Basque/Spanish learners use the ' $h i r$ ' in obligatory contexts a form that could be a blending between the masculine possessive 'his' and the feminine form 'her' bilinguals use as a neuter form or genderless form in English (similar to the demonstrative 'bera' in Basque). The use of the form 'hir' could be an additional evidence for selective transfer (in this case from Basque).

Concerning animacy contexts, the preference of Basque/Spanish learners for the use of the definite determiner the instead of possessive adjectives in obligatory contexts in body part conditions over the L1 Spanish could also be considered a transfer issue. Findings indicated that both non-native groups used the definite article the in obligatory contexts since in both languages definite article are used to express an inalienable body part possession relationship. However, bilingual learners overused this form in obligatory contexts. The lack of grammatical gender in Basque as well as the fact that definite articles encode body part relationships could be possible sources for the transfer of this preference.

Summarizing, due to the difficulties in reassembling features in English, these bilingual learners could resort to some alternatives, such as transfer from both previous systems, to overcome their problems with gender agreement. Unlike L1 Spanish learners, Basque/Spanish participants rely on transfer at low and intermediate levels of proficiency and this causes bilinguals to display a slower developmental rate.

\subsubsection{Summary of the discussion of RQ and hypothesis 4}

Results on transfer discussed under Hypothesis 4 indicated that Basque/Spanish bilinguals did not show native-like accuracy in any of the proficiency groups. Even though non-native learners did not exhibit native-like accuracy, general RT data reflected learners had similar response delays as native speakers have. This would imply 
non-native learners would be able to achieve native-like processing of gender agreement in English. Nevertheless, a more detailed analysis displayed learners processing could be qualitatively different at specific interest areas.

L2 feature availability accounts predict that L2 learners should not support the claims made by computational and representational accounts since non-native learners were expected to show native-like accuracy in the acquisition of [+interpretable] gender feature in English (Clashen and Felser, 2006). In fact, evidence reported in the present dissertation show that claims of the computational and representational hypotheses are not supported. But the difficulties in establishing gender agreement seem to confirm the predictions made by the FRH. Nevertheless, the linguistic aspects examined in the present study pose difficulties at different degrees. Variability accounts proposed for L2 acquisition could also explain L3 acquisition data.

The differences between non-native groups in each condition (i.e. animacy, gendermismatched and default) indicate that transfer is reflected differently for Basque/Spanish bilinguals and L1 Spanish learners. In light of L3 models, evidence in the present dissertation does not provide support to the CEM or the TPM. The predictions of the CEM are not confirmed since Basque does not provide facilitative transfer to L3 learners. As predicted by the TPM non-facilitative transfer was found and Spanish was one of the sources of transfer. Nevertheless, transfer was not holistic and Spanish was not the only source of transfer since Basque also displayed an important role when establishing gender agreement. Table 35 summarizes the predictions that are confirmed under the L3 models. 
Table 35. Summary of the predictions of L3 models

\begin{tabular}{|c|c|c|c|c|}
\hline & $\begin{array}{c}\text { Absolute } \\
\text { L1 } \\
\text { transfer }\end{array}$ & L2 Status & CEM & TPM \\
\hline $\begin{array}{c}\text { Animacy, } \\
\text { attraction and } \\
\text { default forms }\end{array}$ & $\begin{array}{c}\text { Not } \\
\text { applicable } \\
\text { because } \\
\text { participants } \\
\text { are not } \\
\text { successive } \\
\text { bilinguals }\end{array}$ & $\begin{array}{l}\text { Not applicable } \\
\text { because } \\
\text { participants are } \\
\text { not successive } \\
\text { bilinguals }\end{array}$ & $\begin{array}{l}\text { Hypothesis not } \\
\text { confirmed. } \\
\text { Transfer is not } \\
\text { facilitative, } \\
\text { though it occurs } \\
\text { in developing } \\
\text { interlanguages } \\
\text { (as predicted by } \\
\text { the CEM) }\end{array}$ & $\begin{array}{c}\text { Hypothesis } \\
\text { partially } \\
\text { confirmed. } \\
\text { Transfer is } \\
\text { found to be } \\
\text { negative. } \\
\text { However, } \\
\text { transfer seems } \\
\text { not to be } \\
\text { holistic, rather it } \\
\text { seems to be } \\
\text { selective or } \\
\text { based on } \\
\text { underlying } \\
\text { similarities } \\
\text { between } \\
\text { languages }\end{array}$ \\
\hline
\end{tabular}

Besides, transfer effects are also found in the first stages of the developmental sequence of these non-native learners. Basque/Spanish bilinguals almost doubled the developmental error percentage when compared to L1 Spanish learners. In fact the majority of these errors (i.e. the use of two definite articles) could be attributed to Basque.

\subsection{Summary}

Summarizing, this chapter has discussed the findings of this dissertation in the light of the research questions and hypotheses posited in Chapter 4. The first section presented the persistent problems Basque/Spanish bilinguals have in establishing gender agreement in possessive adjectives when compared to gender assignment in subject and object pronouns. The L3 data in this dissertation offered a new panorama in the debate of feature availability in generative linguistics. To date feature availability accounts were not discussed with a combination of three languages. Most previous research only considered one previous language. Findings have been discussed in the light of feature availability accounts and in fact, evidence has been found for difficulties in feature re- 
assembly. Besides, some linguistic aspects (i.e. animacy) have been identified as important factors predicting difficulties in establishing gender agreement. Not only language internal facts, but other factors, such as task, proficiency and transfer, were important factors affecting the accurate comprehension and production of gender agreement. The findings of the experimental study have illustrated that Basque/Spanish bilinguals acquiring English as an L3 had more gender agreement errors the L1 Spanish learners of L2 English. Thus, data indicate that re-assembling features in an L3 could be more demanding than in the L2 due to the impact of transfer.

In Chapter 7, the main conclusion from each research question will be drawn, some pedagogical implication will be offered, limitations of the study identified and lines for further research provided. 


\section{CHAPTER 7. CONCLUSION}

The objective of the present study was to investigate the acquisition of gender agreement with third person singular possessive adjectives (his/her) in L3 English by Basque/Spanish bilinguals. More specifically, this dissertation aimed at examining the effect of animacy and 'gender attraction effects' as well as task, proficiency and transfer in the process. Findings were collected by means of seven experimental tasks (comprehension, written production and oral production) that were specifically designed to target possessive adjectives in English. This section summarizes the general findings obtained for each research question pointed and suggests the lines for further research This chapter is organized as follows: section 7.1 features the general conclusions, section 7.2 outlines the pedagogical implications the findings in the present study might have in the EFL classroom and, finally, section 7.3 acknowledges the limitations of the study and proposes lines for further research. Section 7.4 concludes the study.

\subsection{General conclusions}

\subsubsection{Conclusions RQ 1}

The first research question, repeated here for the reader's convenience, examined the relation between the linguistic contructs, namely, animacy and gender attraction effects and the acquisition of gender agreement. RQ 1 is repeated here for the reader's convenience:

RQ 1: Does the internal structure of the DP play a role? More specifically, does the grammatical gender of the Spanish equivalent $\mathbf{N}$ and animacy have an effect on the acquisition of gender agreement in L3 English?

Hypothesis 1 dealt with the purely linguistic aspects in which the three languages involved in this study differ. More specifically, due to the fact that gender in Basque and English share a [+interpretable] feature as opposed to the [+interpretable] gender feature in the noun and [+uninterpretable] gender agreement in Spanish, animacy and gender attraction effects were unavoidable key factors that should be considered in the experimental design. Based on previous research with L2 language learners, it was predicted that learners would show animacy and gender attraction effects in L3 English. Findings indicated that Basque/Spanish bilingual learners' animacy errors were mainly 
restricted to production tasks, whereas accuracy in comprehension tasks animate and inanimate contexts was similar. RT data did not show any difference between animate and inanimate conditions and non-native learners showed reaction delays similar to native speakers of English. Gender attraction effects were found across-task (no matter task modality) and difficulties in those conditions were also reflected in RT data. Interestingly, these attraction effects were not only found when the possessee of the gender-mismatched condition was animate but also in inanimate and body part contexts indicating that learners somehow transfer the grammatical gender of the Spanish equivalent noun to English.

Hence, Hypothesis 1 was partially confirmed. On the one hand, evidence on gender attraction effects fully supported the prediction made in Hypothesis 1. Previous evidence (Santesteban et al. 2010) was confirmed since gender agreement in English seems to be affected by the syntax of one of the learners' L1s. On the other hand, animacy effects only seem to partially confirm previous research. Although difficulties in animate contexts were expected in all tasks, these effects predominantly surfaced in production or spontaneous tasks. Such a close dependency of animacy effects on spontaneous or highly demanding production tasks has not bee previously reported in the literature.

\subsubsection{Conclusions RQ 2}

The second research question, repeated here for the reader's convenience, investigated non-native learners' accuracy with regard to different tasks.

RQ 2: Does task-type (comprehension vs. production) influence the performance of participants? Are there significant differences between comprehension and production tasks?

Hypothesis 2 considered the different predictions made by representational and computational models as well as by the FRH regarding the availability of the [+interpretable] gender feature in L3 English as well as task effects (comprehension vs. production). Clear findings were reported in this dissertation. Non-native learner groups, Basque/Spanish bilinguals and L1 Spanish learners, display clear difficulties in assigning the appropriate gender feature to the third person singular possessive 
adjective. In fact, this difficulty was enhanced in possessive adjectives when compared to gender assignment in third person singular subject and object pronouns.

However, findings on third person singular possessive adjectives revealed the persistent problems non-native learners have when acquiring a [+interpretable] gender feature in an L2/L3. Even though under representational and computational accounts no difficulties were expected for the acquisition of [+interpretable] features, the findings in the present dissertation do not seem to confirm these hypotheses. In contrast, L2/L3 learners were found to have difficulties in re-assembling features in English, and thus, confirming Lardiere’s $(1998,2009)$ predictions under the FRH.

Inaccurate forms could arise due to a failure in assigning morphologically the appropriate semantic feature of the corresponding discourse referent (i.e. the possessor). Non-targetlike forms in English could be conditioned by the remaping of features already activated in Basque and Spanish. In fact, an error rate above $10 \%$ in advanced learners indicates bilingual learners have reached a fossilization state regarding gender agreement. Besides, following full transfer accounts, a logical inference would be that if features are accessible from the L1, no task effect should be expected (although Lardiere suggests the possibility that accuracy could be higher in receptive tasks rather than in productive ones). Nevertheless, findings in this dissertation reveal clear differences between comprehension and production tasks.

\subsubsection{Conclusions RQ 3}

The third research question, repeated here for the reader's convenience, examined the role of proficiency in the acquisition of gender agreement.

RQ 3: Is there a correlation between proficiency and number of errors? That is, does the number of errors increase as proficiency increases?

Learners were expected to show higher accuracy as proficiency increased (White and Ranta, 2002) since proficiency level has been an important factor especially in minimal input settings (White et al. 2004). Hypothesis 3 was fully confirmed since proficiency was strongly correlated to inaccurate gender agreement percentages in the Basque/Spanish bilingual groups. In the non-native control group, despite the fact that the correlation relationship was not as strong as in the experimental group, L2 learners improved the performance as their English proficiency increased. 
Besides, the different stages in the developmental sequence in the acquisition of gender agreement seems to be clearly influenced by proficiency as well as the previous linguistic system(s). Elementary Basque/Spanish bilingual learners made a similar percentage of gender agreement errors and developmental errors. However, the percentage of gender agreement errors decreased as proficiency increased. On the other hand, the developmental sequences seem to be influenced by cross-linguistic influence. Findings showed Basque/Spanish bilinguals made more developmental errors than L1 Spanish learners. In fact, these errors partially fit in the developmental sequence proposed by White et al. (2007) for Catalan/Spanish and French learners of English. However, Basque/Spanish learners at the lowest proficiency level showed transfer errors not attested in previous research.

\subsubsection{Conclusions RQ 4}

Transfer effects in the acquisition of gender agreement were analyzed in the fourth research question, which is repeated here for the reader's convenience:

RQ 4: What is the role of transfer in establishing gender agreement in L3 English beyond the initial stages and in the ultimate stage?

In Hypothesis 4 on the basis of the L3 models discussed in the literature for initial state learners, which could be extended for learners who are in developing stages of learning, our participants were expected to either show positive transfer effects from Basque (following the CEM) or negative cross-linguistic effects coming solely from Spanish (under the TPM). In fact, results revealed negative transfer effects for both non-native groups, in line with Rothman (2010, 2014). However, the source of transfer also seems to have an effect on accuracy since Basque/Spanish bilinguals almost doubled the percentage of agreement errors when compared to L1 Spanish learners. As our results indicated, L3 learners displayed both animacy and gender attraction effects in establishing gender agreement in English whereas for L2 learners seem to establish the agreement relationship exclusively on the L1 syntax (following Jaensch, 2011). The influence of the previous knowledge from Basque (i.e. animacy) and Spanish (i.e. grammatical gender) caused negative transfer for learners. Although L1 Spanish learners displayed higher accuracy than Basque/Spanish bilinguals, none of the groups achieved native-like accuracy in gender agreement. Regarding RTs non-native learners 
showed longer reaction delays than native speakers, indicating qualitative differences in processing gender agreement in English.

\subsection{Pedagogical implications}

A current line of generative L2 acquisition research focuses on the role of explicit teaching in L2 development on the acquisition of specific morphosyntactic properties (Whong et al. 2013). Besides, previous research in Canadian immersion programs indicated the benefits of focus on form (FonF) (Long and Robinson, 1998) in the ability to assign grammatical gender correctly in French (Lyster, 2004). FonF refers to a pedagogical approach in which the central claim is students' attention to linguistic elements as they arise incidentally in lessons where their overriding focus is on meaning and communication (Long, 1991). FonF claims that comprehensible input is necessary but inssuficient for acquiring the L2 (or the L3). The operazionalization of this pedagogical approach could be benefitial in the following aspects:

- Adult nonnative learners resort to language learning mechanisms (i.e. negative evidence such as error correction) other than the ones used by native speakers. Therefore, FonF could be necessary for adult learners to acquire the L2/L3.

- At lower proficiency levels, attention to form may be neglected in favor of meaning (García Mayo and Perales Haya, 2002). Therefore, FonF activities should compensate it.

- Paying conscious attention to form in the input can foster IL development.

Due to the low perceptual saliency of third person singular possessive adjectives in English, especially at the lower proficiency stages raising learners' awareness in these specific structures could benefit nonnative speakers' accuracy in minimal input settings (Collins et al. 2009). Identifying the type of pedagogical activity that produces better quality of input for learning the target form may enhance the quality of learners' output (Collins et al. 2009). For instance, findings in the present dissertation illustrated that learners had more difficulties in oral production tasks than in comprehension. In this vein, findings could aid teachers to identify those linguistic (i.e. animacy and attraction effects as well as transfer effects) and extra-linguistic factors (i.e. task and proficiency effects) affecting the acquisition of gender agreement in English. Results in this dissertation indicated that learners in both nonnative groups had difficulties that have to 
do with animacy and with gender attraction effects. However, L2 and L3 learners seem to react differently to gender agreement errors in each context. For instance, Basque/Spanish bilinguals seem to have more difficulties than L1 Spanish speakers in establishing gender agreement accurately. The variability in each experimental condition clearly showed those contexts that should be fostered in the foreign classroom. In fact, these difficulties were found in the three proficiency groups, where Basque/Spanish bilinguals showed persistent difficulties with the gender feature, whereas advanced L1 Spanish learners obtained higher accuracy. Besides, the different stages L2 and L3 learners of English seem to follow should also be considered in FonF practices. For instance, stressing the difficulties or problems that could arise from transfer effects to Basque/Spanish bilinguals in intervention studies.

Thus, it could be the case that explicit instruction of gender agreement in possessive adjectives enhancing learners' awareness of the problematic contexts and more practice on these contexts may facilitate the acquisition process. In this vein, the integration of FonF practices in the foreign language classroom may be benefitial, as FonF is viewed as the only feasible way to sustain the accurate provision of morphosyntactic elements in the L3 IL. Nonetheless, examining whether these morphosyntactic constructs are boosted by FonF practices should be considered in further research.

\subsection{Limitations and lines for further research}

The present study has some limitations that should be acknowledged and might be considered as lines of further research. The limitations of each research question will be mentioned separately. An obvious limitation of this experimental design in terms of linguistic constructs is the fact that both animacy and gender attraction effects cannot be examined separately. In other words, given the fact that the three languages involved in this study share some features and differ in some other features, it is difficult to analyze animacy and gender attraction effects independently. Besides, it is unclear whether difficulties are due to locality or directionality. That is, whether learners are transferring the directionality of the gender agreement relationship from Spanish to English or whether difficulties come from the underlying syntactic (sub-)operations (i.e. Agree operation) and the local possessee noun attracts and assigns the corresponding features to the possessive adjective. A third plausible option could be that learners have both 
locality and directionality problems and consequently they have both attraction as well as transfer effects.

Further research should consider examining the metalinguistic knowledge of non-native participants in order to understand whether difficulties are due to animacy or attraction effects and whether locality or directionality constraints caused difficulties. Moreover, it would be interesting to investigate other features (i.e. number) that display a similar distribution as gender in the three languages in order to compare whether learners have these difficulties.

Another possible limitation of the experimental design would be the classification of tasks. In principle, the distribution of tasks included three comprehension tasks, two production tasks and two production tasks. However, findings led us to consider a new distribution. Nonetheless, if learners' inaccuracy data displayed this distribution, further research should consider whether task effects should be based on receptive vs. productive tasks or, in contrast, other factors should be considered.

A future line of research could address the complete developmental sequence for Basque/Spanish in order to identify each stage learners go through. An analysis of less proficient or younger learners could be a better indicative of the very first stages in the developmental sequence. Moreover, further research could consider the impact of the hours of exposure on learners' accuracy. In other words, it would be interesting to examine whether learners who are exposed to more hours to English and receive more input will be able to show higher accuracy rates than learners in a minimal input setting.

Further research should consider aspects of both ultimate attainment as well as transfer effects. On the one hand, near-native learners' data should be considered to tap ultimate attainment at the final stage of the acquisition process. On the other hand, concerning transfer, future research should examine the role of linguistic dominance for Basque/Spanish in order to see whether dominance enhances the preferences for language learners' transfer. Moreover, language learners with different language combinations (i.e. typological related and/ or non-related) should be examined in order to compare the outcomes in this dissertation. 


\subsection{Final implications and concluding remarks}

This study has presented evidence on the acquisition of gender agreement by Basque/Spanish bilinguals learning English as an L3. The present dissertation contributes to current research in terms of feature availability accounts as well as a new combination of languages in the acquisition gender agreement. These findings could contribute to the ongoing debate on feature availability for non-native learners. In fact, these findings show that feature availability could be extended for L2 learners as well as for L3 acquisition, though variability and complexity is increased when three languages are combined. In the interim, feature availability seems to be affected by linguistic aspects (i.e. animacy) as well as task, proficiency and transfer effects.

Nonetheless, one should be aware of the limitations of the present study since it deals with students from a specific combination of languages completing controlled tasks targeting third person singular possessive adjectives. However, this type of research has the advantage of identifying the possible variables influencing the acquisition of gender agreement as a starting point in the acquisition process. Moreover, the data presented in this study can contribute to the growing field of generative L3 acquisition that investigates learners beyond the initial state (Rothman and Halloran, 2013) and to the acquisition of features in L3 acquisition (García Mayo and Villarreal Olaizola, 2011; Jaensch, 2011). 


\section{References}

Abney, S. (1987) The English Noun Phrase in its Sentential Aspect. Unpublished PhD dissertation, MIT.

Adger, D. (2003) Core Syntax. A Minimalist Approach. New York: Oxford University Press.

Alarcón, I. (2009) The processing of gender agreement in L1 and L2 Spanish: Evidence from reaction time data. Hispania, 92 (4), 814-828.

Alarcón, I. (2010). Gender assignment and agreement in L2 Spanish: The effects of morphological marking, animacy, and gender. Studies in Hispanic and Lusophone Linguistics, 3(2), 267-299.

Alarcón, I. (2011). Spanish gender agreement under complete and incomplete acquisition: early and late bilinguals' linguistic behavior within the noun phrase. Bilingualism: Language and Cognition, 14 (3) , 332-350.

Alarcón, I. (2014) Grammatical gender in second language Spanish. In K. L. Geeslin (ed.) The Handbook of Spanish Second Language Acquisition. (pp. 202-218) New York: Wiley-Blackwell.

Alexidou, A. and Wilder, C. (eds.) (1998) Possessors, Predicates, and Movement in the DP. Amsterdam: John Benjamins.

Alexidou, A., Haegeman, L. and Stavrov, M. (2007) Noun Phrase in the Generative Perspective. Berlin: Mouton de Gruyter.

Ambadiang, T. (1999) La flexión nominal: Género y número. Gramática Descriptiva de la Lengua Española, 3, 4843-4914.

Antón-Méndez, I. (1999). Gender and Number Agreement Processing in Spanish. Unpublished Ph.D. dissertation. University of Arizona.

Antón-Méndez, I. (2010). Whose? L2 English speakers' possessive pronoun gender errors. Bilingualism: Language and Cognition, 14(3), 318-331.

Antón-Méndez, I., Nicol, J. L., and Garrett, M. F. (2002). The relation between gender and number processing. Syntax, 5 (1), 1-25. 
Artiagoitia, X. (1998) Determinatzaile Sintagmaren Hipotesia Euskal Gramatikan (The hypothesis of the Determiner Phrase in Basque Grammar). Uztaro, 27, 33-61.

Artiagoitia, X. (2002) The functional structure of the Basque noun phrase. In X. Artiagoitia, P. Goenaga and J.A. Lakarra (eds.) Erramu Boneta: Festschrift for Rudolf P. G. de Rijk (pp.73-90) Bilbao: Supplements of ASJU.

Artiagoitia, X. (2009) Jabetza-Genitiboaren Sintaxia eta Erkatze Anizkuna (The syntax and the multiple comparison of the genitive-possession). EHU manuscript.

Artiagoitia, X. (2011) Izena (The noun). Sareko Euskal Gramatika. University of the Basque Country. Available in http://www.ehu.es/seg/morf/5/6/0. Accessed on October 13th.

Baayen, R. H., Piepenbrock, R. and Gulikers, L. (1995). The CELEX Lexical Database. Philadelphia, PA: Philadelphia Linguistic Data Consortium, University of Pennsylvania.

Barber, H., Salillas, E., and Carreiras, M. (2004) Gender or genders agreement? In M. Carreiras and C. Clifton (eds.), The On-line Study of Sentence Comprehension. Eyetracking, ERPs and Beyond (pp. 309-327). New York: Psychology Press.

Bardel, C. and Falk, Y. (2007) The role of the second language in third language acquisition: the case of Germanic syntax. Second Language Research 23(4), 459-484.

Bardel, C. and Falk, Y. (2012) The L2 status factor and the declarative/procedural distinction. In J. Cabrelli Amaro, S. Flynn and J. Rothman (eds.), Third Language Acquisition in Adulthood (pp. 61-78). Amsterdam: John Benjamins.

Barlow, M. (1992). A Situated Theory of Agreement. New York: Garland Publishing.

Bejar, S. (2003). Phy-syntax: A Theory of Agreement. Unplublished PhD Dissertation. University of Toronto.

Berkes, E. and Flynn, S. (2012). Further evidence in support of the CumulativeEnhancement Model: CP structure development. In S. Flynn, J. Rothman, and J. Cabrelli Amaro (eds.) Third Language Acquisition in Adulthood. (pp. 143-164). Amsterdam: John Benjamins. 
Bernstein, J. (1993) Topics in the Syntax of Nominal Structure across Romance. PhD Dissertation, City University of New York.

Bernstein, J. (2008) Reformulating the Determiner Phrase Analysis. Language and Linguistics Compass, 2, 1246-1270.

Bernstein, J. and Tortora, C. (2005) Two types of possessive forms in English. Lingua, 115, 1221-1242.

Bosque, I. and Picallo, C. (1996) Postnominal adjectives in Spanish indefinite DPs. Journal of Linguistics, 32, 349-385.

Bruhn de Garavito, J. and White, L. (2002) L2 acquisition of Spanish DPs: the status of grammatical features. In A. T. Pérez-Léroux and J. Liceras (eds.) The Acquisition of Spanish Morphosyntax: The L1/L2 Connection (pp. 153-178) Dordrecht: Kluwer.

Cabrelli Amaro, J., Amaro, J. F. and Rothman, J. (2015) The relationship between L3 transfer and structural similarity across development: Raising across an experiencer in Brazilian Portuguese. In H. Peuker (ed.) Transfer Effects in Multilingual Language Development. (pp. 21-52). Amsterdam: John Benjamins.

Cabrelli Amaro, J., Flynn, S. and Rothman, J. (2012) Third language acquisition in adulthood. In J. Cabrelli Amaro, S. Flynn and J. Rothman (eds.) Third Language Acquisition in Adulthood (pp. 1-6). Amsterdam: John Benjamins.

Cardinaletti, A. (1998) On the deficient/strong opposition in possessive systems. In A. Alexiadou and C. Wilder (eds.) Possessors, Predicates, and Movement in the DP (pp.17-54) Amsterdam: John Benjamins.

Carstens, V. M. (1993) On nominal morphology and DP structure. In S. Mchombo (ed.) Theoretical Aspects of Bantu Grammar, (pp. 151-180) Stanford: CSLI Publications.

Carstens, V. M. (2000) Concord in minimalist theory. Linguistics Inquiry, 31, 319-355.

Chomsky, N. (1993) A Minimalist Program for Linguistic Theory. In K. Hale, and S.J. Keyser (eds.) The View from Building 20: Essays in Linguistics in Honor of Sylvain Bromberger. (pp. 1-52) Massachussets: MIT Press.

Chomsky, N. (1995) The Minimalist Program. Cambridge, Massachussets: MIT Press. 
Chomsky, N. (1998) Minimalist inquiries: the framework. MIT Working Papers in Linguistics, 15.

Chomsky, N. (2001) Beyond explanatory adequacy. MIT Occasional Papers in Linguistics, 20.

Chomsky, N. (2007). Approaching UG from below. In U. Sauerland and H. - M. Gartner (eds.), + recursion = language? Chomsky's Minimalism and the View from Syntax-Semantics (pp.1-29). Berlin, Germany: Mouton de Gruyter.

Chomsky, N. (2008). On phases. In R. Freidin, C. P. Otero and M. L. Zubizarreta (Eds.). Linguistic Theory: Essays in Honor of Jean-Roger Vergnaud (pp. 133-166). Cambridge, MA: MIT Press.

Clashen, H. and Felser, C. (2006) Grammatical processing in language learners. Applied Psycholinguistics, 27 (1), 3-42.

Collins, L., Trofimovich, P., White, J., Cardoso, W., and Horst, M. (2009). Some input on the ease/difficult grammar question: an empirical study. The Modern Language Journal, 93 , 336-353.

Corbett, G. G. (1991). Gender. Cambridge: Cambridge University Press.

Corbett, G. G. (2012). Features. Cambridge: Cambridge University Press.

Corbett, G. G. (2013) The expression of gender. Berlin: De Gruyter Mouton.

Corral, J., Barber, H., and Carreiras, M. (2008). EEG time-frequency analyses of syntactic and semantic gender agreement violations. Paper presented at the IV Reunión de la Red Temática de Neurociencia Cognitiva. Santiago de Compostela, Spain.

de Bot, K. and Jaensch, C. (2015) What is special about L3 processing? Bilingualism: Language and Cognition, 18(2), 130-144.

De Vincenzi, M. and di Domenico, E. (1999) A distinction among phi-features: The role of Gender and Number in the retrieval pronoun antecedents. Italian Journal of Linguistics, 11, 41-74. 
Dekydtspotter, L. and Renaud, C. (2009) On the contrastive analysis of features in second language acquisition: uninterpretable gender on past participles in English -French processing. Second Language Research, 25 (2), 255-267.

Dewaele, J. M., and Véronique, D. (2001) Gender assignment and gender agreement in advanced French interlanguage: A cross-sectional study. Bilingualism: Language and Cognition, 4(3), 275-297.

Di Domenico, E. (1995) Features and functional projections in the Noun Phrase: the case of Gender. Paper presented at the 18th Glow Meeting. Tromsoe.

Di Domenico, E. (1997) Per una Teoria el Genere Grammaticale. Padova: Unipress.

Ellis, R. (1991) Second Language Acquisition and Language Pedagogy. Clevedon: Multilingual Matters.

Ellis, R. (2005) Measuring implicit and explicit knowledge of a second language. Studies in Second Language Acquisition, 27, 141-172.

Ezeizabarrena, M. J. (2005) Development in early Basque-Spanish language mixing. Paper presented at V International Symposium on Bilingualism. Barcelona, 20-23 March.

Falk, Y. and Bardel, C. (2011). Object pronouns in German L3 syntax: Evidence for the L2 status factor. Second Language Research 27(1): 59-82.

Falk, Y. Lindqvist, C. and Bardel, C. (2015). The role of L1 explicit metalinguistic knowledge in L3 oral production at the initial state. Bilingualism: Language and Cognition, 18(2), 227-235.

Fernández-García, M. (1999). Patterns of gender agreement in the speech of second language learners. In J. Gutiérrez-Rexach and F. Martínez-Gil (eds.) Advances in Hispanic linguistics: Papers from the 2nd Hispanic Linguistics Symposium (pp. 3-15). Somerville, MA: Cascadilla Press.

Field, J. (2004) Psycholinguistics: The KeyConcepts. London: Routledge. 
Finnemann, M. D. (1992) Learning agreement in the noun phrase: The strategies of the three first year Spanish students. International Review of Applied Linguistics, 30 (2), 121-136.

Flynn, S., Foley, C. and Vinnitskaya, I. (2004) The cumulative-enhancement model for language acquisition: Comparing adults' and children's patterns of development in first, second and third language acquisition of relative clauses. International Journal of Multilingualism 1(1), 3-16.

Foote, R. (2011) Integrated knowledge of agreement in early and late English-Spanish bilinguals. Applied Psycholinguistics, 32, 187-220.

Franceschina, F. (2005) Fossilized Second Language Grammars: The Acquisition of Grammatical Gender. Amsterdam/Philadelphia: John Benjamins.

Franck, J., Vigliocco, G., Antón-Méndez, I. and Collina, S. (2008) The interplay of sound and syntax in sentence production: a cross-linguistic of form effects on agreement. Language and Cognitive Processes, 23, 329-374.

García Mayo, M.P. and Perales Haya, S. (2002) Input processing and attention to form in native speakers of Spanish: Implications for foreign language learning. Interface: Journal of Applied Linguistics 17(1), 13-25.

García Mayo, M. P. and García Lecumberri, M. L. (eds) (2003) Age and the Acquisition of English as a Foreign Language. Clevedon: Multilingual Matters.

García Mayo, M. P. and Rothman, J. (2012). L3 morphosyntax in the generative tradition: From the initial state and beyond. In S. Flynn, J. Rothman, and J. Cabrelli Amaro (eds.) Third Language Acquisition in Adulthood. (pp. 9-32). Amsterdam: John Benjamins.

García Mayo, M. P. and Villarreal Olaizola Olaizola, I. (2011). The development of suppletive and affixal tense and agreement morphemes in the L3 English of BasqueSpanish bilinguals. Second Language Research, 27(1) , 129-149.

García Mayo, M. P. and Slabakova, R. (2015) Object drop in L3 acquisition. International journal of bilingualism. 
García Mayo, M.P., Lázaro Ibarrola, A. and Liceras, J. M. (2005) Placeholders in the English interlanguage of bilingual (Basque/Spanish) children. Language Learning 55(3), 445-489.

Giancaspro, D., Halloran, B. and Iverson, M. (2015). Transfer at the Initial Stages of L3 Brazilian Portuguese: A Look at Three Groups of English/Spanish Bilinguals. Bilingualism: Language and Cognition, 18(2), 191-207.

Goad, H. and White, L. (2006) Ultimate attainment in interlanguage grammars: A prosodic approach. Second Language Research, 22(3), 243-268.

Goad, H., White, L. and Steele, J. (2003) Missing inflection in L2 acquisition: Defective syntax or L1 constrained prosodic representations? Canadian Journal of Linguistics 48(3/4), 243-263.

Grüter, T., Lew-Williams, C. and Fernald, A. (2012) Grammatical gender in L2: A production or a real-time processing problem? Second Language Research, 28 (2), 191215.

Guijarro-Fuentes, P. (2012) The acquisition of interpretable features in L2 Spanish: Personal 'a'. Bilingualism: Language and Cognition, 15 (2), 701-720.

Gutierrez Mangado, J. and García Mayo, M.P. (2008) Non-adult long-distance whquestions in the non-native acquisition of English. In C. Pérez Vidal, M. J. Garau and A. Bel (eds.) A Portrait of the Young in the New Multilingual Spain (pp. 264-286). Clevedon: Multilingual Matters.

Haegeman, L. (1994) Introduction to Government and Binding Theory. Malden: Blackwell.

Haegeman, L. and Gueron, J. (1994) Introduction to Government and Binding Theory. Malden: Blackwell.

Hale. K. and Keyser, S. J. (1993) On argument structure and the lexical expression of syntactic relations. In K. Hale and S. J. Keyser (eds.) The View from Building 20: Essays in Linguistics in Honor of Sylvain Bromberger (pp.53-109) Cambridge, Mass.: MIT Press. 
Halle, M. and Marantz, A. (1993) Distributed Morphology and the Pieces of Inflection. In K. Hale and S. J. Keyser (eds.) The View from Building 20: Essays in Linguistics in Honor of Sylvain Bromberger. MIT Press, 112-176.

Harley, H. and Ritter, E. (2002) Person and number in pronouns: A feature-geometric analysis. Language, 78 (3), 482-526.

Harris, J. (1991) The exponence of gender in Spanish. Linguistic Inquiry 22, 27-62.

Hawkins, R. (1998). The inaccessibility of formal features of functional categories in second language acquisition. Paper presented at Pacific Second Language Research Forum. Tokyo, Japan.

Hawkins, R. and Casillas, G. (2008) Explaining frequency of verb morphology in L2 early speech. Lingua, 118, 595-612.

Hawkins, R. and Chan, C. Y.-H. (1997) The Partial availability of Universal Grammar in second language acquisition: The "failed functional features hypothesis". Second Language Research, 13, 187-226.

Hawkins, R. and Hattori, H. (2006) Interpretation of English multiple wh-questions by Japanese speakers: a missing uninterpretable feature account. Second Language Research 22 (3), 269-301.

Heaton, B. (1966). Composition through Pictures. London: Longman.

Hermas, A. (2010) Language acquisition as computational resetting: verb movement in L3 initial state. International Journal of multilingualism, 7(4), 343-362.

Hermas, A. (2014a). Restrictive Relatives in L3 English: L1 transfer and ultimate attainment convergence. Australian Journal of Linguistics, 34(3), 361-387.

Hermas, A. (2014b). L2 and L3 ultimate attainment: an investigation of two parameters. International Journal of Multilingualism, 11(2), 202-224.

Hernández-Pina, F. (1984). Teorías Psico-sociolingüísticas y su Aplicación a la Adquisición del Español como Lengua Materna (Psycho-sociolinguistic theories and their application to the acquisition of Spanish as a mother tongue). Madrid: Siglo XXI. 
Herschensohn, J. (2013) Age-related effects. In J. Herschensohn and M. YoungScholten (eds.) The Cambridge Handbook of Second Language Acquisition (pp. 317337). Cambridge: Cambridge University Press.

Hockett, C. F. (1958). A Course in Modern Linguistics. New York: The Macmillan Company

Holderness, J. and Hughes, A. (1997) 100+ Ideas for Children: Topic-based Activities. Newcastle: Macmillan/Heinemann.

Hopp, H. (2007). Ultimate Attainment at the Interfaces in Second Language Acquisition: Grammar and Processing. Unpublished $\mathrm{PhD}$ dissertation, University of Groningen.

Hopp, H. (2009) The syntax-discourse interface in near-native L2 acquisition: Off-line and on-line performance. Bilingualism: Language and Cognition, 12, 463-483.

Igoa, J. M., García-Albea, J. E., and Sánchez-Casas, R. (1999) Gender-number dissociations in sentence production in Spanish. Rivista di Linguistica, 11, 163-196.

Imaz Agirre, A. (under review) The processing of gender assignment in Spanish: does canonicity have an effect on Basque speakers?

Imaz Agirre, A. and García Mayo, M. P. (2013) Gender agreement in L3 English by Basque/Spanish bilinguals. Linguistic Approaches to Bilingualism, 3(4), 416-445.

Ionin, T. (2013) Morphosyntax. In Herschensohn, J. and Young-Scholten, M. (eds.) The Cambridge Handbook of Second Language Acquisition (pp. 505-528). Cambridge: Cambridge University Press.

Iverson, M. (2010) Informing the age-of-acquisition debate: L3 as a litmus test. International Review of Applied Linguistics, 48(2/3), 221-243.

Jaensch, C. (2009) L3 enhanced feature sensitivity as a result of higher proficiency in the L2. In Y. -K. I Leung (ed.) Third Language Acquisition and Universal Grammar (pp.115-143) Clevedon: Multilingual Matters.

Jaensch, C. (2011) L3 acquisition of German adjectival inflection: A generative account. Second Language Research, 27 (1), pp. 83-105. 
Juffs, A. (1998). Some effects of fi rst language argument structure and morphosyntax on second language sentence processing. Second Language Research, 14, 406-424.

Juffs, A. (2006). Processing reduced relative vs. main verb ambiguity in English as a second language: A replication study with working memory. In R. Slabakova, S. Montrul, and P. Prevost (eds.) Inquiries in Linguistic Development in Honor of Lydia White (pp. 213-232). Amsterdam: John Benjamins.

Keating, G. D. (2009). Sensitivity to violations of gender agreement in native and nonnative Spanish: An eye-movement investigation. Language Learning, 59 (3), 503535.

Keating, G. D. (2010). The effects of linear distance and working memory on the processing of gender agreement in Spanish. In B. VanPatten and J. Jegerski (Eds.), Research in Second Language Processing and Parsing (pp.113-134). Amsterdam: John Benjamins.

Kibort, A. and Corbett, G. G. (2008). Grammatical features. Accessed 14 November 2014. Downloaded from http://www.features.surrey.ac.uk/.

Kibort, A. and Corbett, G. G. (2010). Features: perspective on a key notion in linguistics. Oxford: Oxford University Press.

Lasagabaster, D. (2001) Bilingualism, immersion programmes and language learning in the Basque Country. Journal of Multilingual and Multicultural Development, 22, 401425.

Lardiere, D. (1998) Dissociating syntax from morphology in a divergent L2 end-state grammar. Second Language Research 14 (4), 359-375.

Lardiere, D. (2000) Mapping features to forms in second language acquisition. In J. Archibald (ed.) Second Language Acquisition and Linguistic Theory (pp.102-129). Cambridge, MA: Blackwell.

Lardiere, D. (2008) Feature assembly in second language acquisition. In J. Liceras, H. Zobl and H. Goodluck (eds.) The Role f Features in Second Language Acquisition. NY: LEA, 107-140. 
Lardiere, D. (2009) Some thoughts on the contrastive analysis of features in second language acquisition. Second Language research, 25 (2), 173-227.

Larrañaga, P. and Guijarro-Fuentes, P. (2013) The linguistic competence of early Basque-Spanish bilingual children and a Spanish monolingual child. International Journal of Bilingualism, 17, 577-601.

Larson, R. (1988) On the double object construction. Linguistic Inquiry, 1(9), 335-391.

Leung, Y.-K.I. (2007) Second language (L2) and third language (L3) French article acquisition by native speakers of Cantonese. International Journal of Multilingualism 4, 117-149.

Leung, Y.-K.I. (2009) (ed.) Third language acquisition and Universal Grammar. Clevedon: Multilingual Matters.

Liceras, J.M. (2002) Uninterpretable features in bilingual acquisition and the issue of language dominance. Paper presented at the European Research Conference Theoretical and Experimental Linguistics, Corinth, Greece, June 1-6.

Liceras, J. M. (2009) On parameters, functional categories and features ... and why the trees shouldn’t prevent us from seeing the forest ... Second language research, 25(2), 279-289.

Liceras, J. M. (2010). Second language acquisition and syntactic theory in the 21st century. Annual Review of Applied Linguistics, 30 , 248-269.

Liceras, J. M., Spradlin, K.T., Senn, C., Sikorska, M., Fernández Fuertes, R., and de la Fuente, E.A. (2003) Second language acquisition and bilingual competence: the Grammatical Features Spell-out Hypothesis. European Association of Second Language Acquisition (EuroSLA-13), Edinburgh, United Kingdom, September 19-21.

Liceras, J. M., Spradlin, K. T., Fernández Fuertes, R. (2005) Bilingual early functionallexical mixing and the activation of formal features. International Journal of Bilingualism, 2, 227-252. 
Liceras, J. M., Fernández Fuertes, R., Perales, S., Pérez-Tattam, R., and Spradlin, K. T. (2008a) Gender and gender agreement in bilingual native and non-native grammars: A view from child and adult functional-lexical mixings. Lingua 118, 827-851.

Liceras, J. M., Zobl, H. and Goodluck, H. (eds.) (2008b) The Role of Features in Second Language Acquisition. NY:Lawrence Erlbaum.

Loewen, S. (2005) Incidental focus on form and second language learning. Studies in Second Language Acquisition, 27(3), 361-386.

Long, M. H. (1991) Focus on form: A design feature in language teaching methodology. In de K. Bot, R. Ginsberg and C. Kramsch (eds.) Foreign Language Research in CrossCultural Perspective (pp. 39-52). Amsterdam: John Benjamins.

Long, M., and Robinson, P. (1998) Focus on form: Theory, research, and practice. In C. Doughty \& J. Williams (Eds.), Focus on form in classroom second language acquisition (pp. 15-63). Cambridge: Cambridge University Press.

Lyster, R. (2004) Differential effects of prompts and recasts in form-focused instruction. Studies in Second Language Acquisition, 26, 399-432.

Mackey, A. and Gass, S. (eds) (2012). Research Methods in Second Language Acquisition: A Practical Guide. Oxford: Blackwell Publishing Ltd.

MacWhinney, B. (2000) The CHILDES Project: Tools for Analyzing Talk. 3rd Edition. Mahwah, New Jersey: Lawrence Erlbaum Associates.

Mallén, E. (1997) A minimalist approach to concord in noun phrases. Theoretical Linguistics, 23, 49-77.

Manterola, J., and Ezeizabarrena, M. J. (2004). La mezcla de códigos (euskeracastellano) en el habla inflantil: una prueba más de la separación gramatical temprana. In C. Pastor (ed.) Perspectivas Interdisciplinares de la Lingüística Aplicada. Tomo I: Adquisición y Aprendizaje (pp.187-201). Valencia: Asociación Española de Lingüística Aplicada.

Marinis, T. (2003) Psycholinguistic techniques in second language acquisition research. Second Language Research, 19 (2), 144-161. 
Mariscal, S. (2008). Early acquisition of gender agreement in the Spanish noun phrase: starting small. Journal of Child Language, 35, 1-29.

McCarthy, C. (2007). Morphological Variability in Second Language Spanish. Unpublished PhD Dissertation.

McCarthy, C. (2008). Morphological variability in the comprehension of agreement: an argument for representation over computation. Second Language Research, 24(4), 459486.

Meyer, A. S., and Bock, K. (1999). Representation and processes in the production of pronouns: Some perspectives from Dutch. Journal of Memory and Language, 41, 281301.

Mills, A. E. (1986) The Acquisition of Gender: A study of English and German. Berlin: Springer.

Montrul, S. and Slabakova, R. (2003) Competence Similarities between Native and Near-Native Speakers: An Investigation of the Preterite/Imperfect Contrast in Spanish, Studies in Second Language Acquisition, 25: 351-398.

Montrul, S, Foote, R. and Perpiñan, S. (2008) Gender agreement in adult second language learners and Spanish heritage speakers: The effects of age and context of acquisition. Language Learning, 58, 503-553.

Montrul, S., de la Fuente, I., Davidson, J. and Foote, R. (2013) The role of experience in the acquisition and production of diminutives and gender in Spanish: Evidence from L2 learners and heritage speakers. Second Language Research, 29 (1), 87-118.

Morales, L., Paolieri, D., Cubelli, R. and Bajo, M. T. (2014). Transfer of Spanish grammatical gender to English: Evidence from immersed and non-immersed bilinguals. Bilingualism: Language and Cognition, 17(4), 700-708.

Moro, M. (2001) The semantic interpretation and syntactic distribution of determiner phrases in Spanish/English codeswitching. Paper presented at the 3rd International Symposium on Bilingualism (ISB3), Bristol, UK, April 17-24.

Muñoz, C. (1991) Why are HE and SHE a problem for Spanish learners of English? RESLA,7, 129-136. 
Muñoz, C. (1994) A Case of Frequency-Based Markedness. Atlantis XVI 1-2, MayNovember, 165-177.

Muñoz, C. (2006) (Ed.) Age and the rate of foreign language learning. Clevedon: Multilingual Matters.

Osterhout, L., Bersick, M., and McLaughlin, J. (1997). Brain potentials reflect violations of gender stereotypes. Memory and Cognition, 25, 273-285.

Paradis, M. (2008). Language and communication disorders in multilinguals. In B. Stemmer and H. A. Whitaker (eds.), Handbook of the Neuroscience of Language (pp. 341-349). Amsterdam: Elsevier.

Parafita Couto, M. C., Munarriz, A., Epelde, I., Deuchar, M. \& Oyharçabal, B. (2015) Gender conflict resolution in Spanish-Basque mixed DPs. Bilingualism: Language and Cognition, 18, 304-323.

Perales, S., García Mayo, M.P. and Liceras, J. M. (2009) The acquisition of L3 English negation by bilingual (Spanish/Basque) learners in an institutional setting. International Journal of Bilingualism 13(1), 3-33.

Pérez-Pereira, M. (1991) The acquisition of gender: what Spanish children can tell us. Journal of child language, 18, 571-590.

Pérez-Vidal, C. (2014). Study abroad and formal instruction contrasted: The SALA Project. In C. Pérez-Vidal (ed.) Language Acquisition in Study Abroad and Formal Instruction Contexts (pp. 17-58). Amsterdam: John Benjamins.

Pesetsky, D. and Torrego, E. (2004) The Syntax of Valuation and the Uninterpretability of Features. Unpublished manuscript MIT.

Picallo, M. C. (1991) Nominals and Nominalizations in Catalan. Probus, 3, 279-316.

Picallo, M. C. and Rigau, G. (1999) El posesivo y las relaciones posesivas. In I. Bosque and V. Demonte (eds), Gramática Descriptiva de la Lengua Española (pp. 973-1023) Madrid: Espasa Calpe. 
Prévost, P. and White, L. (2000) Missing surface inflection hypothesis or impairment in second language acquisition? Evidence from tense and agreement. Second Language Research, 16, 103-133.

Radford, A. (2000). NP shells. Essex Research Reports in Linguistics, 33, 2-20.

Renaud, C. (2010). On the Nature of Agreement in English-French Acquisition: A Processing Investigation in the Verbal and Nominal Domains. Unpublished doctoral dissertation, Indiana University.

Renaud, C. (2011) Constraints on feature selection in second language acquisition: Processing evidence from the French verbal domain. In L. Plonsky and M. Schierloh (eds.) Selected Proceedings of the 2009 Second Language Research Forum: Diverse Contributions to SLA (pp. 129-141). Somerville: Cascadilla Proceedings Project.

Ritter, E. (1991) Two functional categories in noun phrases: evidence from Modern Hebrew. In S. Rothstein (ed.) Syntax and Semantics (pp.37-62). San Diego: Academic Press.

Ritter, E. (1993) Where’s gender? Linguistic Inquiry, 24, 795-803.

Ritter, E. (1995). On the syntactic category of pronouns and agreement. Natural Language and Linguistic Theory, 13, 405-443.

Rothman, J. (2010) On the typological economy of syntactic transfer: Word order and relative clause attachment preference in L3 Brazilian Portuguese. International Review of Applied Linguistics 48 (2-3), 243-271.

Rothman, J. (2011) L3 syntactic transfer selectivity and typological determinacy: The typological primacy model. Second Language Research, 27, 107-27.

Rothman, J. (2013). Cognitive Economy, Non-Redundancy and Typological Primacy in L3 Acquisition: Evidence from initial stages of L3 Romance. In S. Baauw, F. Dirjkoningen and M. Pinto (Eds.) Romance Languages and Linguistic Theory 2011 (pp. 217-247). Amsterdam/Philadelphia: John Benjamins.

Rothman, J. (2015) Linguistic and cognitive motivations for the typological primacy model of third language (L3) transfer: Considering the role of timing of acquisition and 
proficiency in the previous languages. Bilingualism: Language and Cognition, 18(2), $179-190$

Rothman, J. and Halloran, B. (2013) Formal Linguistic Approaches to L3/Ln Acquisition: A Focus on Morphosyntactic Transfer in Adult Multilingualism. Annual Review of Applied Linguistics, 33, 51-67.

Sabourin, L., Stowe, L. A. and de Haan, G. J. (2006) Transfer effects in learning a second language grammatical gender system. Second Language Research 22(1), 1-29.

Sagarra, N. and Herschensohn, J. (2010) The role of proficiency and working memory in gender and number agreement processing in L1 and L2 Spanish. Lingua, 120, 20222039.

Sagarra, N. and Herschensohn, J. (2011) Proficiency and animacy effects on L2 gender agreement processes during comprehension. Language Learning, 61(1), 80-116.

Sagarra, N. and Herschensohn, J. (2013) Processing of gender and number agreement in late Spanish bilinguals. International Journal of Bilingualism, 17 (5), 607-627.

Santesteban, M., Foucart, A., Pickering, M. J. and Branigan, H. (2010) Is selection of possessive pronouns/adjectives in L2 affected by L1 syntax? Poster presented at the 16th Annual Conference on Architectures and Mechanisms for Language Processing (AMLaP). York, UK.

Sanz, C. (2014) Contributions of study abroad research to our understanding of SLA processes and outcomes: The SALA Project, an appraisal. In C. Pérez-Vidal (ed.) Language Acquisition in Study Abroad and Formal Instruction Contexts (pp. 1-14). Amsterdam: John Benjamins

Schwartz, B., and Sprouse, R. (1996). L2 cognitive states and the Full Transfer/Full Access model. Second Language Research, 12, 40-72.

Slabakova, R. and García Mayo, M. P. (2015) The L3 syntax-discourse interface. Bilingualism: Language and Cognition 18(2), 130-144.

Spradlin, K.T., Liceras, J. M. and Fernández Fuertes, R., (2003a) Functional-lexical code mixing patterns as evidence for language dominance in young bilingual children: a minimalist approach. In Liceras, J.M., Zobl, H. and Goodluck, H. (Eds.) Proceedings of 
the 2002 Generative Approaches to Second Language Acquisition (GASLA-6) Conference: L2 Links. Cascadilla Press, Somerville, MA.

Spradlin, K. T., Liceras, J. M. and Fernández Fuertes, R. (2003b) The "Grammatical Features Spell-out Hypothesis" as a diagnostic for bilingual competence. Paper presented at the 4th International Symposium on Bilingualism (ISB4), Arizona State University, Tempe, Arizona, April 30-May 3.

Syndicate, U.C.L.E (2001) Quick Placement Test. Oxford: Oxford University Press.

Trenkic, D. (2004) Definiteness in Serbian/Croatian/Bosnian and some implications for the general structure of the nominal phrase. Lingua, 114, 1401-1427.

Tsimpli, I. A. and Dimitrakopoulou, M. (2007) The Interpretability Hypothesis: evidence from wh-interrogatives in second language acquisition. Second Language Research 23 (2), 215-242.

Tsimpli, I.M. and Mastropavlou, M. (2007) Feature Interpretability in L2 Acquisition and SLI: Greek Clitics and Determiners. In Goodluck, H., Liceras, J. M. and Zobl, H. (eds.). The Role of Formal Features in Second Language Acquisition (pp.143-183). NY: LEA.

Unsworth, S. (2008) Age and input in the acquisition of grammatical gender in Dutch. Second Language Research, 24(3), 365-395.

Unsworth, S. (2013) Assessing the role of current and CUMULATIVE exposure in simultaneous bilingual acquisition: The case of Dutch gender. Bilingualism: Language and Cognition, 16 (1), 86-110.

Valois, D. (1991) The Internal Syntax of DP. Unpublished PhD. Dissertation, UCLA.

VanPatten, B., Keating, D. and Leeser, M. J. (2012) Missing verbal inflections as a representational problem: evidence from self-paced reading. Linguistic Approaches to Bilingualism, 2 (2), 109-140.

Vergnaud, J. R., and Zubizarreta, M. L. (1992). The definite determiner and the inalienable construction in French and in English. Linguistic Inquiry, 23 (4), 595-652. 
Vigliocco, G., and Franck, J. (1999). When sex and syntax go hand in hand: Gender agreement in language production. Journal of Memory and Language, 40, 455-478.

Villarreal Olaizola, I. (2011) Tense and Agreement in the Non-native English of Basque-Spanish Bilinguals: Content and Language Integrated Learning vs. English as a School Subject Learners. Unpublished PhD dissertation, University of the Basque Country.

Villarreal Olaizola, I. and García Mayo, M.P. (2009) Tense and agreement morphology in the interlanguage of Basque/Spanish Bilinguals: CLIL vs. non-CLIL. In Y. Ruiz de Zarobe and R. M. Jiménez Catalan (eds.), Content and Language Integrated Learning: Evidence from Research in Europe. (pp. 157-175) Clevedon: Multilingual Matters.

White, J. (2008) Speeding up acquisition of his and her: Explicit L1/L2 contrasts help. In J. Philip, R. Oliver and A. Mackey (eds.) Child's play? Second Language Acquisition and the Younger Learner. (pp. 193-228) Amsterdam: John Benjamin.

White, J. and Ranta, L. (2002) Examining the Interface between Metalinguistic Task Performance and Oral Production in a Second Language. Language Awareness, 11:4, 259-290.

White, J., Muñoz, C. and Collins, L. (2007) The His/Her Challenge: Making Progress in a ‘Regular’ L2 Programme. Language Awareness 16 (4), 278-299.

White, L. (2003a) Second Language Acquisition and Universal Grammar. Cambridge: Cambridge University Press.

White, L. (2003b) Fossilization in steady state L2 grammars: Persistent problems with inflectional morphology. Bilingualism: Language and Cognition, 6 (2), 129-141.

White, L. (2008) Some puzzling features of L2 features. In J. M. Liceras, H. Zobl and H. Goodluck (eds.), The Role of Features in Second Language Acquisition (pp. 301326). Mahwah, NJ: Lawrence Erlbaum.

White, L., Valenzuela, E., Kozkowska- MacGregor, M. and Leung, Y. K. I. (2004). Gender and number agreement in nonnative Spanish. Applied Psycholinguistics, 25(1), 105-133. 
Whong, M., Gil, K.-H. and Marsden, H. (2013) Universal Grammar and the Second Language Classroom. Berlin: Springer.

Whong, M., Gil, K.-H. and Marsden, H. (2014) Beyond paradigm: The 'what' and the 'how' of classroom research. Second Language Research, 30(4), 551-568.

Yusa, N., Koizumi, M., Kim, J., Kimura, N., Uchida, S., Yokoyama, S., Miura, N., Kawashima, R. and Hagiwara, H. (2011). Second-language instinct and instruction effects: Nature and nurture in second-language acquisition. Journal of Cognitive Neuroscience 23, 2716-2730.

Zobl, H. (1984) Uniformity and source-language variation across developmental continua”. In W. E. Rutherford (ed.) Language Universals and Second Language Acquisition (pp. 185-218). Amsterdam: John Benjamins.

Zobl, H. (1985) Grammars in search of input and intake. In S. M. Gass and C. G. Madden (eds.) Input in Second Language Acquisition. Rowley, Mass.: Newbury House, 329-334. 

REFERENCES 